NIST NCSTAR 1-4D

Federal Building and Fire Safety Investigation of the World Trade Center Disaster

\title{
Smoke Management Systems
}

Michael J. Ferreira

Steven M. Strege 
. 
NIST NCSTAR 1-4D

\section{Federal Building and Fire Safety Investigation of the World Trade Center Disaster}

\section{Smoke Management Systems}

Michael J. Ferreira

Steven M. Strege

Hughes Associates, Inc.

September 2005

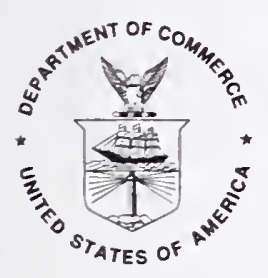

U.S. Department of Commerce

Carlos M. Gutierrez, Secretary

Technology Administration

Michelle O'Neill, Acting Under Secretary for Technology

National Institute of Standards and Technology

William Jeffrey, Director 


\section{Disclaimer No. 1}

Certain commercial entities, equipment, products, or materials are identified in this document in order to describe a procedure or concept adequately or to trace the history of the procedures and practices used. Such identification is not intended to imply recommendation, endorsement, or implication that the entities, products, materials, or equipment are necessarily the best available for the purpose. Nor does such identification imply a finding of fault or negligence by the National Institute of Standards and Technology.

\section{Disclaimer No. 2}

The policy of NIST is to use the International System of Units (metric units) in all publications. In this document, however, units are presented in metric units or the inch-pound system, whichever is prevalent in the discipline.

\section{Disclaimer No. 3}

Pursuant to section 7 of the National Construction Safety Team Act, the NIST Director has determined that certain evidence received by NIST in the course of this Investigation is "voluntarily provided safety-related information" that is "not directly related to the building failure being investigated" and that "disclosure of that information would inhibit the voluntary provision of that type of information" (15 USC 7306c).

In addition, a substantial portion of the evidence collected by NIST in the course of the Investigation has been provided to NIST under nondisclosure agreements.

\section{Disclaimer No. 4}

NIST takes no position as to whether the design or construction of a WTC building was compliant with any code since, due to the destruction of the WTC buildings, NIST could not verify the actual (or as-built) construction, the properties and condition of the materials used, or changes to the original construction made over the life of the buildings. In addition, NIST could not verify the interpretations of codes used by applicable authorities in determining compliance when implementing building codes. Where an Investigation report states whether a system was designed or installed as required by a code provision, NIST has documentary or anecdotal evidence indicating whether the requirement was met, or NIST has independently conducted tests or analyses indicating whether the requirement was met.

\section{$\underline{\text { Use in Legal Proceedings }}$}

No part of any report resulting from a NIST investigation into a structural failure or from an investigation under the National Construction Safety Team Act may be used in any suit or action for damages arising out of any matter mentioned in such report (15 USC 281a; as amended by P.L. 107-231).

National Institute of Standards and Technology National Construction Safety Team Act Report 1-4D Natl. Inst. Stand. Technol. Natl. Constr. Sfty. Tm. Act Rpt. 1-4D, 248 pages (September 2005) CODEN: NSPUE2

\section{U.S. GOVERNMENT PRINTING OFFICE WASHINGTON: 2005}




\section{ABSTRACT}

This report documents the design and installation of the smoke management systems in World Trade Center (WTC) 1, 2, and 7 and compares the designs to the requirements contained in applicable codes and standards. The normal operation of the fully functional smoke management systems in WTC 1 and WTC 2 on September 11, 2001, is also documented.

The report provides an overview of smoke management system concepts, discusses the various considerations impacting smoke management system design, and provides a history of the development of smoke control related requirements within various national codes and standards. The report also summarizes the smoke management systems in WTC 1,2, and 7, and the applicable Building Code of the City of New York (BCNYC) requirements pertaining to smoke management systems for each building. The performance of the installed smoke management systems for WTC 1 and WTC 2 as well as other candidate smoke management system configurations were evaluated using the CONTAM building airflow and contaminant dispersal computer model for specified fire scenarios. These scenarios included the severe aircraft impact related event scenarios that occurred on September 11,2001, in order to providc a context in which to evaluate smoke management system performance in WTC 1 and WTC 2.

The report concludes that the smoke management systems in WTC 1 and WTC 2 were not initiated on September 11,2001, and had the designed smoke purge sequence been initiated it is unlikely that the system would have functioned as designed, due to loss of electrical power and/or damage to the heating, ventilating, and air conditioning (HVAC) shafts and other structural elements in the impact zone. In addition, none of the potential smoke management system configurations evaluated in this report would have provided sufficient pressure differentials to contain smoke for the postulated aircraft impact damage scenarios, even if these systems were capable of operation after the building sustained damage from the aircraft impact. The report further concludes that stair pressurization would have been ineffective in improving conditions for occupants trying to exit the building.

Installation of combination fire/smoke dampcrs in HVAC ductwork, which was not required in WTC 1 or WTC 2. would have acted to slow the development of hazardous conditions on the uppcrmost floors of the building, but would likely not have had a significant effect on the ability of occupants to egress the building due to the impassibility of the exit stairways.

Keywords: airflow, building codes, modeling, smoke, smoke management, World Trade Center 
This page intentionally left blank. 


\section{TABLE OF CONTENTS}

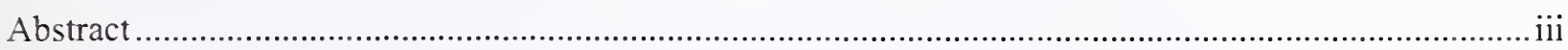

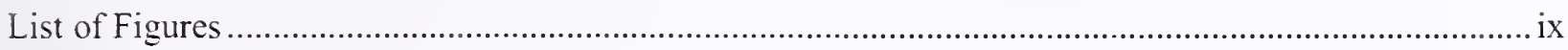

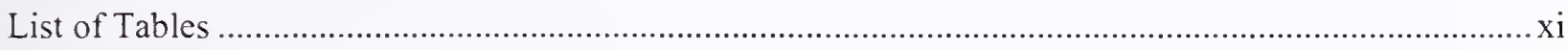

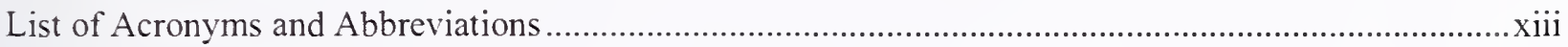

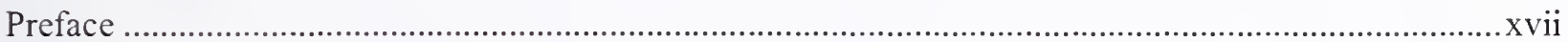

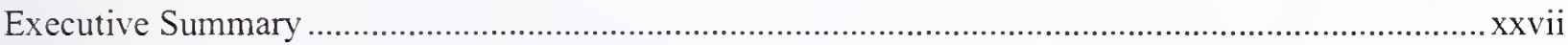

\section{Chapter 1}

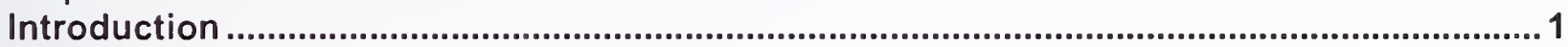

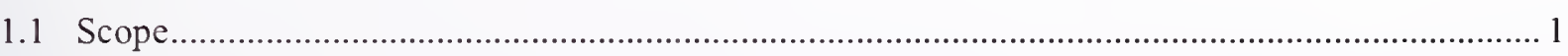

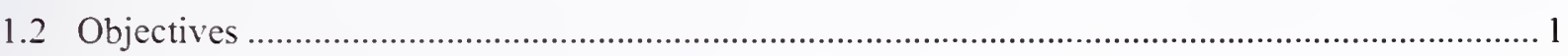

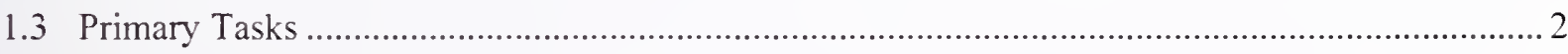

\section{Chapter 2}

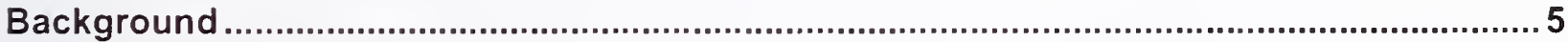

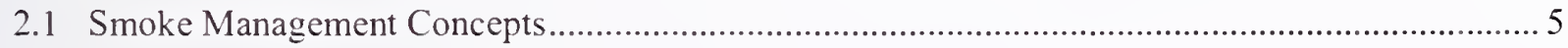

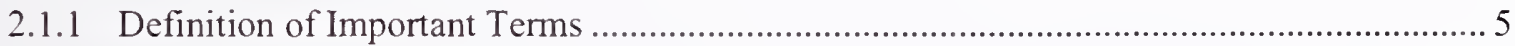

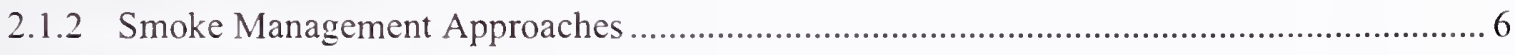

2.1.3 Factors Affecting Smoke Management ................................................................ 12

2.1.4 Smoke Management System Reliability ................................................................ 16

2.2 Evolution of Smoke Management System Code Requirements .......................................... 19

2.2.1 Historical Milestones..................................................................................... 19

2.2.2 Smoke Management in the Model Building Codes ................................................... 21

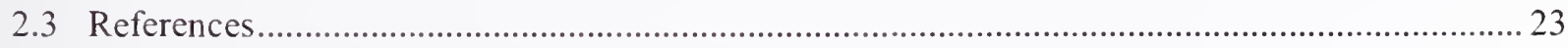

\section{Chapter 3}

Applicable Codes and Standards ..........................................................................227

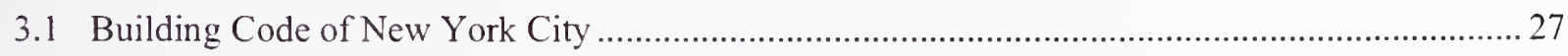

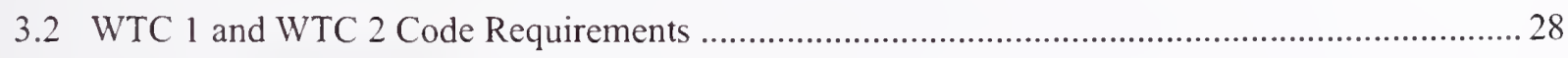

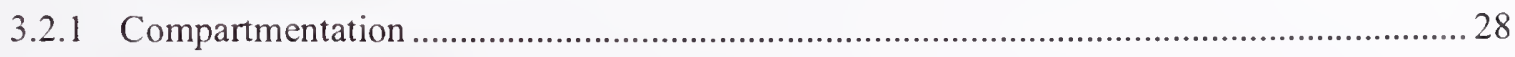

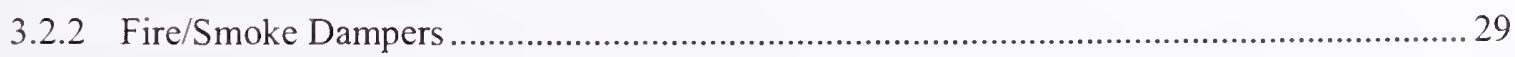

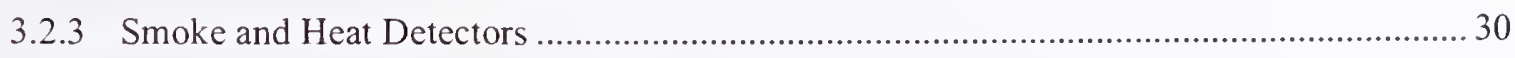

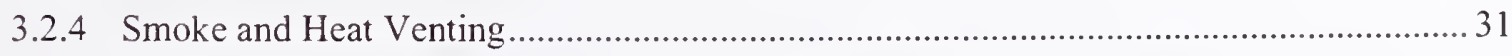

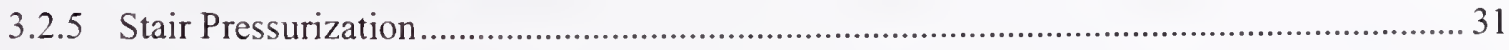




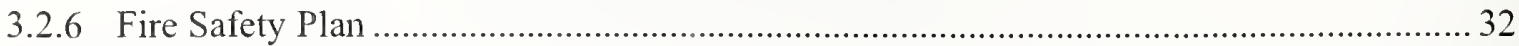

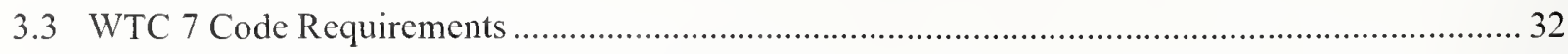

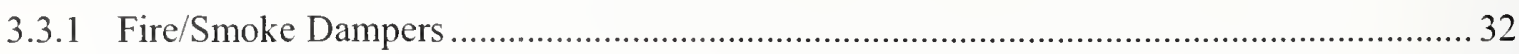

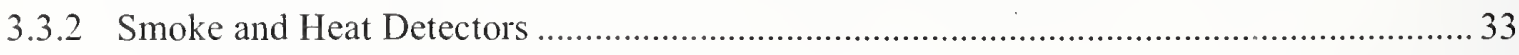

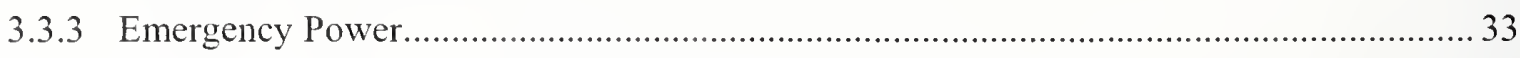

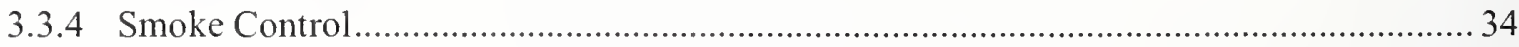

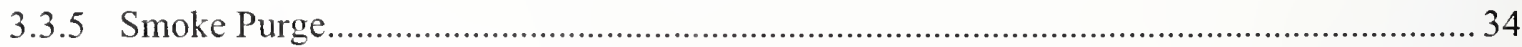

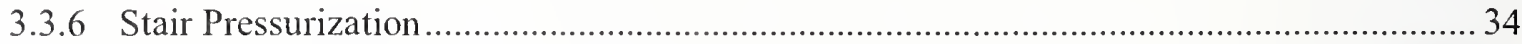

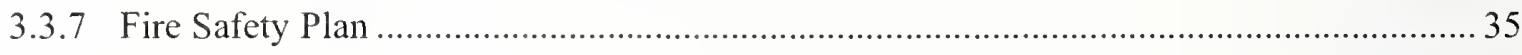

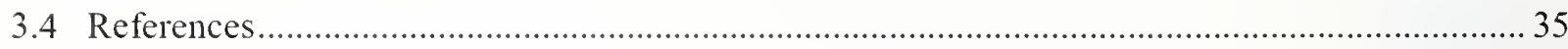

\section{Chapter 4}

Building Descriptions ..................................................................................... 37

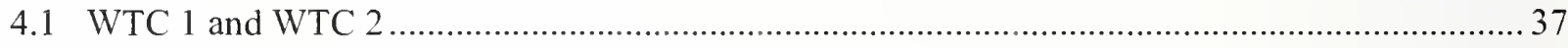

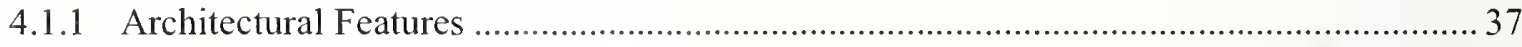

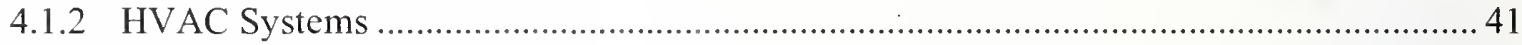

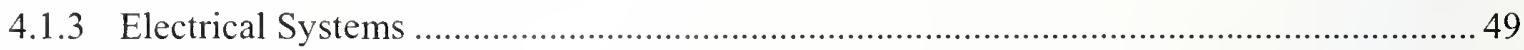

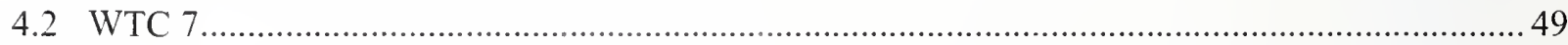

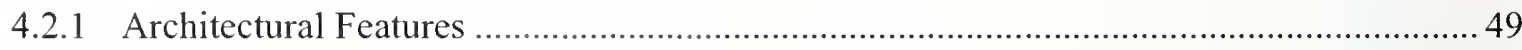

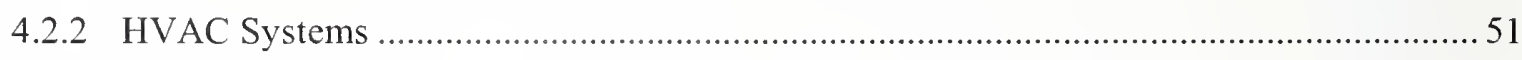

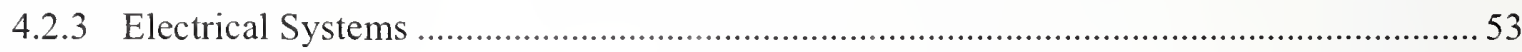

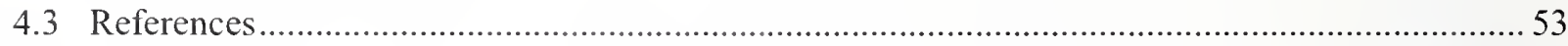

\section{Chapter 5}

Relevant History_Past Studies and Fire-Related Events ............................................55

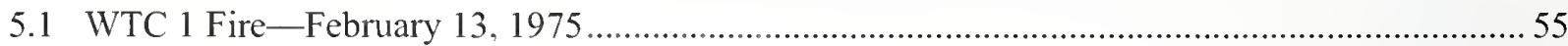

5.1.1 Post-Event Building Modifications-1975 Fire........................................................ 56

5.1.2 Important Considerations_-1975 Fire ................................................................... 56

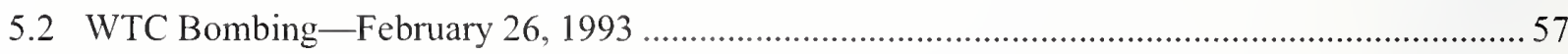

5.2.1 Post-Event Building Modifications - 1993 Bombing ................................................. 58

5.2.2 Important Considerations-1993 Bombing ............................................................ 58

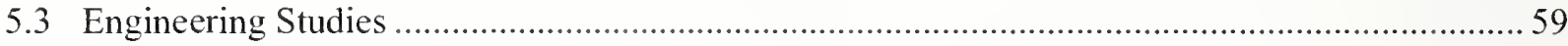

5.3.1 Prototype Stair Pressurization System Study ….......................................................... 59

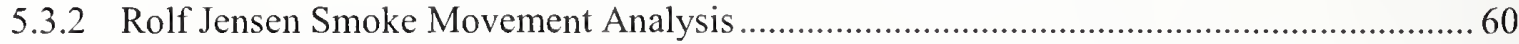

5.3.3 Hughes/Dillon Smoke Management System Evaluation........................................... 60

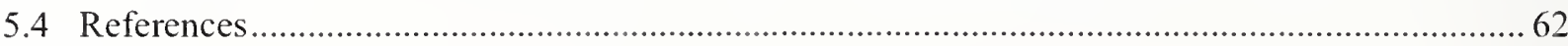




\section{Chapter 6}

Smoke Management System Design and Installation 63

6.1 WTC 1 and WTC 2 63

6.1.1 Sequence of Operations. 64

6.1.2 Applicable Code Requirements .67

6.1.3 Emergency Power. 67

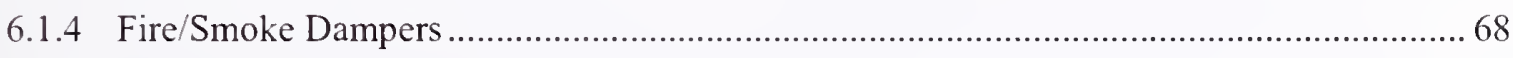

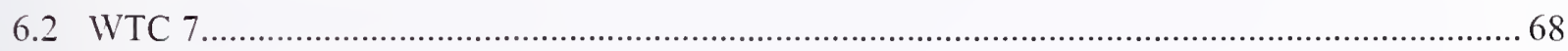

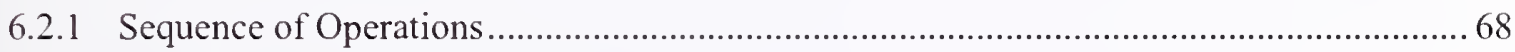

6.2.2 Applicable Code Requirements ............................................................................ 69

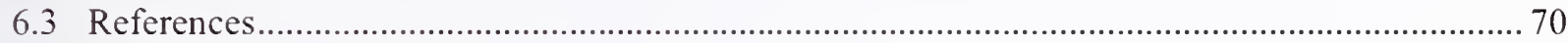

\section{Chapter 7}

Evaluation of System Performance on September 11, 2001 ..........................................71

7.1 Actions of Emergency Response Personnel...................................................................... 71

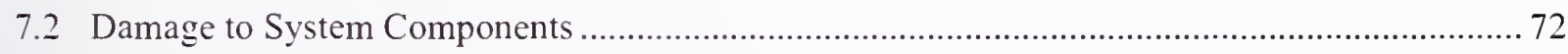

7.2.1 Exit Stair and Elevator Shaft Damage ............................................................. 76

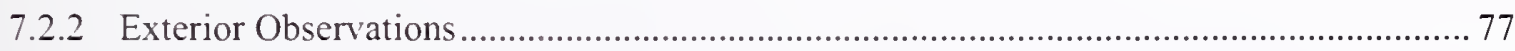

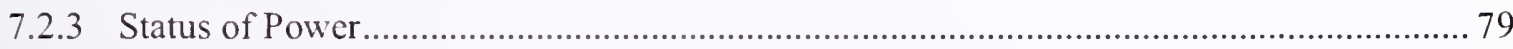

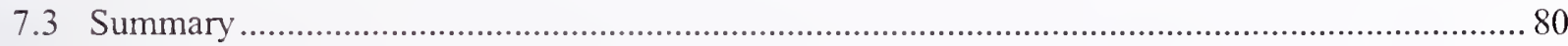

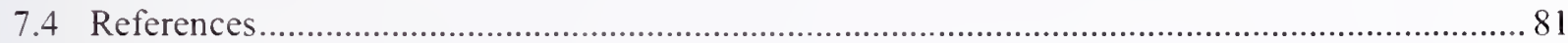

\section{Chapter 8}

Evaluation of Potential Smoke Management System Effectiveness ..................................8 83

8.1 Smoke Management System Approaches ................................................................... 83

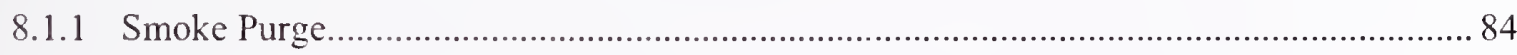

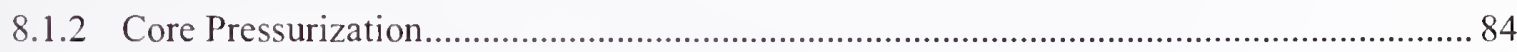

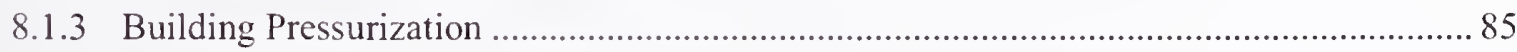

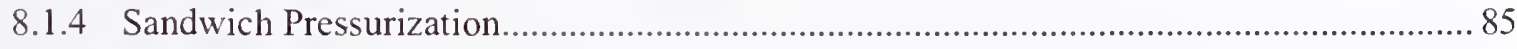

8.1.5 Zoned Smoke Control With Stair Pressurization ........................................................ 86

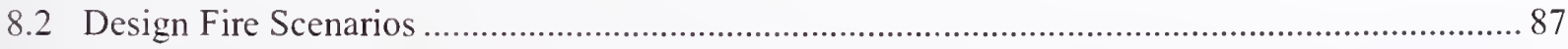

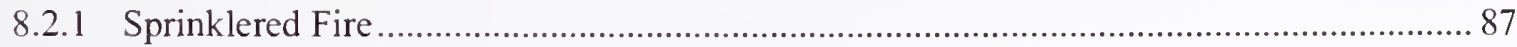

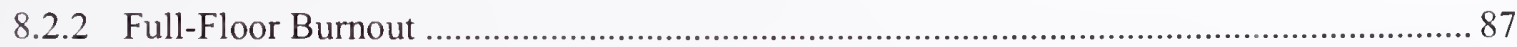

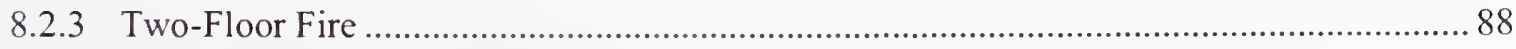

8.2.4 WTC 1 and WTC 2, September 11, 2001, Fire Scenarios (No Shaft Damage) ................ 88

8.2.5 WTC 1 and WTC 2, September 11, 2001, Fire Scenarios (Shaft Damage Assumed) .......88 


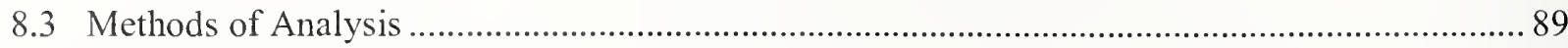

8.3.1 CONTAM Building Airflow Model........................................................................ 90

8.3.2 System Performance Criteria ............................................................................ 92

8.3.3 Calibration of the Model .......................................................................................... 94

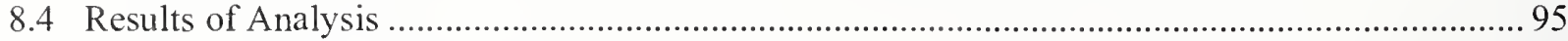

8.4.1 Sprinklered Fire Scenario-Results .............................................................................. 95

8.4.2 Full-Floor Burnout Scenario-Results ..................................................................... 96

8.4.3 Two-Floor Fire Scenario-Results..................................................................... 97

8.4.4 WTC 1 and WTC 2, September 11, 2001, Fire Scenarios (No Shaft Damage)-

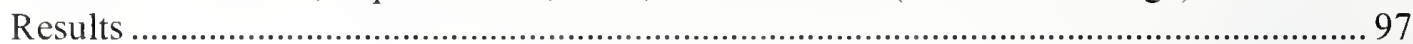

8.4.5 WTC 1 and WTC 2, September 11, 2001, Fire Scenarios (Shaft Damage

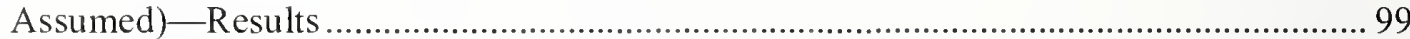

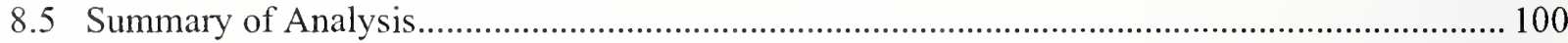

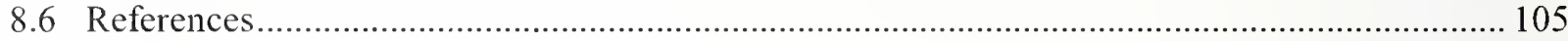

\section{Chapter 9}

Summary.

9.1 Evaluation of Smoke Management Systems Available on September 11, 2001 ..................... 107

9.2 Alternate Means of Smoke Management ................................................................... 108

9.2.1 Design Requirements in Prevailing Codes and Standards.......................................... 108

9.2.2 Past Recommendations for Changes to Smoke Management Systems .......................... 109

9.2.3 Summary of Potential Changes .................................................................................... 109

9.3 Evaluation of Smoke Management System Performance ....................................................... 110

9.3.1 Impact of Stair Pressurization Systems ......................................................................... 111

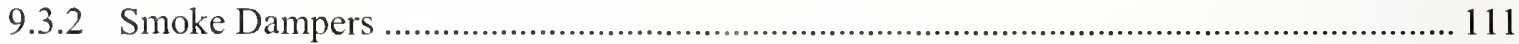

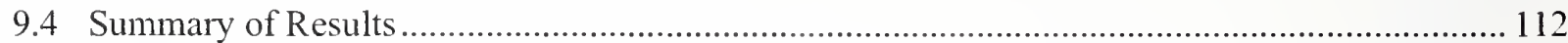

Appendix A

NIST Preliminary Damage Estimates ...............................................................113

\section{Appendix B}

CONTAM Model Construction

\section{Appendix C}

CONTAM Model Calibration 


\section{LIST OF FIGURES}

Figure $\mathrm{P}-1$. The eight projects in the federal building and fire safety investigation of the WTC disaster. xix

Figure 2-1. Exhaust method of smoke management. 7

Figure 2-2. Positive pressurization smoke management system................................................... 9

Figure 2-3. Negative pressurization smoke management system............................................... 10

Figure 2-4. Airflow method of smoke management................................................................... 12

Figure 2-5. Building airflows due to winter stack effect. .......................................................... 13

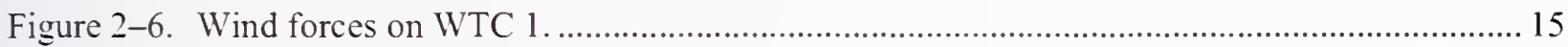

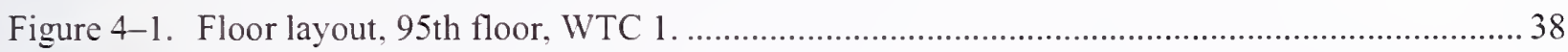

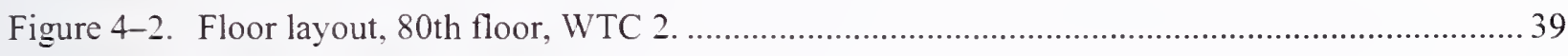

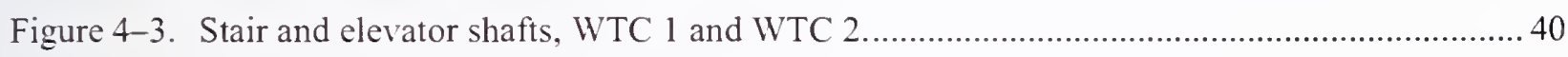

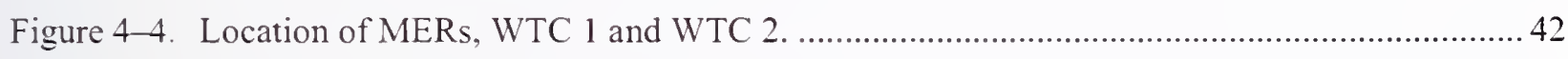

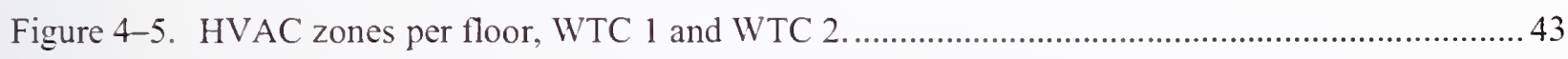

Figure 4-6. Schematic, supply HVAC units, lower level 75th floor MER, WTC 2........................... 44

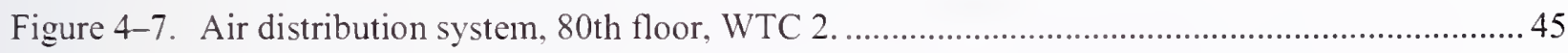

Figure 4-8. Exhaust HVAC units, upper level 75th floor MER, WTC 2 ........................................... 46

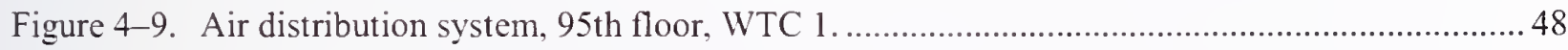

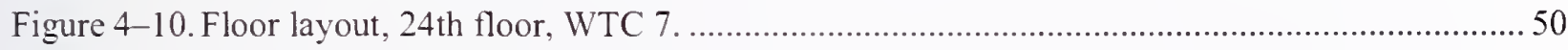

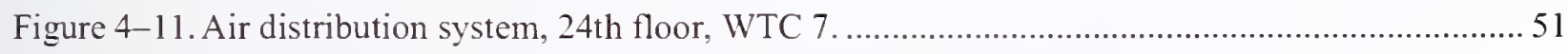

Figure 6-1. Documented smoke purge sequence of operations, WTC 1 and WTC 2..........................65

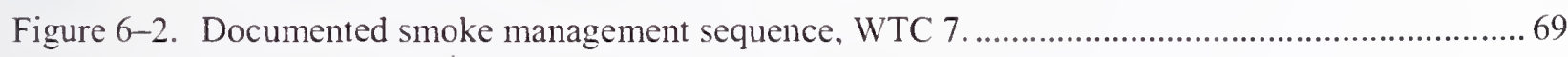

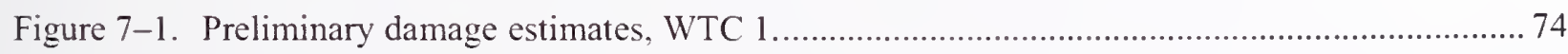

Figure 7-2. Preliminary damage estimates, WTC 2 ............................................................... 75

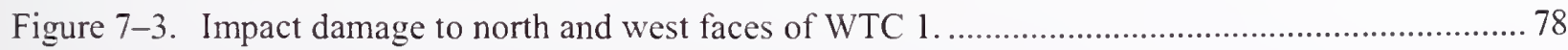

Figure 8-1. Modeled versus real flow conditions. ...................................................................... 92

Figure 8-2. Effect of core pressure on airflows in impact zones. .................................................. 98 
This page intentionally left blank. 


\section{LIST OF TABLES}

Table P-1. Federal building and fire safety investigation of the WTC disaster................................xviii

Table P-2. Public meetings and briefings of the WTC Investigation. xxi

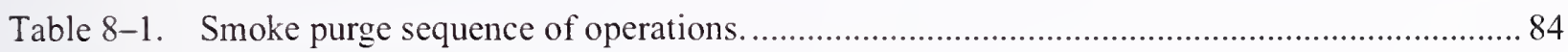

Table 8-2. Core pressurization sequence of operations.............................................................. 85

Table 8-3. Building pressurization sequence of operations........................................................... 85

Table 8-4. Sandwich pressurization sequence of operations..................................................... 86

Table 8-5. Zoned smoke control with stair pressurization sequence of operations..............................86

Table 8-6a. CONTAM modeling results, sprinklered fire scenario. ................................................ 101

Table 8-6b. CONTAM modeling results, full-floor burnout and two-floor fire scenario..................... 102

Table 8-6c. CONTAM modeling results, WTC 1 and WTC 2 (no shaft damage) fire scenarios.......... 103

Table 8-6d. CONTAM modeling results, WTC 1 and WTC 2 (with shaft damage) fire scenarios........ 104 
This page intentionally left blank. 


\section{LIST OF ACRONYMS AND ABBREVIATIONS}

\section{Acronyms}

\begin{tabular}{|c|c|}
\hline AHU & air handling unit \\
\hline ANSI & American National Standards Institute \\
\hline ASHRAE & American Society of Heating, Refrigerating, and Air-Conditioning Engineers \\
\hline ASTM & ASTM International \\
\hline $\mathrm{BCNYC}$ & Building Code of the City of New York \\
\hline $\mathrm{BOCA}$ & Building Officials and Code Administrators \\
\hline CFAST & Consolidated Fire and Smoke Transport \\
\hline CFD & computational fluid dynamics \\
\hline Con Ed & Consolidated Edison \\
\hline CONTAM & $\begin{array}{l}\text { National Institute of Standards and Technology Building Airflow and Contaminant } \\
\text { Dispersal Model }\end{array}$ \\
\hline DCE & Dillon Consulting Engineers \\
\hline DTAP & dissemination and technical assistance program \\
\hline EMR & elevator machine room \\
\hline $\mathrm{FCU}$ & fan coil unit \\
\hline FDNY & New York City Fire Department \\
\hline FEMA & Federal Emergency Management Agency \\
\hline GSA & General Services Administration \\
\hline HAI & Hughes Associates, Inc. \\
\hline HVAC & heating. ventilating, and air conditioning \\
\hline IBC & International Building Code \\
\hline ICC & International Code Council \\
\hline JFK & John F. Kennedy International Airport \\
\hline MER & mechanical equipment room \\
\hline NBFU & National Board of Fire Underwriters \\
\hline NFPA & National Fire Protection Association \\
\hline NIST & National Institute of Standards and Technology \\
\hline NOAA & National Oceanic and Atmospheric Administration \\
\hline
\end{tabular}




\begin{tabular}{ll} 
NRCC & National Research Council Canada \\
NYBFU & New York Bureau of Fire Underwriters \\
NYPD & New York City Police Department \\
OCC & Operations Control Center \\
PANYNJ & Port Authority of New York and New Jersey \\
PATH & Port Authority Trans-Hudson \\
R\&D & research and development \\
RJA & Rolf Jensen \& Associates \\
SFBC & San Francisco Building Code \\
SFPE & Society of Fire Protection Engineers \\
SSB & Salomon Smith Barney \\
UBC & Uniform Building Code \\
UL & Underwriters Laboratories \\
USC & United States Code \\
UUKL & Underwriters Laboratories Product Category-Smoke Control Equipment \\
VAV & variable air volume \\
WTC & World Trade Center \\
WTC 1 & World Trade Center 1 (North Tower) \\
WTC 2 & World Trade Center 2 (South Tower) \\
WTC 7 & World Trade Center 7 \\
\hline
\end{tabular}

\section{Abbreviations}

$\begin{array}{ll}{ }^{\circ} \mathrm{C} & \text { degrees Celsius } \\ { }^{\circ} \mathrm{F} & \text { degrees Fahrenheit } \\ \mu \mathrm{m} & \text { micrometer } \\ \mathrm{cfm} & \text { cubic feet per minute } \\ \mathrm{ft} & \text { foot } \\ \mathrm{ft} / \mathrm{min} & \text { foot per minute } \\ \mathrm{ft}^{2} & \text { square foot } \\ \mathrm{ft}^{3} & \text { cubic feet } \\ \mathrm{H}_{2} \mathrm{O} & \text { water } \\ \text { in. } & \text { inch }\end{array}$




$\begin{array}{ll}\text { in. } \mathrm{H}_{2} \mathrm{O} & \text { inches of water gauge (unit of pressure) } \\ \text { in. } & \text { square inch } \\ \mathrm{L} & \text { liter } \\ \mathrm{lb} & \text { pound } \\ \mathrm{lb}_{\mathrm{f}} & \text { pounds-force } \\ \mathrm{m} & \text { meter } \\ \mathrm{m}^{2} & \text { square meter } \\ \mathrm{m}^{3} \mathrm{~h} & \text { cubic meter per hour } \\ \mathrm{mph} & \text { miles per hour } \\ \mathrm{min} & \text { minute } \\ \mathrm{MW} & \text { megawatt } \\ \mathrm{N} & \text { newton } \\ \mathrm{Pa} & \text { pascal } \\ \mathrm{S} & \text { second } \\ \mathrm{V} & \text { volt }\end{array}$


This page intentionally left blank. 


\section{Preface}

\section{Genesis of This Investigation}

Immediately following the terrorist attack on the World Trade Center (WTC) on September 11, 2001, the Federal Emergency Management Agency (FEMA) and the American Society of Civil Engineers began planning a building performance study of the disaster. The week of October 7, as soon as the rescue and search efforts ceased, the Building Performance Study Team went to the site and began its assessment. This was to be a brief effort. as the study team consisted of experts who largely volunteered their time away from their other professional commitments. The Building Performance Study Team issued its report in May 2002, fulfilling its goal "to determine probable failure mechanisms and to identify areas of future investigation that could lead to practical measures for improving the damage resistance of buildings against such unforeseen events."

On August 21, 2002, with funding from the U.S. Congress through FEMA, the National Institute of Standards and Technology (NIST) announced its building and fire safety investigation of the WTC disaster. On October 1, 2002, the National Construction Safety Team Act (Public Law 107-231), was signed into law. The NIST WTC Investigation was conducted under the authority of the National Construction Safety Team Act.

The goals of the investigation of the WTC disaster were:

- To investigate the building construction. the materials used, and the technical conditions that contributed to the outcome of the WTC disaster.

- To serve as the basis for:

- Improvements in the way buildings are designed, constructed, maintained, and used;

- Improved tools and guidance for industry and safety officials;

- Recommended revisions to current codes, standards, and practices; and

- Improved public safety.

The specific objectives were:

1. Determine why and how WTC 1 and WTC 2 collapsed following the initial impacts of the aircraft and why and how WTC 7 collapsed;

2. Determine why the injuries and fatalities were so high or low depending on location, including all technical aspects of fire protection, occupant behavior, evacuation, and emergency response;

3. Determine what procedures and practices were used in the design, construction, operation, and maintenance of WTC 1, 2, and 7; and

4. Identify, as specifically as possible, areas in current building and fire codes, standards, and practices that warrant revision. 
NIST is a nonregulatory agency of the U.S. Department of Commerce's Technology Administration. The purpose of NIST investigations is to improve the safety and structural integrity of buildings in the United States, and the focus is on fact finding. NIST investigative teams are authorized to assess building performance and emergency response and evacuation procedures in the wake of any building failure that has resulted in substantial loss of life or that posed significant potential of substantial loss of life. NIST does not have the statutory authority to make findings of fault nor negligence by individuals or organizations. Further, no part of any report resulting from a NIST investigation into a building failure or from an investigation under the National Construction Safety Team Act may be used in any suit or action for damages arising out of any matter mentioned in such report (15 USC 281 a, as amended by Public Law 107-231).

\section{Organization of the Investigation}

The National Construction Safety Team for this Investigation, appointed by the then NIST Director, Dr. Arden L. Bement, Jr., was led by Dr. S. Shyam Sunder. Dr. William L. Grosshandler served as Associate Lead Investigator, Mr. Stephen A. Cauffiman served as Program Manager for Administration, and Mr. Harold E. Nelson served on the team as a private sector expert. The Investigation included eight interdependent projects whose leaders comprised the remainder of the team. A detailed description of each of these eight projects is available at http://wtc.nist.gov. The purpose of each project is summarized in Table $\mathrm{P}-1$, and the key interdependencies among the projects are illustrated in Fig. $\mathrm{P}-1$.

Table P-1. Federal building and fire safety investigation of the WTC disaster.

\begin{tabular}{|c|c|}
\hline Technical Area and Project Leader & Project Purpose \\
\hline $\begin{array}{l}\text { Analysis of Building and Fire Codes and } \\
\text { Practices; Project Leaders: Dr. H. S. Lew } \\
\text { and Mr. Richard W. Bukowski }\end{array}$ & $\begin{array}{l}\text { Document and analyze the code provisions, procedures, and } \\
\text { practices used in the design, construction, operation, and } \\
\text { maintenance of the structural, passive fire protection, and } \\
\text { emergency access and evacuation systems of WTC } 1,2 \text {, and } 7 \text {. }\end{array}$ \\
\hline $\begin{array}{l}\text { Baseline Structural Performance and } \\
\text { Aircraft Impact Damage Analysis; Project } \\
\text { Leader: Dr. Fahim H. Sadek }\end{array}$ & $\begin{array}{l}\text { Analyze the baseline performance of WTC } 1 \text { and WTC } 2 \text { under } \\
\text { design, service, and abnormal loads, and aircraft impact damage on } \\
\text { the structural, fire protection, and egress systems. }\end{array}$ \\
\hline $\begin{array}{l}\text { Mechanical and Metallurgical Analysis of } \\
\text { Structural Steel; Project Leader: Dr. Frank } \\
\text { W. Gayle }\end{array}$ & $\begin{array}{l}\text { Determine and analyze the mechanical and metallurgical properties } \\
\text { and quality of steel, weldments, and connections from steel } \\
\text { recovered from WTC } 1,2 \text {, and } 7 \text {. }\end{array}$ \\
\hline $\begin{array}{l}\text { Investigation of Active Fire Protection } \\
\text { Systems; Project Leader: Dr. David } \\
\text { D. Evans; Dr. William Grosshandler } \\
\end{array}$ & $\begin{array}{l}\text { Investigate the performance of the active fire protection systems in } \\
\text { WTC } 1,2 \text {, and } 7 \text { and their role in fire control, emergency response, } \\
\text { and fate of occupants and responders. }\end{array}$ \\
\hline $\begin{array}{l}\text { Reconstruction of Thermal and Tenability } \\
\text { Environment; Project Leader: Dr. Richard } \\
\text { G. Gann }\end{array}$ & $\begin{array}{l}\text { Reconstruct the time-evolving temperature, thermal environment, } \\
\text { and smoke movement in WTC } 1,2 \text {, and } 7 \text { for use in evaluating the } \\
\text { structural performance of the buildings and behavior and fate of } \\
\text { occupants and responders. }\end{array}$ \\
\hline $\begin{array}{l}\text { Structural Fire Response and Collapse } \\
\text { Analysis; Project Leaders: Dr. John } \\
\text { L. Gross and Dr. Therese P. McAllister }\end{array}$ & $\begin{array}{l}\text { Analyze the response of the WTC towers to fires with and without } \\
\text { aircraft damage, the response of WTC } 7 \text { in fires, the performance } \\
\text { of composite steel-trussed floor systems, and determine the most } \\
\text { probable structural collapse sequence for WTC } 1,2 \text {, and } 7 \text {. }\end{array}$ \\
\hline $\begin{array}{l}\text { Occupant Behavior, Egress, and Emergency } \\
\text { Communications; Project Leader: Mr. Jason } \\
\text { D. Averill }\end{array}$ & $\begin{array}{l}\text { Analyze the behavior and fate of occupants and responders, both } \\
\text { those who survived and those who did not, and the performance of } \\
\text { the evacuation system. }\end{array}$ \\
\hline $\begin{array}{l}\text { Emergency Response Technologies and } \\
\text { Guidelines; Project Leader: Mr. J. Randall } \\
\text { Lawson }\end{array}$ & $\begin{array}{l}\text { Document the activities of the emergency responders from the time } \\
\text { of the terrorist attacks on WTC } 1 \text { and WTC } 2 \text { until the collapse of } \\
\text { WTC } 7 \text {, including practices followed and technologies used. }\end{array}$ \\
\hline
\end{tabular}




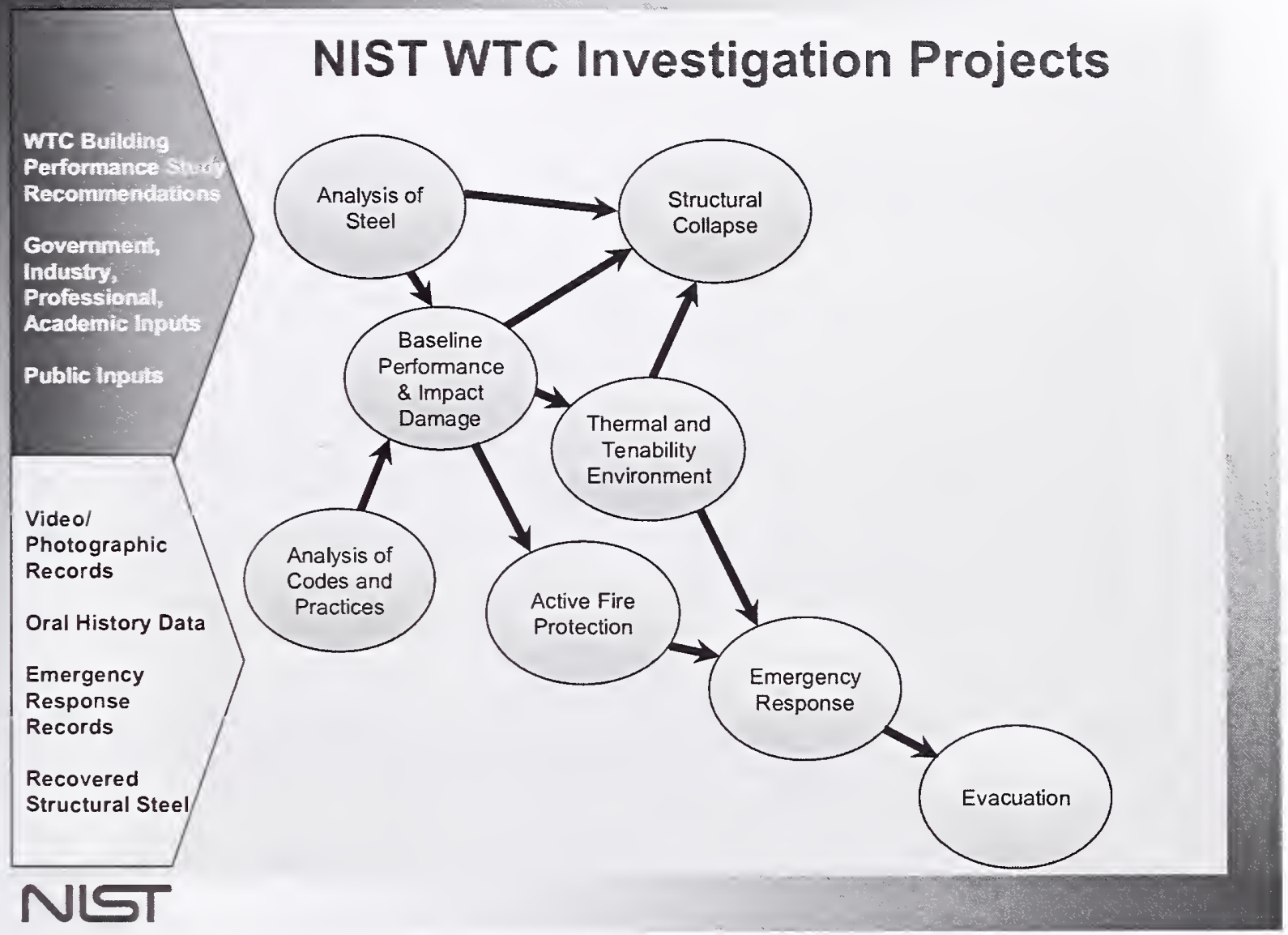

Figure $\mathrm{P}-1$. The eight projects in the federal building and fire safety investigation of the WTC disaster.

\section{National Construction Safety Team Advisory Committee}

The NIST Director also established an advisory committee as mandated under the National Construction Safety Team Act. The initial members of the committee were appointed following a public solicitation. These were:

- Paul Fitzgerald. Executive Vice President (retired) FM Global, National Construction Safety Team Advisory Committee Chair

- John Barsom, President, Barsom Consulting, Ltd.

- John Bryan, Professor Emeritus, University of Maryland

- David Collins, President, The Preview Group, Inc.

- Glenn Corbett, Professor, John Jay College of Criminal Justice

- Philip DiNenno, President, Hughes Associates, Inc. 
- Robert Hanson, Professor Emeritus, University of Michigan

- Charles Thornton, Co-Chairman and Managing Principal, The Thornton-Tomasetti Group, Inc.

- Kathleen Tierney, Director, Natural Hazards Research and Applications Information Center, University of Colorado at Boulder

- Forman Williams, Director, Center for Energy Research, University of California at San Diego

This National Construction Safety Team Advisory Committee provided technical advice during the Investigation and commentary on drafts of the Investigation reports prior to their public release. NIST has benefited from the work of many people in the preparation of these reports, including the National Construction Safety Team Advisory Committee. The content of the reports and recommendations, however, are solely the responsibility of NIST.

\section{Public Outreach}

During the course of this Investigation, NIST held public briefings and meetings (listed in Table P-2) to solicit input from the public, present preliminary findings, and obtain comments on the direction and progress of the Investigation from the public and the Advisory Committee.

NIST maintained a publicly accessible Web site during this Investigation at http:/wtc.nist.gov. The site contained extensive information on the background and progress of the Investigation.

\section{NIST's WTC Public-Private Response Plan}

The collapse of the WTC buildings has led to broad reexamination of how tall buildings are designed, constructed, maintained, and used, especially with regard to major events such as fires, natural disasters, and terrorist attacks. Reflecting the enhanced interest in effecting necessary change, NIST, with support from Congress and the Administration, has put in place a program, the goal of which is to develop and implement the standards, technology, and practices needed for cost-effective improvements to the safety and security of buildings and building occupants, including evacuation, emergency response procedures, and threat mitigation.

The strategy to meet this goal is a three-part NIST-led public-private response program that includes:

- A federal building and fire safety investigation to study the most probable factors that contributed to post-aircraft impact collapse of the WTC towers and the 47-story WTC 7 building, and the associated evacuation and emergency response experience.

- A research and development (R\&D) program to (a) facilitate the implementation of recommendations resulting from the WTC Investigation, and (b) provide the technical basis for cost-effective improvements to national building and fire codes, standards, and practices that enhance the safety of buildings, their occupants, and emergency responders. 
Table P-2. Public meetings and briefings of the WTC Investigation.

\begin{tabular}{|c|c|c|}
\hline Date & Location & Principal Agenda \\
\hline June 24,2002 & New York City, NY & $\begin{array}{l}\text { Public meeting: Public comments on the Draft Plan for the } \\
\text { pending WTC Investigation. }\end{array}$ \\
\hline August 21.2002 & Gaithersburg, MD & Media briefing announcing the formal start of the Investigation. \\
\hline December 9, 2002 & Washington. DC & $\begin{array}{l}\text { Media briefing on release of the Public Update and NIST request } \\
\text { for photographs and videos. }\end{array}$ \\
\hline April 8, 2003 & New York City, NY & $\begin{array}{l}\text { Joint public forum with Columbia University on first-person } \\
\text { interviews. }\end{array}$ \\
\hline April $29-30,2003$ & Gaithersburg, MD & $\begin{array}{l}\text { NCST Advisory Committee meeting on plan for and progress on } \\
\text { WTC Investigation with a public comment session. }\end{array}$ \\
\hline May 7.2003 & New York City, NY & Media briefing on release of May 2003 Progress Report. \\
\hline August $26-27,2003$ & Gaithersburg, MD & $\begin{array}{l}\text { NCST Advisory Committee meeting on status of the WTC } \\
\text { investigation with a public comment session. }\end{array}$ \\
\hline September 17,2003 & New York City, NY & $\begin{array}{l}\text { Media and public briefing on initiation of first-person data } \\
\text { collection projects. }\end{array}$ \\
\hline December 2-3, 2003 & Gaithersburg, MD & $\begin{array}{l}\text { NCST Advisory Committee meeting on status and initial results } \\
\text { and release of the Public Update with a public comment session. }\end{array}$ \\
\hline February 12, 2004 & New York City, NY & $\begin{array}{l}\text { Public meeting on progress and preliminary findings with public } \\
\text { comments on issues to be considered in formulating final } \\
\text { recommendations. }\end{array}$ \\
\hline June 18,2004 & New York City, NY & Media/public briefing on release of June 2004 Progress Report. \\
\hline June $22-23,2004$ & Gaithersburg, MD & $\begin{array}{l}\text { NCST Advisory Committee meeting on the status of and } \\
\text { preliminary findings from the WTC Investigation with a public } \\
\text { comment session. }\end{array}$ \\
\hline August 24, 2004 & Northbrook, IL & $\begin{array}{l}\text { Public viewing of standard fire resistance test of WTC floor } \\
\text { system at Underwriters Laboratories, Inc. }\end{array}$ \\
\hline October 19-20,2004 & Gaithersburg, MD & $\begin{array}{l}\text { NCST Advisory Committee meeting on status and near complete } \\
\text { set of preliminary findings with a public comment session. }\end{array}$ \\
\hline November 22,2004 & Gaithersburg, MD & $\begin{array}{l}\text { NCST Advisory Committee discussion on draft annual report to } \\
\text { Congress, a public comment session, and a closed session to } \\
\text { discuss pre-draft recommendations for WTC Investigation. }\end{array}$ \\
\hline April 5, 2005 & New York City, NY & $\begin{array}{l}\text { Media and public briefing on release of the probable collapse } \\
\text { sequence for the WTC towers and draft reports for the projects on } \\
\text { codes and practices, evacuation, and emergency response. }\end{array}$ \\
\hline June 23,2005 & New York City, NY & $\begin{array}{l}\text { Media and public briefing on release of all draft reports for the } \\
\text { WTC towers and draft recommendations for public comment. }\end{array}$ \\
\hline $\begin{array}{l}\text { September 12-13, } \\
2005\end{array}$ & Gaithersburg, MD & $\begin{array}{l}\text { NCST Advisory Committee meeting on disposition of public } \\
\text { comments and update to draft reports for the WTC towers. }\end{array}$ \\
\hline $\begin{array}{l}\text { September 13-15, } \\
2005\end{array}$ & Gaithersburg, MD & $\begin{array}{l}\text { WTC Technical Conference for stakeholders and technical } \\
\text { community for dissemination of findings and recommendations } \\
\text { and opportunity for public to make technical comments. }\end{array}$ \\
\hline
\end{tabular}

- A dissemination and technical assistance program (DTAP) to (a) engage leaders of the construction and building community in ensuring timely adoption and widespread use of proposed changes to practices, standards, and codes resulting from the WTC Investigation and the R\&D program, and (b) provide practical guidance and tools to better prepare facility owners, contractors, architects, engineers, emergency responders, and regulatory authorities to respond to future disasters.

The desired outcomes are to make buildings, occupants, and first responders safer in future disaster events. 


\section{National Construction Safety Team Reports on the WTC Investigation}

A final report on the collapse of the WTC towers is being issued as NIST NCSTAR 1. A companion report on the collapse of WTC 7 is being issued as NIST NCSTAR 1A. The present report is one of a set that provides more detailed documentation of the Investigation findings and the means by which these technical results were achieved. As such, it is part of the archival record of this Investigation. The titles of the full set of Investigation publications are:

NIST (National Institute of Standards and Technology). 2005. Federal Building and Fire Safety Investigation of the World Trade Center Disaster: Final Report on the Collapse of the World Trade Center Towers. NIST NCSTAR 1. Gaithersburg, MD, September.

NIST (National Institute of Standards and Technology). 2006. Federal Building and Fire Safety Investigation of the World Trade Center Disaster: Final Report on the Collapse of World Trade Center 7. NIST NCSTAR 1A. Gaithersburg, MD.

Lew, H. S., R. W. Bukowski, and N. J. Carino. 2005. Federal Building and Fire Safety Investigation of the World Trade Center Disaster: Design, Construction, and Maintenance of Structural and Life Safety Systems. NIST NCSTAR 1-1. National Institute of Standards and Technology. Gaithersburg, MD, September.

Fanella, D. A., A. T. Derecho, and S. K. Ghosh. 2005. Federal Building and Fire Safety

Investigation of the World Trade Center Disaster: Design and Construction of Structural Systems. NIST NCSTAR 1-1A. National Institute of Standards and Technology. Gaithersburg, MD, September.

Ghosh, S. K., and X. Liang. 2005. Federal Building and Fire Safety Investigation of the World Trade Center Disaster: Comparison of Building Code Strnctural Requirements. NIST NCSTAR 1-1B. National Institute of Standards and Technology. Gaithersburg, MD, September.

Fanella, D. A., A. T. Derecho, and S. K. Ghosh. 2005. Federal Building and Fire Safety Investigation of the World Trade Center Disaster: Maintenance and Modifications to Structural Systems. NIST NCSTAR 1-1C. National Institute of Standards and Technology. Gaithersburg, $\mathrm{MD}$, September.

Grill, R. A., and D. A. Johnson. 2005. Federal Building and Fire Safety Investigation of the World Trade Center Disaster: Fire Protection and Life Safety Provisions Applied to the Design and. Construction of World Trade Center 1, 2, and 7 and Post-Construction Provisions Applied after Occupancy. NIST NCSTAR 1-1D. National Institute of Standards and Technology. Gaithersburg, MD, September.

Razza, J. C., and R. A. Grill. 2005. Federal Building and Fire Safety Investigation of the World Trade Center Disaster: Comparison of Codes, Standards, and Practices in Use at the Time of the Design and Construction of World Trade Center 1, 2, and 7. NIST NCSTAR 1-1E. National Institute of Standards and Technology. Gaithersburg, MD, September.

Grill, R. A., D. A. Johnson, and D. A. Fanella. 2005. Federal Building and Fire Safety

Investigation of the World Trade Center Disaster: Comparison of the 1968 and Current (2003) New 
York City Building Code Provisions. NIST NCSTAR 1-1F. National Institute of Standards and Technology. Gaithersburg, MD, September.

Grill, R. A., and D. A. Johnson. 2005. Federal Building and Fire Safety Investigation of the World Trade Center Disaster: Amendinents to the Fire Protection and Life Safety Provisions of the New York City Building Code by Local Law's Adopted While World Trade Center 1, 2, and 7 Were in Use. NIST NCSTAR 1-1G. National Institute of Standards and Technology. Gaithersburg, MD, September.

Grill, R. A., and D. A. Johnson. 2005. Federal Building and Fire Safety Investigation of the World Trade Center Disaster: Post-Constrnction Modifications to Fire Protection and Life Safety Systenls of World Trade Center 1 and 2. NIST NCSTAR 1-1H. National Institute of Standards and Technology. Gaithersburg, MD, September.

Grill, R. A.. D. A. Johnson, and D. A. Fanella. 2005. Federal Bnilding and Fire Safety Imestigation of the World Trade Center Disaster: Post-Constrnction Modifications to Fire Protection, Life Safety, and Structural Systems of World Trade Center 7. NIST NCSTAR 1-1I. National Institute of Standards and Technology. Gaithersburg, MD, September.

Grill, R. A.. and D. A. Johnson. 2005. Federal Building and Fire Safety Investigation of the World Trade Center Disaster: Design, Installation, and Operation of Fuel System for Emergency Power in World Trade Center 7. NIST NCSTAR 1-1J. National Institute of Standards and Technology. Gaithersburg, MD, September.

Sadek, F. 2005. Federal Building and Fire Safety Investigation of the World Trade Center Disaster: Baseline Structural Performance and Aircrafi Impact Damage Analysis of the World Trade Center Towers. NIST NCSTAR 1-2. National Institute of Standards and Technology. Gaithersburg, MD, September.

Faschan, W. J., and R. B. Garlock. 2005. Federal Building and Fire Safety Investigation of the World Trade Center Disaster: Reference Strmctmal Models and Baseline Performance Analysis of the World Trade Center Towers. NIST NCSTAR 1-2A. National Institute of Standards and Technology. Gaithersburg, MD, September.

Kirkpatrick, S. W., R. T. Bocchieri, F. Sadek, R. A. MacNeill, S. Holmes, B. D. Peterson, R. W. Cilke, C. Navarro. 2005. Federal Building and Fire Safety Investigation of the World Trade Center Disaster: Analysis of Aircraft Impacts into tle World Trade Center Towers, NIST NCSTAR 1-2B. National Institute of Standards and Technology. Gaithersburg, MD, September.

Gayle, F. W., R. J. Fields, W. E. Luecke, S. W. Banovic, T. Foecke, C. N. McCowan, T. A. Siewert, and J. D. McColskey. 2005. Federal Building and Fire Safety Investigation of the World Trade Center Disaster: Mechanical and Metallnrgical Analysis of Strmctural Steel. NIST NCSTAR 1-3. National Institute of Standards and Technology. Gaithersburg, MD, September.

Luecke, W. E., T. A. Siewert, and F. W. Gayle. 2005. Federal Building and Fire Safety Investigation of the World Trade Center Disaster: Contemporaneous Strnctmral Steel Specifications. NIST Special Publication 1-3A. National Institute of Standards and Technology. Gaithersburg, MD, September. 
Banovic, S. W. 2005. Federal Burlding and Fire Safety Investigation of the World Trade Center Disaster: Steel Inventory and Identification. NIST NCSTAR 1-3B. National Institute of Standards and Technology. Gaithersburg, MD, September.

Banovic, S. W., and T. Foecke. 2005. Federal Building and Fire Safety Investigation of the World Trade Center Disaster: Damage and Failure Modes of Structural Steel Components. NIST NCSTAR 1-3C. National Institute of Standards and Technology. Gaithersburg, MD, September.

Luecke, W. E., J. D. McColskey, C. N. McCowan, S. W. Banovic, R. J. Fields, T. Foecke, T. A. Siewert, and F. W. Gayle. 2005. Federal Building and Fire Safety Investigation of the World Trade Center Disaster: Mechanical Properties of Structural Steels. NIST NCSTAR 1-3D. National Institute of Standards and Technology. Gaithersburg, MD, September.

Banovic, S. W., C. N. McCowan, and W. E. Luecke. 2005. Federal Building and Fire Safety Iwvestigation of the World Trade Center Disaster: Plysical Properties of Structural Steels. NIST NCSTAR 1-3E. National Institute of Standards and Technology. Gaithersburg, MD, September.

Evans, D. D., R. D. Peacock, E. D. Kuligowski, W. S. Dols, and W. L. Grosshandler. 2005. Federal Building and Fire Safety Investigation of tle World Trade Center Disaster: Active Fire Protection Systems. NIST NCSTAR 1-4. National Institute of Standards and Technology. Gaithersburg, MD, September.

Kuligowski, E. D., D. D. Evans, and R. D. Peacock. 2005. Federal Building and Fire Safety Investigation of the World Trade Center Disaster: Post-Construction Fires Prior to September 11, 2001. NIST NCSTAR 1-4A. National Institute of Standards and Technology. Gaithersburg, MD, September.

Hopkins, M., J. Schoenrock, and E. Budnick. 2005. Federal Building and Fire Safety Investigation of the World Trade Center Disaster: Fire Snppression Systents. NIST NCSTAR 1-4B. National Institute of Standards and Technology. Gaithersburg, MD, September.

Keough, R. J., and R. A. Grill. 2005. Federal Building and Fire Safety Investigation of the World Trade Center Disaster: Fire Alarn Systems. NIST NCSTAR 1-4C. National Institute of Standards and Technology. Gaithersburg, MD, September.

Ferreira, M. J., and S. M. Strege. 2005. Federal Building and Fire Safety Investigation of the World Trade Center Disaster: Smoke Managenent Systems. NIST NCSTAR 1-4D. National Institute of Standards and Technology. Gaithersburg, MD, September.

Gann, R. G., A. Hamins, K. B. McGrattan, G. W. Mulholland, H. E. Nelson, T. J. Ohlemiller, W. M. Pitts, and K. R. Prasad. 2005. Federal Building and Fire Safety Investigation of the World Trade Center Disaster: Reconstruction of the Fires in the World Trade Center Towers. NIST NCSTAR 1-5. National Institute of Standards and Technology. Gaithersburg, MD, September.

Pitts, W. M., K. M. Butler, and V. Junker. 2005. Federal Building and Fire Safety Investigation of the World Trade Center Disaster: Visnal Evidence, Damage Estimates, and Timeline Analysis. NIST NCSTAR 1-5A. National Institute of Standards and Technology. Gaithersburg, MD, September. 
Hamins, A., A. Maranghides, K. B. McGrattan, E. Johnsson, T. J. Ohlemiller, M. Donnelly, J. Yang, G. Mulholland, K. R. Prasad, S. Kukuck, R. Anleitner and T. McAllister. 2005. Federal Building and Fire Safety Investigation of the World Trade Center Disaster: Experiments and Modeling of Structural Steel Elements Exposed to Fire. NIST NCSTAR 1-5B. National Institute of Standards and Technology. Gaithersburg, MD, September.

Ohlemiller, T. J., G. W. Mulholland, A. Maranghides, J. J. Filliben, and R. G. Gann. 2005. Federal Building and Fire Safety Investigation of the World Trade Center Disaster: Fire Tests of Single Office Workstations. NIST NCSTAR 1-5C. National Institute of Standards and Technology. Gaithersburg, MD, September.

Gann, R. G., M. A. Riley, J. M. Repp, A. S. Whittaker, A. M. Reinhorn, and P. A. Hough. 2005. Federal Building and Fire Safety Investigation of the World Trade Center Disaster: Reaction of Ceiling Tile Systems to Shocks. NIST NCSTAR 1-5D. National Institute of Standards and Technology. Gaithersburg, MD, September.

Hamins, A., A. Maranghides, K. B. McGrattan, T. J. Ohlemiller, and R. Anleitner. 2005. Federal Building and Fire Safety Investigation of the World Trade Center Disaster: Experiments and Modeling of Multiple Workstations Burning in a Compartmem. NIST NCSTAR 1-5E. National Institute of Standards and Technology. Gaithersburg, MD, September.

McGrattan, K. B., C. Bouldin, and G. Forney. 2005. Federal Building and Fire Safety Investigation of the World Trade Center Disaster: Computer Simulation of the Fires in the World Trade Center Towers. NIST NCSTAR 1-5F. National Institute of Standards and Technology. Gaithersburg, MD, September.

Prasad, K. R., and H. R. Baum. 2005. Federal Building and Fire Safety Investigation of the World Trade Center Disaster: Fire Structure Interface and Thermal Response of the World Trade Center Towers. NIST NCSTAR 1-5G. National Institute of Standards and Technology. Gaithcrsburg, $\mathrm{MD}$, September.

Gross, J. L., and T. McAllister. 2005. Federal Building and Fire Safety Investigation of the World Trade Center Disaster: Structural Fire Response and Probable Collapse Sequence of the World Trade Center Towers. NIST NCSTAR 1-6. National Institute of Standards and Technology. Gaithcrsburg, MD, September.

Carino, N. J., M. A. Starnes, J. L. Gross, J. C. Yang, S. Kukuck, K. R. Prasad, and R. W. Bukowski. 2005. Federal Building and Fire Safety Investigation of the World Trade Center Disaster: Passive Fire Protection. NIST NCSTAR 1-6A. National Institute of Standards and Technology. Gaithersburg, MD, September.

Gross, J., F. Hervey, M. Izydorek, J. Mammoser, and J. Treadway. 2005. Federal Building and Fire Safety Investigation of the World Trade Center Disaster: Fire Resistance Tests of Floor Truss Systems. NIST NCSTAR 1-6B. National Institute of Standards and Technology. Gaithersburg, $\mathrm{MD}$, September.

Zarghamee, M. S., S. Bolourchi, D. W. Eggers, Ö. O. Erbay, F. W. Kan, Y. Kitane, A. A. Liepins, M. Mudlock, W. I. Naguib, R. P. Ojdrovic, A. T. Sarawit, P. R Barrett, J. L. Gross, and 
T. P. McAllister. 2005. Federal Building and Fire Safety Imestigation of the World Trade Center Disaster: Component, Connection, and Sibsystem Structural Analysis. NIST NCSTAR 1-6C. National Institute of Standards and Technology. Gaithersburg, MD, September.

Zarghamee, M. S., Y. Kitane, Ö. O. Erbay, T. P. McAllister, and J. L. Gross. 2005. Federal Building and Fire Safety Investigation of the World Trade Center Disaster: Global Structwral Analysis of the Response of the World Trade Center Towers to Impact Danrage and Fire. NIST NCSTAR 1-6D. National Institute of Standards and Technology. Gaithersburg, MD, September.

McAllister, T., R. W. Bukowski, R. G. Gann, J. L. Gross, K. B. McGrattan, H. E. Nelson, L. Phan, W. M. Pitts, K. R. Prasad, F. Sadek. 2006. Federal Building and Fire Safety Imvestigation of the World Trade Center Disaster: Structural Fire Response and Probable Collapse Sequence of World Trade Center 7. (Provisional). NIST NCSTAR 1-6E. National Institute of Standards and Technology. Gaithersburg, MD.

Gilsanz, R., V. Arbitrio, C. Anders, D. Chlebus, K. Ezzeldin, W. Guo, P. Moloney, A. Montalva, J. Oh, K. Rubenacker. 2006. Federal Bnilding and Fire Safety Investigation of the World Trade Center Disaster: Structural Analysis of the Response of World Trade Center 7 to Debris Damage and Fire. (Provisional). NIST NCSTAR 1-6F. National Institute of Standards and Technology. Gaithersburg, MD.

Kim, W. 2006. Federal Bwilding and Fire Safety Investigation of the World Trade Center Disaster: Analysis of September 11, 2001, Seismogram Data. (Provisional). NIST NCSTAR 1-6G. National Institute of Standards and Technology. Gaithersburg, MD.

Nelson, K. 2006. Federal Building and Fire Safety Investigation of the World Trade Center Disaster: The Con Ed Snbstation in World Trade Center 7. (Provisional). NIST NCSTAR 1-6H. National Institute of Standards and Technology. Gaithersburg, MD.

Averill, J. D., D. S. Mileti, R. D. Peacock, E. D. Kuligowski, N. Groner, G. Proulx, P. A. Reneke, and H. E. Nelson. 2005. Federal Burilding and Fire Safety Investigation of the World Trade Center Disaster: Occupant Belhavior, Egress, and Emergency Commmication. NIST NCSTAR 1-7. National Institute of Standards and Technology. Gaithersburg, MD, September.

Fahy, R., and G. Proulx. 2005. Federal Building and Fire Safety Investigation of the World Trade Center Disaster: Analys is of Published Accounts of the World Trade Center Evacuation. NIST NCSTAR 1-7A. National Institute of Standards and Technology. Gaithersburg, MD, September.

Zmud, J. 2005. Federal Building and Fire Safety Investigation of the World Trade Center Disaster: Technical Documentation for Survey Administration. NIST NCSTAR 1-7B. National Institute of Standards and Technology. Gaithersburg, MD, September.

Lawson, J. R., and R. L. Vettori. 2005. Federal Building and Fire Safety Investigation of the World Trade Center Disaster: The Emergency Response Operations. NIST NCSTAR 1-8. National Institute of Standards and Technology. Gaithersburg, MD, September. 


\section{EXECUTIVE SUMMARY}

The information presented in this report describes the design, installation, and performance of the smoke management systems installed in World Trade Center (WTC) 1, 2, and 7. The work described in this report is in support of the investigation of active fire protection systems. This is part of the federal building and fire safety investigation being performed by the National Institute of Standards and Technology (NIST).

Specific objectives associated with this effort include the following:

- Document the design and installation of the smoke management systems and compare designs to applicable code and standard requirements.

- Document the normal operation of the fully functional smoke management systems, and its potential effect on smoke conditions in WTC 1 and WTC 2 on September 11, 2001.

In order to establish a context in which to evaluate the WTC smoke management systems, this report provides an overview of smoke management system concepts, discusses the various considerations affecting smoke management system design, and provides a history of the development of smoke control related requirements within various national codes and standards.

The report also summarizes the smoke management systems provided in WTC 1,2, and 7, and the Building Code of the City of New York (BCNYC) requirements pertaining to smoke management systems for each building. The performance of the installed smoke management systems for WTC 1 and WTC 2 as well as other candidate smoke management system configurations was evaluated using the CONTAM building airflow and contaminant dispersal computer model for specified fire scenarios. These scenarios include the severe aircraft impact related events that occurred on September 11, 2001, in ordcr to provide a context in which to evaluate smoke management system performance in WTC 1 and WTC 2.

\section{E.1 APPLICABLE CODE REQUIREMENTS}

As a compact entity created under a clause of the U.S. Constitution, the Port Authority of New York and New Jersey (PANYNJ or Port Authority) is not governed by state or local building codes. Although not required to conform to the BCNYC, the Port Authority's longstanding policy was to assure that its facilities in the City of New York met and, where appropriate, exceeded the requirements of the BCNYC. In 1993, the Port Authority and the New York City Department of Buildings entered into a memorandum of understanding in which the Port Authority's longstanding policy was restated. Under this policy, the Port Authority required that the construction drawings for WTC 1,2, and 7 conform to the requirements of the BCNYC. WTC 1 and WTC 2 were constructed under the 1968 edition of the BCNYC. WTC 7 was constructed under the 1968 BCNYC, including amendments to January 1, 1985, incorporated in the following local laws enacted after 1968:

- Local Law No. 5, Fire Safety Requirements and Controls, January 18, 1973 
- Local Law No. 16, Local Laws of the City of New York for the Year 1984, March 27, 1984

- Local Law No. 33, Local Laws of the City of New York for the Year 1978, October 6, 1978

- Local Law No. 54, Local Laws of the City of New York for the Year 1970, November 17, 1970

- Local Law No. 55, Local Laws of the City of New York for the Year 1976, November 1, 1976

- Local Law No. 84, Fire Safety Pressurization Requirements in Certain Office Buildings, December 13, 1979

- Local Law No. 86, Dates for Compliance with the Local Laws Enacted for Fire Safety Requirements and Controls in Certain Buildings, December 13, 1979

The BCNYC differs from other building codes in one major respect. Changes to a building code generally affect only new buildings and are applied to an existing building only when a major renovation or change in occupancy occurs within the building. Many provisions contained within the local laws amending the BCNYC are applied retroactively; thus, these provisions are required to be implemented in existing buildings. All of the requirements included in the local laws listcd above werc in effect at the time of construction of WTC 7, since the local laws all predate the design and construction dates of WTC 7. However, only some of the provisions were retroactively applied to WTC 1 and WTC 2.

In accordance with the $\mathrm{BCNYC}$ requirements, WTC 1, 2, and 7 were required to be equipped with fire dampers at all duct openings into vertical shaft enclosures, and at penetrations of fire resistance rated floors or ceilings. Smoke dampers were required in the main supply duct and main return duct for heating, ventilating, and air conditioning (HVAC) systems having a capacity of over $15,000 \mathrm{ft}^{3} / \mathrm{min}$ and were arranged to close automatically by the operation of duct smoke detectors. Smoke detectors were required at the return shaft inlet on each floor. Activation of a detector was required to stop air supply to and return from the affected floor. In addition, WTC 7 was required to have either a combined fire/smoke damper or independent fire and smoke dampers at any penetration of construction required to have a fire resistance rating, under the provisions of Local Law No. 16 pertaining to smoke control.

Local Law No. 5 required that unsprinklered high-rise buildings be subdivided by fire separations into fire compartments on each floor of the building. WTC 1 and WTC 2 were originally subdivided into quadrants to meet this requirement, but were later provided with full automatic sprinkler protection, negating this requirement. WTC 7 was not required to provide compartmentation, as the building was fully sprinklered at the time of its construction.

Local Law No. 5 required existing office buildings to be provided with one or more smoke shafts by means of which smoke and heat could be mechanically vented to the outdoors. In lieu of providing smoke shafts, all enclosed exit stairs could be provided with stair pressurization. This requirement applied retroactively to WTC 1 and WTC 2 .

Local Law No. 16 added requirements for smoke control that included the provision of smoke dampers in HVAC ductwork and separation of ventilation systems serving specified areas of buildings. In addition, a 
mechanical means to exhaust six air changes per hour, or $1 \mathrm{cfm} / \mathrm{ft}^{2}$ (whichever is greater) from the largest floor of a building, operated manually to exhaust one floor at a time, was required. Under the Port Authority policy, these provisions of Local Law No. 16 applied to WTC 7.

Local Law No. 16 required that an emergency power system be provided having the capacity to operate life safety related equipment in high-rise buildings, including ventilation systems for smoke venting or control and stair pressurization. This provision was not applied retroactively to WTC 1 and WTC 2.

Local Law No. 86 stated that existing buildings would be exempt from the smoke shaft and optional stair pressurization requirements if they were provided with automatic sprinklers throughout. This provision applied retroactively to WTC 1 and WTC 2; therefore, negating the stair pressurization requirement of Local Law No. 5 as automatic sprinkler systems were installed throughout WTC 1, 2, and 7.

\section{E.2 BUILDING DESCRIPTIONS}

Building construction details and building systems comprising WTC 1,2, and 7 were evaluated to develop an understanding of building features that may have impacted smoke movement within the buildings and the design/function of smoke management systems. Building HVAC systems are described in somewhat greater detail below in order to understand the capabilities of the HVAC systems to perform smoke management functions.

\section{E.2.1 WTC 1 and WTC 2}

WTC 1 and WTC 2 were comprised of 110 stories above grade and seven levels below grade, and each had an approximate footprint area of $42,900 \mathrm{ft}^{2}$. WTC 1 and WTC 2 were similar architecturally, with minor differences in layout. The interiors of each floor differed due to the particular tenant build-out on that floor. In addition, the service core for the North Tower (WTC 1) was oriented east/west while the service core for the South Tower (WTC 2) was oriented north/south. The service core gradually decreased in size on the upper floors of the building as the numbers of elevators contained on the floors decreased.

The core spaces were separated from the perimeter spaces in the building by a 2 hour fire resistance rated barrier extending slab-to-slab. The cores contained the elevators, exit stairs, bathrooms, and miscellaneous equipment rooms. The pcrimeter office spaces were gcnerally open-plan office spaces containing office cubicles. Individual office spaces on the perimeter were generally separated by nonrated partitions extending only to the drop ceiling. The ventilation plenum above the drop ceiling was open around the perimeter of the floor.

Each tower was provided with three emergency exit stairways, enclosed in 2 hour rated gypsum wallboard construction. The plan location of the stairways shifted at some levels, with occupants required to move from one stairway segment to another via a horizontal transfer corridor, separated from the stair shafts by fire rated doors. Stairs 1 and 2 had transfers at the 42nd, 48th, 76th, and 82nd levels. Stair 1 had an additional transfer on the 26th floor. Stair 3 had only a single transfer, at the 76th floor. Stairs 1 and 2 were located closer to the perimeter of the core, while Stair 3 was located more toward the center of the core. 
Ninety-nine elevator shafts were located in each building. In order to facilitate movement of the thousands of office workers who regularly worked in the towers to the upper office floors in the building, a system of express and local elevators was installed in the building. High-speed express elevators shuttled pcople from the lobby to sky lobbies on the 44th floor and 78th floor of the building. Escalators connected the sky lobbies to the floors immediately above and below. Local elevators provided access from the sky lobby floors to the upper floors of the building. Freight elevators 49 and 50 extended to different heights in the building, with freight elevator 50 extending the full height of the building.

Building ventilation (heating and cooling) was provided in WTC 1 and WTC 2 by HVAC systems located in four mechanical equipment rooms (MERs) locatcd on the 7th, 41st, 75th, and 108th floors of each building. Each MER was approximately two stories tall and had an upper and lower level. With the exception of the 108th floor MER, which was located at the top of the building, above the floors that it served, the MERs served the floors immediately above and below the floors in which they were located. The WTC 1 aircraft impact occurred in the uppermost portion of the building (92nd through 98th floors), served by the 108th floor MER. The WTC 2 aircraft impact occurred slightly lower in the building (77th through 84 th floors), served by the 75 th floor MER.

HVAC supply fans were located on the lower level of each MER. Supply air was provided to the building via core, interior, and perimeter HVAC units. There were two core supply ventilation zones (north/south in WTC 2 and east/west in WTC 1, due to the orientation of the core), four interior space HVAC zones (corresponding to the four quadrants of the building), and four perimeter zones (north/south/east/west). The core and interior units provided low pressure air that was conditioned at each unit in the MER. Perimeter supply air was provided by high pressure fans and was conditioned at induction units located around the perimeter of the building on each floor. The induction units were roughly $18 \mathrm{in}$. high and were located in front of the windows at the perimeter of the office space.

Exhaust HVAC fans wcre located on the upper level of each MER. Four sets of return air shafts were located along the east and west sides of the core, returning air from the interior HVAC zones at the four quadrants of each floor. Whereas supply ventilation was provided by a ducted supply system utilizing metal ductwork, the return ventilation was provided by way of gypsum wallboard return shafts. Air was drawn through return grilles on each floor into a return plenum above the occupied spaces on each floor. Return air was then drawn to the MER exhaust fans via the gypsum wallboard shafts.

The original air distribution system configuration may have been substantially modified on some floors of the buildings, based on the needs of the tenants occupying various floors of the building and the design standards being used at the time of individual tenant retrofits. On some floors new ductwork was connccted to the base building HVAC ductwork at the major supply air shafts and connections remained from the return plenum to the return air shafts. Perimeter heating and cooling was provided on certain floors using small fan coil units (FCUs) located around the perimeter of the return air plenum, replacing most of the perimeter induction units. The FCUs were designed to draw air from the plenum, heat or cool the air as necessary as it passed through the coil, and then distribute the air via a small number (2-4) of supply air diffusers ducted from each FCU.

The smoke management system (smoke purge) for WTC 1 and WTC 2 utilized only the interior air systems and core systems, which were not modified substantially as a result of tenant retrofits. Perimeter air was not used for smoke management. Further, the plenum exhaust arrangement and total air quantities remained unchanged, despite individual tenant retrofit configurations. While smoke movement may have 
been impacted on a given floor due to changes to the ventilation systcm on individual floors, overall pressure differentials would be expected to remain the same.

\section{E.2.2 WTC 7}

WTC 7 was completed in 1987 and was located to the north of the WTC complex on the opposite side of Vesey Street. The building consisted of 47 stories above-grade and had a footprint area of approximately $48,000 \mathrm{ft}^{2}$. WTC 7 was built over an existing Con Ed substation and a shipping ramp that served the entire WTC complex. The lower six floors of the building contained the substation, electrical switchgear, emergency generators, transformers, and fuel storage tanks. Floors 3 and 4 also contained a conference center for Salomon Smith Barney (SSB), the tenant occupying the largest portion of the building. Floors 7 through 25 housed multiple tenants, with most occupying a single floor. Floors 7 and 8,11 through 13,19 through 21 , and 26 through 27 were occupied by multi-floor tenants. SSB occupied floors 28 through 45 .

The service core for the building was located in the east-west direction, and contained the elevators, exit stairs, bathrooms, and mechanical/electrical equipment rooms. The perimeter spaces were generally either open-plan office spaces containing cubicles or hard-walled individual office spaces. Individual office spaces were generally separated by non-rated partitions extending only to the drop ceiling. The ventilation plenum above the drop ceiling was open around the perimeter of the floor. The building was protected throughout by automatic sprinklers with the exception of certain equipment rooms on the lower floors of the building.

The building was served by low-rise (floors 7 through 20), mid-rise (floors 21 thruogh 37), and high-rise (floors 38 through 45) elevators, as well as service and freight elevators that ran the entirc height of the building. There were a total of 31 elevators serving the building. Two exit stairs served the building, and were referred to as Stair 1 (or Stair A) and Stair 2 (or Stair B). The position of Stair 1 remaincd constant on each floor of the building. The position of Stair 2 shifted at the 23rd floor, due to the location of the low-rise elevators serving the lower floors.

The individual floors of WTC 7 were served by HVAC equipment located in a fan room on each floor. This is in contrast to WTC 1 and WTC 2, which had dedicated MER floors that served multiplc floors of the buildings.

During the early 1990 s, SSB performed a major tenant retrofit to floors 28 through 45 . The retrofit included combining adjacent floors into single floors, relocation of HVAC shafts, and installation of new HVAC equipment to supplement base building equipment. Two two-story trading floors were crcated by combining the $40 \mathrm{th} / 41 \mathrm{st}$ and $42 \mathrm{nd} / 43 \mathrm{rd}$ floors. The trading floors each had a raised floor that scrved as a return plenum. HVAC fans and electrical/data services were located beneath the raised floors.

In addition to the trading floors, various SSB floors were retrofit with technology spaces housing computer equipment. Individual HVAC units were provided to recirculate air within these spaces. A large auditorium was included in the northwest corner of the building, spanning the 38 th/39th floors. Cafeteria spaces with kitchens were also located on the 34 th and 41 st floors.

Building ventilation (heating and cooling) was provided on the tenant floors (floors 7 through 47) for the base building configuration in WTC 7 by variable air volume (VAV) air handling units (AHUs) located on each floor. Each floor in WTC 7 was served by an AHU located in the fan room on that floor that 
consisted of two fans feeding into a common plenum. Conditioned air was then distributed to the floor in two zones, corresponding to the north/east and south/west portions of the building. The fan room served as a return plenum. Return air was drawn into the fan room via three branch ducts leading from the fan room. Make-up air was drawn into the fan room via make-up air shafts that connected to the exterior of the building via louvers either at the roof or at the 6 th floor.

In accordance with the BCNYC, the WTC 7 HVAC systems were designed to incorporate a smoke purge mode, by which each floor of the building could be exhausted/purged of smoke manually on a floor-by-floor basis from the fire command center, which was located on the 3rd floor of the building at the main lobby security desk. Two smoke exhaust fans were originally located within the building on the 6 th floor and 47th floor. The return air ductwork was connected to the exhaust duct. Return air either dumped into the fan room via the return dampers in each branch duct or was exhausted via the smoke exhaust riscr. A smoke exhaust damper opened at the shaft and the return dampers closed to exhaust smoke in the smoke purge mode. Curtain fire dampers were located throughout the building where ductwork crossed fire rated shaft walls, in accordance with the BCNYC. Separate pneumatic smoke dampers were used in the fan room to direct airflow within HVAC ductwork.

Major changes/additions to the building HVAC systems were made during the SSB tenant retrofit. AHUs were added to handle the increased air conditioning loads created by the extensive computer and data processing equipment. Existing building systems were modified to add an increased make-up air capacity. A new, larger, make-up air shaft was added. The shaft was relocated to create more usable space by allowing the removal of the original fan room on the trading floors and other select floors. A transfer fan and ductwork were added to provide outside air to the existing outside air shaft in its original location below the 24 th floor.

In order to bring additional make-up air into the building, a large make-up AHU was installed in a new rooftop mechanical penthouse. This provided forced ventilation make-up air rather than the open shaft configuration present in the original building. Additional AHUs and exhaust fans were also located in the penthouse.

A new smoke exhaust fan was added to replace the existing smoke purge fan. An additional smoke purge fan was also installed to provide smoke exhaust from the 45 th through 47 th floors of the building. Dedicated smoke exhaust fans were also provided for the trading room floors.

Several new fan rooms were added to house the additional AHUs. A fan room was added at the midpoint of the west wall of WTC 7 on the SSB floors. A louvered opening was provided to the exterior of the building from each fan room along the west wall. Various types of HVAC equipment were located within these fan rooms, including kitchen exhaust fans serving the cafeteria spaces on the 34 th and 41 st floors.

New fan rooms were also added to serve the two-story trading floors. The new fan rooms were located along the east wall of WTC 7, on the upper level of the trading floors (referred to as the mechanical mezzanine level). Fans within the east fan rooms returned air via ductwork from beneath the raised trading room floor, re-conditioned the air, and then supplied air at the upper level of the two-story space. Small FCUs were located beneath the raised floor to draw return air through the trading desks back into the raised-floor return plenum. 
The SSB tenant modifications incorporated combination fire/smoke dampers at many locations within the $\mathrm{HVAC}$ ductwork in accordance with the $\mathrm{BCNYC}$ requirements for fire separation and to direct airflow within HVAC ductwork.

\section{E.3 RELEVANT HISTORY}

Two major fire-related events in the history of the WTC complex resulted in building modifications that affected the spread of fire and smoke within WTC 1 and WTC 2 in the event of a fire, and had the potential to impact the smoke management systems installed in the towers. The first incident involved a major fire that occurred on the 11 th floor of WTC 1 on February 14, 1975. The second incident resulted from a car bomb that exploded in the WTC complex parking garage on February 26, 1993, resulting in smoke spread throughout the towers.

Three important engineering studies were performed pertaining to the smoke management systems in WTC 1 and WTC 2. A study of an early prototype stair pressurization system was performed in WTC 1. This study was examined to understand the feasibility of employing stair pressurization in the towers. Two engineering studies were performed subsequent to the 1993 bombing that examined the effectiveness of various smoke management approaches and recommended changes to the smoke management system design for the towers.

\section{E.3.1 WTC 1 Fire-February 13, 1975}

On February 14, 1975, a fire occurred in WTC 1. The fire originated from an unknown source at approximately 11:30 p.m. in an office suite occupying roughly the entire southeast quadrant of the 11 th floor of the building.

A worker noticed the fire and reported it to the WTC police headquarters. The city fire department was called; three policemen responded to the fire floor with a fire equipment cart (typically stationed in the 44 th and 78th floor sky lobbies of each tower), and the building engineer was advised to be prepared to put the HVAC system in the "purge" mode. When police reached the fire floor, they reported a serious fire and the HVAC system was placed in the purge mode.

In accordance with New York City Local Law No. 5, the floor had been subdivided into quadrants via fire barriers, which contained the fire to the southeast quadrant of the building. The fire involved roughly $9,000 \mathrm{ft}^{2}$ of the 11 th floor, destroying about half the contents and damaging the remainder of the contents in this area. Because fire barriers did not extend into the return plcnum above the office space on each floor, hot smoke migrated around the perimeter of the floor within the open return plenum and was exhausted via the exhaust risers serving the other three quadrants of the building. The fire was eventually extinguished by the New York City Fire Department (FDNY).

The published accounts of the 1975 fire describe the use of the WTC 1 smoke purge sequence as an active fire protection measure used to improve conditions during the fire, as opposed to using the HVAC system purge as part of post-fire cleanup efforts. These reports document that during a fire, office areas could be put on 100 percent exhaust, with the core getting 100 percent supply, accomplished in 32 floor segments corresponding to a single HVAC zone. Because this sequence differs from the sequence of operations 
listed in the building operations manuals with regard to the operation of the smoke purge sequence, it is unclear what the actual smoke purge sequence was at the time of the 1975 fire.

The primary enhancement to WTC 1 and WTC 2 following the 1975 fire that impacted the issues of smoke movement and smoke management in the buildings was an improvement with regard to the provision of firestopping to unsealed vertical penetrations. The fire illustrated the ability of fire and smoke to spread vertically in high-rise buildings via unprotected vertical openings.

\section{E.3.2 WTC Bombing-February 26, 1993}

On February 26, 1993, a bomb exploded in a parking garage located in the sub-levels of the WTC complex. When the building HVAC systems shut down due to loss of electrical power, the building was subjected to extreme stack effect forces, since at the time of the bombing the outside temperature was in the twenties (degrees Fahrenheit). Because the explosion caused penetrations into several elevator shafts in WTC 1 on the sub-grade levels, in addition to creating openings into the lobby level, smoke was rapidly transported to the upper portions of the WTC 1 due to forces caused by the explosion and stack effect.

A review committee was convened by the City of New York subsequent to the 1993 bombing that included representatives from the New York City Building and Fire Departments and the Port Authority of New York and New Jersey (PANYNJ or Port Authority). The committee concluded that the "complex issue of smoke control" was beyond the scope of the committee at that time and required future review. However, the committee recommended that building code requirements for smoke dampers should be clarified and that elevator lobbies should be provided in new high-rise buildings to resist the passage of smoke. Despite this recommendation, elevator lobbies are only required in high-rise residential buildings under the current provisions of the BCNYC.

The report concluded that stair pressurization systems, not installed in the WTC towers, would not function in an incident involving a mass evacuation due to the simultaneous opening of more than three stairway doors. The report did conclude, however, that the BCNYC (Reference Standard 5-18) lacked regulatory provisions for periodic testing and maintenance of stair pressurization systems and recommended that these requirements be added. Finally, the committee report recommended that the issue of providing fire towers in new high-rise commercial office buildings be revisited. The requirement for fire towers (stairways separated from the interior environment of the building via open-air balconies) was included in the 1938 edition of the BCNYC, but removed in the 1968 edition of the code. Fire towers are not required under the current provisions of the BCNYC.

A number of changes were eventually made to the buildings as a result of the committee's recommendations. Improvements were made to exiting, and a new fire alarm system was installed in each building. In one published account of the 1993 bombing it was purported that emergency power was provided for smoke purge fans. No other sources were found to corroborate this assertion.

The 1993 bombing demonstrated that the stack effect could be a primary driver of rapid smoke spread through high-rise buildings. The bombing showed that large amounts of smoke can be transmitted to the upper floors of a building due to a fire on the lower floor of the building, particularly when that fire produces a large quantity of smoke, such as was the case for the terrorist bombing. The 1993 bombing 
also clearly demonstrated that, as expected, stack effect is enhanced by openings created in the vertical shafts within the building, such as stair and elevator shafts.

Smoke spread via the stainvays was substantial in the building during the 1993 event due to the large number of open stair doors occurring as a result of the mass evacuation of occupants in the building. The stairways, which were designed to provide an exit capacity that met or exceeded prevailing code requirements for the buildings, did not provide the exit capacity to ensure rapid egress of all of the occupants of the building. As a result, doors remained blocked open by building occupants entering/exiting the stairways, increasing the magnitude of the airflow up the stairs due to stack effect.

The 1993 bombing also clearly showed the importance of emergency power to maintain the function of building systems, including emergency lighting systems, in the event of a fire.

\section{E.3.3 Engineering Studies}

Several engineering studies were performed between the time the WTC complex was constructed and the WTC disaster to evaluate candidate smoke management system approaches for various areas of the complex. Three particular studies were conducted to examine smoke management systems in the towers (WTC 1 and WTC 2). These studies must be considered in the evaluation of the smoke management systems actually in place on September 11,2001.

Between 1976 and 1979. the Port Authority performed a study aimed at understanding the feasibility of providing stair pressurization systems in WTC 1 and WTC 2. Beginning in 1976, tests were run using building air handling systems located in the 7th floor MER and 41st floor MER of WTC 1, reconfigured to supply air to Stair 3.

This stair pressurization system study examined stair pressurization system performance with the building HVAC systems in normal mode and smoke purge mode. At the time of the study, the smoke purge sequence was defined as pressurizing the core using core supply ventilation and exhausting the interior spaces using the low pressure return fans. Perimeter supply/exhaust fans were shut down in purge mode.

The study demonstrated that the system as designed was unable to meet the performance criteria outlined in Local Law No. 5. With three doors open, differential pressures were generally low. With doors closed, door opening forces were excessive. The study concluded that stair pressurization systems should be installed based on the prototype design, with modifications being made to the design as stair pressurization technology improved. Based on the results of the study, construction drawings were prepared outlining the proposed stair pressurization systems.

Local Law No. 86 (enacted on December 13, 1979) stated that existing buildings shall be exempt from the smoke shaft and optional stair pressurization requirements if they were provided with automatic sprinklers throughout. A decision was made sometime after this date to fully sprinkler WTC 1 and WTC 2. As a result, stair pressurization systems were never installed in WTC 1 and WTC 2.

Subsequent to the 1993 bombing, an analysis was performed by Rolf Jensen \& Associates (RJA). The SMOKESIM computer model was used to verify and explain the movement of smoke in WTC 1 following the explosion. The report also addressed the potential effectiveness of elevator venting, stair venting, and stair pressurization to improve conditions in the building. 


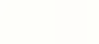


was constructed was modified/supplemerted to add smoke management system capabilities during tenant retrof ft6. Instances where conflicting or incomplete information was provided are fully documented in this report.

\section{E.4.1 WTC 1 AND WTC 2}

The tower buildings (WTC 1 and WTC 2) were equipped with a non-dedicated smoke management system (a smoke purge system). Non-dedicated refers to the fact that the system utilized the base building HVAC systems that provided ventilation to the buildings under normal operating conditions, as opposed to a dedicated system that only existed for the purposes of smoke management. No dedicated smoke management systems were installed in the buildings.

The normal base building HVAC systems could be manually configured or operated in a smoke purge mode that allowed smoke to be removed from the building. Smoke purge could only be accomplished for an entire ventilation zone served by a particular MER; thus, in the smoke purge mode the entire ventilation zone represents a single smoke zone. Because no operable fire/smoke dampers were present within the ventilation ductwork, it was not possible to provide the smoke purge, or any other smoke management sequence, on a floor-by-floor basis.

Smoke detectors were located at the exhaust duct inlets on each floor and within the HVAC system ductwork in the MER to provide automatic shutdown of individual fans in the presence of smoke. Automatic shutdown of the ventilation systems could be overridden in the smoke purge mode.

The fire safety plan for WTC 1 and WTC 2, revised in January of 1999, defines smoke purge as the removal of smoke and other gaseous combustion products from the (fire) area "after a fire has been extinguished." As documented in the fire safety plan, mechanical systems could be configured to perform the smoke purge function by the Port Authority mechanical section staff when requested by the chief officer of the responding FDNY units. The FDNY would ask the WTC fire safety director to provide a smoke purge for a given zone. The WTC fire safety director would then instruct the mechanical section staff to perform the requested action.

The smoke purge sequence is documented in WTC Instruction Manual No. 23, Operation and Maintenance of Fire Protection Sy:stem, dated February 1986. The documented sequence involves using the interior exhaust fans to exhaust an entire multi-floor ventilation zone. Based on the information contained in the fire safety plan for WTC 1 and WTC 2 and WTC Instruction Manual No. 23, it could be concluded that the buildings were equipped with a manual purge system that utilized the interior zone exhaust fans serving the four quadrants of the building to remove smoke after a fire was extinguished. Core supply/exhaust fans and perimeter supply fans would be shut down. Smoke purge could be accomplished within each HVAC zone, the largest of which had 32 floors. However, a number of sources were found containing conflicting information regarding how the smoke purge system functioned and how it was intended to be used.

Accounts of the 1975 fire state that the smoke purge sequence pressurized the core with 100 percent outside air and exhausted 100 percent from the office spaces. These accounts also state that during the 1975 fire, the smoke purge sequence for the fire floor and adjacent floors was initiated from the appropriate MER shortly after discovery of the fire, once police had examined the fire floor and identified the presence of a significant fire. This documented sequence of events is important, as it signifies that the 
system was used at that time as an active fire protection system, to control smoke during the fire event and that the documented "core pressurization" mode differed from the sequence of operations.

WTC Instruction Manual No. 23 makes the statement that "in the event of smoke in an interior tenant's space involving personnel evacuation, the smoke purge procedure to be used is as follows..." In referencing an event involving personnel evacuation, this statement also implies use of the smoke purge sequence as an active fire protection sequence rather than a post-fire smoke cleanup sequence. The Federal Emergency Management Agency (FEMA) report summarizing events on September 11, 2001, states (in Sec. 2.1.3.3) that, "a zoned smoke control system... was designed to limit smoke spread from the tenant areas to the core area, thereby assisting both individuals evacuating from an area and those responding to the scene by limiting smoke spread into the core." Again, this statement implies an active smoke management system based on the concept of pressurizing the core, which conflicts with the documented smoke purge sequence for the buildings.

The Port Authority was asked to clarify the operation of the smoke purge sequence, since the available information regarding its intended operation provides conflicting accounts of smoke purge operation. According to the Port Authority, 'the operation of the smoke purge sequence is as follows:

During a fire/smoke incident, the fans stayed in operation until shut down by a smoke detector on interlocking exhaust fans or at the direction of FDNY. FDNY would also direct what mode of operation the fans should be in. If fans were still operating, as would often be the case, the engineer at FDNY direction would key over to purge mode. This would sequence spill dampers to open $100 \%$. In addition, building operating procedure during a purge was to run the interior supply fans for purging [the] affected quadrant. During purge, the interior fan's outside supply air dampers would go to $100 \%$ open. For example, during a smoke incident on 38NE in tower one, ACS 41-6 [northeast interior supply fan] would be operating on purge, outside damper open 100\%. ACR 41-4,5 and/or 6 [northeast interior return fans] would be operating on purge, spills open $100 \%$. Core fans would not normally operate during a smoke purge unless conditions warranted and requested by FDNY.

According to the Port Authority, smoke purge would occur by starting the supply and exhaust fans serving one of the four interior quadrants within a ventilation zone. Core supply/exhaust fans and perimeter supply fans would be shut down. HVAC systems serving the other ventilation zones in the building would be left operating unless they were shut down at the direction of FDNY. The Port Authority further recognized that WTC Instruction Manual No. 23 had not been updated since the base building fire alarm system was upgraded after the 1993 bombing. Therefore, this manual did not always reflect the most current fire protection system configuration.

Operation of the smoke management system for WTC 1 and WTC 2 could be achieved by aligning the equipment within the individual MERs or at a central control panel located in the Operations Control

1 E-mail communication from the Port Authority to NIST, dated February 18, 2004, responding to questions posed by NIST. 
Center (CCC) on the B1 level of WTC 2. At either location, building personnel had to perform two distinct operations:

1. Align the HVAC systems in smoke purge mode.

2. Start the appropriate HVAC fans.

Operation of the purge switch aligned all dampers that served as part of that quadrant's HVAC systems in a 100 percent outside air configuration. This would mean that supply and spill dampers would be fully open and that return dampers would be closed.

To achieve the smoke purge, it was up to the operator of the systems to turn on thosc fans necessary to achieve system operation. It would be equally possible to initiate an exhaust only type sequence as outlined in the fire safety plan, the core pressurization sequence (supply and exhaust operating) reportedly initiated during the 1975 fire, or the sequence stated by the Port Authority as the smoke purge sequence in effect on September 11,2001. Alignment of the system would be up to the understanding of the operator as to the proper function of the smoke purge sequence, when called upon to initiate this sequence.

With regard to the use of the smoke purge function to aid in active smoke management during a fire event versus during post-fire cleanup operations, it would be up to the responding fire department personnel to initiate system operation. Depending on the type of fire event, it is possible that the system could have been used either during the fire or after it was extinguished.

For the purposes of this report. the function of the smoke purge system documented by the Port Authority was assumed to be in effect on September 11,2001. It was also assumed that the system was to be uscd after the fire was extinguished, at the discretion of the responding fire departmcnt personnel.

At the time the buildings were constructed, the ability to provide a smoke purge from each HVAC zone was the only smoke management system provided in the buildings. When it was enacted in 1973, Local Law No. 5 retroactively imposed the requirements for smoke shafts for existing high-rise buildings. In lieu of such smokc shaft(s), stair pressurization systems could be provided.

In order to rcspond to the requirements of Local Law No. 5, the Port Authority initiated a pilot study into the requirements for pressurizing the exit stairs in WTC 1 and WTC 2. Stair pressurization was examined as a means of meeting the requirements of Local Law No. 5 since the smoke shaft rcquirements would have been prohibitive for a building the size of WTC 1 and WTC 2. Existing buildings that were sprinklered throughout were exempt from the smoke shaft and optional stair pressurization requirement by Local Law No. 86 (enacted in 1979). A decision was made at some subsequent time to fully sprinkler the WTC buildings. Therefore, the Port Authority did not move forward with the stair pressurization option. Because WTC 1 and WTC 2 were fully retrofitted with automatic sprinklers, smoke and heat venting and/or stair pressurization was not required in WTC 1 and WTC 2 on September 11, 2001.

WTC 1 and WTC 2 were equipped throughout with fire dampers at duct penetrations into vertical shafts, as required by the BCNYC. Combination fire/smoke dampers were not required by the code to be provided in existing buildings. Since tenant retrofit projects generally connected to the existing base building systems, fire/smoke dampers at HVAC shafts were not generally provided during tenant retrofits. 
As documented in Chapter 3, emergency power was not retroactively required by the $\mathrm{BCNYC}$, but was provided following the 1993 bombing in WTC 1 and WTC 2 serving all emergency systems (lighting, fire alarm system, etc.) and the building elevators. While one account summarizing the building restoration activities following the 1993 bombing purported that emergency power was provided for smoke purge fans, the Port Authority stated that emergency power was not provided to WTC 1 and WTC 2 base building smoke purge fans. However, the MERs were equipped with redundant power sources from different substations.

No other redundant features were identified with respect to the HVAC systems used to accomplish the smoke purge functions. No back-up systems or emergency power was provided.

\section{E.4.2 WTC 7}

WTC 7 was designed with a dedicated smoke management system (a smoke purge system) that utilized dedicated HVAC equipment that served only a smoke management function. This type of system differed from that used in WTC 1 and WTC 2, which utilized the HVAC systems that provided normal ventilation to the buildings to perform the smoke purge function. In WTC 7, dedicated smoke exhaust fans/dampers could be manually aligned at the fire command center to provide smoke purge from a specified floor within the building. Since the smoke purge function could be provided on a floor-by-floor basis, each floor of the building constituted an individual smoke control zone.

The building operations manual for WTC 7 specifies three alarm modes pertaining to operation of the building HVAC systems. ALARM-1 initiated shutdown of HVAC equipment based on duct smoke detection. ALARM-2 initiated smoke purge on the affected floor. ALARM-3 specified the smoke purge sequence for non-affected floors. The smoke management sequence pertaining to the smoke purge function involved exhausting the fire floor and pressurizing the remaining floors with supply air.

Local Law No. 16 required that all buildings in occupancy group $\mathrm{E}$ (business) be provided a manual override capability to exhaust one floor at a time at a rate of 6 air changes per hour, or $1 \mathrm{cfm} / \mathrm{ft}^{2}$, whichever is greater. For WTC 7, with a footprint area of approximately $48,000 \mathrm{ft}^{2}$, this would require an exhaust capacity of at least $48,000 \mathrm{ft}^{3} / \min \left(81,552 \mathrm{~m}^{3} / \mathrm{h}\right)$. The base building system serving the lower floors (up to the 23rd floor) of the building provided a smoke exhaust capacity of $36,000 \mathrm{ft}^{3} / \mathrm{min}$ $\left(61,164 \mathrm{~m}^{3} / \mathrm{h}\right)$, which is not consistent with the minimum value specified by code. An $84,000 \mathrm{ft}^{3} / \mathrm{min}$ $\left(142,716 \mathrm{~m}^{3} / \mathrm{h}\right)$ exhaust fan was provided for the SSB floors during the tenant retrofit.

WTC 7 was sprinklered throughout and was therefore exempted from the requirement for stair pressurization systems. The building was provided with a Class E fire alarm system per code, was provided with emergency power serving all emergency systems, and was equipped throughout with fire dampers at duct penetrations into vertical shafts.

\section{E.5 EVALUATION OF SYSTEM PERFORMANCE ON SEPTEMBER 11, 2001}

The purpose of this study was to document the normal operation of the fully functional smoke management systems on smoke conditions in WTC 1 and WTC 2 on September 11, 2001. Elements involved the evaluation of expected system performance for postulated design fires in business 
occupancies, as well as documentation of the expected performance of fully functional smoke management systems in the towers.

The smoke management systems in WTC 1 and WTC 2 were designed to provide a manual smoke purge function. Given the design and intended operation of the smoke management systems, two key questions must be answered to approximate the performance of the system on September 11, 2001:

1. Was manual operation of the smoke purge systems in either WTC 1 or WTC 2 initiated by emergency response personnel?

2. Were the systems capable of operating given the damage caused by the aircraft impacts on each building?

In order to answer the second question, damage to both the building electrical and mechanical systems had to be evaluated. It had to be determined whether electrical power was available to the building mechanical systems subsequent to impact so that they were capable of operating. Then, potential damage to HVAC system components had to be evaluated to determine whether the systems were capable of performing as designed.

\section{E.5.1 Actions of Emergency Response Personnel}

The events of September 11,2001, clearly represented an extraordinary challenge, both to emergency response personnel, and to the installed building systems. The damage caused by an aircraft impact into a building is outside the range of typical design considerations for most building systems, including fire protection systems. In addition, from a fire department perspective, a fire involving multiple floors of the uppermost portion of WTC 1 or WTC 2, or worse in both buildings simultaneously, represents a difficult operational environment.

As documented in Chapter 7, the WTC fire safety director on duty on September 11, 2001 stated that no recommendation was given on his part to initiate a smoke purge sequence, nor was smoke purge performed on September 11, 2001, to his knowledge. There is no record of FDNY personnel having initiated a smoke purge sequence in WTC 1 or WTC 2.

Radio and phone traffic from various sources was reviewed in an effort to determine if any attempts were made to manipulate building ventilation systems or initiate the smoke purge sequence locally from one of the MERs in WTC 1 or WTC 2. One reference to smoke purging was found where a maintenance worker reporting heavy smoke from "Stair A" on the 103rd floor in WTC 1 transmitted the message "Need immediate purge." At roughly the same time, an unidentified male was recorded on the same radio channel transmitting the message "Electric, we have Staircase C (inaudible), is there any way to pump any outdoor air in?" No conversations were identified confirming use of the ventilation systems.

\section{E.5.2 Damage to System Components}

The exact extent of damage within individual floors of WTC 1 and WTC 2 may never be known because the collapse of the buildings prohibited a detailed inspection of the impact area. However, the potential extent of damage was estimated based on the results of engineering analysis and based on observations recorded by people located within WTC 1 and WTC 2 at the time of the events. 
Potential damage estimates were overlaid onto representative floor plans for the impact areas in WTC 1 and WTC 2 in order to determine the potential damage to key electrical/mechanical system components located in the core spaces. The damage estimates wcre corroborated to a ccrtain extent by observations of people in various locations in the buildings after aircraft impact. The observers primarily described stair shaft damage, damage to freight elevator 50 , and in some cases elevator shafts. HVAC shaft conditions could be corroborated by visual evidence of smoke spread seen from the exterior of the building. An attempt was also made to corroborate the extent of core damage using obscrvations of the presence of power in the building.

Numerous accounts were recorded of all three exit stairs in WTC 1 being blocked on the 92nd floor and above. The extent of damage into the core of WTC 1 is also evidenced by damage to elevator shafts in the core, particularly freight elcvator 50. A notable event occurring in WTC 1 was a reported "explosion/fireball" that occurred in the lobby of WTC 1 due to jet fuel that was ignited at the base of an elevator shaft. This is further evidence of core damage as far in as the express elevator shafts.

In WTC 2, the core layout was such that the three exit stairs were located remotely from one another on the impact floors. As a result, the aircraft impact left the northwest stair in the building (Stair 1) relatively undamaged. At least four survivors were able to safely exit the building via Stair 1 from floors as high as the 91 st floor. However, given that damage to two out of three exit stairs was substantiated by survivor testimony and that significant damage was caused to the exterior walls in the northeast corner of WTC 2 , the path of damage would also logically include the ventilation shafts located on the east half of the impact floors.

Potential damage to the HVAC shafts was also determined to some degree by examining photographic evidence depicting the exterior of the buildings after the time of aircraft impact. Initial damage estimates support the hypothesized damage to the HVAC shafts in one-half of each building within the impact zone. The damage would have created large holes in the gypsum wallboard exhaust shafts and potentially shear off or collapse metal supply ductwork. If the HVAC shafts were undamaged, the fire dampers at the HVAC shaft walls would have been expccted to close in an intense fire, limiting the extent of airflow via the ventilation shafts. Fire dampers would not be expected to be as effective in limiting smoke spread as combination fire/smoke dampers, which are designed to be smoke-tight and close earlier in the fire event.

In WTC 1, spread of large amounts of smoke via the ventilation shafts was evident in the examination of pictures of the exterior of WTC 1 subsequent to impact. A significant amount of smoke can be seen exiting the 108th floor MER from a localized area on the north face of the building and along the length of the west face of the building. At the 108th floor MER in WTC 1, the smoke emanating from the north face of the building corresponds to the location of the supply fan inlet for the northwest interior supply zone. The exhaust plenum for the northwest quadrant exhaust fans is located along the west face of the MER. The visual evidence supports damage to the primary ventilation shaft serving the northwest quadrant of the impact zone.

Since the damage estimate suggests similar damage to the northeast shaft, a similar pattern of smoke exiting the 108th floor MER would be expected to be seen at the northeast supply inlet and east exhaust outlets. However, due to the direction of the wind driven smoke plume from the fire toward the southeast, it is difficult to see patterns of smoke emanating from the MER at this location on the exterior of the building. Therefore, large amounts of smoke exiting supply/ventilation shafts serving the northeast quadrant of the impact zone, which would substantiate the shaft damage to the northeast quadrant 
ventilation shafts, could not be verified from visual observations of the exterior of the building, as the smoke plumes obscured views of this area of the building.

Once smoke enters the ventilation ductwork, it can very quickly spread to all areas of the upper floors of the building via the air distribution plenum in the ceiling. This is contrasted to smoke entering a floor via elevator doors, which might have to pass through multiple barriers in the core and office space to reach the perimeter offices. As a result, smoke spread via the ventilation shafts has the potential to cause a more rapid deterioration of smoke conditions in the perimeter office spaces than smoke spread via the elevator and stair shafts.

The hypothesized rapid spread of smoke vertically via the ventilation shafts in WTC 1 is supported by the fact that smoke conditions became untenable (high heat/high toxicity) to the extent that people trapped on the uppermost floors of WTC 1 were observed breaking windows to obtain outdoor air and some jumped from the building to escape the rapidly deteriorating conditions in the building shortly after impact in WTC 1. The FDNY noted people jumping from the building shortly after their arrival in the lobby of WTC 1 .

In WTC 2, shaft damage (stair/elevator/ventilation shafts) would also have caused smoke to spread upward through the building. However, in WTC 2 the ventilation shaft above the 83 rd floor impact terminated at the $91 \mathrm{st}$ floor. This prevented a direct pathway for the smoke to follow to the uppcr floors. Smoke would have to spread upward into the building to floors above the 91 st floor through the other primary vertical airflow paths, which were limited primarily to the local elevator banks.

The fact that there were relatively few vertical airflow paths between the impact zone in WTC 2 and the uppermost floors of the building is supported by the length of time conditions remained tenable in some areas of the upper floors of the building. Numerous occupants of WTC 2 were trapped on the upper floors of the building, and several people used their cell phones to call family members. The experience of occupants on the upper floors of the building supports the fact that spaces in the uppermost portion of WTC 2 were tenable for periods as long as 45 min after impact.

An attempt was made to identify the presence or lack of power to the MER floors serving the impact zones in WTC 1 and WTC 2 by using survivor testimony and transcripts of phonc calls made by people trapped above the impact zone. Little evidence was available regarding the presence of electrical power, particularly on the upper floors of the buildings. Isolated reports were noted of "lights flickcring" and going out in the buildings. These accounts also corresponded to floors where ceiling collapse and other minor structural damage was noted. Therefore, loss of lighting could have coincided with local structural damage rather than being indicative of an overall loss of electrical power. Despite the lack of definitive survivor testimony with regard to the presence of electrical power in WTC 1 and WTC 2, estimates support damage to one or more of the electrical closets/risers in each building. In WTC 1, damage likely occurred to both the north and central electrical closets/risers. In WTC 2, damage likely occurred to at least the east electrical closet/riser.

\section{E.5.3 Summary of System Performance on September 11, 2001}

Examination of the available evidence provides strong indications that the smoke management systems in WTC 1 and WTC 2 played no role in the events that occurred on September 11, 2001. There is no evidence to support the fact that an attempt was made to activate the smoke purge sequence. In the chaos 
following the aircraft impacts and preceding the collapse of the buildings, the focus was on rescue operations rather than on manipulation of building systems.

Should a decision have been made to attempt to align the building ventilation systems into the smoke purge mode, it is doubtful that this would have had any impact on overall smoke conditions within the building. Upon arriving at the scene FDNY personnel had a difficult time determining the exact floors of impact, especially for WTC 1 . Since the WTC 1 impact occurred near the boundary between ventilation zones at the 91 st/92nd floors, and the impact was thought to have originally occurred on floors somewhere between the 80th and 90th floors (Smith 2002), smoke purge may have been inadvertently initiated for the 59th-91st floor HVAC zone in WTC 1.

The aircraft impacts caused significant damage to the core spaces in both WTC 1 and WTC 2, making it unlikely that the smoke purge could have been accomplished in either building. In WTC 1, it is likely that the impact eliminated or significantly impaired electrical power on floors above the impact zone.

Therefore, because power would not have been available at the 108th floor MER (which served the zone of impact), HVAC systems would not have been operational. In addition, the ventilation shafts for at least the north half of the building were likely damaged, thus reducing the possibility for the smoke purge to function properly even if the HVAC systems had been operable.

In WTC 2, it is possible that electrical power may have been available to the fans located in the 75th floor MER, which was located below the impact zone in this building. Survivor testimony indicates that power may have been available up to the 75th floor. Initially, all fans would have shut down due to detection of substantial quantities of smoke by the duct smoke detectors. Damage estimates suggest that the HVAC shafts utilized to accomplish smoke purging would likely have been damaged on the east side of the building, eliminating half of the smoke venting capacity for the floor. Even if the ventilation shafts on the west side of the building remained intact, the performance of the smoke venting system would have been reduced. Damage to HVAC shafts had a particularly detrimental impact on WTC 1, where smoke conditions deteriorated in the uppermost portions of the building at a much faster rate than WTC 2 .

\section{E.6 EVALUATION OF POTENTIAL SMOKE MANAGEMENT SYSTEM EFFECTIVENESS}

In order to fully understand the potential impact of smoke management systems for events like those occurring on September 11,2001, it is important to analyze how various smoke management system configurations might have performed in WTC 1 and WTC 2, had they been available on September 11, 2001. To develop an understanding of the capabilities of the various smoke management system configurations that were evaluated, it is also important to analyze their performance for other hypothetical fire scenarios in high-rise buildings, both typical/expected design scenarios and worst case scenarios. All of the smoke management approaches analyzed utilized some variation of the pressurization method of smoke management. The pressurization method is the smoke management system design method for well-compartmented structures with low-ceiling spaces.

The performance of each of the smoke management approaches, given the postulated design fire scenarios, was evaluated using the CONTAM building airflow and contaminant dispersal model, developed by NIST. CONTAM is a recognized tool for the evaluation of smoke management systems that are based on the pressurization method of smoke management. Based on a review of the various issues 
relating to the use of tenability (dilution) analysis, it was determined that the pcrformance of the candidatc smoke management approaches would be evaluated based solely on the ability to provide pressure differentials consistent with the pressurization method of smoke control.

The various codes and standards that reference the use of pressurization smoke control require the provision of 0.05 in. $\mathrm{H}_{2} \mathrm{O}(12.5 \mathrm{~Pa})$ pressure differentials in sprinklered buildings and 0.1 in. $\mathrm{H}_{2} \mathrm{O}(25 \mathrm{~Pa})$ in non-sprinklered buildings to contain smoke. It is important to note, however, that these pressures are measured with a building's HVAC systems placed in smoke management mode, without the presence of a fire. The required pressure differentials are high enough to contain heated smoke were a fire to be present in sprinklered and non-sprinklered occupancies, and are used for design purposes. Since the modeling performed using CONTAM includes the temperature of the fire compartment as a parameter in the model, it is only necessary that the system maintain a positive pressure differential to contain smoke when the barrier across which the pressure is maintained is fairly tight. For barriers containing large openings, creation of a positive pressure differential may not be sufficient to contain smoke. Unless sufficient airflow velocity is applied to hold back the smoke, two-ivay flow will occur. Heated smoke will flow from the fire compartment at the uppermost portion of the large opening, and pressurization air will be introduced into the fire compartment through the lower portion of the large opening.

The CONTAM model of WTC 1 that was constructed as part of the $1996 \mathrm{HAI} / \mathrm{DCE}$ study was used as the baseline to which modifications were made to perform the modeling effort documented in this report. As part of the 1996 study, calibration measurements were made of actual airflows and pressure differentials obtained at various locations in WTC 1 for different ventilation modes. For the current modeling effort, the 1996 calibration data were reviewed, and an attempt was made to better calibrate the model to match the data. Limitations relating to the calibration data included several uncertainties that existed with regard to the accuracy of the reported data, and the determination of the exact configuration of the building (openings and HVAC system alignment) at the time the calibration measurements were made.

After extensive effort, it was determined that a single building configuration could not be developed that conclusively matched the 1996 calibration data. The primary obstacle was the existence of too many independent variables (leakage types, wind/weather conditions, HVAC system alignments, design versus measured supply/return airflow, unknown architectural changes to individual floor plans) to allow for a single building model that matched all of the data for the various ventilation modes. It was determined that in order to accurately represent the uncertainty involved in the type of modeling being performed, and the potential range of results given this uncertainty, three separate building configurations would be used in the modeling. Examining the CONTAM results for a particular fire scenario/smokc management approach for the three building configurations as a group cnabled an assessment of whether smoke management may have been effective for that fire scenario.

\section{E.6.1 Smoke Management System Approaches}

Five distinct smoke management approaches were examined for the WTC towers. These approaches are as follows:

1. Smoke Purge

2. Core Pressurization 


\section{Building Pressurization}

\section{Sandwich Pressurization}

\section{Zoned Smoke Control with Stair Pressurization}

The smoke purge approach is based on the documented smoke purge sequence for WTC 1 and WTC 2 as it appears in WTC Instruction Manual No. 23, Operation and Maintenance of Fire Protection System, dated February 1986. The sequence involved placing the interior HVAC zone exhaust fans and core exhaust fans (toilet exhausts, elevator machine room [EMR] exhausts) in the multi-floor ventilation zone containing the fire in 100 percent exhaust mode. HVAC systems in all other ventilation zones in the buildings were aligned in a summer normal mode. Perimeter supply fans were shut down.

The core pressurization approach is a slight variation of the documented smoke purge sequence for WTC 1 and WTC 2, in that rather than the exhaust fans in the core, the core supply fans were activated to prohibit smoke spread into the core from the surrounding office spaces. Accounts of the 1975 fire and other sources cite this variation as being the "smoke purge" sequence provided for the building.

The building pressurization approach is an approach that was recommended in the $1996 \mathrm{HAl} / \mathrm{DCE}$ study. This approach was recommended to be used in the event of a severe fire involving a substantial portion of one floor of the building, where windows were observed to be broken out. The approach involves turning on the supply fans in the entire building and turning on the exhaust fans only in the ventilation zone of fire origin. The intent of this approach was to exhaust smoke where possible from the floor containing the fire, and to induce a substantial airflow toward the floor of fire origin to force smoke out of the broken windows.

The sandwich pressurization approach was not previously examined for WTC 1 and WTC 2 in any of the engineering studies reviewed in the preparation of this report. The approach analyzed is not the classic floor-by-floor sandwich approach, which involves exhausting the floor of fire origin and pressurizing the floors above and below. The HVAC systems in WTC 1 and WTC 2 were not equipped with operable fire/smoke dampers; thus, it was not possible to configure the system to exhaust and supply to only single floors within a ventilation zone. Instead, an approach was examincd where the sandwich was achieved by ventilation zones. In the event of a fire, the ventilation zone of origin would have all of its exhaust fans turned on, and supply fans turned off. The ventilation zones above and below would have all supply fans activated and exhaust fans turned off. These actions would create a multi-floor sandwich effect in the building, with the net effect being the crcation of a pressure differential between the core and perimeter spaces within the HVAC zone of fire origin.

The final approach analyzed, zoned smoke control with stair pressurization, was an approach based on best practices in smoke management system design enforced in many jurisdictions in the United States as of Scptcmber 11, 2001. It was assumed that the building was retrofitted with stair pressurization systems, as required for all new high-rise construction by the major building codes in the United States, and was capable of exhausting on a floor by floor basis within the ventilation zone containing the fire to create the desired pressure differential with respect to the floors above and below. Other ventilation zones were assumed to operate in the summer normal mode. It was assumed that operable fire/smoke dampers were also installed in all supply/exhaust ducts at the appropriate shaft connections and that these dampers were closed within the zone of fire origin. 


\section{E.6.2 Design Fire Scenarios}

Several different design fire scenarios were evaluated for WTC 1 and WTC 2, encompassing the range of expected fires that could be envisioned within the office spaces of the building. The fire scenarios were limited to those that could occur on the above-grade office floors of the building. Other possible fire scenarios could result in smoke migration through the towers due to a fire in the sub-gradc areas or adjacent spaces within the WTC complex (i.e., truck dock fire, car fire in the garagc, fire in the concourse). Because the focus of this report is on examining the fires that occurred on September 11, 2001, (which occurred on the uppermost floors of the building) and bounding these events with other comparable fires, it was relevant to examine only those fire scenarios on the office floors of the building. The design fire scenarios that were evaluated are as follows:

1. Sprinklered Fire

2. Full-Floor Burnout

3. Two-Floor Fire

4. WTC 1 and WTC 2, September 11, 2001, Fire Scenarios (No Shaft Damage)

5. WTC 1 and WTC 2, September 11, 2001, Fire Scenarios (Shaft Damage Assumed)

The first fire scenario assumes that a typical fire in a sprinklered building would typically involve only a single fuel package, or a small number of adjacent fuel packages, and would either be controllcd by the automatic sprinkler system, or be extinguished. A simplifying assumption is to assume that the temperature in the zone of origin never exceeds the opcration temperature of the sprinklers, which were assumed to have an activation temperature of $165^{\circ} \mathrm{F}\left(74^{\circ} \mathrm{C}\right)$. Given the large size of the majority of the office spaces in the towers, some of which encompassed an entire floor, the avcrage tempcraturc throughout the floor would be expected to be lcss than the assumed $165^{\circ} \mathrm{F}$.

The second fire scenario, the full-floor burnout scenario, is a design scenario for a fire involving the contents of a typical office building floor. In a fully-sprinklered building, a full-floor burnout would only be possible with some sort of catastrophic failure of the sprinkler system, or with a fuel load that excceds the capacity of the sprinkler system. The full-floor burnout scenario is essentially the same as the "uncontrolled fire" sccnario analyzcd in the $1996 \mathrm{HAI} / \mathrm{DCE}$ study. The full floor burnout firc scenario evaluated in this report assumed a temperature on the floor of fire origin of $1,800^{\circ} \mathrm{F}\left(1,000^{\circ} \mathrm{C}\right)$, consistent with the tcmperature assumed in the 1996 rcport for fully involved fires. This fire scenario assumed that 58 windows on each face (as assumed in the 1996 study) were broken out. This provided a sufficient influx of air to sustain roughly a $250 \mathrm{MW}$ fire.

The third fire scenario, the two-floor fire scenario, corresponds to a multi-floor event caused by a small explosion. The purpose of this fire scenario was to examine smoke management system performance for a multi-floor fire scenario of far less severity than the aircraft impact caused on September 11, 2001. This scenario also challenges the typical floor-to-floor separation that exists in typical building fire scenarios due to an intact floor slab. The fire scenario assumes that a small explosion has opened up a $100 \mathrm{ft}^{2}(9.3$ $\mathrm{m}^{2}$ ) hole in the floor slab at the midpoint along one of the faces of the building. The explosion does no damage to the core but causes half the windows on the near face of thc building to be blown out by the 
blast. It is assumed that sprinkler piping may be damaged, but some sprinklers opcrate, to reduce the overall temperature on the two open floors of the building. The average temperature on the two floors is assumed to be identical to that of the sprinklered fire scenario, $165^{\circ} \mathrm{F}\left(74^{\circ} \mathrm{C}\right)$.

The fourth fire scenario was used to model smoke management system performance under the conditions in WTC 1 and WTC 2 on September 11,2001. Estimates of the size of the exterior openings after aircraft impact including impact damage and window breakage, were used along with the preliminary damage estimates to model the damage conditions existing within each building. Where the extent of damage was unknown, estimates regarding the extent of damage were used. The sensitivity of the model was checked to determine how the results would vary for wide variations to the assumed extent of damage. For example, the size of the hole between floors within the impact zone was difficult to estimate. The models uscd a floor opening equal to the footprint of the impact damage depicted in the NIST damage figures up to, but not including, the core. Several estimates of the temperature within the impact zone in the towers were made. It is estimated that the temperature may have been as low as $750{ }^{\circ} \mathrm{F}\left(400^{\circ} \mathrm{C}\right)$ in some areas of the impact zone and as high as $1,800^{\circ} \mathrm{F}\left(1,000^{\circ} \mathrm{C}\right)$ in the hottest areas of the impact zone. Both the lower cited temperature and the upper cited temperature were used to model the temperature throughout the impact zone. For all cases, the outside air temperature was modeled as $70^{\circ} \mathrm{F}\left(21^{\circ} \mathrm{C}\right)$ with the wind out of the north at $11.2 \mathrm{mph}(5 \mathrm{~m} / \mathrm{s})$.

The fifth and final fire scenario was a hypothetical fire scenario in which the majority of the structural damage occurring on September 11, 2001, was modeled, but with no damage occurring to the building's core. This scenario, although unlikely, was modeled to estimate the pcrformance of the candidate smoke management system approaches for a scenario involving a multi-floor fire event with high temperatures throughout the fire compartment and large openings in the exterior of the building.

\section{E.6.3 Results of the Analysis}

The five candidate smoke management system approaches were evaluated to determine whether these approaches could provide adequate pressurization to confine smoke to the zone of fire origin for the five postulated fire scenarios.

The smoke purge and the core pressurization approaches were shown to create adequate pressure differentials for only the sprinklered fire scenario. Substantial negative pressure differentials, indicating flow of smoke from the zone of fire origin into the core, occurred for the other fire scenarios.

The building pressurization approach created high pressure differentials from the core to the perimeter office spaces for all fire scenarios except the multi-floor September 11 aircraft impact scenarios. Positive pressures were demonstrated for both the undamaged core and shaft damage September 11 scenarios in WTC 1, but sufficient airflow velocity was not created to prohibit smoke spread via large openings in ventilation shafts and in the core/officc space boundaries resulting from aircraft impact damage. Use of the building pressurization method could potentially create excessive door opening forces that could hinder or prohibit the egress of building occupants. The magnitude of the door opening forces is a function of the fire scenario, size of interior and exterior openings, and location of the floor(s) of fire origin relative to the location of the MER.

The zoned smoke control with stair pressurization approach was shown to be effective for the sprinklered fire scenario, the full-floor burnout, and the two-floor fire. For each of these fire scenarios, however, stack 
effect was shown to have a substantial impact on the performance of the system, in some cases causing airflow from the floor of fire origin into the core. Therefore, this approach might not be effectivc using a single speed fan, or a fixed airflow quantity. It is likely that fan speed would have to be adjusted based on differential pressure readings to ensure the success of a smoke management system using this approach. Because the zoned smoke control method involves exhausting from a single floor of the building, it was not effective for the multi-floor aircraft impact scenarios. In addition, stair pressurization did not prohibit smoke spread into the stairs when large openings in the stairway walls were present due to aircraft impact damage.

The sandwich pressurization approach was determined to be effective for the sprinklered fire, full-floor burnout, and two-floor fire scenarios, even in the presence of stack effect. Positive pressures wcre demonstrated in the model scenarios for both the undamaged core and shaft damage September 11 scenarios in WTC 1, but sufficient airflow velocity was not created to prohibit smoke spread via large openings into ventilation shafts or the core resulting from aircraft impact damage.

\section{E.7 SUMMARY}

The following results were reported to NIST by the contractor based on the information and analysis documented in this report:

- The smoke management systems in WTC 1 and WTC 2, which provided the capability for a manual smoke purge within an individual HVAC zone on a quadrant-by-quadrant basis, were not initiated on September 11, 2001.

- Had the smoke purge sequence been initiated in WTC 1 or WTC 2, it is unlikely the systcm would have functioned as designed, due to loss of electrical power and/or damage to the HVAC shafts and other structural clements in the impact zone.

- Provision of active smoke management systems and/or combination fire/smoke dampers was not required by the $1968 \mathrm{BCNYC}$ or rctroactive provisions in the various local laws enacted after WTC 1 and WTC 2 were constructed for existing high-rise buildings provided with automatic sprinklers throughout.

- None of the potential smoke management system configurations evaluated in this rcport would have provided sufficient pressure differentials to contain smoke for the postulated aircraft impact damage scenarios, even if these systems were capable of operation after the building sustained damage from the aircraft impact.

- The smoke purge sequence in existence on or before Septcmbcr 11, 2001, would have been expected to be capable of limiting the spread of smoke from the zone of fire origin only for fire scenarios in which the sprinkler system was operational and controlled the fire. Other smoke management strategies capable of being implemented using the existing WTC 1 and WTC 2 ventilation systems may also have been capable of controlling smoke from the postulated full-floor burnout and two-floor fire scenarios evaluated in this report had these strategies been identified and implcmented into the sequence of operations. 
- During the events occurring on September 11,2001, stair pressurization likely would have been ineffective in improving conditions for occupants trying to exit the building.

- Installation of combination fire/smoke dampers in HVAC ductwork, which was not required in WTC 1 or WTC 2, would have acted to slow the development of hazardous conditions on the uppermost floors of the building, but would likely not have had a significant effect on the ability of occupants to egress the building due to the impassibility of the exit stairways. 


\section{Chapter 1 \\ INTRODUCTION}

\subsection{SCOPE}

The work described in this report is in support of the investigation of active fire protection systems. The purpose of this project is to investigate the performance of the active fire protection systems in World Trade Center (WTC) 1, 2, and 7 and their role in fire control, emergency response, and fate of occupants and responders. Information related to the overall scope or results of the analysis of active fire protection systems may be found in National Institute of Standards and Technology (NIST) NCSTAR 1-4. ${ }^{2}$

\subsection{OBJECTIVES}

This effort involves evaluation of the design, installation, and performance of the smoke management systems installed in WTC 1,2, and 7. Specific objectives associated with this effort include the following:

- Document the design and installation of the smoke management systems and compare designs to applicable code and standards requirements.

- Document the normal operation of the fully functional smoke management systems, and its potential effect on smoke conditions in WTC 1 and WTC 2 on September 11, 2001.

In order to establish a context in which to evaluate the WTC smoke management systems, Chapter 1 provides an overview of smoke management system concepts. Chapter 2 of this report summarizes the various considerations impacting smoke management system design, along with a brief history of the development of smoke control related requirements within various national codes and standards. Chapter 3 summarizes the local Building Code of the City of New York (BCNYC) requirements and compares these code requirements to applicable national codes and standards.

Chapter 4 provides a brief building description of WTC 1,2, and 7, with a focus on the building ventilation systems, which are the key components in a building's smoke management systems. Other building elements impacting smoke movement and control are also described in this chapter.

Two major fire-related events in the history of the WTC complex had an impact on decisions that affect the spread of fire and smoke within WTC 1 and WTC 2 in the event of a fire, and had the potential to impact the smoke management systems installed in the towers. The first incident involved a major fire that occurred on the 11 th floor of WTC 1 on February 14, 1975. The second incident resulted from a car bomb that exploded in the WTC complex parking garage on February 26, 1993, resulting in smoke spread throughout the towers. Chapter 5 provides a summary of these two events and discusses changes to the

2 This reference is to one of the companion documents from this Investigation. A list of these documents appears in the Preface to this report. 
buildings made subsequent to cach event impacting smoke movement and control. Chapter 5 also summarizes two engineering studies performed subsequent to the 1993 bombing that recommended changes to the tower smoke management system design, as well as a study of an early proto-type stair pressurization system.

Chapter 6 addresscs the documentation of the smoke management systems (if any) provided in WTC 1, 2, and 7. Chapter 6 also compares the installed systems to the requirements contained in the applicable codes and standards.

Chapter 7 addresses the documentation of the normal operation of the fully functional smoke management systems in WTC 1 and WTC 2, and its potential effect on smoke conditions in the towers on September 11,2001.

Chapter 8 discusses the use of the CONTAM building airflow and contaminant dispersal computer model to evaluate the performance of several smoke management system configurations in the towers under specified fire scenarios. These fire scenarios included the severe aircraft impact related events that played out on September 11,2001, as well as less severe fire scenarios typical of business occupancies. This additional modeling was performed in an effort to provide analysis that can be used to support one of the overall objectives of the NIST-led investigation, the identification of areas in current building and fire codes, standards, and practices that may warrant revision.

Chapter 9 provides a discussion of the analysis and conclusions reached by this report.

\subsection{PRIMARY TASKS}

Task 1: Document the design and installation of the smoke management systems and compare designs to applicable code and standard requirements.

The necessary input required to evaluate the performance of the installed smoke management systems in WTC 1, 2, and 7 required detailcd documentation of what was in each building on September 11, 2001, as well as applicable code requirements. This required review of Port Authority of New York and New Jersey documents, system operations manuals, drawings, and other relcvant documents. Task 1 involved identification and documentation of such information at the greatest level of detail possible in order to address issues of performance in the follow-on tasks.

This task had several elements, including the following:

- Documentation of the smoke management strategies employed within the buildings and the location of smoke control zones designated by the system designs

- Documentation of the location and function of the major components of the smoke management system, including air handlers, ducts, dampers, and shafts

- Documentation of smoke management system sequences of operation and automatic initiating devices (if any)

- Documentation of smoke management control pancl locations and design 
- Documentation of design performance criteria, such as smoke exhaust rates or required pressure differentials

- Documentation of emergency power systems (if any) providing back-up power for the existing smoke management systems

- Documentation of past smoke control studies performed after the 1993 bombing of the WTC and design changes made (if any) subsequent to these studies

- Identification of differences in the design of the smoke management systems installed in WTC 1, 2, and 7

- Comparisons between documented existing systems for each of the three buildings with applicable codes and standards requirements for these occupancies

Task 2: Document the normal operation of the fully functional smoke management systems, and its potential effect on smoke conditions in WTC 1 and WTC 2 on September 11, 2001.

Estimates were made of the likely performance of the systems that cxisted in the north and South Tower buildings (WTC 1 and WTC 2) under varying fire exposures. These estimates were made using the CONTAM computer-based building airflow and contaminant dispersal model to estimate the performance of smoke management systems for specified fire and damage scenarios.

Elements of this task include the following:

- Documentation of expected system performance for design fires in business occupancies, based on the existing smoke management systems as documented in Task 1

- Documentation of redundant systems, if any, that were installed and pre-planned to provide smoke management in the event that the primary system was unavailable

- Documentation of the probable effect of fully functional smoke management systcms in WTC 1 and WTC 2 on smoke conditions in the buildings above the floors impacted by the aircraft on September 11, 2001 
This page intentionally left blank. 


\section{Chapter 2 \\ BACKGROUND}

\subsection{SMOKE MANAGEMENT CONCEPTS}

Smoke management is a term used interchangeably with smoke control to define the use of active or passive means to minimize and control smoke movement within a building in the event of a fire. Active smoke management generally involves the use of ventilation systems to control the movement of smoke. Passive smoke management generally involves the use of smoke barriers to provide compartmentalization within a building to minimize smoke spread. Although some attempts have been made by design professionals to attach different meanings (and implied performance) to differentiate management from control, these terms are considered to have the same meaning for the purposes of this report.

The objectives of smoke management systems are generally defined in the codes and standards in tcrms of meeting life safety objectives with regard to the occupants of a building; although, there are instances where a smoke management system may be used to provide property protection or aid in fire department operations and post-fire clean-up.

The primary references used by professionals involved in designing statc-of-the-art smoke management systems are:

- Principles of Smoke Management (Klote and Milke 2002), publishcd by the Amcrican Society of Heating, Refrigerating and Air-Conditioning Engineers (ASHRAE)

- NFPA 92A, Smoke Control Systems, published by the National Fire Protcction Association (NFPA)

- NFPA 92B, Guide for Smoke Management Systems in Malls, Atria, and Large Areas, published by NFPA

Another valuable technical reference is the book Smoke Movement and Control in High-Rise Buildings, authored by George T. Tamura, who conducted pioneering research in smoke control at the National Research Council Canada (NRCC).

\subsubsection{Definition of Important Terms}

Heating, Ventilating, and Air Conditioning (HVAC) System-Within the context of smoke management system design, the system of fans, dampers, and ductwork that distributes air to and from the spaces within a building.

Fire Damper - A multi-blade device located within HVAC system ductwork that is equipped with a spring-loaded fusible element that when exposed to hcated air/smoke above a specified design temperature will close to prohibit fire propagation to adjacent spaces via the ductwork. In the United States, fire dampers are generally required to conform with Underwriters Laboratories (UL) 
Standard 555, Standard for Safety Fire Dampers. Fire dampers are not generally designed to be air-tight nor to prohibit the passage of smoke.

Sinoke Barrier-A continuous membrane, either vertical or horizontal, such as a wall, floor, or ceiling assembly, that is designed and constructed to restrict the movement of smoke (NFPA 2000b). A smoke barrier may or may not be required to have a fire-resistance rating.

Smoke Damper-A multi-blade device located within HVAC system ductwork that functions similarly to a fire damper, but in addition is equipped with a local smoke detector that will cause the damper to close when the presence of smoke is detected. In lieu of a local detector, some smoke dampers are controlled automatically by a building's smoke management system. Smoke dampers are designed to prohibit the passage of smoke and are classified for leakage in accordance with UL standard UL 555S, Standard for Safety Leakage Rated Dampers for Use in Smoke Control Systems.

Smoke Managenent/Smoke Control-A means for minimizing smoke migration through a building due to a fire occurring within that building.

Swoke Purging - A means for reducing the amount of smoke within a space in a building using mechanically supplied ventilation. Smoke purging generally involves introducing smoke-free supply air into the space and exhausting smoke-filled air from the space directly to the exterior of the building, with no re-circulation back into the building via the supply system. Smoke purging can be used during the fire event to provide dilution of a smoke-filled environment in an effort to improve tenability or during postfire operations to remove smoke from the building once the fire has been extinguished.

Tenability System-A smoke management system that as part of its basis for design anticipates occupant contact with smoke. Such a design considers various tenability criteria (i.e., smoke temperature, visibility, toxicity) to determine acceptable occupant exposure during egress. A timed egress analysis is typically performed in conjunction with such a design.

\subsubsection{Smoke Management Approaches}

The ASHRAE text Principles of Smoke Mamagement (Klote and Milke 2002) states that "smoke movement can be managed by use of one or more of the following mechanisms: compartmentation, dilution, air-flow, pressurization, or buoyancy." National Fire Protection Association (NFPA) 92A (NFPA 2000b) defines smoke control as the use of pressurization produced by mechanical fans. As stated by Klote and Milke, "by this definition, stairway pressurization, elevator pressurization, and zoned smoke control are all types of smoke control systems."

\section{Compartmentation}

Compartmentation is a passive smoke control approach where smoke spread is minimized by the use of smoke barriers between defined areas of the building, typically referred to as smoke zones. The leakage characteristics arc defined so that the allowable openings contained in the barrier are small enough as to resist the passage of smoke. Features such as firestopping of barrier penetrations, door gaskets/sweeps/drop seals, and stair/elevator vestibules are used to provide compartmentation. Smoke dampers in HVAC ductwork and automatic door hold-open devices may also be used to provide compartmentation in the event of smoke detection in a given zone. 


\section{Exhaust Method}

The exhaust method of smoke control is an active smoke control approach that uses mechanical ventilation along with the buoyancy of the smoke to maintain smoke at a height $6 \mathrm{ft}$ to $10 \mathrm{ft}$ above the highest occupied floor of a large space such as an atrium. The buoyancy of the smoke causes it to rise to the upper levels of the space, which acts as a smoke reservoir to contain the descending smoke. The most commonly used approach is to provide mechanical smoke exhaust from the upper portions of the space, sized at a rate equal to the volumetric flow of the smoke entering the smoke layer to maintain the smoke layer above a design smoke layer interface. Figure 2-1 illustrates conceptually the exhaust method of smoke management $\left(M_{\text {exhaust }}\right.$ - mechanical exhaust rate; $M_{\text {plume }}$ - mass flow rate of plume as it enters the smoke layer).

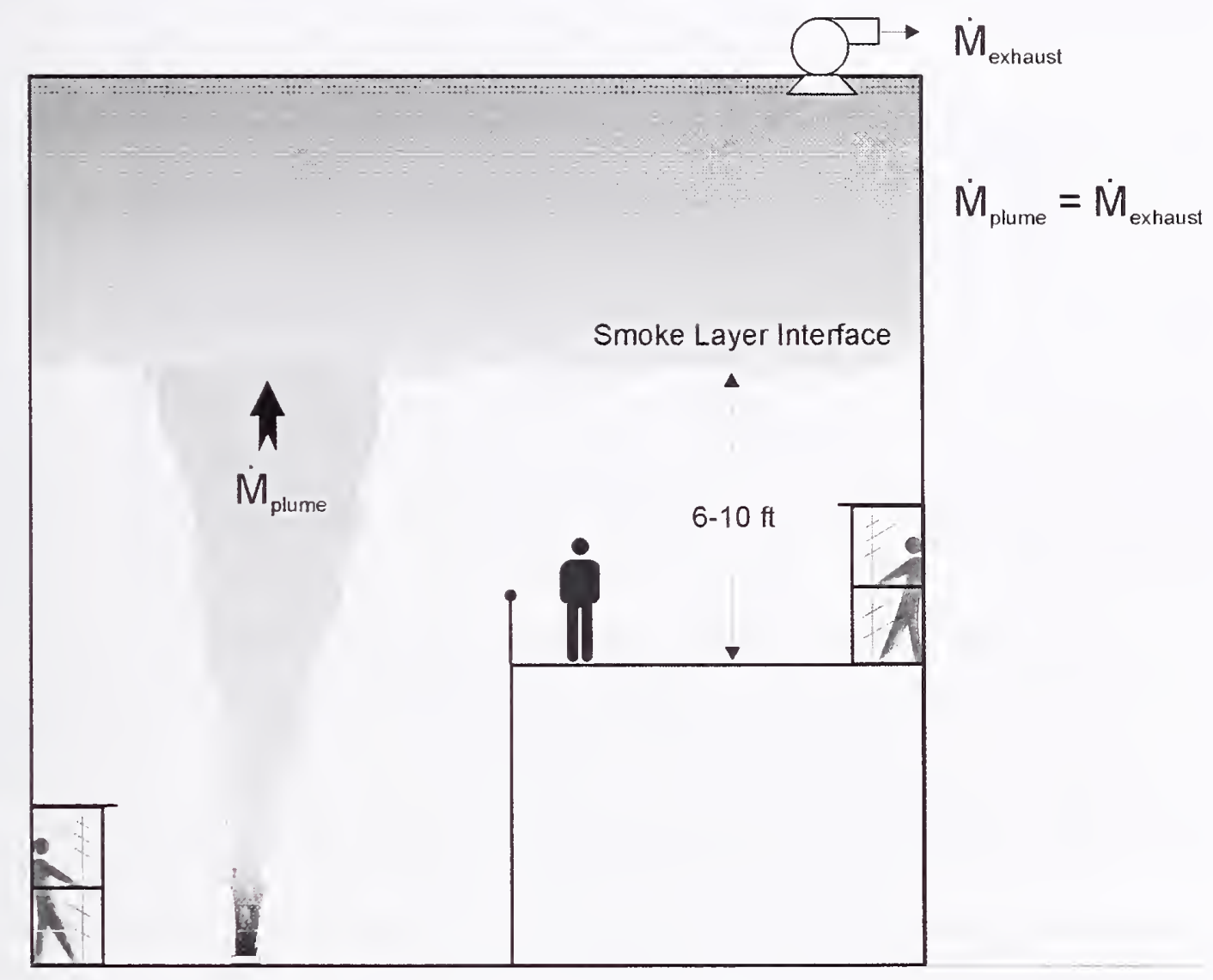

Figure 2-1. Exhaust method of smoke management.

NFPA 92B (NFPA 2000c) describes the calculation methods associated with smoke management system design for large volume spaces such as atriums. The calculations described have been adopted in the atrium requirements included in the various model building codes adopted in the United States. NFPA 92B, while discussing the exhaust method of smoke control, also recognizes the use of natural ventilation to exhaust atrium-like spaces, a method not widely employed in the United States. NFPA 92B also discusses tenability approaches, recognizing that in some configurations, such as very large volume spaces, the amount of air being entrained into the fire plume dilutes the smoke to such an extent that the smoke in the descending layer presents little hazard to building occupants. 
The exhaust method is not intended for use in low-ceiling spaces, as a smoke reservoir is needed to maintain the smoke above the level of building occupants. Sprinkler operation may also impact this approach for spaces with low ceiling heights, cooling the smoke so that it loses stratification and descends below the desired smoke layer interface.

\section{Pressurization Method}

For highly compartmented buildings with predominately low-ceiling spaces, such as high-rise office buildings (including open-plan office buildings, which are compartmented at the core and floor to floor), the pressurization method is an appropriate smoke management approach. The pressurization method involves use of mechanical ventilation systems to induce a pressure differential across a smoke barrier between the zone of fire origin and adjacent spaces, in order to contain the smoke to the zone of fire origin.

The pressure differential required to achieve containment is a function of the smoke temperature within the zone of origin and the smoke layer height within the space, which impacts the buoyancy pressure of the layer. For unsprinklered buildings, the design pressure difference is generally $0.10 \mathrm{in} . \mathrm{H}_{2} \mathrm{O}(25 \mathrm{~Pa})$, calculated based on an assumed gas temperature of $1,700^{\circ} \mathrm{F}\left(925^{\circ} \mathrm{C}\right)$ and a ceiling height of $9 \mathrm{ft}$. For sprinklered buildings, the design pressure is $0.05 \mathrm{in} . \mathrm{H}_{2} \mathrm{O}(12.5 \mathrm{~Pa})$, including a $0.03 \mathrm{in}$. $\mathrm{H}_{2} \mathrm{O}$ safety factor. For zoned smoke management systems, the pressure difference is measured between the smoke zone and adjacent spaces while the affected areas are in the smoke-management mode (NFPA 2000b). It should be noted that because of the lower pressure differential required for sprinklered spaces, it is essential that sprinklers operate to ensure that the smoke management works properly. A system designed to $0.05 \mathrm{in}$. $\mathrm{H}_{2} \mathrm{O}$ will not create a sufficient pressure differential to hold back the high temperature smoke resulting from an unsprinklered fire.

When designing a pressurization smoke management system it is important to not create excessive pressure differential to the extent that door overpressures may impede safe egress from a building. Depending on the size of the door and force applied by the door closer, maximum allowable pressure differentials typically range from 0.21 in $\mathrm{H}_{2} \mathrm{O}-0.45$ in. $\mathrm{H}_{2} \mathrm{O}(52.2 \mathrm{~Pa}-112.0 \mathrm{~Pa})$ and are designed to maintain maximum door opening forces below $30 \mathrm{lb}_{\mathrm{f}}(133.4 \mathrm{~N})$ (NFPA 2000b). However, some jurisdictions enforce maximum door opening forces as low as $15 \mathrm{lb}_{\mathrm{f}}(66.7 \mathrm{~N})(\mathrm{CBC} 1998)$.

There are two general types of pressurization smoke management systems: positive pressure systems, and negative pressure systems. These two types of systems are depicted in Figs. 2-2 and 2-3. 


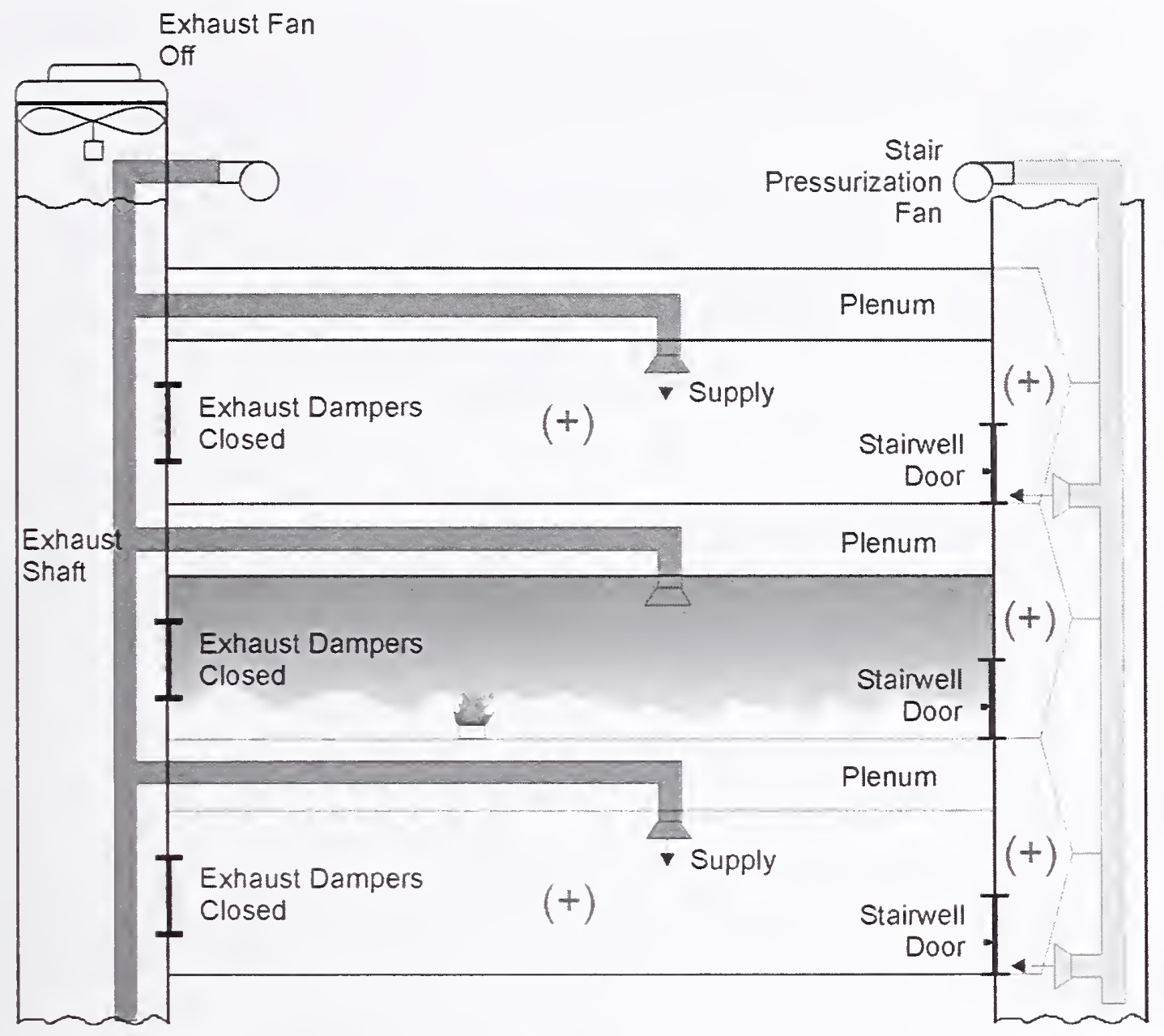

Figure 2-2. Positive pressurization smoke management system. 


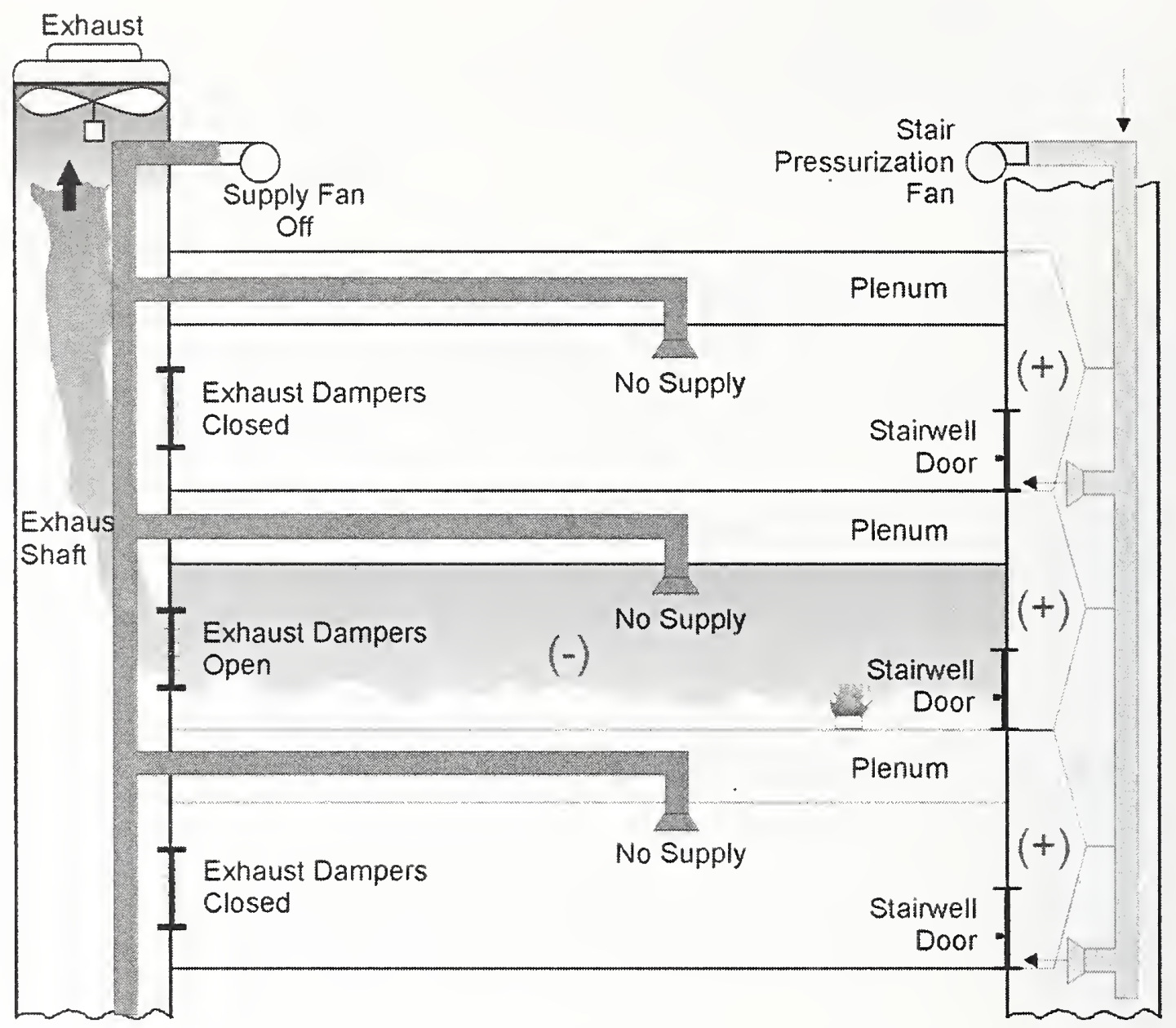

Figure 2-3. Negative pressurization smoke management system.

Positive pressurization systems supply air to the zones adjacent to the zone of fire origin to create a positive pressure in the adjacent zones with respect to the fire zone. Although a properly designed positive pressurization system should perform adequately to contain smoke, there are two drawbacks to using this type of system. First, excessive overpressures or imbalanced positive pressures may force smoke from the zone of fire origin into unintended areas of the building, thereby promoting smoke spread. Second, positive pressure systems do not result in the removal smoke from the building.

Negative pressurization systems typically exhaust the zone of fire origin, either alone or in combination with supply in adjacent zones, to achieve the desired pressure differential. The simplest approach is to shut down ventilation in adjacent zones and exhaust the zone of fire origin. The benefit of this type of system is that smoke is directly removed from the building, improving conditions within the zone of fire origin and within the building as a whole.

Stair pressurization is a type of positive pressurization smoke management system and is designed to limit smoke spread into the stairways of buildings such as a high-rise buildings. The intent of stairway pressurization systems is to maintain the primary egress paths of a building clear of smoke. Stairway pressurization, depicted in both Figs. 2-2 and 2-3, is required by the building codes currently enforced in the United States regardless of the smoke control approach selected in high-rise buildings. It is interesting 
to note that in the various building codes enforced in the United States, stairway pressurization requirements are generally included in the section of the code containing the requirements for means of egress. and are not included in the section of the code pertaining to smoke control system design.

For pressurization smoke management systems, system performance is often dependent on maintaining the integrity of the smoke barriers surrounding the zone to which smoke is to be contained. The applicable codes and standards generally contain requirements specifying maximum allowable smoke barrier leakage. While a looser system of barriers may be successful in providing the required performance, so long as fan capacity is increased to maintain the desired pressure differential, maintaining the integrity of smoke barriers is generally recommended as a basis of design.

\section{Airflow Method}

For large openings where the pressurization method is not applicable, it is possible to prevent smoke from migrating through the opening by means of an opposed airflow directed to limit smoke migration from the fire zone. In general, it is also preferable that the area of the opening be relatively small in relation to the plane in which it is contained. In addition, the airflow method is typically only used for opcnings that are in the vertical plane, such as doorways, hallways, etc.

As shown in Fig. 2-4, if the airflow is not of sufficiently high velocity, or the temperature of the heatcd smoke is excessive, smoke backflow is still possible at the uppermost portion of the opening, resulting in two-way flow through the opening. The airflow method is generally more applicable to conditions whcre the smoke is diluted and of relatively low temperature. In addition, it is generally required that use of this method not result in excessive airflows toward a fire, so as not to unduly intensify the fire, disrupt plume dynamics, or interfere with exiting. This technique is not recommended in the ASHRAE text Principles of Smoke Management, "except when the fire is suppressed or, in the rare cases when fuel can be restricted with confidence" (Klote and Milke 2002).

\section{Dilution}

The term smoke purge, defined in Sec. 2.1.1, refers to the use of supply and exhaust ventilation to reduce the concentration of smoke within a space. Smoke purge is most often employed in post-fire cleanup operations; however, when this approach is used during a fire event, it is often referred to as dilution. System performance using dilution is often determined based on maintaining tenable smoke conditions. Tenability is a function of various criteria, including smoke temperature, toxicity, and visibility distance.

Use of the dilution method to improve smoke conditions within a space containing a fire may be ineffective unless a fire is relatively small and the space in which it is contained is relatively large. Klote and Milke (2002) provide the following cautionary text regarding the use of dilution near a fire:

There is no theoretical or experimental evidence that using a building's HVAC system for smoke dilution will result in any significant improvement in tenable conditions within the fire space. It is well known that HVAC systems promote a considerable degree of air mixing within the spaces they serve. Because of this and the fact that very large quantities of smoke can be produced by building fires, it is generally believed that dilution of smoke by an HVAC system in the fire space will 
not result in any practical improvement in the tenable conditions of that space. Thus it is recommended that smoke purging systems intended to improve hazard conditions within the fire space or in spaces connected to the fire space by large openings not be used.

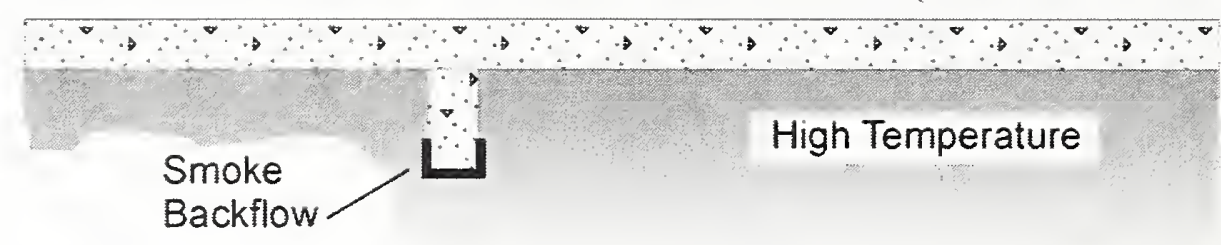

Low Air

Velocity

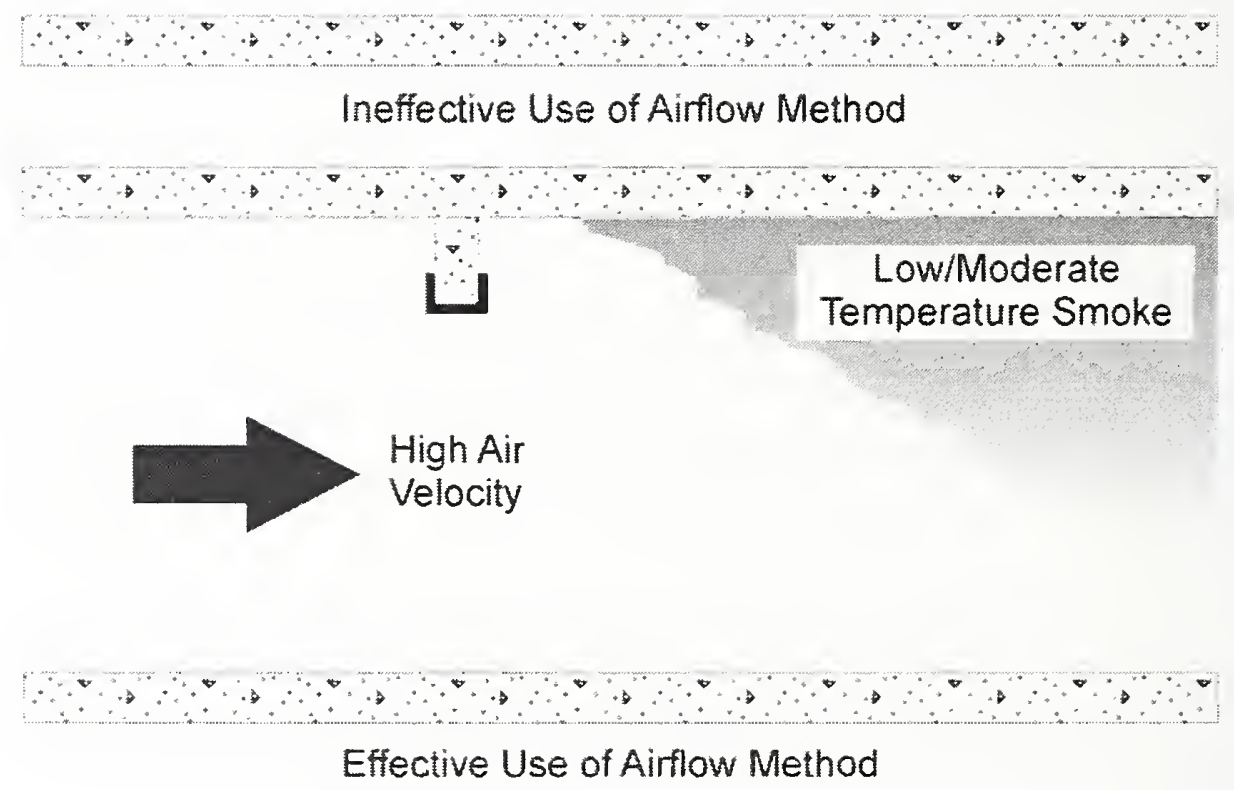

Figure 2-4. Airflow method of smoke management.

Use of the dilution method to improve smoke conditions remote from a fire may be effective, providing that the rate of smoke leakage is small compared to either the total volume of the protected space or the rate of air supplied to and removed from the space (smoke purge rate).

\subsubsection{Factors Affecting Smoke Management}

The performance of a building's smoke management systems can be impacted by a number of factors, including: stack effect, wind, air movement caused by the building's HVAC systems, and temperature associated with the fire (i.e., buoyancy and expansion of hot combustion products). 


\section{Stack Effect}

Stack effect is a phenomenon which induces an upward or downward airflow within buildings due to the temperature difference between a building's interior and the outdoors. Gencrally, when the ambient air is colder than the building interior, air will move upward through the building. This is sometimes referred to as normal stack effect and will occur under winter conditions. When the ambient air temperature is warmer than the building temperature, air will move downward through the building. This is referred to as reverse stack effect and will occur under summer conditions. The magnitude of the stack effect induced airflow is directly dependent on the magnitude of the temperature differential between the building and ambient, as well as the building's height. Building airflows resulting from winter (normal) stack effect are depicted in Fig. 2-5.

Because the magnitude of a stack effect is a function of temperature, stack effect is of greatest concern when the temperature differential between the inside of a building and outside the building is greatest. Except for extremely hot locales, such as Phoenix or Las Vegas, winter (normal) stack effect conditions are typically of greater concern than summer (reverse) stack effect conditions. Winter stack effect is of greater concern for buildings located in New York City, due to the greater prcvalence of colder outdoor air temperatures.

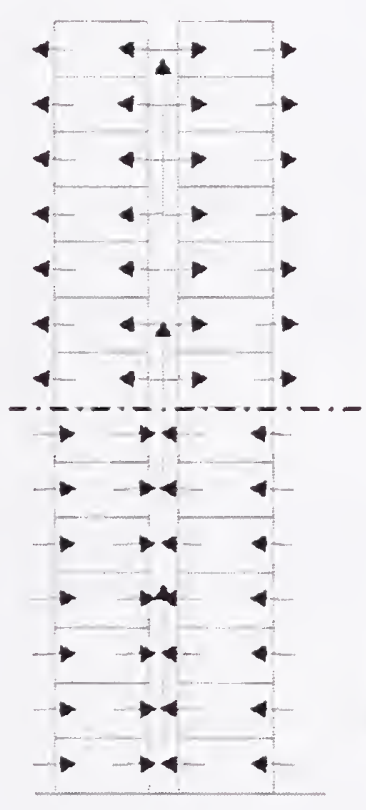

Air Flow
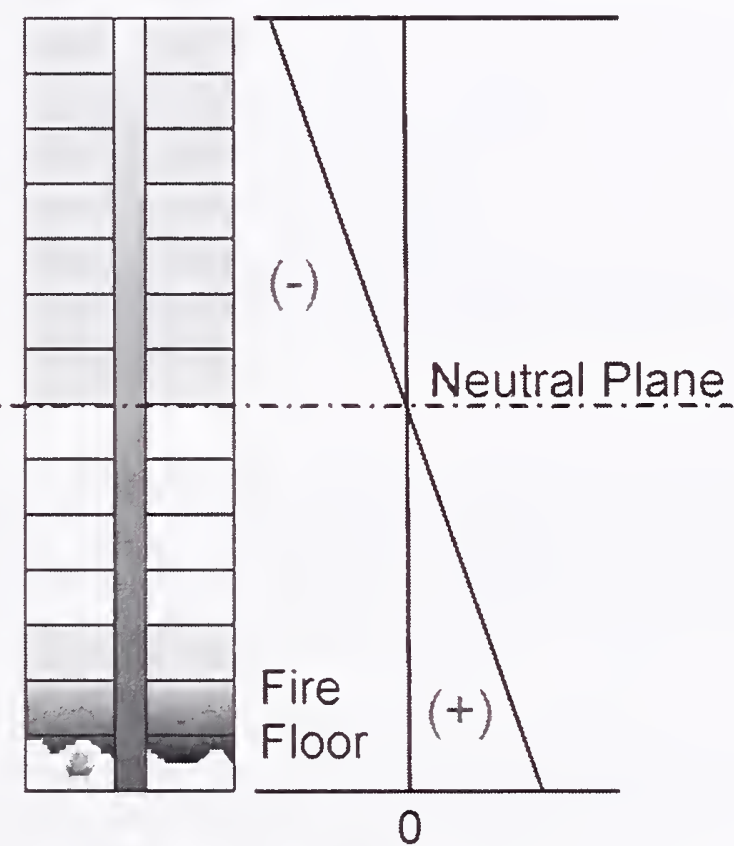

Smoke Spread

Pressure Difference, $\Delta p_{\text {so }}$

Figure 2-5. Building airflows due to winter stack effect. 
Climate data for the New York City area, measured at JFK International Airport were obtained from the ASHRAE Handbook (ASHRAE 2001). The extreme summer and winter conditions (corresponding to 99 percent dry bulb temperatures) recommended by ASHRAE for use in the design of smoke management systems are as follows:

\section{Minimum design temperature (winter): $\quad 15^{\circ} \mathrm{F}\left(-9.4^{\circ} \mathrm{C}\right)$ \\ Maximm design temperature (stmmer): $\quad 88^{\circ} \mathrm{F}\left(31^{\circ} \mathrm{C}\right)$}

Stack effect has a greater impact for extremely tall buildings, as the magnitude of the stack effect is dependent on the temperature differential as well as the distance from the neutral plane. For World Trade Center (WTC) buildings 1 and 2, at the winter design temperature, stack effect pressures are on the order of 1.1 in. $\mathrm{H}_{2} \mathrm{O}(280 \mathrm{~Pa})$ at the bottom and top of the building. Considering that these pressures are an order of magnitude higher than the design pressure for unsprinklered buildings, it is evident that stack effect can be a significant contributor to smoke spread in tall buildings.

\section{Wind}

The effect of wind on a building is a very complcx phenomenon, which is affected by wind speed and direction, building shape, building height, and other nearby buildings. Wind pressures can vary widely across each face of a building, making input of wind pressure into computer simulations difficult. Wind is a transient phenomenon. The magnitude of the wind and its direction can fluctuate wildly. Therefore, many assumptions must be made in order to model wind in a smoke control analysis. In the absence of accurate wind pressure data from sources such as wind tunnel models or computational fluid dynamics (CFD) programs, idealizations of wind pressure magnitudes must be made. For buildings that are rectangular in shape, average wind pressure coefficients have been calculated based on average values across a building face.

Buildings that are exposed to the wind, without significant obstructions, expcrience a positive wind pressure on the wall facing the wind and negative wind pressures on the other three faces. The shape of the building as well as the wind velocity has an effect on the magnitude of the wind pressures on the various faces of the building. A simplified representation of wind-driven pressure differentials on WTC 1 is depicted in Fig. 2-6.

Figure 2-6 depicts a northerly wind impacting the building. On September 11, 2001, wind fluctuated out of the north/northwest at speeds between 5-15 mph, or an average of $10 \mathrm{mph}$.

The ASHRAE Fundamentals Handbook lists a design wind speed of $27 \mathrm{mph}$ for the City of New York (JFK International Airport). This wind speed corresponds to the 1 percent extreme wind speed. The text accompanying this information indicates that this wind speed is used in the design of smoke management systems and that it is appropriate for this application (ASHRAE 2001).

Wind generally acts to promote horizontal, rather than vertical air movement through a building, resulting in smoke spread from the windward side to the leeward side of a building. For buildings with relatively tight exterior walls, no operable exterior windows, and office spaces connected by a common HVAC plenum, wind effects tend to be minimal on smoke spread within the building. However, should windows be broken out (as may result from a fully involved fire on an office floor), or should other large openings 
be created in the exterior walls of a building (as a result of an aircraft impact) wind can have a greater impact on smoke spread. Wind driven flows may help to force smoke into vertical shafts in the building (such as stairways or elevator hoistways), resulting in increased smoke spread to other floors due to buoyancy driven flows or stack effect.

\section{$(-) \Delta \mathrm{p}$}

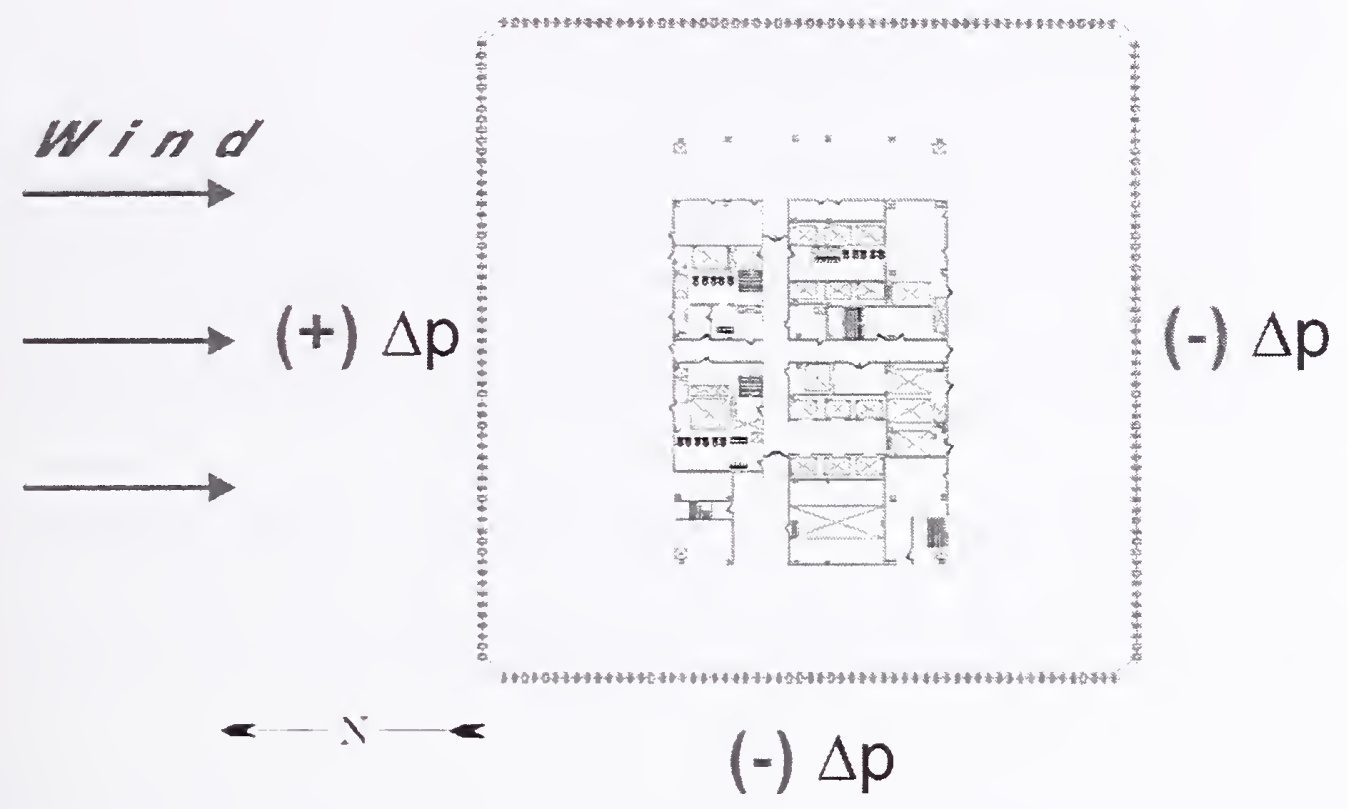

Figure 2-6. Wind forces on WTC 1.

\section{HVAC Systems}

Building HVAC systems in addition to those dedicated for smoke control purposes, need to be evaluated for their contribution to smoke movement within a building. HVAC systems that are not shut down during a fire, or are set in a mode that re-circulates air through the building, may directly cause smokc spread through the building.

HVAC ductwork systems are often equipped with duct smoke detectors that shut down the associated fans in an effort to limit smoke spread via the fan. However, the ductwork system may provide another conduit for smoke spread from floor-to-floor, particularly if the ductwork contains fire dampers rather than smoke dampers. Smoke temperatures may not be sufficient to cause closure of the dampcrs (particularly in sprinklered fire scenarios), resulting in the movement of smoke past the open fire damper and through the HVAC duct system.

\section{Temperature Effects}

For an unsprinklered fire, buoyancy of hot fire gases can be a significant contributor to smoke movement through a building. Smoke will form a layer in the upper part of the fire compartment and adjacent spaces, and spread vertically via shaft openings and other openings to floors above. For a sprinklered fire, the contribution of these buoyant forces to overall smoke movement in the building is reduced. Once the 
sprinkler is activated, the water spray will cool the hot gases. The momentum of the water spray will also stir the smoke layer, resulting in a morc uniform smoke concentration within the room.

The temperature of the fire gases for an unsprinklered fire may also affect smoke management system performance if the severity of the fire threatens the integrity of the smoke barriers (which are often rcquired by code to have a fire resistance rating as well). As previously stated, maintenance of smoke barrier integrity is an important aspect of smoke management design.

\subsubsection{Smoke Management System Reliability}

The reliability of an installed smoke management system is a function of a number of factors, including the relative simplicity of the system, and the frequency and type of testing performed on the system. The ASHRAE text Principles of Smoke Management (Klote and Milke 2002) provides a brief discussion of system reliability, nothing that overall system reliability declines with increasing system complexity. This discussion recognizes, however, that the analysis provides only very rough estimates of reliability, due to the difficulty of obtaining data about the reliability of smoke management system components.

A survey of the fire protection literature and discussions with persons knowledgeable in the area of smoke management system design conducted during the preparation of this report failed to identify any data on smoke management system component failure, nor did this inquiry identify any instances where operation of a smoke management system (successfully or unsuccessfully) during a fire could be adequately documented.

In the absence of data to document smoke management system/component failure rates, it is necessary to perform testing to verify the proper operation of a smoke management system. In general, three types of tcsting are requircd to ensurc proper system operation over the life of a building:

1. Commissioning/Acceptance Testing

2. Periodic Performance Testing

3. Automatic Component Testing

\section{Commissioning/Acceptance Testing}

System commissioning, otherwise known as acceptance testing, is performed when the smoke control system is first installed in a building. This typically occurs when the building is being constructed, as building codes do not often require retroactive installation of smoke control in existing buildings. The purpose of this type of testing is to ensure that the system has bcen properly installed and that all sequences of operation perform as designed. In addition to verifying the proper installation and functionality of individual system components (i.e., fans, dampers, ductwork), automatic operation of system components and manual operation (typically via a fire fighter's control panel) are verified. For pressurization smoke management systems, including stair pressurization systems, pressure differentials are verified to meet the design intent.

It is important during commissioning that all related fire protection or building systems be tested to the extent that their operation impact the operation of the smoke management systems. Fire/smoke detection 
devices and/or sprinkler water flow switches that initiate the smoke management system must be testcd. In addition, the emergency/standby power systems must also be tested. Finally, the integrity of any barrier, partition, or floor assembly intended to resist smoke passage (smoke barrier) be either visually inspected or tested to verify that it will meet the design intent.

\section{Periodic Performance Testing}

Periodic performance testing is critical to ensure proper operation of a smoke management system over the life of a building. During a periodic test, all sequences of operation should be verified, and performance parameters such as pressure differentials should be re-measured as part of the test. It is possible that ongoing construction or maintenance work may have damaged a system componcnt or in the case of a pressurization system, modified a smoke barrier in such a way as to affect its air leakage, which will impact the pressure differential capable of being achieved across that smoke barrier.

NFPA 92A (2000b) and NFPA 92B (2000c) recommend annual or semi-annual periodic testing frequencies, depending on whether a smoke management system is a dedicated, or non-dedicated system. A dedicated system is one that is installed in the building solely to perform a smoke management function and is unused until called upon to perform in the event of a fire. Stair pressurization fans are typically dedicated system components. A non-dedicated system is one that uses components that are predominately used in the daily operation of the overall HVAC systems. The reliability of system components that are used frequently is expected to be much higher, due to the fact that any problem with system operation would likely be quickly corrected in order to ensure continued opcration of the normal building HVAC systems.

Up until the most recent editions of NFPA 92A and NFPA 92B (2000 editions), these documents existed as design guides. Therefore, the periodic testing frequencies are suggested practices, and are not written into any of the model building codes in the United States. While individual jurisdictions may require and enforce rigorous periodic testing, either at more frequent or less frequent intcrvals than those recommended by NFPA, some jurisdictions may require little or no periodic testing of smoke control systems. In fact, anecdotal evidence suggests that a majority of smoke control systems installed in highrise buildings may undergo limited or no periodic testing.

\section{Automatic Component Testing}

Automatic smoke management systcm component testing involves the periodic (usually weckly) selftesting of individual system components (i.e., fans and dampers) by the fire alarm or smoke management panel that controls the system. The panel incorporates a time clock and a programmed sequence that exercises system components once per week and receives positive confirmation that the component operated properly. For fans, the self-test typically involves turning on the fan just long enough to receive positive confirmation of airflow via a pressure transducer, current transducer or sail switch. For dampers, the self-test typically involves cycling the damper into both the open and closed positions and receiving positive confirmation of each position via contact switches. The fire alarm or smoke control panel prints a report of each self-test and identifies components that failed to operate propcrly, and also generates a fault condition so that this failure may be identificd by building personnel. 
The automatic testing feature is a relatively new development, and is increasingly common in smoke management systems designed after 1998. This feature came into being primarily to address the issue of supervision of smoke management system components. Various building codes and standards required that system components be supervised, with typical language stated as follows: "Supervision shall include positive confirmation of actuation, testing, manual override, and the presence of power downstream of all disconnects."

The requirement to monitor power conductors for the presence of power downstream of all disconnects is somewhat problematic. The presence or absence of power to a fan will verify only that power is supplied to a fan. In the case of a fan that is normally OFF, such a monitor would show no power to the fan until the system is activated. The case where maintenance activities have resulted in the opening of a disconnect device in the circuit would not be detected or prevented by such a monitoring device, and hence, there is no improvement in system reliability by the installation of such a device.

In the case of a fan that is normally ON, such a monitor would show the presence of power to the fan, and would alert building personnel to an instance where maintenance activities resulted in a fan being shut off. If a fan is normally operating, it is reasonable to assume that there is some reason for the airflow, and that occupants will notice the absence of that airflow in rather short order, initiating a service call.

A device that monitors the presence of power cannot verify air movement, much less the proper quantity or direction of air movement. Underwriters Laboratories developed UL listing category UUKL-Smoke Control System Equipment in part to address this issue as well as other problems that exist with system supervision.

The basic standard used by UL to investigate fire alarm/smoke control panels is UL 864, Control Units for Fire-Protective Signaling Systenrs. This standard does not cover the motors, fans, dampers, ducts, etc., which provide the HVAC function, and which are covered under their respective product categories. UL 864 does not investigate the safety of end-to-end supervision of power conductors.

UL 864 was originally written, and is primarily used, as the governing standard for fire alarm system control units. The 9th Edition of UL 864, published in September, 2003, includes a section titled Sinoke Control Service, which has been added to include the requirements for smoke control system equipment to obtain the UUKL listing. Prior to 2003, UL provided manufacturers of smoke control equipment with a letter of interpretation outlining the requirements for obtaining the UUKL listing.

In drafting their standards (i.e., UL 864) for the listing of products to be used in complying with the various building and fire codes, UL considered all of the code language contained in the three model building codes. UL recognized that the traditional mcans to maintain the integrity of a system is electrical supervision of wiring and that the proper operation of the fans and dampers involves mechanical parts that may not be supervised by such electrical supervision. UL therefore considered end-process verification to be an acceptable alternative (Shudak 1998).

UL 864 applies different testing criteria to HVAC systems based on their use. For those systems that are dedicated entirely to smoke control function, UL requires the following:

- Monitoring of the interconnecting wiring between the fire alarm control panel and the auxiliary relay controlling the motor control center for the fan 
- End process verification of the operational status of each fan or damper

- Automatic weekly activation of the smoke control system, with annunciation of the failure of any required function to operate

The UL requirements to maintain the integrity of non-dedicated components (those components of the HVAC system within a building that are operated regularly) of the smoke control system are significantly less demanding. UL determined that the normal comfort level associated with the operability or nonoperability of the equipment is an acceptable means of maintaining system integrity for non-dedicated systems. Combined with the monitoring of the interconnecting wiring between the fire alarm control panel and the auxiliary relay controlling the motor control center for the fan, and end proccss verification of the operational status of each fan or damper during system operation, system reliability is maintained at an acceptable level.

Prior to 1998, only a few of the major manufacturers of fire alarm system equipment had panels that carried the UUKL listing. Since that time, all of the major manufacturers have obtained UUKL listings on their products. While not currently codified in any of the major building codes, several jurisdictions, such as the City of San Francisco, now require, by way of local code amendments, the installation of UUKL smoke control panels in conjunction with smoke management system installation.

In summary, the ability to perform automatic weekly self testing of smoke control system components has gone a long way toward improving the reliability of today's smoke management systems. This technology is relatively new and is currently used in only a small proportion of the smoke management systems installed in high-rise buildings in the United States.

\subsection{EVOLUTION OF SMOKE MANAGEMENT SYSTEM CODE REQUIREMENTS}

In order to evaluate the adequacy of the smoke management systems installed in WTC 1, 2, and 7 at the time of the terrorist events of September 11,2001, it is not only important to undcrstand the applicable code requirements for the buildings (discussed in Chapter 3), but also to develop an understanding of the timeframe in which various passive and active smoke-related code provisions came into being, both as concepts in the technical literature and as requirements in the major model building codes in the United States. This provides a reference as to what was considered state-of-the-art smoke management system design at various points over the life of the buildings.

The fire protection literature was reviewed along with past editions of the Building Officials and Code Administrators (BOCA) National Building Code and the Uniform Building Code (UBC), as wcll as NFPA guides and standards. More recent developments in the International Building Code (IBC) and NFPA's model building code (NFPA 5000) pertaining to smoke management systems were also considered.

\subsubsection{Historical Milestones}

The origin of smoke management in buildings can be traced to an article that appeared in the NFPA Quarterly in 1939 titled Smoke Hazards of Air-Conditioning Systems (NBFU 1939). The article 
summarizes a study performed by the National Board of Fire Underwriters (NBFU) and identifies the hazards associated with the spread of fire and smoke via HVAC system ductwork.

The NBFU study states that in the event of fire occurring in an air-conditioned building, either inside or outside of the duct system or in the vicinity of air intakes, it is necessary to shut down the "blowers" so that the movement of air will not augment the fire, and interrupt the continuity of the duct system using dampers so that smoke, flame, and heat may not travel from their source to the places where damage may be caused. The current air-conditioning standard published by the NFPA, NFPA 90A contains requirements that are consistent with the findings of the NBFU study (Klote 1994).

It is interesting to note that the NBFU study examines the use of smoke-tight dampers operated electrically or pneumatically based on smoke detection using photoelectric smoke detectors, a requirement that would not make its way into the building codes until a much later time. The study also states that "with some changes in design, an air-conditioning system could be arranged so as to reverse its flow at time of fire and eject smoke and products of combustion from the building." However, the study further concluded that "very few systems could be so arranged except at a cost that would be prohibitive, and a further study of the matter casts grave doubts on the advisability of such an arrangement" (NBFU 1939).

According to John Klote, co-author of the ASHRAE text Principles of Smoke Management (Klote and Milke 2002), the major impact of the 1939 NBFU study was that for many years the approach for managing smoke was limited to shutting down the HVAC system. Combined with the then-prevailing higher emphasis on property damage over life safety, this practice led to the development of a fire damper standard well before a smokc damper standard (Klote 2004).

The issue of smoke management in buildings did not gain further momentum until the late 1960s/early1970s, right about the time that the WTC complex was being designed and built. The first edition of UL 555-Standard for Fire Dampers was published in 1968. ASHRAE also held a symposium covering fire hazards in buildings and air-handling systems at its annual meeting in 1968. A second ASHRAE symposium addressing these issues was held in 1970, followed by the International Conference on Firesafety in High-Rise Buildings in 1971. This conference was sponsored by the U.S. General Services Administration (GSA) (Klote 1994).

The early 1970s saw several full-scale test programs that examined the effectiveness of smoke management systems (Klote 1995). In 1973, the Atlanta Building Department conducted tests in the Henry Grady Hotel to evaluate the effectiveness of stairway pressurization with and without stair . vestibules, as well as elevator hoistway pressurization. Also during 1973, the Brooklyn Polytechnic Institute tested the effectiveness of stairway pressurization in a 22-story office building on Church Street in New York City. In 1976, an installed stair pressurization system in a new 7-story office building in Hamburg, Germany was tested by way of a full-scale fire test. In each of these test programs pressurization smoke management systems were shown to be effective in managing the spread of smoke created by full-scale unsprinklered test fires.

In 1973, the ASHRAE handbook introduced a chapter titled Fire and Smoke Control, providing general information about fire protection, smoke production, smoke movement, and smoke control (Klote 1994). In subsequent years ASHRAE sponsored a series of seminars to educate design professionals on smoke management system design. In 1983, ASHRAE published a text titled Design of Smoke Control Systems 
in Buildings (Klote and Fothergill 1983), which outlined the engineering principles pertaining to smoke management system design. This book was later updated as Design of Smoke Management Systems (Klote and Milke 1992).

In 1983, the same year that ASHRAE published its design book, Underwriters Laboratories published the first edition of UL 555S-Leakage Rated Dampers for use in Smoke Control Systenis. The 1985 edition of NFPA 90A-Installation of Air Conditioning and Ventilation Systems required that smoke dampers be installed in duets which penetrate smoke barriers and that the smoke dampers satisfy the provisions of UL 555S.

The NFPA formed its Teehnieal Committee on Smoke Management Systems in 1985. This committee authored the first edition of NFPA 92A-Recommended Practice for Smoke-Control Systems, published in 1988. NFPA 92A was intended to be used for systems designed based on the pressurization method of smoke control and brought together many of the previous developments in smoke management system design, refereneing UL 555 for fire dampers, UL 555S for smoke dampers, and NFPA 90A for HVAC system design. The document also references the ASHRAE text Design of Smoke Control Systems in Buildings (Klote and Fothergill 1983) for further guidance on detailed design information. The committee went on to author the first edition of NFPA 92B-Gride for Smoke Management Systems in Malls, Atria, and Large Areas, published in 1991.

In 1989, the National Institute of Standards and Technology (NIST) conducted a series of tests of zoned smoke eontrol systems at the Plaza Hotel in Washington, D.C. (Klote 1990). Fans wcre used to pressurize the stairway. exhaust the fire floor, and pressurize the floors above and below the fire floor. The experiments demonstrated that the smoke control system workcd as intended (Klote 1995). The approach used in these tests would later become commonly referred to as "sandwieh pressurization."

\subsubsection{Smoke Management in the Model Building Codes}

Past editions of the BOCA National Building Code and the UBC were reviewed baek to 1968 in order to understand the evolution of smoke control system requirements in the model building codes. The year 1968 was selected because (as discussed in Chapter 3 of this report), WTC 1 and WTC 2 were construeted under the provisions of the 1968 Building Code of New York City (BCNYC). The BOCA code was selected for comparison since this code covered the majority of the northeastern United States until approximately 1999. The UBC was seleeted sinee this eode in reeent years included the most stringent smoke control requirements of the major model building codes enforced in the Unitcd States.

Prior to 1970 , both BOCA and UBC required provision of stairways in high-rise buildings constructed as smokeproof enclosures that are naturally ventilated. This means that building occupants had to traverse an open air vestibule prior to entering a stairway, such that the stairway did not direetly conneet to the interior of the building. The 1970 edition of the UBC and 1971 supplement to the BOCA code specify the first requirements for meehanical ventilation options for smokeproof enelosures, requiring that vestibules be purged at a specified air ehange rate and stair shafts be pressurized to $0.05 \mathrm{in}$. $\mathrm{H}_{2} \mathrm{O}$ with all stair doors closed. At that time, both model eodes only required that at least one of the required exits be a smokeproof enelosure. The chapter pertaining to exits was revised in the 1982 edition of the UBC, and required that all required high rise exits be smokeproof enelosures. The code did allow exemptions for enclosed stairways equipped with a minimum exhaust of $2,500 \mathrm{ft}^{3} / \mathrm{min}$ and positive pressure maintenance 
of $0.25 \mathrm{in} . \mathrm{H}_{2} \mathrm{O}$ with all stair doors closed. The 1985 edition of the UBC added the requirement that a building be fully protected by an automatic sprinkler system in order to use this exemption. The UBC requirements for smokeproof cnclosures remained essentially unchanged until they were eliminated in 1992. BOCA made the change requiring all exits to be smokeproof enclosures starting in 1990.

Both UBC (1973 edition) and BOCA (1978 edition) initially required fire dampers only in HVAC ductwork at shaft and fire barrier penetrations. The 1988 edition of the UBC first specified the requirement for approved smoke dampers, although no standard was actually referenced. The 1989 supplement to the UBC referenced the newly created UBC Standard 43-12 for smoke dampers, which was based on UL 555S, Standard for Safety Leakage Rated Damages for Use in Smoke Control Systems. Smoke dampers were requircd wherever ducts penetrated smoke and draft barriers. The 1987 edition of the BOCA code first required approved smoke dampers wherever ducts penetrated a smoke barrier; however, no corresponding standard (i.e., UL 555S) was specified up to and including the 1999 edition of the BOCA code.

In the 1970 s and 1980s, smoke management system requirements varied from providing spccified air change rates to exhaust smoke from a fire floor to providing break-out windows to vent smoke from the building. The 1973 edition of the UBC and the 1978 edition of the BOCA code required that high-rise office buildings have ventilation for the removal of smoke on every floor. Several methods of venting were allowed including using the HVAC equipment in fully-sprinklered buildings or mechanically venting the largest compartment served at a rate of 60 air changes per hour (this option was removed in 1979), or using panels or windows in the exterior walls that were capable of venting smoke. If the HVAC equipment was used, this equipment was required to provide a minimum of one exhaust air change every 10 min ( 6 air changes per hour) for the area involved. The 1982 edition of UBC included requirements for mechanical smoke removal from atria. Four air changes per hour were required for an atrium volume less than $600,000 \mathrm{ft}^{3}$ while 6 air changes per hour were required for atriums with greater volumes. Local amendments to the code spccified different smoke control approaches. For example, the 1992 edition of the San Francisco Building Code (SFBC) required that "systems be capable of exhausting 6 air changes per hour and supplying make-up air to the occupied space of any 2 adjacent floors, while simultaneously supplying outside air to (without return or exhaust from) the floors directly above and below the exhausted floors" (SFBC 1992).

The 1992 supplement to the BOCA code removed the requirement for smoke control systems in high-rise buildings. Sec. 1019, Smoke Control Systems, was also rewritten to state that active smoke control is not required in atria where it can be demonstrated that the smoke interface level requirement can be met by passive means. The BOCA smoke interface level requirement was maintenance of the smoke layer above the highest unprotected opening or maintenance of a clear height of at least $6 \mathrm{ft}$ above the highest floor of exit access open to the atrium. The most recent editions of the BOCA code, up to and including the 1999 edition, did not require zoned smoke control in high-rise buildings. Stairways were required to be pressurized but did not have to be provided with vestibules.

In 1994, a substantial revision was made to the smoke control requirements included in the UBC, resulting in UBC Sec. 905-Smoke Control. This code section represents the first code language based on the scientific and engineering principles included in NFPA 92A and NFPA 92B. The 1994 UBC specifies that a zoned smoke control system be provided for high-rise buildings, even though these buildings were now required to be fully sprinklered. In fact, the smoke control system design was predicated on the building being sprinklered in that the design pressure specified for sprinklcred buildings was $0.05 \mathrm{in}$. 
$\mathrm{H}_{2} \mathrm{O}$. Stairways were required to have vestibules and be pressurized, but these requirements were included in the provisions of the code pertaining to means of egress. The 1994 UBC provisions remained unchanged in the 1997 edition of the code.

In the late 1990s, a major restructuring occurred with regard to the model building codes in the United States. The BOCA, UBC, and the Standard Building Code groups formed the International Code Council (ICC) and proceeded to develop a single family of model codes that would replace their individual model codes. The first complete set of ICC codes, including the International Building Code (IBC) was published in 2000. At about the same time, the NFPA published its own building code, NFPA 5000, which was completed in 2002 and included in the 2003 edition of the National Fire Codes. The 2000 and subsequent 2003 editions of IBC largely adopted the smoke management system design requirements contained in UBC Sec. 905. NFPA 5000, 2003 edition, references NFPA 92A and NFPA 92B, which are currently being converted from design guides into standards.

In both the 2000 and 2003 editions of the IBC and the 2003 edition of NFPA 5000, provision of a zoned smoke management system is no longer required for sprinklered high-rise buildings. The smoke management system provisions are only invoked for atriums and special occupancies such as correctional facilities. Stair pressurization systems are required by both the IBC and NFPA 5000 for high-rise buildings.

During the draft review and comment process in the development of the IBC, at least five different proponents made proposals for the inclusion of a IBC Sec. 403.13, Smoke Control,requiring smoke control systems in high-rise buildings (ICC 1999). The main reason cited by the proponents was concern about smoke migration to uppcr levels of a building due to stack effect occurring in winter months. In each case the committee disapproved of the proposed change. Reasons for disapproval included a perceived low benefit versus a high cost in buildings that are sprinklered (which is required for high-risc buildings), as well as the lack of an adverse life loss history in high rise buildings and the resulting lack of data to substantiate the need for smoke control.

\subsection{REFERENCES}

ASHRAE. 2001. ASHRAE Fundamentals Handbook. American Society of Heating, Refrigerating and Air-Conditioning Engineers, Atlanta, GA.

BOCA/BBC, various editions. 1965-1999. BOCA Basic Building Code, Building Officials and Code Administrators, International, Country Club Hills, IL.

CBC. 1998. California Building Code. Title 24, Part 2. Vol. 1, Sacramento, CA.

ICC (International Code Council). 1999. Proposed Code Changes to the IBC (International Building Code). International Code Council, Country Club Hills, IL.

ICC (International Code Council). 2000. IBC (International Building Code). International Code Council, Country Club Hills, IL.

ICC (International Code Council). 2003. IBC (International Building Code). International Code Council, Country Club Hills, IL. 
Klote, J. H. 1990. Fire Experiments of Zoned Smoke Control at the Plaza Hotel in Washington, DC. NISTIR 90-4253. National Institute of Standards and Technology. Gaithersburg, MD.

Klote, J. H. 1994. Fire and smoke control: an historical perspective. ASHRAE Journal, July.

Klote, J. H. 1995. An overview of smoke control research. ASHRAE Transactions: Symposia. Vol. 101, No. 1.

Klote, J. H., and J. W. Fothergill. 1983. Design of Smoke Control Systems for Buildings. U.S. Department of Commerce, National Bureau of Standards. Washington, DC.

Klote, J. H., and J. A. Milke. 1995. Design of Smoke Management Systems. American Society of Heating, Refrigerating and Air-Conditioning Engineers (ASHRAE). Atlanta, GA.

Klote, J. H., and J. A. Milke. 2002. Principles of Smoke Management. American Society of Heating, Refrigerating and Air-Conditioning Engineers (ASHRAE). Atlanta, GA.

Klote, J. H. 2004. John H. Klote, Inc., Leesburg, VA, personal communication to M. Ferreira, Hughes Associates, Inc. Baltimore, MD, Development of fire and smoke damper standards with regards to property damage and life safety. December 29.

NBFU (National Board of Fire Underwriters). 1939. Smoke Hazards of Air-Conditioning Systems. NFPA Quarterly, Volume 33, p. 113-122.

NFPA (National Fire Protection Association). 1985. Installation of Air Conditioning and Ventilation Systems. NFPA 90A, Quincy, MA.

NFPA (National Fire Protection Association). 1988. Recommended Practice for Smoke-Control Systems. NFPA 92A, Quincy, MA.

NFPA (National Fire Protection Association). 2000a. Recommended Practice for Smoke-Control Systems. NFPA 90A, Quincy, MA.

NFPA (National Fire Protection Association). 2000b. Recommended Practice for Smoke-Control Systems. NFPA 92A, Quincy, MA.

NFPA (National Fire Protection Association). 2000c. Guide for Smoke Management Systems in Malls, Atria, and Large Areas. NFPA 92B, Quincy, MA.

NFPA (National Fire Protection Association). 2003. Building Construction and Safety Code. NFPA 5000, Quincy, MA.

SFBC (San Francisco Building Code). 1992. Building Code. SFBC 1992, San Francisco, CA.

Shudak, L. J. 1998. Letter of Interpretation: Testing of Smoke Control Equipment (UUKL) Underwriters Laboratories. Northbrook, IL.

Tamura, G. T. 1995. Smoke Movement and Control in High-Rise Buildings. National Research Council Canada, Ottawa, ON. 
UBC, various editions. 1967-1997. ICBO Uniform Building Code. International Conference of Building Officials, Whittier, CA.

UL (Underwriters Laboratories). 2003a. Standard for Safety Fire Dampers. UL Standard 555, Northbrook, IL.

UL (Underwriters Laboratories). 2003b. Standard for Safety Leakage Rated Dampers for Use in Smoke Control Systems. UL Standard 555S, Northbrook, IL.

UL (Underwriters Laboratories). 2003c. Control Units for Fire Protective Signaling Systems. UL Standard 864, Northbrook, IL. 
This page intentionally left blank. 


\section{Chapter 3 \\ APPLICABLE CODES AND STANDARDS}

A study was performed as part of the analysis of building and fire codes of the National Institute of Standards and Technology (NIST) World Trade Center (WTC) Investigation to document the code requirements in the code of record under which WTC 1,2, and 7 were built as well as the changes in building code regulations occurring subsequent to construction of the buildings that were enforced retroactively. The results of this study are documented in the report, Fire Protection and Life Safety Provisions Applied to the Design and Construction of WTC 1, 2, and 7 and Post-Construction Provisions Applied after Occupancy (NIST NCSTAR 1-1D). The summary of code requirements pertaining to smoke management systems contained in this chapter is paraphrased from NIST NCSTAR 1-1D.

The WTC was constructed and maintained under the jurisdiction of the Port Authority of Ncw York and New Jersey (PANYNJ or Port Authority). While Port Authority facilities are not technically subject to the requirements of the local building codes, the PANYNJ voluntarily followed the New York City codes where applicable. In accordance with the instructions issued by the Port Authority at the start of the WTC project, WTC construction drawings were required to conform to the requirements of the Building Codc of the City of New York (BCNYC).

As stated in the Rolf Jensen \& Associates report, WTC 1 and WTC 2 were constructed under the 1968 edition of the BCNYC. The 1968 BCNYC, including amendments to January 1, 1985, was used to provide the fire protection and life safety provisions during the design and construction phases (base building) of WTC 7.

\subsection{BUILDING CODE OF NEW YORK CITY}

At the time of construction of WTC 1,2, and 7, the majority of the northeast portion of the United States used building codes based on the Building Officials and Code Administrators (BOCA) national building code, with local amendments. New York City has developed a unique building code that refcrences technical guidelines and installation requirements from a mixture of nationally recognized standards (National Fire Protection Association [NFPA], American Society for Testing and Materials, American National Standards Institute, etc.) as well as New York City developed refcrence standards.

WTC 1 and WTC 2 were designed according to the requirements of the 1968 BCNYC. In subsequent years, a number of local laws provided changes to fire protection and life safety provisions in the $\mathrm{BCNYC}$. These local laws are as follows:

- Local Law No. 5, Fire Safety Requirements and Controls (effective date immcdiately except as noted), January 18, 1973.

- Local Law No. 16, Local Laws of the City of New York for the Year 1984 (effective date immediately except as noted), March 27, 1984. 
- Local Law No. 33, Local Laws of the City of New York for the Year 1978 (effective date inmediately), October 6, 1978.

- Local Law No. 54, Local Laws of the City of New York for the Year 1970 (effective date immediately), November 17, 1970.

- Local Law No. 55, Local Laws of the City of New York for the Year 1976 (effective date immediately), November 1, 1976.

- Local Law No. 84, Fire Safety Pressurization Requirements in Certain Office Buildings (effective date immediately), December 13, 1979.

- Local Law No. 86, Dates for Compliance with the Local Laws Enacted for Fire Safety Requirements and Controls in Certain Buildings (effective date immediately), December 13, 1979.

The BCNYC differs from other model building codes in one major respect. Changes to a building code generally affect only new buildings and are applied to an existing building only when a major renovation or change in occupancy occurs within the building. Many provisions contained within the local laws amending the BCNYC are applied retroactively; thus, these provisions are required to be implemented in existing buildings.

All of the rcquirements included in the local laws listed above were in effect at the time of construction of WTC 7, since the local laws all predate the 1985 construction date of WTC 7. However, only some of the provisions are retroactively applicable to WTC 1 and WTC 2. These retroactive provisions are summarized in Sec. 3.2.

\subsection{WTC 1 AND WTC 2 CODE REQUIREMENTS}

The following is a summary of the $1968 \mathrm{BCNYC}$ provisions and post construction (retroactive) provisions that were in force at the time of construction of WTC 1 and WTC 2, as they pertain to smoke management systems and related requirements.

\subsubsection{Compartmentation}

All new buildings classified in occupancy group E (business), and existing office buildings, $100 \mathrm{ft}$ or more in height having air-conditioning and/or mechanical ventilation systems that serve more than the floor on which the equipment is located, unsprinklered floor areas, more than $40 \mathrm{ft}$ above curb level, shal] be subdivided by fire separations into spaces or compartments as required (C26-504.1, added by Local Law No. 5, Sec. 6).

- All unsprinklered floor areas shall be segregated by 1 hour fire separations into spaces or compartments not to exceed $7,500 \mathrm{ft}^{2}$.

- Where the floor area exceeds $10,000 \mathrm{ft}^{2}$, at least one of the subdividing fire separations shall be of 2 hour construction, creating areas of refuge. 
- The floor area or any subdivided area may be increased to not more than $15,000 \mathrm{ft}^{2}$ if complete area protection by approved devices for the detection of products of combustion other than heat is provided within such increased area and provided further that at least one of the subdividing fire separations shall be of 2 hour construction where the floor area exceeds $15,000 \mathrm{ft}^{2}$, creating areas of refuge as previously noted.

- In existing buildings, existing 1 hour fire separations may be accepted in lieu of the 2 hour fire separation provided all of the requirements previously noted are complied with.

- Compartmentation is not required when complete sprinkler protection is provided.

- Existing office buildings $100 \mathrm{ft}$ or more in height shall comply with the following requirements:

- At least $1 / 3$ of the total floor area of the building not in compliance with the requirements above on February 7, 1973, shall comply with the requirements above by Decembcr 13, 1981. Complete plans showing such compliance shall be filed with, and a permit secured from the commissioner, by September 13, 1980 (Local Law No. 5, Sec. 6, dates revised by Local Law No. 86, Sec. 1).

- At least $2 / 3$ of the total floor area of the building not in compliance with the requirements above on February 7, 1973, must be in compliance on or before August 7, 1984 (Local Law No. 5. Sec. 6, dates revised by Local Law No. 86, Sec. 1).

- Full compliance must be provided on or before February 7, 1988 (Local Law No. 5, Sec. 6, dates revised by Local Law No. 86, Sec. 1).

- In existing office buildings $100 \mathrm{ft}$ or more in height, the commissioner may waivc or modify the above requirements and accept alternatives fulfilling the intent of the requirements if compliance would cause practical difficulty or undue hardship. Where compliance with the time requirements above would cause unduc hardship, the commissioner, with the approval of the fire commissioner, may extend the time for compliance (Local Law No. 5, Sec. 6, revised by Local Law No. 86 , Sec. 1).

\subsubsection{Fire/Smoke Dampers}

Fire dampers are required in accordance with NFPA 90A (C26-504.5(a)) in the following locations:

- Duct penetrations of walls with a 2 hour fire resistance rating or grcater (Reference Standard 13-1 $\$ 902 . a)$.

- Each opening in required vertical shaft enclosures (Refercnce Standard 13-1 $\$ 902 . b)$.

- Each outlet or inlet opening in vertical shaft enclosure of duct systems serving two or more floors (Reference Standard 13-1 $\$ 902 . c$ ). 
- As an alternate, dampers may be provided at each point where the vertical duct pierces a floor it serves (Reference Standard 13-1 §902.c).

- Branch duct penetrations of vertical duct shaft enclosures (Reference Standard 13-1 §902.c).

- Outdoor air intakes (Reference Standard 13-1 §902.e).

- Aluminum Class I duct penetrations of fire resistance rated floors (Reference Standard 13-1 $\$ 902 . d)$.

Fire dampers are not rcquired at the following locations (Reference Standard 13-1 §903):

- Non-aluminum or Class I vertical shaft branch duct penetrations with a cross-sectional area of less than $20 \mathrm{in}^{2}$ which supply only air conditioning units discharging air at not over $4 \mathrm{ft}$ above the floor (Reference Standard 13-1 $\$ 903 . a$ ).

- Non-aluminum or Class I duct penetrations of a floor (at one place only) with a crosssectional area of less than $20 \mathrm{in}^{2}{ }^{2}$ which supply air conditioning units in one story only that discharge air at not over $4 \mathrm{ft}$ above the floor (Reference Standard 13-1 $\$ 903 . \mathrm{b}$ ).

- Duct penetrations in systems scrving only one floor and used only for exhaust to the outside and not penetrating a fire wall or fire partition or passing entirely through the vertical shaft enclosure (Reference Standard 13-1 §903.d).

- Branch ducts connected to a return riser where subducts are extended at least $22 \mathrm{in}$. upward (Reference Standard 13-1 §903.e).

- Fire dampers should be automatic closing $11 / 2$ hour fire rated with a fusible link or other heat actuated device rated approximately $50^{\circ} \mathrm{F}$ above the maximum system operating temperature (Reference Standard 13-1 \$905.and §905.g).

Duct openings permitted in fire resistance rated ceilings should be protected with fire dampers (C26-502.5(b)). Smoke dampers should be installed in the main supply duct and the main return duct in systems over $15,000 \mathrm{ft}^{3} /$ min capacity (Reference Standard 13-1 $\$ 1003$ ). Smoke dampers should be arranged to close automatically when the system is not in operation, by the operation of duct smoke detectors, and by the manual emergency fan stop (Reference Standard 13-1 §1003).

\subsubsection{Smoke and Heat Detectors}

Local Law No. 5 requires an approved smoke detecting device at the return shaft at each floor in order to monitor each inlet to the return air shaft. Activation of any of the detectors installed in the HVAC system shall stop the air supply to and the return from the affectcd floor. Airflow may be halted by the activation of an approved remote controlled reversible fire shutter or by automatically shutting down the air supply fans and the air return fans serving the floor where activated. 


\subsubsection{Smoke and Heat Venting}

Buildings classified in occupancy group E (business), $100 \mathrm{ft}$ or more in height, having air-conditioning and/or mechanical ventilation systems that serve more than the floor on which the equipment is located, shall be provided with at least one smoke shaft by means of which smoke and hcat shall be mechanically vented to the outdoors as provided in Reference Standard 5-17 (C26-504.15(b)) (Local Law No. 5, Sec. 7). Reference Standard 5-17 was added by Local Law No. 5, Sec. 32.

Existing office buildings, $100 \mathrm{ft}$ or more in height, having air-conditioning and/or mechanical ventilation systems that serve more than the floor on which the equipment is located, shall be provided with at least one smoke shaft by means of which smoke and heat shall be mechanically vented to the outdoors as provided in Reference Standard 5-17 or in lieu of such smoke shaft(s), all interior enclosed stairs other than a fire tower or access stairs may be provided with a system of pressurization for fire emergency use (C26-504.15(c)) (Local Law No. 5 Sec. 7, revised by Local Law No. 86, Sec. 2).

- Where the pressurization system(s) option has been chosen, the system(s) shall be providcd in accordance with Reference Standard 5-18.

- The smoke and heat venting requirements shall be completed by September 13, 1982.

New buildings that are sprinklered throughout shall be exempt from the smoke shaft requirements (C26-504.15(b)) (Local Law No. 5. Sec .7).

Existing buildings that are sprinklered throughout shall be exempt from the smoke shaft and optional stair pressurization requirements under the following conditions (C26-504.15(b)) (Local Law No. 86, Sec. 2):

- The installation shall proceed in conformance with a schedule acceptable to the commissioner.

- At least $1 / 3$ of the total floor area of the building, including but not limited to the entrance lobby, corridors and elevator landing areas, is sprinklered by December 13, 1981.

- At least 2/3 of the total floor area of the building is sprinklcred by December 13, 1982.

- $\quad$ The building is sprinklercd throughout by December 13, 1983.

- Where compliance with the time requirements would cause undue hardship, the commissioner, with approval of the fire commissioner, may extend the time for compliance.

\subsubsection{Stair Pressurization}

Stair pressurization is not directly required by code in an occupancy classified as group E (business). However, stair pressurization can be used to eliminate the requirement for smoke and heat venting. If stair pressurization is provided, each stair shall be provided in accordance with Reference Standard 5-18 (Reference Standard 5-18 added by Local Law No. 5, Sec. 33, amended by Local Law No. 84, Sec. 3). 


\subsubsection{Fire Safety Plan}

A fire safety plan for fire drill and evacuation procedures shall be submitted to the commissioncr. The applicable parts of the fire safety plan shall be distributed to the tenants and service employees. All occupants of the building shall participate and cooperate in carrying out the provisions of the fire safety plan (C19-161.2, added by Local Law No. 5, Sec. 1).

\subsection{WTC 7 CODE REQUIREMENTS}

The following is a summary of the $1968 \mathrm{BCNYC}$ provisions and subsequent local law provisions that were in force at the time of construction of WTC 7, as they pertain to smoke management systems and related requirements. Compartmentation requirements that pertained to WTC 1 and WTC 2 (see Scc. 3.2.1) at the time of construction did not apply to WTC 7 since this building was provided with complete sprinkler protection at the time of its construction.

\subsubsection{Fire/Smoke Dampers}

Fire dampers are required to be provided in accordance with NFPA 90A (C26-504.5(a)) in the following locations:

- Duct penetrations of walls with a 2 hour fire resistance rating or greater (Reference Standard 13-1 \$902.a).

- Each opening in required vertical shaft enclosures (Reference Standard 13-1 $§ 902 . b)$.

- Each outlet or inlet opening in vertical shaft enclosure of duct systems serving two or more floors (Reference Standard 13-1 §902.c).

- As an alternate, dampers may be provided at each point whcre the vertical duct pierces a floor it serves (Reference Standard 13-1 §902.c).

- Branch duct penetrations of vertical duct shaft enclosures (Reference Standard 13-1 $\$ 902 . c$ ).

- Outdoor air intakes (Reference Standard 13-1 §902.e).

- Aluminum Class I duct penctrations of fire resistance rated floors (Reference Standard 13-1 $\S 902 . d)$.

Fire dampers are not required at the following locations (Reference Standard 13-1 §903):

- Non-aluminum or Class I vertical shaft branch duct penetrations with a cross-sectional area of less than 20 in. $^{2}$ which supply only air conditioning units discharging air at not over $4 \mathrm{ft}$ above the floor (Reference Standard 13-1 §903.a).

- Non-aluminum or Class I duct penetrations of a floor (at one place only) with a crosssectional area of less than $20 \mathrm{in}^{2}{ }^{2}$ which supply air conditioning units in one story only that discharge air at not over $4 \mathrm{ft}$ above the floor (Reference Standard 13-1 §903.b). 
- Duct penetrations in systems serving only one floor and used only for exhaust to the outside and not penetrating a fire wall or fire partition or passing entirely through the vertical shaft enclosure (Reference Standard 13-1 \$903.d).

- Branch ducts connected to a return riser where subducts are extended at least $22 \mathrm{in}$. upward (Reference Standard 13-1 §903.e).

- Fire dampers should be automatic closing $11 / 2$ hour fire rated with a fusible link or other heat actuated device rated approximately $50^{\circ} \mathrm{F}$ above the maximum system operating temperature (Reference Standard 13-1 $\$ 905$. and $\S 905 . g$ ).

Duct openings permitted in fire resistance rated ceilings should be protected with fire dampers (C26-502.5(b)). Smoke dampers should be installed in the main supply duct and the main return duct in systems over $15,000 \mathrm{ft}^{3} /$ min capacity (Reference Standard 13-1 $\$ 1003$ ). Smoke dampers should be arranged to close automatically when the system is not in operation, by the operation of duct smoke detectors, and by the manual emergency fan stop (Reference Standard 13-1 \$1003).

\subsubsection{Smoke and Heat Detectors}

Local Law No. 5 requires an approved smoke detecting device at the return shaft at each floor in order to monitor each inlet to the return air shaft. Activation of any of the detectors installed in the HVAC system shall stop the air supply to and the return from the affected floor. Airflow may be halted by the activation of an approved remote controlled reversible fire shutter or by automatically shutting down the air supply fans and the air return fans serving the floor where activated.

\subsubsection{Emergency Power}

An emergency power system shall be provided in high-rise buildings in occupancy group $\mathrm{E}$ (business) (C26-610.3, added by Local Law No. 16, Sec. 50).

The emergency power system shall have the capacity to operate the following equipment, where such equipment is installed (C26-610.1, added by Local Law No. 16, Sec. 50):

1. Fire pumps

2. At least three elevators at one time, with manual transfer to other elevators

3. Alarm systems

4. Communications systems

5. Emergency lighting, if battery packs are not provided

6. Ventilating systems used for smoke venting or control

7. Stair pressurization 
Emergency power generation equipment shall be registered with the Department of Environmental Protection, Bureau of Air Resources in accordance with the requirements of section 1403.2-3.09 of the administrative code (C26-610.2, added by Local Law No. 16, Sec. 50).

\subsubsection{Smoke Control}

Smoke control shall be installed in all buildings classified in occupancy group E (business) as follows (C26-1300.8(a), added by Local Law No. 16, Sec. 53):

- Ventilation systems supplying different occupancy groups shall not be interconnected, provided however that a ventilation system may serve two occupancy groups located on the same floor when the accessory use occupies less than 20 percent of the floor area occupied by the principal use.

- Ventilation systems supplying corridors shall not be interconnected with systems serving other spaces, except that this requirement shall not apply to floors used exclusively as office space in buildings classified in occupancy group E (business) which are fully sprinklered.

- A ventilation system supplying any part of a means of egress shall not be interconnected with any other ventilation system.

- A ventilation system supplying public areas and assembly spaces shall have smoke detecting devices that will shut down the system upon detecting smoke.

Either a combined heat and smoke damper or independent heat and smoke dampers shall be installed at any penetration of construction required to have a fire resistance rating, unless otherwise provided by section C26-504.5.

\subsubsection{Smoke Purge}

In all buildings classified in occupancy group $\mathrm{E}$ (business), there shall be provided a system of mechanical means of sufficient capacity to exhaust six air changes per hour or $1 \mathrm{cfm} / \mathrm{ft}^{2}$, whichever is greater, from the largest floor in the building, using either dedicated fan equipment or the building ventilation system arranged to shut down automatically with manual override capability to exhaust one floor at a time through a roof or an approved location on an exterior wall other than a lot line wall (C26-1300.8(b), added by Local Law No. 16, Sec. 53).

\subsubsection{Stair Pressurization}

Stair pressurization is not directly required by code in an occupancy classified as group $\mathrm{E}$ (business). However, stair pressurization can be used to eliminate the requircment of smoke and heat venting. If stair pressurization is provided, each stair shall be provided in accordance with Reference Standard 5-18 (Reference Standard 5-18 added by Local Law No. 5, Sec. 33, amended by Local Law No. 84, Sec. 3). 


\subsubsection{Fire Safety Plan}

A fire safety plan for fire drill and evacuation procedures shall be submitted to the commissioner. The applicable parts of the fire safety plan shall be distributed to the tenants and service employees. All occupants of the building shall participate and cooperate in carrying out the provisions of the fire safety plan (C19-161.2, added by Local Law No. 5, Sec. 1).

\subsection{REFERENCES}

BCNYC (Building Code of the City of New York). 1968. Building Code-Local Law No. 76 of the City of New York. New York, NY.

BCNYC (Building Code of the City of New York). 1970. Local Laws of the City of New York for the Year 1970 -Local Law No. 54 of the City of New York. New York, NY, November.

BCNYC (Building Code of the City of New York). 1973. Fire Safety Requirements and Controls -Local Law No. 5 of the City of New York. New York, NY, January.

BCNYC (Building Code of the City of New York). 1976. Local Laws of the City of New York for the Year 1976 -Local Law No. 55 of the City of New York. New York, NY, November.

BCNYC (Building Code of the City of New York). 1978. Local Laws of the City of New York for the Year 1978 -Local Law No. 33 of the City of New York. New York, NY, October.

BCNYC (Building Code of the City of New York). 1979a. Fire Safety Pressurization Requirements in Certain Office Buildings -Local Law No. 84 of the City of New York. New York, NY, December.

BCNYC (Building Code of the City of New York). 1979b. Dates for Compliance with the Local Laws Enacted for Fire Safety Requirements and Controls in Certain Buildings -Local Law No. 86 of the City of New York. New York, NY, December.

BCNYC (Building Code of the City of New York). 1984. Local Laws of the City of New York for the Year 1984 -Local Law No. 16 of the City of New York. New York, NY, March.

NFPA (National Fire Protection Association). 2000. Recommended Practice for Smoke-Control Systems. NFPA 90A, Quincy, MA. 
This page intentionally left blank. 


\section{Chapter 4 \\ BUILDING DESCRIPTIONS}

The purpose of this chapter is not to provide an exhaustive description of the construction features and building systems comprising World Trade Center (WTC) 1, 2, and 7, but rather to provide pertinent details pertaining to building features that may have impacted smoke movement within the buildings or the design/function of smoke management systems. Building heating, ventilating, and air conditioning (HVAC) systems are described in somewhat greater detail in order to understand the capabilities of the HVAC systems to perform smoke management functions.

\subsection{WTC 1 AND WTC 2}

WTC 1 and WTC 2 were constructed in the late 1960s and early 1970 s. The buildings were the first constructed as part of the seven-building WTC complex and were occupied by 1972. The buildings were 110 stories above grade and seven levels below grade. WTC 1 (North Tower-Tower A) at 1,368 ft was slightly higher than WTC 2 (South Tower-Tower B) at 1,362 ft. Each building had a square floor plate measuring $207 \mathrm{ft} 2 \mathrm{in}$. on a side. The buildings each had an approximate footprint area of $42,900 \mathrm{ft}^{2}$.

\subsubsection{Architectural Features}

WTC 1 and WTC 2 were similar architecturally, with minor differences in layout. The interior of each floor differed due to the particular tenant build-out on that floor. In addition, the service core for the North Tower (WTC 1) was oriented east/west while the service core for the South Tower was oriented north/south. The service core gradually decreased in size on the upper floors of the building as the numbers of elevators contained on the floors decreased.

The core spaces were separated from the perimeter spaces in the building by a 2 hour fire resistance rated barrier extending slab-to-slab. The cores contained the clevators, exit stairs, bathrooms, and miscellaneous equipment rooms. The perimeter office spaces were generally open-plan office spaces. Individual office spaces on the perimeter were generally separated by non-rated partitions extending only to the drop ceiling. The ventilation plenum above the drop ceiling was open around the perimeter of the floor. When the building was originally constructed, the perimeter office spaces were separated roughly into fourths by fire resistance rated partitions extending from the floor to the plenum ceiling. The firerated compartmentation was required by the provisions of the Building Code of the City of New York (BCNYC) Local Law No. 5. When the building was retrofitted with automatic sprinklers, the fire resistive separations sub-dividing a floor were no longcr required. Therefore, when floors were renovated, the separations were generally removed, and open plan layouts extending around the perimeter of a floor became more common.

The towers were segmented roughly in thirds vertically by two mechanical equipment rooms (MERs) encompassing the entire $4 \mathrm{l}$ st floor and 75 th floor, in addition to the MERs at the top (108th floor) and bottom (7th floor) of the buildings. The aircrafts that crashed into WTC 1 and WTC 2 impacted the upper third of each building, between the 75th floor MER and 108th floor MER. 
The floor layouts for representative floors in WTC 1 and WTC 2 are depicted in Figs. 4-1 and 4-2, respectively. The floors depicted are typical of the primary aircraft impact floor in each building, the 95 th floor in WTC 1 and the 80th floor in WTC 2. Figs. 4-1 and 4-2 show the differences in orientation of the service core, locations of electrical risers, and shaft types and location.

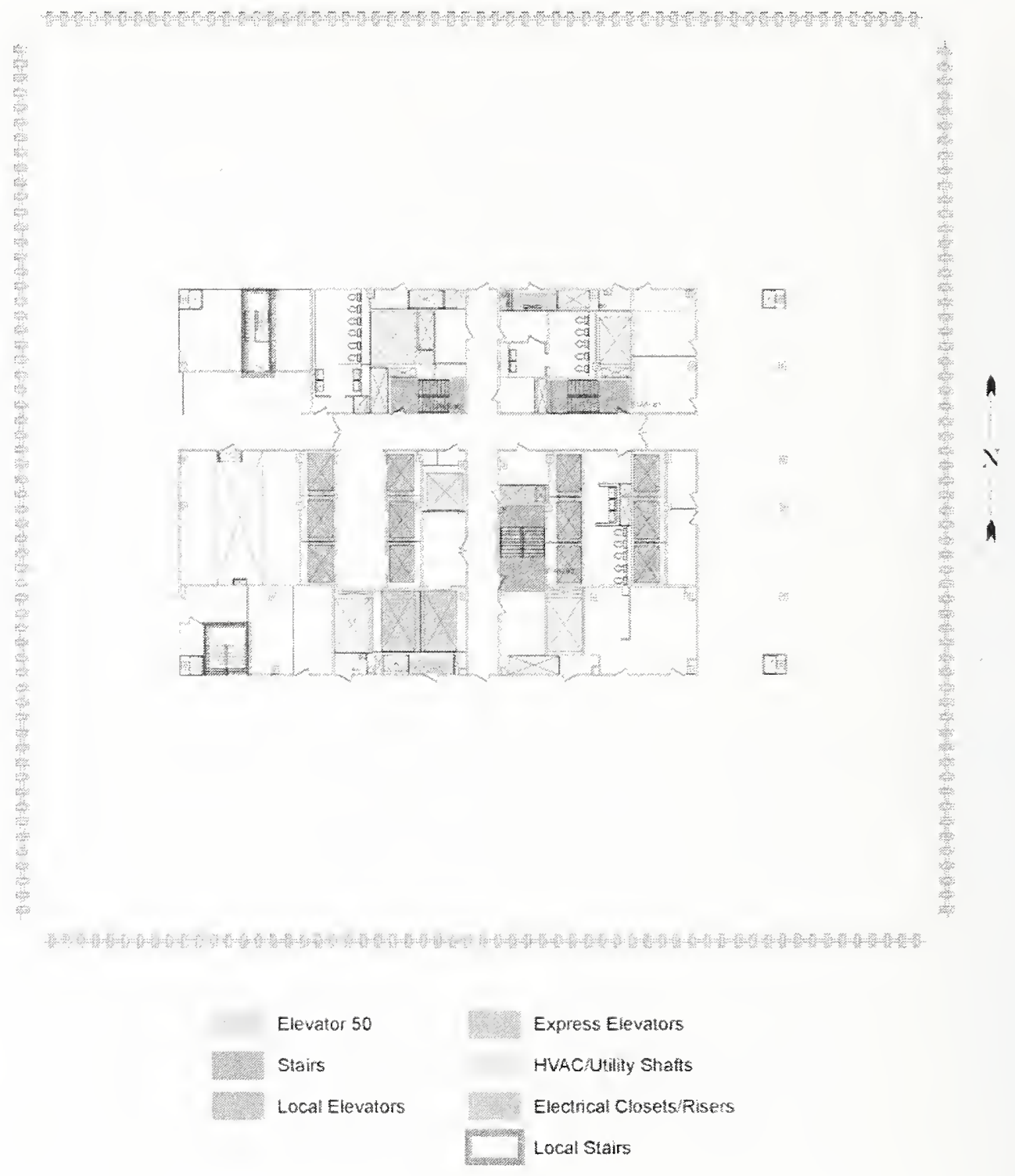

Figure 4-1. Floor layout, 95th floor, WTC 1.

During tenant renovations, tenants occupying multiple floors often added additional convenience stairs connecting multiple levels. The stairs were most often open to two levels, interrupted by a rated partition and stair door at every other level. As an example, Marsh \& McLennan was a building tenant occupying the 93rd through 100th floors of WTC 1 (also the zone of aircraft impact for this building). Up to three convenience stairs were provided on the Marsh \& McLennan floors, open at every other level. Figure 4-1 depicts the two convenience stairs on the 95th floor; one happens to be open at that floor, the other has a rated partition with a door. 


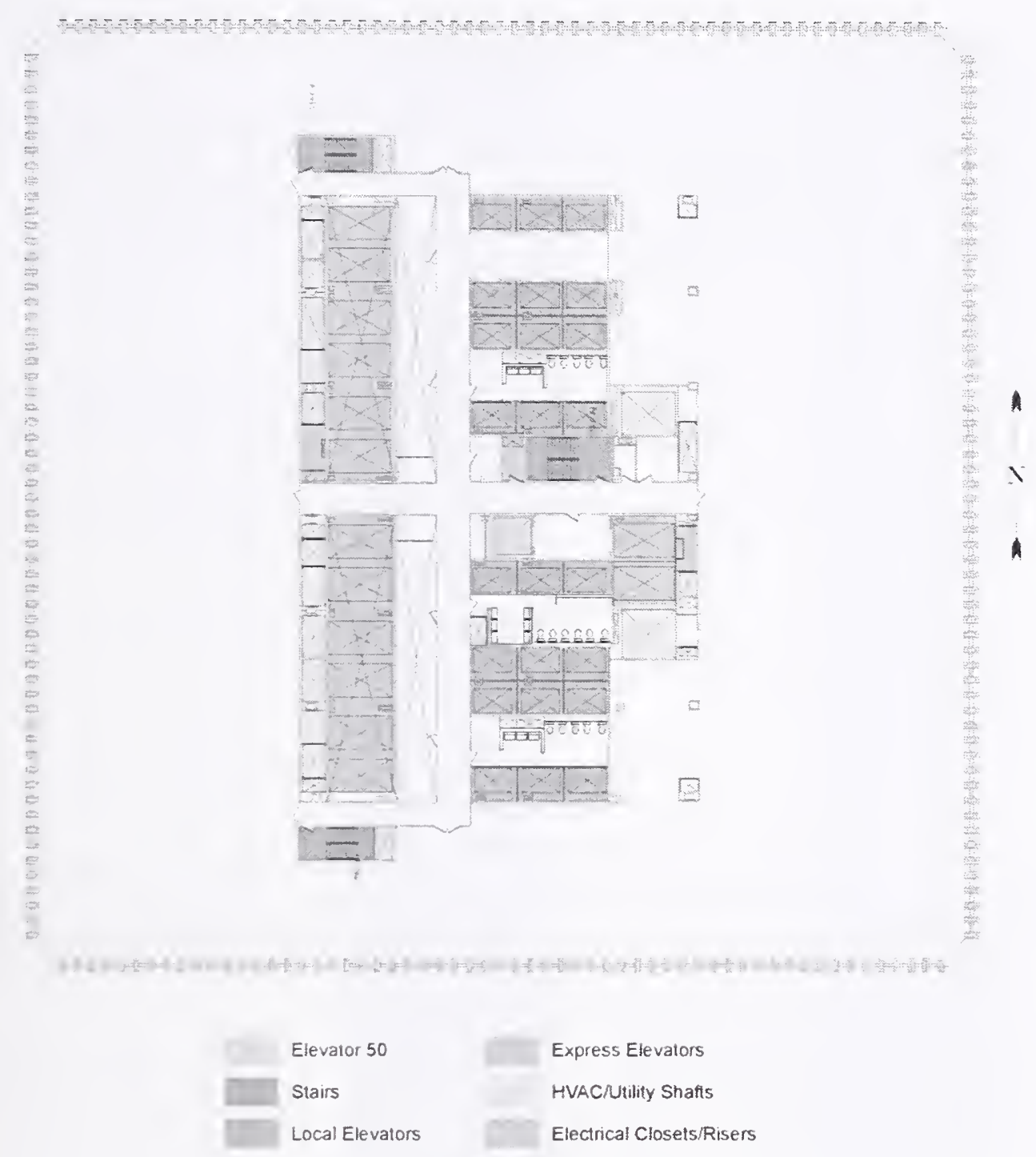

Figure 4-2. Floor layout, 80th floor, WTC 2.

It is well-documented that vertical shafts are the primary conduit for smoke spread in high-rise buildings. It has been estimated that in a high-rise building up to 65 percent of the vertical airflow (and thus, smoke spread) is via the stair and elevator shafts, while the remaining 35 percent is via the other vertical shafts in the building (Tamura and Shaw 1976). Figure 4-3 depicts the stairs and elevator shafts in the building. 


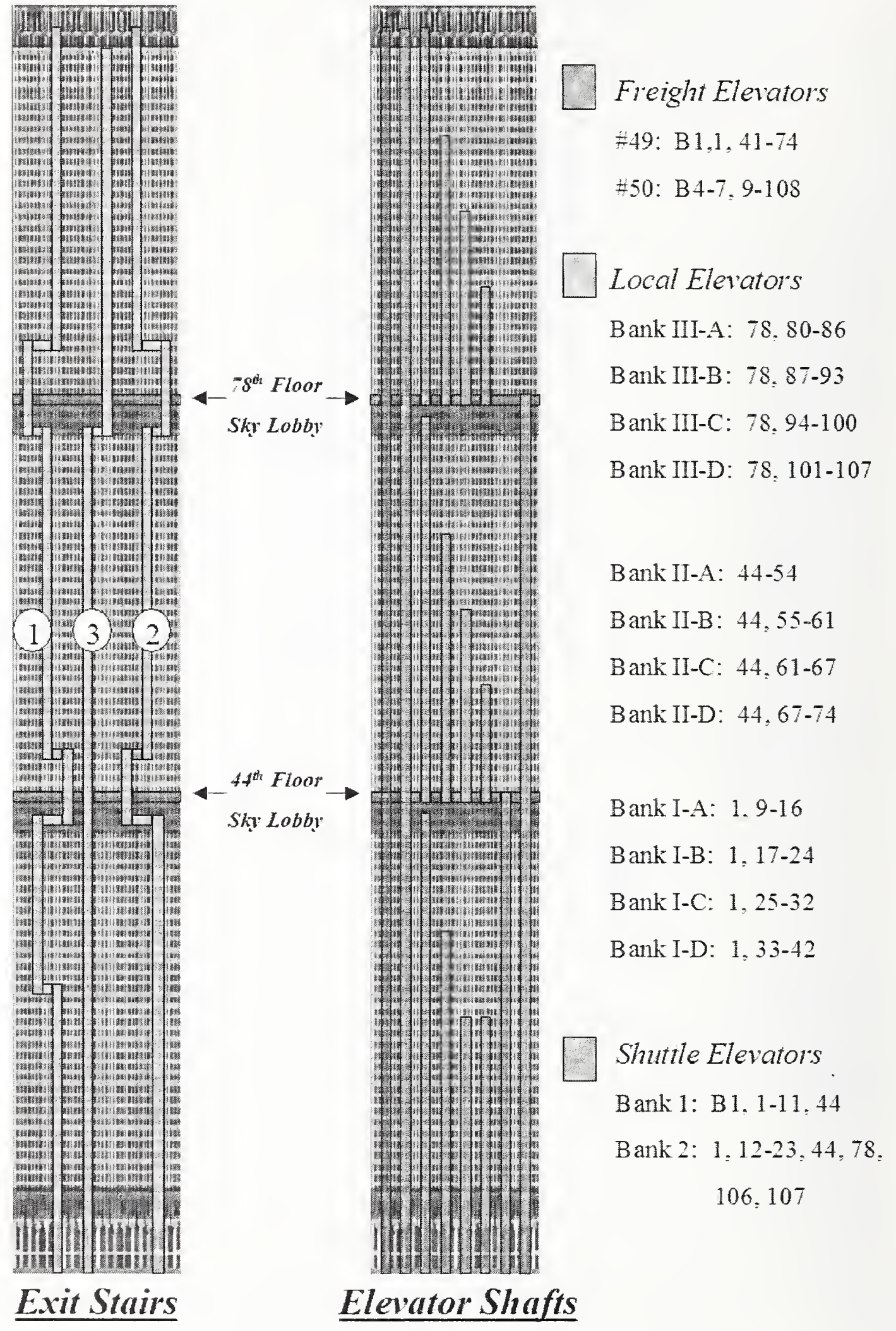

Figure 4-3. Stair and elevator shafts, WTC 1 and WTC 2. 
As seen in Fig. 4-3, each tower was provided with three emergency exit stairways, enclosed in 2 hour rated gypsum wallboard construction. The plan location of the stairways shifted at some levels, with occupants required to move from one stairway segment to another via a horizontal transfer corridor, separated from the stair shafts by fire rated doors. Stairs 1 and 2 had transfers at the $42 \mathrm{nd}, 48 \mathrm{th}, 76 \mathrm{th}$, and 82 nd level. Stair 1 had an additional transfer on the 26th floor. Stair 3 had only a single transfer, at the 76th floor. Stairs 1 and 2 were located more on the perimeter of the core, while Stair 3 was located more toward the center of the core. Figures 4-1 and 4-2 show the different stair locations on the 80th and 95th floors of the buildings.

Figure 4-3 also shows the locations of the ninety-nine elevator shafts in each building. In order to facilitate movement of the thousands of office workers who regularly worked in the towers to the upper office floors in the building, a system of express and local elevators was installed in each building. High-speed express elevators shuttled people from the lobby to sky lobbies on the 44th floor and 78th floor of each building. Escalators connected the sky lobbies to the floors immediately above and below.

Local elevators provided access from the sky lobby floors to the upper floors of the buildings. Freight elevators 49 and 50 extended to different heights in the buildings, with freight elevator 50 extending the full height of each building.

\subsubsection{HVAC Systems}

Building ventilation (heating and cooling) was provided in WTC 1 and WTC 2 by HVAC systems located in four MERs located on the 7th, 41 st, 75th, and 108th floors of each building. The building HVAC systems for WTC 1 and WTC 2 are described in detail in Operation \& Maintenance Manual \#15-HVAC System, Towers $A$ \& B (PANYNJ 1987) and are summarized in the paragraphs that follow.

The buildings were effectively broken up into four vertical HVAC zones, as shown in Fig. 4-4. Each MER was approximately two stories tall and had an upper and lower level. With the exception of the 108th floor MER, which was located at the top of the building above the floors that it served, the MERs served the floors immediately above and below the floor on which they were located. As seen in Fig. 4-4, the WTC 1 aircraft impact occurred in the uppermost portion of the building (92nd through 98th floors), served from above by the 108th floor MER. The WTC 2 aircraft impact occurred slightly lower in the building ( 77 th through 84 th floors), on floors served from below by the 75 th floor MER.

HVAC supply fans were located on the lowcr level of each MER. Supply air was provided to the building via core, interior, and perimeter HVAC units. As shown in Fig. 4-5, there were two core supply ventilation zones (north/south in WTC 2, east/west in WTC 1, due to the orientation of the core), four interior space HVAC zones (corresponding to the four quadrants of the building), and four perimeter zones (north/south/east/west). The core and interior units provided low pressure air that was conditioncd at each unit in the MER. Perimetcr supply air was provided by high pressure fans and was conditioned at induction units located around the perimeter of the building on each floor. 


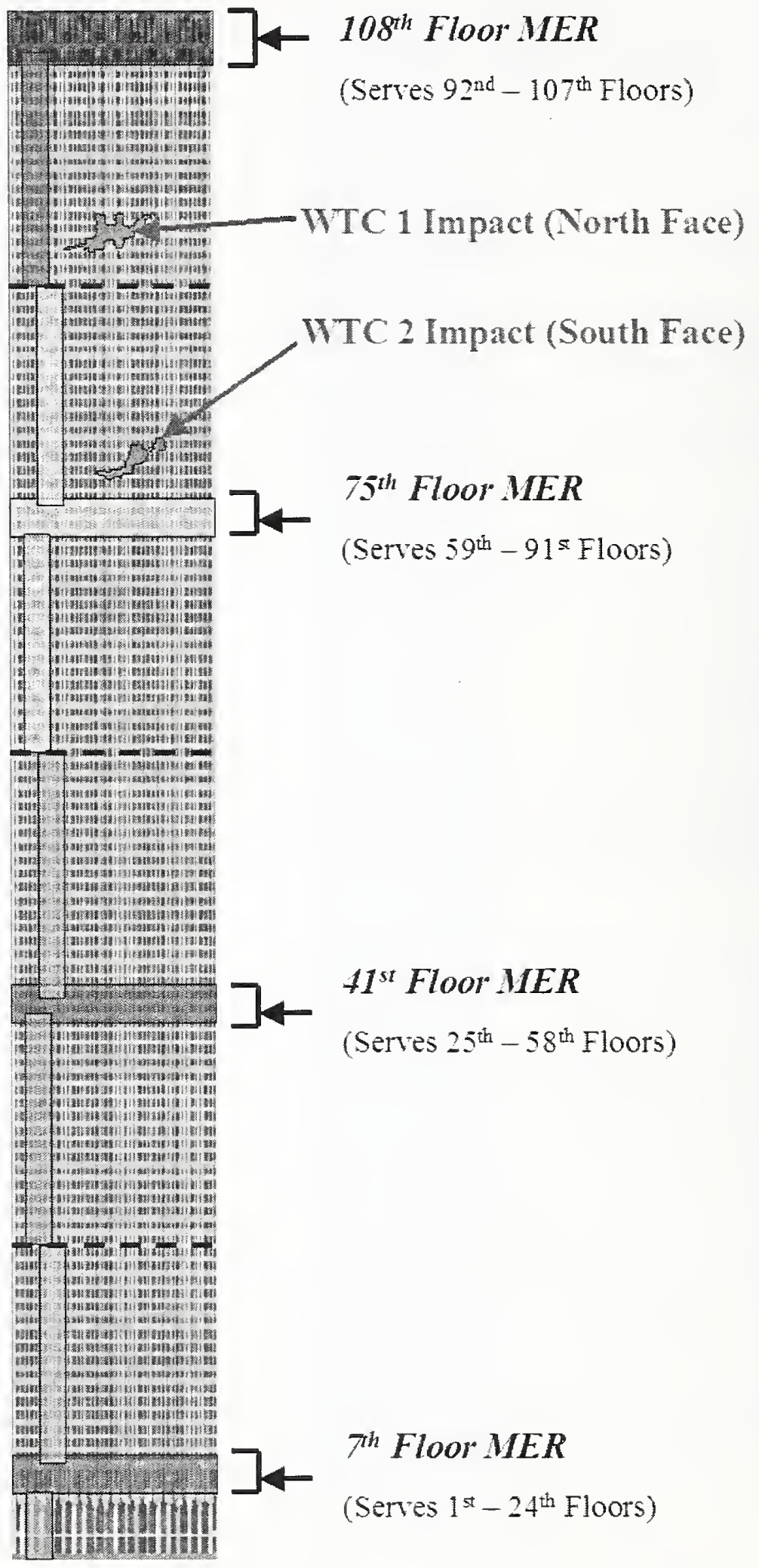

Figure 4-4. Location of MERs, WTC 1 and WTC 2. 


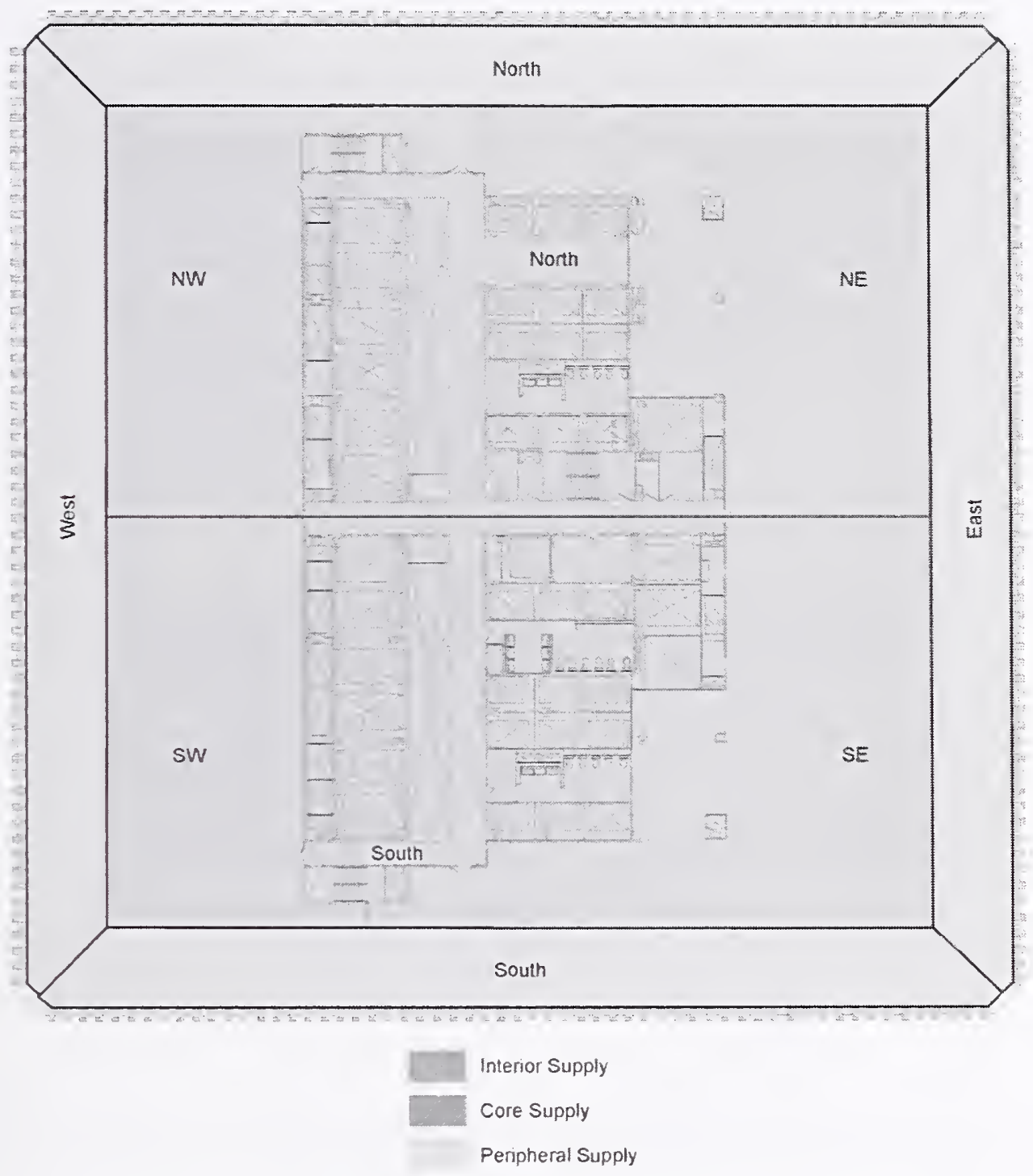

Figure 4-5. HVAC zones per floor, WTC 1 and WTC 2.

Figure 4-6 shows the location of the various supply HVAC units on the lower level of the 75th floor MER in WTC 2. This MER was selected since it served both floors above and below the MER, and was also the MER serving the floors of impact in WTC 2. For WTC 2, the primary HVAC shafts were located at the east and west sides of the core. The supply fans were also located on the east/west sides of the floor and used air drawn from supply plenums running along both the east and west sides of the MER. It can be seen that there were two HVAC units that served the core spaces. One unit provided supply air to the north core zone on all floors served by the MER, with the other unit supplying the south core zones. Ductwork ran from the fans to several shafts within the core. These shafts ran both upward and downward to the floors served. 


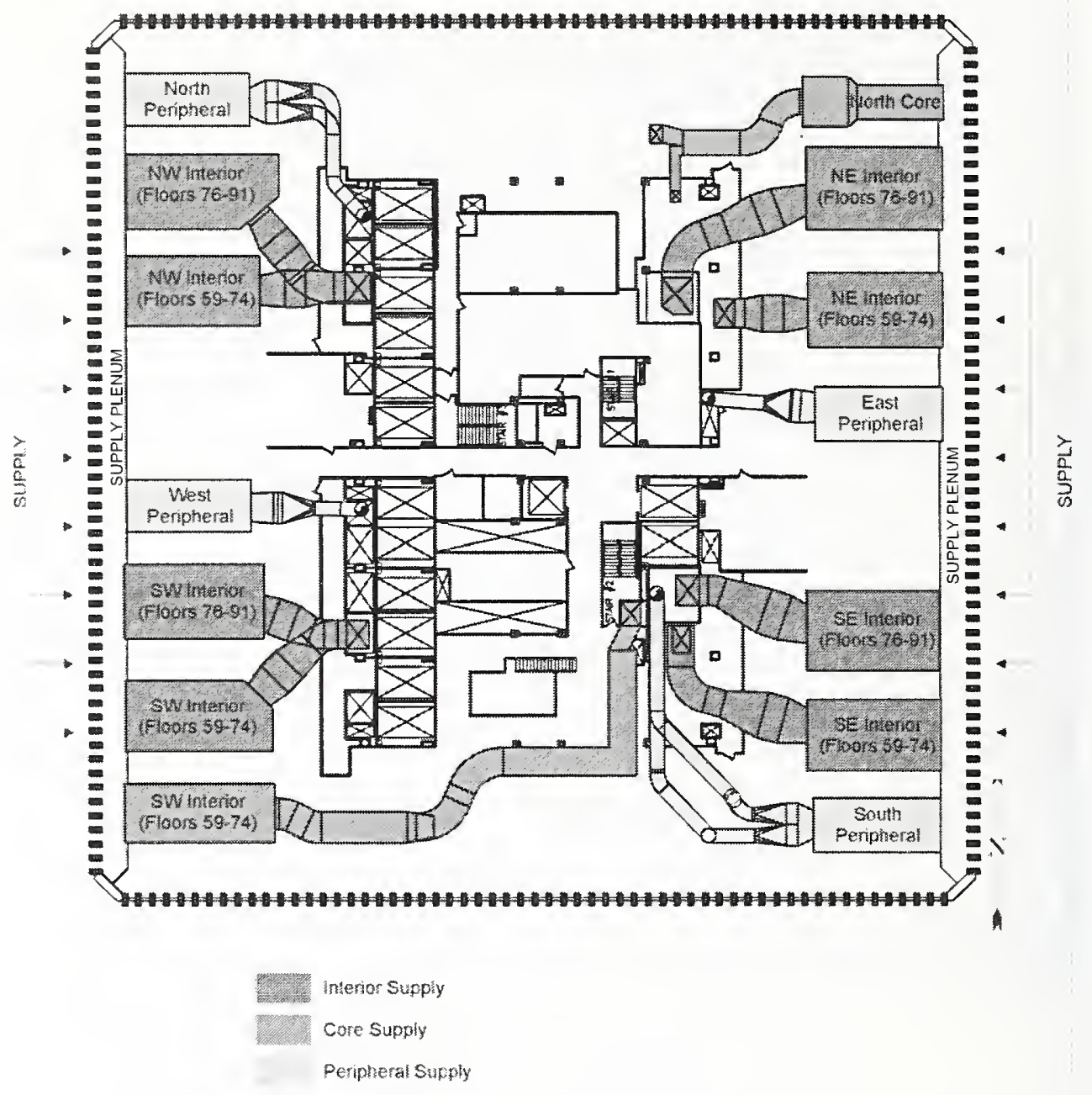

Figure 4-6. Schematic, supply HVAC units, lower level 75th floor MER, WTC 2.

Interior space supply air was provided by eight large HVAC units. Four groups of two fans each were located in each quadrant of the MER. One fan in each group served the floors above the MER, while the other unit served the floors below the MER. The fan location corresponds to the location of the interior zones served. For example, the fans located in the northeast corner of the MER served the interior zones in the northeast quadrant interior ventilation zone.

The four high pressure perimeter zone fans each served either the north, south, east, or west zones. It can be seen (Fig. 4-6) that two runs of high pressure circular ductwork branched out from each fan and were routed to the same shaft. One high pressure duct extended upward to the floors above the MER, and the other dropped down to the floors below. In contrast to the high pressure ductwork, the low pressure ductwork used by the core and interior HVAC units was generally rectangular in shape.

The high pressure supply ductwork supplied air from the perimeter HVAC units in the MERs to induction units located around the perimeter of floor. The induction units stood roughly $18 \mathrm{in}$. high and were located in front of the windows at the perimeter of the office space. High pressure air was discharged through nozzles in each induction unit across a coil, with the air being heated or cooled depending on the temperature of the water flowing through the coil. The function of the induction units was to offset the 
high heating/cooling loads at the perimeter of the building and to induce circulation of the room air in combination with the overhead interior supply registers.

Figure 4-7 shows a simplified representation of the air distribution systems as originally designed for a typical tenant floor, in this case the 80th floor in WTC 2. As previously stated, low pressure supply air was ducted to air inlets in the four perimeter HVAC zones in the four quadrants of the building. Air inlets were generally slot diffusers integrated in the overhead light fixtures. All HVAC ductwork ran in the return plenum above each floor. It should be noted, however, that the high pressure perimeter zone ductwork actually served the floor above, entering the perimeter induction units from the plenum below the floor served. Fire dampers were provided at the exhaust air inlets into the return shafts and within the supply ductwork at the shaft walls, as depicted in Fig. 4-7. Smoke detectors were also provided at the exhaust air inlets to facilitate shutdown of the HVAC systems in the event of a fire.

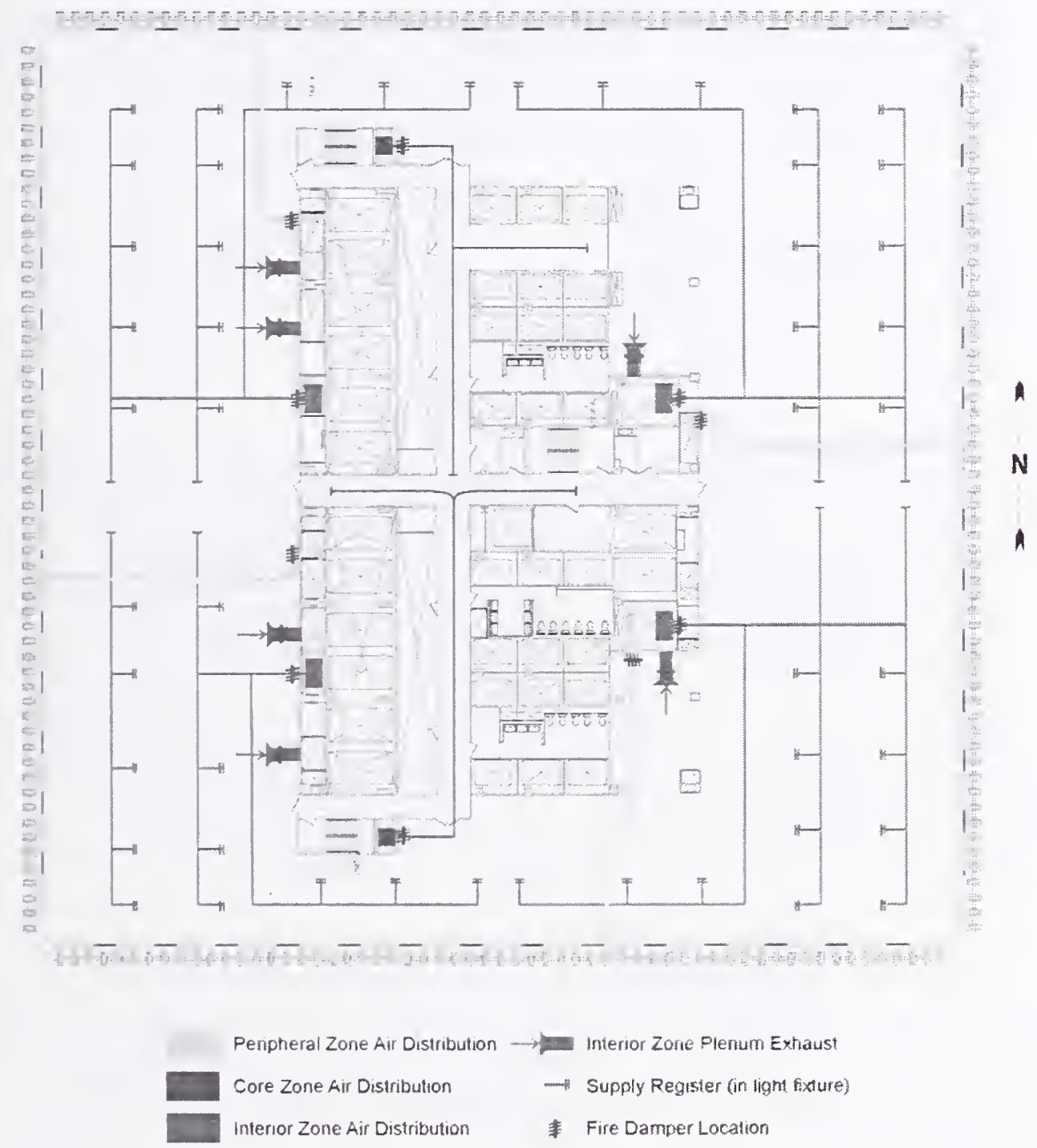

Figure 4-7. Air distribution system, 80th floor, WTC 2. 
Return HVAC fans were located on the upper level of each MER. Figure 4-8 depicts the return fan locations on the 75th floor MER in WTC 2. Four sets of return air shafts were located along the east and west sides of the core, returning air from the interior HVAC zones at the four quadrants of each floor. Whereas supply ventilation was provided by a ducted supply system utilizing metal ductwork, the return ventilation was provided by way of gypsum wallboard return shafts. Air was drawn through return grilles on each floor into a return plenum above thc occupied spaces on each floor. Return air was then drawn to the MER exhaust fans via the gypsum wallboard shafts.

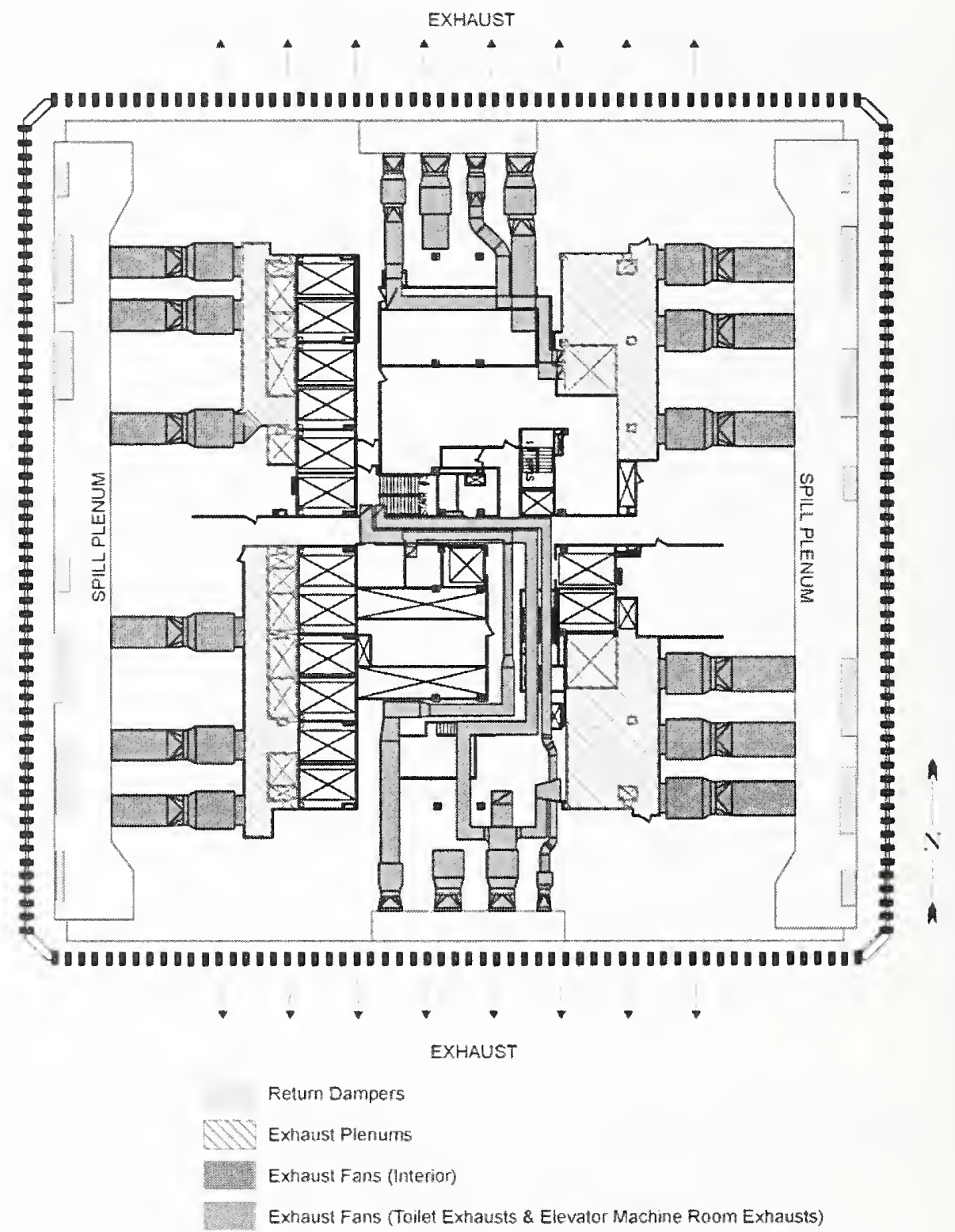

Figure 4-8. Exhaust HVAC units, upper level 75th floor MER, WTC 2. 
The return fans discharged air from the return shafts into spill plenums on the east and west sides of the MER. Two sets of dampers were located within the spill plenum:

1. Return dampers

2. Exhaust dampers

The return dampers, located in the floor of the spill plenum, allowed air to be re-circulated to the supply air fans. Alternately, air could be discharged directly to the exterior of the building. The amount of air exhausted/recirculated was a function of the outside air temperature. More air was recirculated under extreme hot and cold outside air conditions to reduce the cooling/heating load on the HVAC systems and reduce the cost of space conditioning.

Air was returned from the core spaces via small fans located on the north and south sides of the MER (shown in Fig. 4-8). Exhaust air fans for the core provided toilet exhaust and elevator machine room (EMR) exhaust. Because of the nature of these exhaust streams no exhaust air was recirculated from the core back into the building.

The air distribution system configuration described above was the base building design at the time that WTC 1 and WTC 2 were constructed. While the air distribution systems remained as designed on some floors of the building (with little to no modification), these systcms may have been substantially modified on other floors of the buildings, based on the needs of the tenants and the design standards bcing used at the time of tenant retrofits.

An example of such modifications is the HVAC systems serving the Marsh \& McLennan offices on the 93rd through 100th floors of WTC 1. The lower floors of this office space were also the aircraft impact floors in WTC 1. The Marsh \& McLennan floors were retrofit in the years just preceding Septembcr 11, 2001. Therefore, the HVAC systems were relatively new in this area of the building. Figure 4-9 shows a simplified representation of the air distribution system on the 95th floor of WTC 1.

The Marsh \& McLennan HVAC systems utilized the base building supply air for the interior HVAC zones. New ductwork connected to the base building HVAC ductwork at the major supply air shafts and connections remained from the retum plenum to return air shafts. However, perimeter heating and cooling was provided using small fan coil units (FCUs) located around the perimeter of the retum air plcnum, as most of the perimeter induction units were removed from the Marsh \& McLennan floors. Thc FCUs were designed to draw air in from the plenum, heat or cool the air as necessary as it passed through the coil, and then distribute the air via a small number (2-4) of supply air diffuscrs ducted to each FCU.

As seen in Fig. 4-9, several re-circulating air handling units (AHUs) were installcd on the 95th floor to provide additional HVAC capacity for a computer room located on that floor. These AHUs re-circulated air within the computer room. 


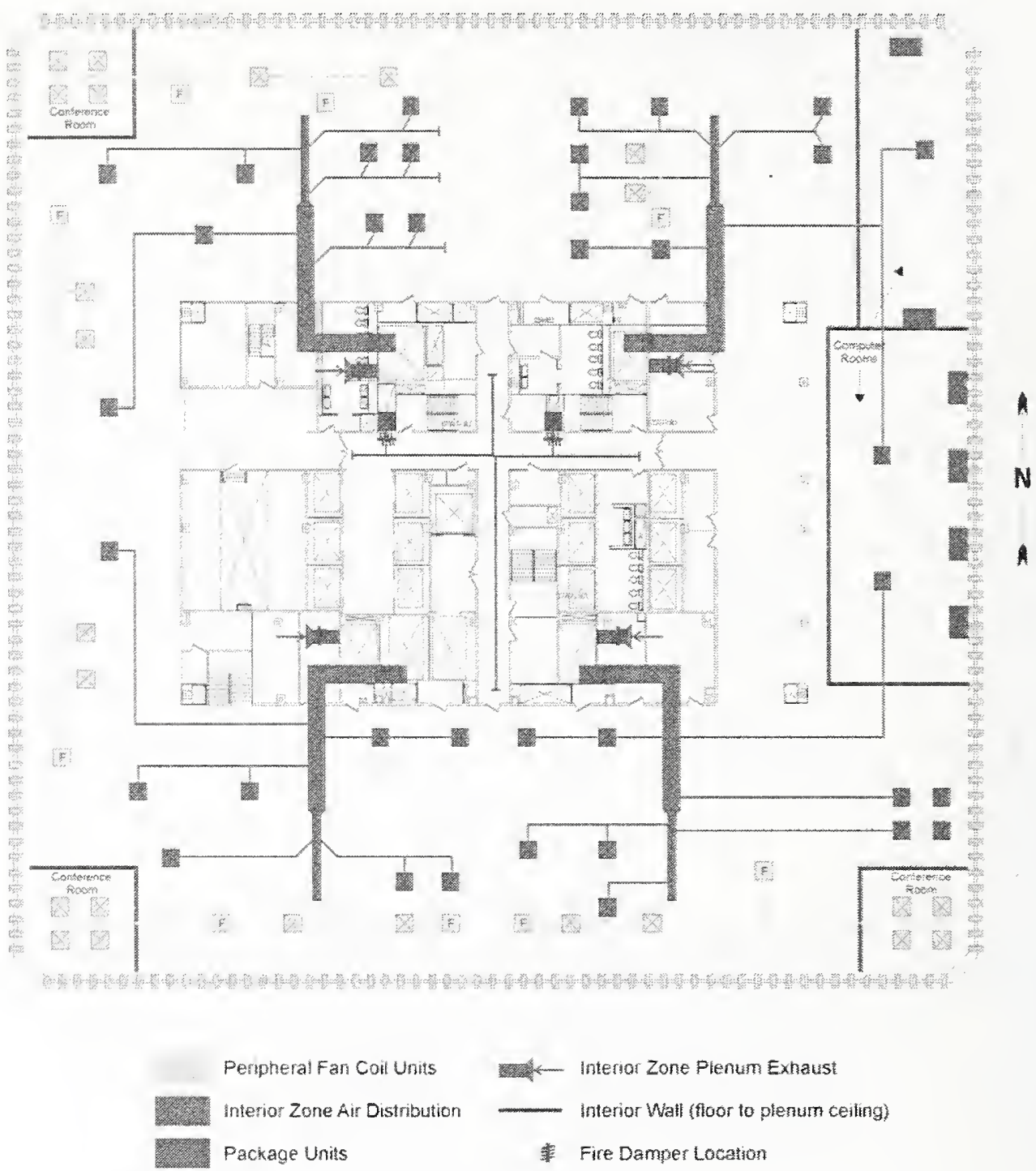

Figure 4-9. Air distribution system, 95th floor, WTC 1.

Supply air provided by the high pressure ductwork outlets on each floor was sometimes used to supply other HVAC systems. For instance, a small AHU was located on the 99th floor of WTC 1 to provide additional heating/cooling to a conference center located on that floor. This AHU received supply air by connecting to one of the four high pressure HVAC ducts serving the floor.

By examining modifications to the Marsh \& McLennan HVAC systems, it can be seen that the HVAC configuration for each floor of WTC 1 and WTC 2 had the potential to vary, creating unique layouts for many floors of the building. However, these changes were not likely to have an effect on smoke management system performance since the changes impacted the use of the high pressure perimeter air as well as the patterns in which air was distributed within a given floor. As will be discussed in Chapter 6 of this report, the smoke management systems for WTC 1 and WTC 2 utilized only the interior air systems and core systems, which were not modified substantially as a result of tenant retrofits. Perimeter air was not used for smoke management. Further, the plenum return arrangement and total air quantities remained unchanged, despite individual tenant retrofit configurations. While smoke movement may have been impacted on a given floor, overall pressure differentials would be expected to remain the same. 


\subsubsection{Electrical Systems}

Electrical power for the building was provided via two separate feeds from a Consolidated Edison (Con Ed) substation located on the lower floors of WTC 7. An additional power feed was provided subsequent to the 1993 bombing via the Port Authority Trans-Hudson train tunnel from New Jersey.

Emergency generators and fuel tanks located on the B6 level of the complex just to the southwest of WTC 1 provided emergency power to all emergency systems (emergency lighting, fire alarm system and fire pumps) and the elevators in the building.

Three electrical risers were located in each building. The electrical closets/risers were designated "north," "central," and "south" in WTC 1. The risers were designated "east," "central," and "west" in WTC 2. The location of the electrical closets on each floor are depicted in Figs. 4-1 and 4-2. Electrical substations were provided on each MER level.

\section{$4.2 \quad$ WTC 7}

WTC 7 was completed in 1987 and was located to the north of the WTC complex on the opposite side of Vesey Street. The building was 47 stories above-grade and had a height of $618 \mathrm{ft}$. WTC 7 had a footprint area of approximately $40,000 \mathrm{ft}^{2}$ and was designated Type I-C construction.

WTC 7 was built over an existing Con Ed substation and a shipping ramp that served the entire WTC complex. The lower six floors of the building contained the substation, electrical switchgear, emergency generators, transformers, and fuel storage tanks. Floors 3 and 4 also contained a conference center for Salomon Smith Barney (SSB), the tenant occupying the largest portion of the building. Floors 7 through 25 housed multiple tenants, with most occupying a single floor. Floors 7 and 8, 11 to 13, 19 to 21, and 26 to 27 were occupied by multi-floor tenants. SSB occupied floors 28 through 45 .

WTC 7 collapsed on September 11,2001, at 5:20 p.m. National Institute of Standards and Technology (NIST) is investigating the cause of failure of WTC 7 and hypotheses regarding the collapse of this building are discussed in NIST NCSTAR 1-6E.

\subsubsection{Architectural Features}

Figure 4-10 depicts the floor layout for a typical floor in WTC 7. The service core for the building was located in the east-west direction, and contained the elevators, exit stairs, bathrooms, and mechanical/electrical equipment rooms. The perimeter spaces were generally either open-plan office spaces or hard-walled individual office spaces. Individual office spaces were generally separated by nonrated partitions extending only to the drop ceiling. The ventilation plenum above the drop ceiling was open around the perimeter of the floor. The building was protected throughout by automatic sprinklers with the exception of certain equipment rooms on the lower floors of the building.

The building was served by low-rise (floors 7 through 20), mid-rise (floors 21 through 37), and high-rise (floors 38 through 45) elevators, as well as service and freight elevators that ran the entire height of the building. There were a total of 31 elevators serving the building. The locations of high-rise and mid-rise elevators and freight/service elevators are shown in Fig. 4-10. 


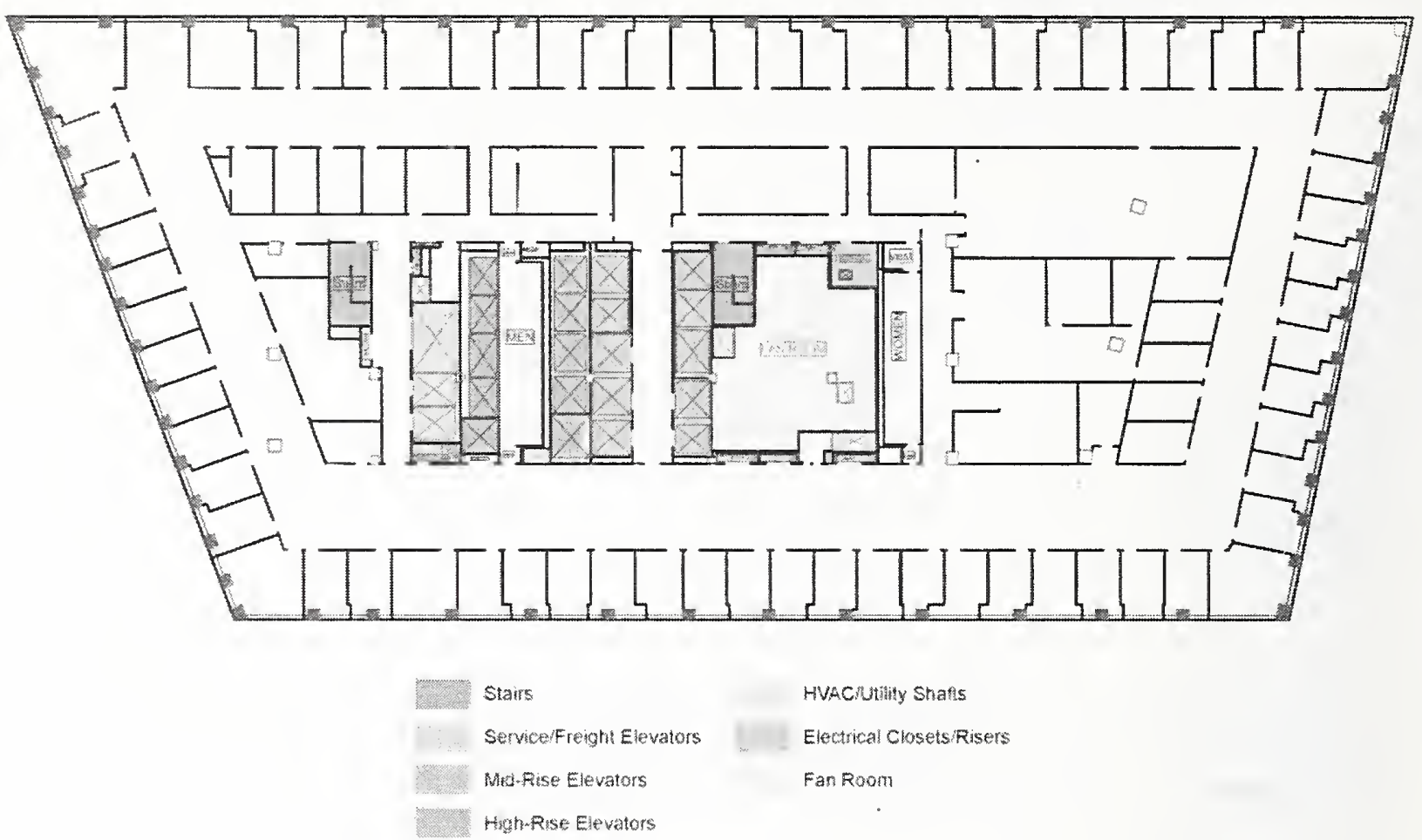

Figure 4-10. Floor layout, 24th floor, WTC 7.

Two exit stairs served the building and were referred to as Stair 1 (or Stair A) and Stair 2 (or Stair B). The position of Stair 1 remained constant on each floor of the building. The position of Stair 2 shifted at the 23rd floor, due to the location of the low-rise elevators serving the lower floors. Below the 23rd floor Stair 2 was located approximately where the electrical closet is shown, to the east of its location in Fig. 4-10.

The individual floors of the original building layout were served by HVAC equipment located in a fan room on each floor. This is in contrast to WTC 1 and WTC 2, which had dedicated MER floors that served multiple floors of the buildings, as shown in Fig. 4-4.

During the early 1990 s, SSB performed a major tenant retrofit to floors 28 through 45 . The retrofit included the combining of adjacent floors into single floors, the relocation of HVAC shafts, and the provision of new HVAC equipment to supplement base building equipment. Two two-story trading floors were created by combining the $40 \mathrm{th} / 41 \mathrm{st}$ and $42 \mathrm{nd} / 43 \mathrm{rd}$ floors. The trading floors each had a raised floor that served as a return plenum. HVAC fans and electrical/data services were located beneath the raised floors.

In addition to the trading floors, various SSB floors were retrofit with technology spaces housing computer equipment. A large auditorium was included in the northwest corner of the building, spanning the 38 th/39th floors. Cafeteria spaces with kitchens were also located within the building. 


\subsubsection{HVAC Systems}

Building ventilation (heating and cooling) was provided on the tenant floors (floors 7 through 47) for the base building configuration in WTC 7 by variable air volume (VAV) AHUs located on each floor. The building HVAC systems for WTC 7 are described in the WTC 7 Operations Manual (PANYNJ 1988).

Each floor in WTC 7 was served by an AHU located in the fan room on that floor that consisted of two fans feeding into a common supply plenum. Conditioned air was then distributed to the floor in two zones, corresponding to the north/east, and south/west portions of the building. The fan room served as a return plenum. Return air was drawn into the fan room via three branch ducts leading from the fan room. Make-up air was drawn into the fan room via make-up air shafts that connected to the exterior of the building either at the roof or at the 6th floor via louvers. The base building HVAC configuration for WTC 7 is depicted in Fig. 4-11.

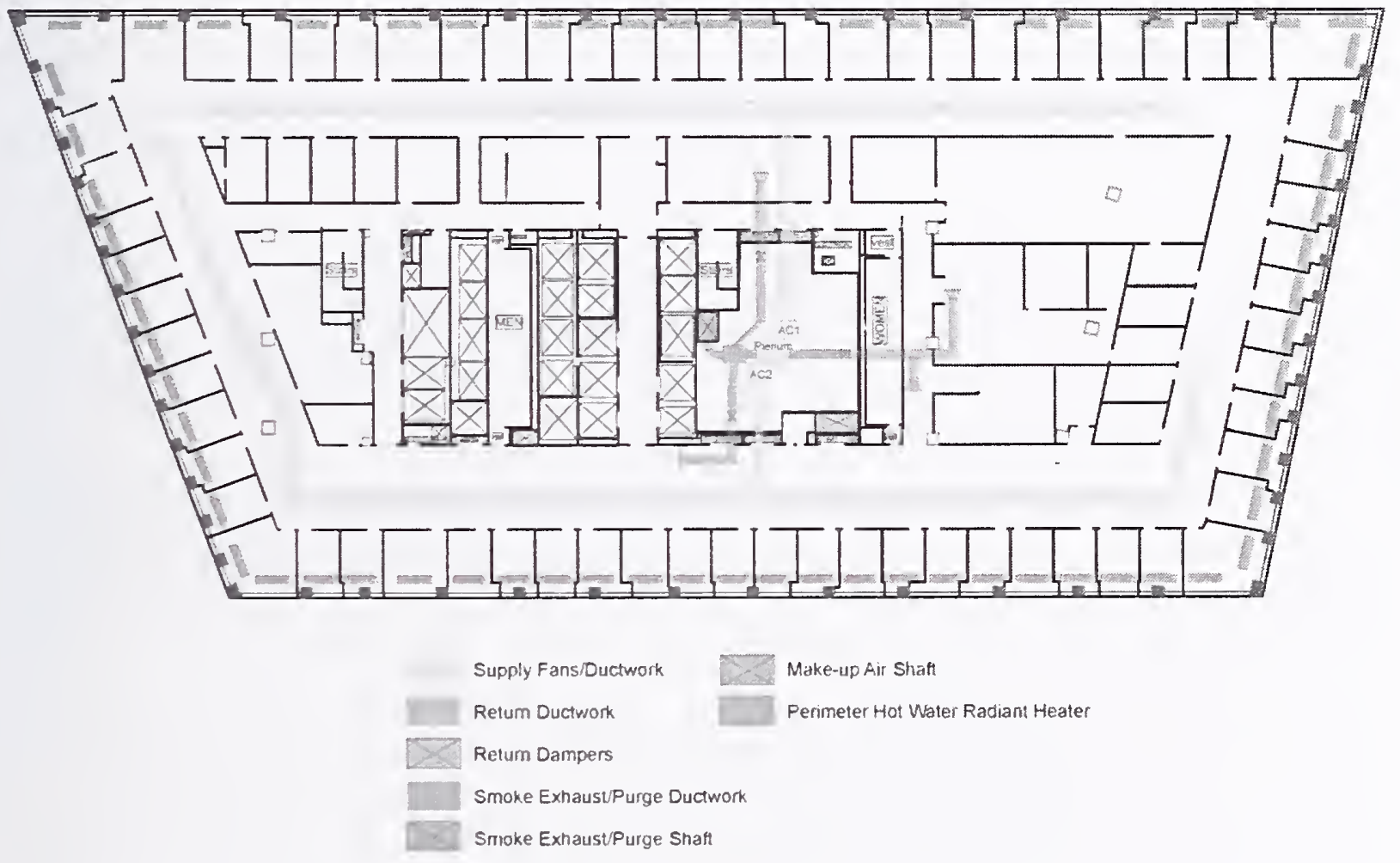

Figure 4-11. Air distribution system, 24th floor, WTC 7.

The WTC 7 HVAC systems were designed to incorporate a smoke purge mode, by which each floor of the building could be exhausted/purged of smoke manually on a floor-by-floor basis from the fire command center, which was located on the 3 rd floor of the building at the main lobby security desk (PANYNJ 1988).

Two smoke exhaust fans, each having a capacity of $36,000 \mathrm{ft}^{3} / \mathrm{min}\left(61,164 \mathrm{~m}^{3} / \mathrm{h}\right)$ were originally located at two locations within the building. Exhaust fan SX-5-1 was located on the 6th floor and served floors 7 through 23. Exhaust fan SX-47-1 was located on the 47th floor and served floors 24 through 47 . As shown in Fig. 4-11, the smoke exhaust duct was located near Stair 2 within the fan room. The return air 
ductwork was connected to the exhaust duct. Return air either dumped into the fan room via the return dampers in each branch duct or was exhausted via the smoke exhaust riser. A smoke exhaust damper . opened at the shafts and the return dampers closed to exhaust smoke in the smoke purge mode.

Curtain fire dampers were located throughout the building where ductwork crossed fire rated shaft walls. Separate pneumatic smoke dampers were used in the fan room to direct airflow within HVAC ductwork.

Major changes/additions to the building HVAC systems were made during the SSB tenant retrofit. AHUs were added to handle the increased air conditioning loads created by the extensive computer and data processing equipment. Existing building systems were modified to add an increased make-up air capacity. A new, larger, make-up air shaft was added near the existing smoke shaft in the vicinity of Stair 2 . The shaft was relocated to create more usable space by allowing the removal of the original fan room on the trading floors and other select floors. A transfer fan and ductwork were added to provide outside air to the existing outside air shaft in its original location below the 24 th floor.

In order to bring additional make-up air into the building, a large make-up AHU ivas installed in a new rooftop mechanical penthouse. This provided forced ventilation make-up air rather than the open shaft configuration present in the original building. Additional AHUs and exhaust fans were also located in the penthouse.

A new smoke exhaust fan was added to replace the existing SX-37-1 smoke purge fan. The new, larger, fan had a capacity of $84,000 \mathrm{ft}^{3} / \mathrm{min}\left(142,000 \mathrm{~m}^{3} / \mathrm{h}\right)$. An additional smoke purge fan (SX-47-2) was also installed, to provide smoke exhaust from the 45th through 47 th floors of the building. Dedicated smoke exhaust fans were also provided for the trading room floors (SX-40-1, SX-41-1, SX-42-1, SX-43-1). Each of these fans had a capacity of $15,560 \mathrm{ft}^{3} / \min \left(26,452 \mathrm{~m}^{3} / \mathrm{h}\right)$.

Several new fan rooms were added to house the additional AHUs. A fan room was added at the midpoint of the west wall of WTC 7 on the SSB floors. A louvered opening was provided to the exterior of the building from each fan room along the west wall. Various types of HVAC equipment were located within these fan rooms, including kitchen exhaust fans serving the cafeteria spaces on the 34th and 41 st floors.

New fan rooms were also added to serve the two-story trading floors. The new fan rooms were located along the east wall of WTC 7, on the upper level of the trading floors (referred to as the mechanical mezzanine level). Fans within the east fan rooms returned air via ductwork from beneath the raised trading room floor, re-conditioned the air, and then supplied air at the upper level of the two-story space. Small FCUs were located beneath the raised floor to draw return air through the trading desks back into the raised-floor return plenum.

In several locations throughout the SSB floors, individual FCUs were provided within the return plenums to recirculate and condition air within the perimeter spaces of the building. Free standing Leibert units (recirculating HVAC systems) were also provided within technology spaces/computer rooms to provide local air conditioning within these spaces.

The SSB tenant modifications incorporated combination fire/smoke dampers at many locations within the HVAC ductwork to provide fire separation and to direct airflow within HVAC ductwork. 


\subsubsection{Electrical Systems}

Electrical power for WTC 7 was provided from the Con Edison substation on the lower floors of the building and stepped down by transformers on the 5 th floor of the building to be distributed throughout the building. Within electrical substations on each floor, one of the $277 \mathrm{~V}$ legs was stepped down to supply $120 \mathrm{~V}$ branch circuits. Emergency power generators were located on various levels of the building and supplied backup power for communications equipment, elevators, emergency lighting in corridors and stairways, and fire pumps. Individual backup batteries were provided for emergency lighting units located in exit stairways, elevator lobbies, and elevator cabs (McAllister 2002).

\subsection{REFERENCES}

BCNYC (Building Code of the City of New York). 1973. Fire Safety Requirements and Controls -Local Law No. 5 of the City of New York. New York, NY, January.

McAllister. T., ed. 2002. World Trade Center Building Performance Study: Data Collection, Preliminary Observations, and Recommendations. FEMA 403. Federal Emergency Management Agency. Washington, DC, May.

PANYNJ (Port Authority of New York and New Jersey). 1987. World Trade Center Mannal No. 15: Operation \& Maintenance of HVAC System, Towers A \& B. New York, NY, June.

PANYNJ (Port Authority of New York and New Jersey). 1988. World Trade Center 7 Operations Manual. New York, NY.

Tamura, G. T., and C. Y. Shaw. 1976. Air leakage data for the design of elevator and stair shaft pressurization systems. ASHRAE Transactions. Vol. 82, Part 2. American Society of Heating, Refrigeration and Air-Conditioning Engineers, Atlanta, GA. 
This page intentionally left blank. 


\section{Chapter 5 \\ RELEVANT HISTORY-PASt STUdies AND FIRE-RELATEd EVENTS}

Two major fire-related events in the history of the World Trade Center (WTC) complex had an impact on decisions that affected the spread of fire and smoke within WTC 1 and WTC 2 in the event of a fire and had the potential to impact the smoke management systems installed in the towers. The first incident involved a major fire that occurred on the 11 th floor of WTC 1 on February 14, 1975. The second incident involved a car bomb that exploded in the WTC complex parking garage on February 26, 1993, resulting in smoke spread throughout the towers. The following sections provide a summary of these two events and discuss changes to the buildings that were made subsequent to each event that impacted smoke movement and control. Two engineering studies performed subsequent to the 1993 bombing that recommended changes to the smoke management system design for the towers are also discussed in this chapter, as well as a study of an early prototype stair pressurization system.

\section{$5.1 \quad$ WTC 1 FIRE-FEBRUARY 13, 1975}

On February 13, 1975, a fire occurred in WTC 1 (Powers 1975; Lathrop 1975). The firc was reported by a worker in the building at approximately 11:35 p.m., who noticed flames under the door leading to the office suite occupying roughly the entire southeast quadrant of the 11 th floor of the building. It was later estimated that the fire originated in an executive office in this area from an unknown source at approximately $11: 30$ p.m.

The worker reported the fire to the WTC police headquarters. According to the Ncw York Burcau of Fire Underwriters (NYBFU) report (Powers 1975), the police put into effect the planned firc procedure. The city fire department was called, three policemen responded to the fire floor with a fire equipment cart (typically stationed in the 44th and 78th floor sky lobbies of each tower), and the building engineer was advised to be prepared to put the heating, ventilating, and air conditioning (HVAC) system in the "purge" mode. When police reached the fire floor, they reported a serious fire, and the HVAC system was placcd in the purge mode.

Subsequent to the start of the firefighting efforts, a search of the building disclosed that firc had spread to the telephone closets on the 9th through the 19th floors, via a 12 in. by 18 in. unprotected cable opening in the floors closets. These fires were reportedly readily extinguished, and they did not spread from the telephone closets.

At the time of the fire, each floor of the building was subdivided into quadrants via fire barriers, which contained the fire to the southeast quadrant of the building, which was consistent with the requirements of New York City Local Law No. 5. The fire involved roughly $9,000 \mathrm{ft}^{2}$ of the 11 th floor, destroying about half the contents and damaging the remainder of the contents in this area (Powers 1975). The fire barriers did not extend into the return plenum above the office space on each floor. Therefore, the return plenum was open around the perimeter of the building. 
The fusible link on the fire shutter at the southeast quadrant exhaust shaft operated and closed down the exhaust inlet sometime after the fire gained in intensity. However, hot smoke migrated around the perimeter of the floor within the open return plenum and was exhausted via the exhaust risers serving the other three quadrants of the building. High temperatures in the plenum reportedly (Powers 1975) radiated enough heat into the offices in the uninvolved quadrants on the 11 th floor to melt plastic phones and char papers on desk tops, but ignition did not occur outside the area of fire origin. The fire was eventually extinguished by the New York City Fire Department (FDNY).

\subsubsection{Post-Event Building Modifications-1975 Fire}

The primary enhancement to WTC 1 and WTC 2 following the 1975 fire that impacted the issues of smoke movement and smoke management in the buildings was an improvement with regard to unsealed vertical penetrations. The fire illustrated the ability of fire and smoke to spread vertically in high-rise buildings via unprotected vertical openings. As a direct result of the fire, the floor openings were firestopped with vermiculite concrete poured into forms around the cables in the telephone closets. The louvers in the doors to the closets were sealed with steel plates.

\subsubsection{Important Considerations-1975 Fire}

There are several items identified in the Powers and Lathrop accounts of the 1975 fire that potentially relate to the understanding of the installed smoke management systems and their potential function on September 11, 2001.

Both Powers and Lathrop describe the use of the WTC 1 smoke purge sequence as an active fire protection measure used to improve conditions during the 1975 fire, as opposed to using the HVAC system purge as part of post-fire cleanup efforts. With regard to the function of the purge mode, Powers (1975) states that "this means that outdoor air was being blown into the core area to keep it free of smoke and air was being drawn out of all the tenant areas on this floor to prevent smoke from spreading throughout the building." He also states that "in the case of fire, the supply air fans for the air conditioning section are shut down and only the return air fans operate and discharge to the outside of the building... The other part of this protection is achieved by supplying outdoor air to the core and shutting down its normal vents. This pressurizes the elevators as well as the stairs and keeps the exit corridors free of smoke." Lathrop (1975) also documents that during a fire, office areas could be put on 100 percent exhaust, with the core getting 100 percent supply, accomplished in 32 floor segments corresponding to a single HVAC zone. As will be discussed in Chapter 6 of this report, this differs from the sequence of operations listed in the building operations manuals with regard to the smoke purge sequence.

The NYBFU report (Powers 1975) recognized that when a fire shutter closes, the ability of that exhaust shaft to exhaust smoke is "nullified." The report recommended that in unsprinklered buildings, detectors be provided at the return air shafts on each floor to cause them to discharge the return air and stop the delivery of outdoor air to the fire area.

The Lathrop account of the 1975 fire implied that the smoke purge system cleared smoke from all floors except the fire floor. This is significant since the building was unsprinklered at the time of the fire and the fire was substantial in nature, involving over $9,000 \mathrm{ft}^{2}$ of office space. Yet, fire/smoke spread to other floors was minor and was due primarily to unprotected openings in the telephone closets. 
It is significant to note that since the fire occurred in February, and at a time when the building HVAC systems were largely shut down, stack effect would have been expected to have been substantial at the time of the fire. Since the floor of fire origin was low in the building (11th floor), stack effect flows would cause air to flow inward toward the building's core then upward via stair/elevator shafts and open HVAC ducting. Yet, little smoke spread to other floors was noted. The degree of passive compartmentation present in the building at the time of the fire, coupled with the operation of smoke exhaust from the zone of fire origin appears to have been effective in minimizing the smoke movement that would have occurred due to stack effect.

\section{$5.2 \quad$ WTC BOMBING-FEBRUARY 26, 1993}

At 12:18 p.m. on February 26. 1993, a bomb exploded in a parking garage located in the sub-levels of the WTC complex (Isner and Klem 1993). The task force that investigated the bombing concluded that the explosion and subsequent fire were caused by the detonation of at least $1,000 \mathrm{lb}$ of explosives located in a van parked on the B2 level of the complex, in an area of the garage adjacent to WTC 1 and under WTC 3 (then referred to as the Vista Hotel). The explosion created a crater involving six levels of the underground portion of the complex. The uppermost portion of this large open space connected to the lobby of the Vista Hotel via an $18 \mathrm{ft}$ by $22 \mathrm{ft}$ hole in the lobby's floor slab. The blast also created a large hole in the glass wall separating the hotel lobby from the lobby of WTC 1.

The explosion damaged four of seven operating electrical feeders (an eighth was undergoing maintenance at the time of the bombing), causing short circuits in the system. This resulted in loss of normal electrical power to most areas of WTC 1 and WTC 2. Normal lighting systems and the building HVAC systems shut down. Emergency generators operated for approximately $20 \mathrm{~min}$ before overheating, causing automatic shutdown of the diesel engines. The lighting system in the stairways of both towers operated for approximately 1 hour and $15 \mathrm{~min}$. while the emergency lighting systems were being powered by the normal or emergency electrical system. However, normal electrical power was eventually shut down due to a concern for firefighter safety in and around the blast area, causing the remaining occupants in the stairways to have to evacuate in complete darkness.

As noted in Chapter 4 of this report, the tower buildings were designed to be maintained at a slight positive pressure by the building HVAC systems. When the building HVAC systems shut down due to loss of electrical power, the building was subjected to extreme stack effect forces, since at the time of the bombing the outside temperature was in the twenties (degrees Fahrenheit) (Isner and Klem 1993). Because the explosion caused penetrations into several elevator shafts in WTC 1 on the subgrade levels and lobby level, smoke was rapidly transported to the upper portions of the WTC 1 due to forces caused by the explosion and stack effect. A Port Authority of New York and New Jersey (PANYNJ or Port Authority) engineer working on the 44th floor of WTC 1 when the explosion occurred reported that smoke reached his location about $1 \mathrm{~min}$ after the explosion, resulting in a rapid decrease in visibility (Isner and Klem 1993). Smoke eventually spread throughout WTC 1 and to a lesser degree to WTC 2.

Although smoke spread to most areas of WTC 1 and WTC 2 as a result of the bombing, the event resulted in a relatively low loss of life, limited to the six people killed in the immediate area of the blast. Even though it took building occupants in some cases up to 3 hours to negotiate their way out of the building via the stairways, through smoke dense enough to dramatically reduce visibility, the smoke was diluted sufficiently such that only respiratory irritation was caused. 


\subsubsection{Post-Event Building Modifications-1993 Bombing}

A review committee was convened by the City of New York, including representatives from the New York City building and fire departments and the Port Authority. The committee's mission was to study the 1993 WTC bombing and determine the adequacy and effectiveness of the existing New York City building and fire codes as they related to high-rise buildings (World Trade Center Review Committee 1994). With regard to smoke management systems, the committee concluded that the "complex issue of smoke control" was beyond the scope of the committee at that time and required future review. However, the committee recommended that building code requirements for smoke dampers should be clarified and that elevator lobbies should be provided in new high-rise buildings to resist the passage of smoke. Despite this recommendation, elevator lobbies are only required in high-rise residential buildings under the current provisions of the Building Code of New York City (BCNYC).

The report concluded that stair pressurization systems, not installed in the WTC towers, would not function in an incident involving a mass evacuation due to the simultaneous opening of more than three stairway doors. The report did conclude, however, that the BCNYC, Reference Standard 5-18 lacked rcgulatory provisions for periodic testing and maintenance of stair pressurization systems and recommended that these requirements be added. Finally, the committee report recommended that the issue of providing fire towers in new high-rise commcrcial office buildings be revisitcd. The requirement for fire towers, stairways separated from the interior environment of the building via open-air balconies, was included in the 1938 edition of the BCNYC, but removed in the 1968 edition of the code. Provision of fire towers is not required under the current provisions of the BCNYC.

A number of changes were eventually made to the buildings as a result of the committee's recommendations, as reported by the Port Authority risk management staff in an article titled "The World Trade Center Complex," published in Fire Engineering (Port Authority Risk Management Staff 1993). The enhancements made include the following:

- 1,600 emergency battery-powered lighting units were installed in exit stairways, elevator lobbies, and elevator cabs.

- Phosphorescent signs were installed to guide the way to floor entry doors in exit stairways.

- Phosphorescent tape-paint was applicd to stair treads, handrails, and the perimeters of doorways in the exit stairways.

- New fires alarm and communications systems were installcd in each building with a separate command center located in each building.

In a separate article published in the December 1993 Fire Engineering issue, titled "Fire Prevention and Building Restoration Activities" (Corcoran 1993), it was purported that emergency power was provided for smoke purge fans. No other sources were found to corroborate this assertion.

\subsubsection{Important Considerations-1993 Bombing}

The 1993 bombing demonstrated that the stack effect could be a primary driver of rapid smoke spread through high-rise buildings. The bombing showed that large amounts of smoke can be transmitted to the 
upper floors of a building due to a fire on a lower floor of the building, particularly when that fire produces a large quantity of smoke, such as was the case for the 1993 bombing. The 1993 bombing also clearly demonstrates that, as expected, stack effect is enhanced by openings created in the vertical shafts within the building, such as stair and elevator shafts.

Smoke spread via the stairways was substantial in WTC 1 during the 1993 event due to the large number of open stair doors occurring as a result of the mass evacuation of occupants in the building. The stairways, which were designed with an exit capacity that met or exceeded prevailing code requirements for the buildings, did not provide the exit capacity to ensure rapid egress of all of the occupants of the building. As a result, doors remained blocked open by building occupants entering/exiting the stairways, increasing the magnitude of the airflow up the stairs due to stack effect.

The 1993 bombing also clearly showed the importance of cmergcncy power to maintain the function of building systems, including emergency lighting systems, in the event of a fire.

\section{$5.3 \quad$ ENGINEERING STUDIES}

Between the time the WTC complex was constructed and the 2001 WTC disaster, several engineering studies were performed to evaluate candidate smoke management system approaches for various areas of the complex. Three particular studies were conducted to examine smoke management systems in the towers (WTC 1 and WTC 2). These must be considered in the evaluation of the smoke management systems actually in place on September 11,2001.

\subsubsection{Prototype Stair Pressurization System Study}

Between 1976 and 1979, the Port Authority performed a study aimed at understanding the feasibility of providing stair pressurization systems in WTC 1 and WTC 2 (PANYNJ 1979).

Beginning in 1976, tests were conducted using building air handling systems locatcd in the 7th floor mechanical equipment room (MER) and 41 st floor MER of WTC 1, reconfigured to supply air to Stair C (Stair 3). The goal of the tests was to meet the performance criteria outlined in Local Law No. 5, which was to provide $0.05(12.5 \mathrm{~Pa})$ in. $\mathrm{H}_{2} \mathrm{O}$ across closed stair doors with three doors open to the stair and $0.1(25 \mathrm{~Pa})$ in. $\mathrm{H}_{2} \mathrm{O}$ across stair doors with all doors closed, along with a $35 \mathrm{lb}_{\mathrm{f}}(156 \mathrm{~N})$ maximum door opening force.

The stair pressurization system study examined stair pressurization system performance with the building HVAC systems in normal mode and smoke purge mode. At the time of the study, the smoke purge sequence was defined as pressurizing the core using core supply ventilation and exhausting the interior spaces using the low pressure return fans. Perimeter supply/exhaust fans were shut down in purge mode.

The study demonstrated that the system as designed was unable to meet the performance criteria outlined in Local Law No. 5. With 3 doors open, differential pressures were generally low (approximately 0.03 in. $\mathrm{H}_{2} \mathrm{O}$ ). With doors closed, door opening forces approached $35 \mathrm{lb}_{\mathrm{f}}$. The study concluded that stair pressurization systems should be installed based on the prototype design, with modifications being made to the design as stair pressurization technology improved. Based on the results of the study, construction drawings were prepared outlining the proposed stair pressurization systems. 
Local Law No. 86 (enacted on December 13, 1979) stated that existing buildings shall be exempt from the smoke shaft and optional stair pressurization requirements if they were provided with automatic sprinklers throughout. A decision was made sometime after this datc to fully sprinkler WTC 1 and WTC 2. As a result, stair pressurization systems were never installed in WTC 1 and WTC 2.

\subsubsection{Rolf Jensen Smoke Movement Analysis}

Subsequent to the 1993 bombing, an analysis was performed by Rolf Jensen \& Associates (RJA). Computer modeling was used to attempt to verify and explain the movement of smoke in WTC 1 following the explosion (RJA 1995). The report also addressed the potential effectiveness of elevator venting, stair venting and stair pressurization to improve conditions in the building.

RJA performed modeling using the SMOKESIM computer model, a precursor to the CONTAM model describcd in Chapter 8 of this report. The modeling effort only examined building airflows and pressure differentials, as the capabilities of the SMOKESIM model were not fully developed to handle contaminant (i.e., smoke spread) calculations for a building as large as the WTC towers.

The RJA report concluded that the results of the modeling generally agreed with reported smoke spread given the wind/weather/damage conditions on February 26, 1993. The report also concluded that stair venting, defined as exhausting a stair using mechanical vcntilation, was not an effective protection measure. Although stair venting decreases the amount of smoke migrating onto floor areas at the top of the building, it causes stack effect to be increased, and more smoke to be drawn into the stairs on the lower floors of the building. Elevator venting was found to improve overall conditions in the building.

Stair pressurization was found to be feasible, and capable of maintaining adequate pressure $\left(0.05\right.$ in. $\left.\mathrm{H}_{2} \mathrm{O}\right)$ with stair doors closed. However, it was concluded that some sort of relief venting was needed at the top of each stair segment to relieve unacceptable door opening forces at the top of the stair due to stack effect. This was particularly true for Stair 3, which had the longest stair segment uninterrupted by a horizontal transfer corridor.

With or without overpressure relief, stair pressurization was found to be capable of maintaining a slightly positive pressure in the stair with several doors open. However, as expected, positive pressure could not be maintained with all stair doors open, as would be the case in a mass evacuation scenario.

\subsubsection{Hughes/Dillon Smoke Management System Evaluation}

During the same timeframe that RJA was conducting their smoke movement study (1994-1995), Hughes Associates, Inc. (HAI) and Dillon Consulting Engineers (DCE) were performing a joint study of smoke movement and control for the concoursc and plaza portion of the WTC complex. The study evaluated proposed changes to the plaza/concourse level to add additional public (i.e., a food court, atria) and retail space. The purpose of this study was to evaluate the effectiveness of a proposed smoke control approach for the plaza/concourse levels.

When the initial study was completed, HAI/DCE were asked to examine smoke management for the office buildings in the WTC complex, with a primary emphasis on the towers (WTC 1 and WTC 2). $\mathrm{HAI} / \mathrm{DCE}$ were instructed to examine potential configurations using the existing HVAC systems in the 
towers to improve smoke control performance, without examining the provision of stair pressurization systems.

The resulting study (HAI and DCE 1996) used the DOS-based computer model CONTAM96, another precursor to the window's-based CONTAM version of the model used to complete the analysis described in Chapter 8 of this report. A key component of the study was to use the model to examine system performance in terms of tenability (visibility distance, toxicity) as well as pressure differentials. System success could thus be achieved by maintaining acceptable smoke conditions in areas remote from the fire, even though sufficient pressure was not achieved to maintain total containment of the smoke.

The HAI/DCE study examined numerous fire scenarios. The study examined fires originating in the Port Authority Trans-Hudson (PATH) terminal, loading dock, parking garage, and lobby, as well as fires on various office floors. In addition, the study examined fire scenarios where the installed sprinkler system was assumed to fail to function. resulting in an uncontrolled fire on an office floor. Finally, wind and stack effects were examined.

The study concluded that for most fire scenarios, a sequence involving pressurizing the core in the HVAC zone of fire origin and exhausting the perimeter office spaces (core pressurization) provided adequate smoke control performance. The study also strongly rccommended that smokc management systems be activated automatically using smoke detectors installed in the building. This was a somewhat controversial recommendation as automatic activation of smoke management systems is generally not allowed for high-rise buildings in New York City.

The HAI/DCE report provided a recommended sequence of operations that could be used to better control smoke given an uncontrolled fire event on a floor that involved visiblc flame and heat exiting the building via broken windows. The approach involves placing all of the HVAC systems in the building on supply only and shutting down return fans. This approach cffectively pressurizes the entire building and forces smoke out the broken windows on the fire floor. It is cautioned, however, that this approach should only be used when occupants have already evacuated the fire floor and windows have been broken out due to the fire, as high door opening forces may be created.

Several other recommendations were made involving the other buildings in the WTC complex. These findings are not summarized here because they do not impact WTC 1 and WTC 2. One intcresting finding of the HAI/DCE study, however, pertains to the interrelationship of the buildings in the WTC complex. During the course of the study, measurements of airflows and pressures were taken at various points throughout the complex. It was found that during extremely cold ambient temperatures $\left(15^{\circ} \mathrm{F}\left[-9.4{ }^{\circ} \mathrm{C}\right]\right.$ on the day of the test) and when many ventilation systems are shutdown (night modc), the neutral plane of the entire complex is at a height above the other tallest connected building in the complex, WTC 3 (the Marriott hotel, formally the Vista hotel).

Because WTC 1, 2, 3, 4, and 5 were essentially connected to one another via the concourse and other subgrade levels, the substantial stack effect caused by the two towers created patterns of air flow toward the towers from the other buildings. Even at their uppermost floors airflow was into WTC 3, 4, and 5 from outside. It was also found that a substantial source of air was drawn up the escalators in the concourse leading from the PATH station. This air in turn is being drawn through the PATH tunnel from the opposite side of the Hudson River, in New Jersey. Thcrefore, during extreme weather conditions, the air entering the PATH tunnel in New Jersey exited the top of WTC 1 and WTC 2 due to stack effect. The 
implications of the interdependence of the various buildings in the WTC complex with regard to stack effect will bc discussed further in Chapter 8 of this report. The computer modeling described in Chapter 8 cxamines the impact of stack effect on smoke management system performance.

\subsection{REFERENCES}

BCNYC (Building Code of the City of Ncw York). 1973. Fire Safety Requirements and Controls -Local Law No. 5 of the City of Ncw York. New York, NY, January.

BCNYC (Building Code of the City of New York). 1979. Dates for Compliance with the Local Laws Enacted for Fire Safety Requirements and Controls in Certain Buildings -Local Law No. 86 of the City of New York. New York, NY, December.

Corcoran, D. 1993. Fire prevention and building restoration activities. In The World Trade Center Bombing: Report and Analysis. Fire Engineering. Manning, W. A. ed. Vol. 146, No. 12. December.

HAI (Hughes Associates, Inc.) and DCE (Dillon Consulting Engineers). 1996. Smoke Management Evaluation Study of The World Trade Center Complex Exchiding the Concourse and Plaza. Prepared for the PANYNJ (Port Authority of New York and New Jersey). New York, NY.

Isner, M. S., and T. J. Klem. 1993. Explosion and fire disrupt World Trade Center. NFPA Journal. National Fire Protection Association. November/Dccember.

Lathrop, J. K. 1975. World Trade Center Fire New York, New York. Fire Joumal. July.

PANYNJ (Port Authority of New York and New Jersey). 1979. Stair pressurization study (Tower 1, Stair C) engineering documents. New York, NY.

The Port Authority Risk Management Staff. 1993. The World Trade Center Complcx. In The World Trade Center Bombing: Report and Analysis. Fire Engineering. Manning, W. A. ed. Vol. 146, No. 12. December.

Powers, W. R., Superintendent. 1975. One World Trade Center Fire New York, NY, February 13, 1975. NYBFU (New York Board of Underwriters), New York, NY.

RJA (Rolf Jenson and Associates). 1995. World Trade Center Smoke Movement Analysis. Preparcd for PANYNJ (Port Authority of New York and New Jersey). New York, NY.

World Trade Center Review Committee. 1994. The Report of the World Trade Center Review Committee. The City of New York Department of Buildings. New York, NY. 


\section{Chapter 6 \\ SMOKE MANAGEMENT SYSTEM DESIGN AND INSTALLATION}

In order to document the smoke management systems, multiple documents were provided by the Port Authority of New York and New Jersey (PANYNJ or Port Authority) for review, in order to determine how the systems were designed and operated. These documents included the following:

- Base building architectural and mechanical drawings for World Trade Center (WTC) 1, 2, and 7

- Tenant retrofit architectural and mechanical drawings (when available)

- Operations and maintenance manuals

- Fire safety plans

- Answers to questions posed via National Institute of Standards and Technology (NIST) to the Port Authority and other knowledgeable personnel

In the case of WTC 1 and WTC 2, information obtained that documented the operation of smoke management systems presented conflicting versions of how the systems operated. In the case of WTC 7, the base building systems installed when the building was constructed was modified/supplemented to add smoke management system capabilities during tenant retrofits. Instances where conflicting or incomplete information was provided are fully documented in this report.

\subsection{WTC 1 AND WTC 2}

The tower buildings (WTC 1 and WTC 2) were equipped with a non-dedicated smoke management system (a smoke purge system) that utilized the base building heating, ventilating, and air conditioning (HVAC) systems that provided normal ventilation to the buildings. The smoke purge sequence is discussed in detail in Sec. 6.1.1 of this report. No dedicated smoke management systems were installed in the buildings.

The normal base building HVAC systems in WTC 1 and WTC 2 are summarized in Chapter 4 of this report. These HVAC systems could be manually aligned in a smoke purge mode that allowed smoke to be removed from the building. Smoke purge could only be accomplished for an entire ventilation zone served by a particular mechanical equipment room (MER) (ventilation zones are depicted in Fig. 4-4); thus, in the smoke purge mode the entire ventilation zone represented a single smoke zone. Because no operable fire/smoke dampers were present within the ventilation ductwork, it was not possible to provide the smoke purge, or any other smoke management sequence, on a floor-by-floor basis.

Smoke detectors were located at the exhaust duct inlets on each floor and within the HVAC system ductwork in the MER to provide automatic shutdown of individual fans in the presence of smoke. Automatic shutdown of the ventilation systems could be overridden in the smoke purge mode. 


\subsubsection{Sequence of Operations}

The fire safety plan for WTC 1 and WTC 2, revised in January of 1999 (PANYNJ 1999), defines smoke purge as the removal of smoke and other gaseous combustion products from the (fire) area "after a fire has been extinguished." As documented in the fire safety plan, mechanical systems could be aligned to perform the smoke purge function by the Port Authority mechanical section staff when requested by the chief officer of the responding New York City Fire Department (FDNY) units. The FDNY would ask the WTC fire safety director to provide a smoke purge for a given zone. The WTC fire safety director would then instruct the mechanical section staff to perform the requested action.

The smoke purge sequence is documented in WTC Instruction Manual No. 23, Operation and Maintenance of Fire Protection Systeml, dated February 1986 (PANYNJ 1986). The documented sequence is as follows:

Based on the information contained in the fire safety plan for WTC 1 and WTC 2 and WTC Instruction Manual No. 23, it could be concluded that the buildings were equipped with a manual purge system that utilized the interior zone exhaust fans serving the four quadrants of the building to remove smoke after a fire was extinguished. Core supply/exhaust fans and perimeter supply fans would be shut down. Smoke purge could be accomplished within each HVAC zone, the largest of which having 32 floors, as depicted in Fig. 4-4. However, a number of sources contain conflicting information regarding how the smoke purge system functioned and how it was intended to be used.

Accounts of the 1975 fire (Powers 1975; Lathrop 1975) state that the smoke purge sequence pressurized the core with 100 percent outdoor air and exhausted 100 percent from the office spaces. These accounts also state that during the 1975 fire, the smoke purge sequence for the fire floor and adjacent floors was initiated from the appropriate MER shortly after discovery of the fire, once police had examined the fire floor and identified the presence of a significant fire. This documented sequence of events is important, as it signifies that the system was used at that time as an active fire protection system, to control smoke during the fire event and that the described "core pressurization" mode differed from the sequence of operations (Fig. 6-1) documented in WTC Instruction Manual No. 23.

WTC Instruction Manual No. 23 makes the statement that "in the event of smoke in an interior tenant's space involving personnel evacuation, the smoke purge procedure to be used is as follows..." In referencing an event involving personnel evacuation, this statement also implies use of the smoke purge sequence as an active fire protection sequence rather than a post-fire smoke cleanup sequence. The Federal Emergency Management Agency (FEMA) report summarizing events on September 11, 2001, (McAllister 2002) states (in Sec. 2.1.3.3) that, "a zoned smoke control system... was designed to limit smoke spread from the tenant areas to the core area, thereby assisting both individuals evacuating from an area and those responding to the scene by limiting smoke spread into the core." Again, this statement implies an active smoke management system based on the concept of pressurizing the core, which conflicts with the documented smoke purge sequence for the buildings. 


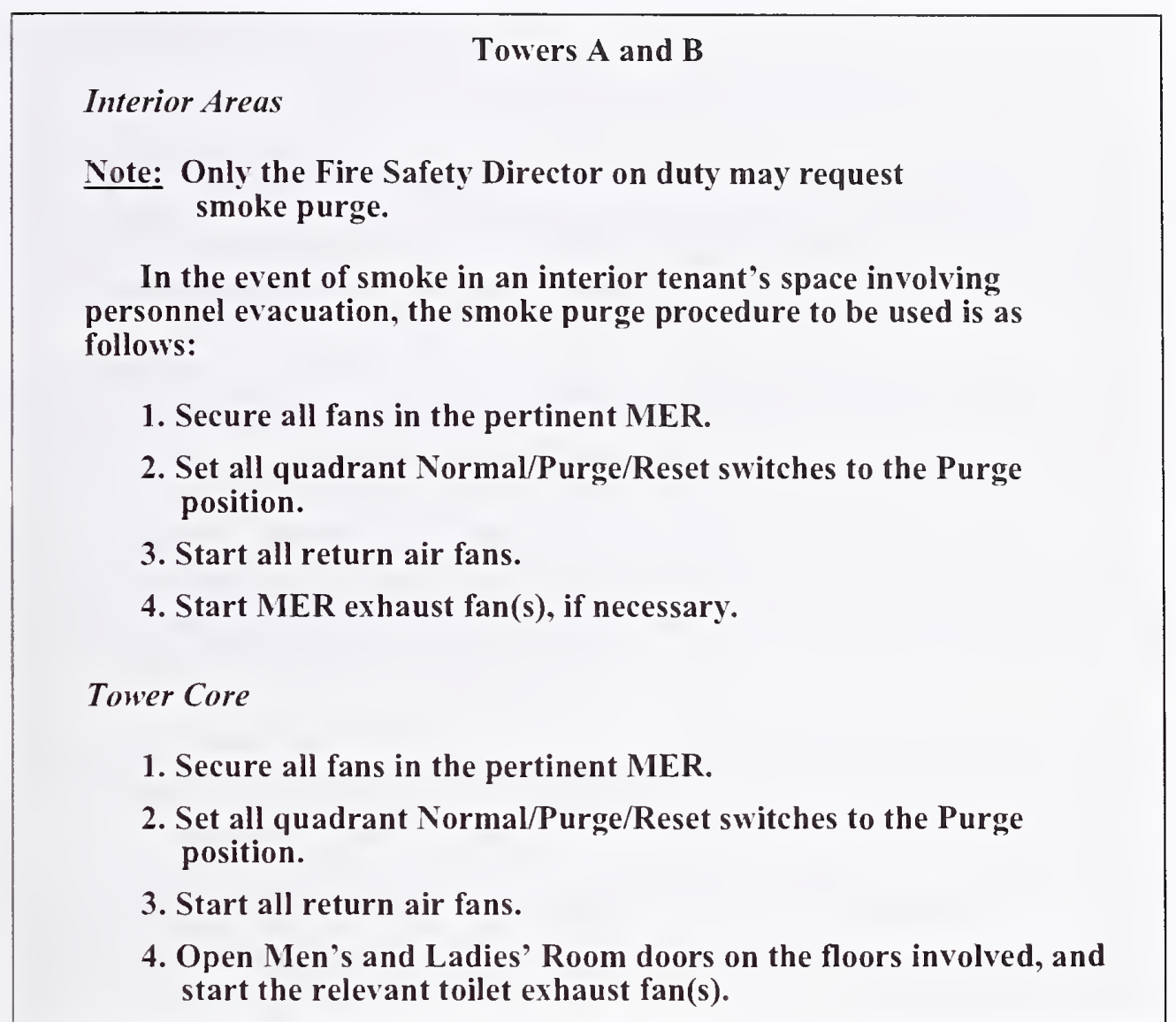

Source: PANYNJ 1986. Reproduced with permission of The Port Authority of New York and New Jersey.

Figure 6-1. Documented smoke purge sequence of operations, WTC 1 and WTC 2.

The Port Authority was asked to clarify the operation of the smoke purge sequence, since the available information regarding its intended operation provides conflicting accounts of smoke purge operation. According to the Port Authority, ${ }^{3}$ the operation of the smoke purge sequence is as follows:

During a fire/smoke incident, the fans stayed in operation until shut down by a smoke detector on interlocking exhaust fans or at the direction of FDNY. FDNY would also direct what mode of operation the fans should be in. If fans were still operating, as would often be the case, the engineer at FDNY direction would key over to purge mode. This would sequence spill dampers to open $100 \%$. In addition, building operating procedure during a purge was to run the interior supply fans for purging [the] affected quadrant. During purge, the interior fan's outside supply air dampers would go to $100 \%$ open. For example, during a smoke incident on 38NE in tower one, ACS 41-6 [northeast interior supply fan] would be operating on purge, outside damper open $100 \%$. ACR 41-4,5 and/or 6 [northeast interior return fans] would be operating on purge,

3 E-mail communication from the Port Authority to NIST, dated February 18, 2004, responding to questions posed by NIST. 
spills open $100 \%$. Core fans would not normally operate during a smoke purge unless conditions warrantcd and requested by FDNY.

According to this version of the sequence of operations, smoke purge would occur by starting the supply and exhaust fans serving one of the four interior quadrants within a ventilation zone. Core supply/exhaust fans and perimcter supply fans would be shut down. HVAC systems serving the other ventilation zones in the building would be left operating unless they were shut down at the direction of FDNY.

The Port Authority further recognized that WTC Instruction Manual No. 23 had not been updated since the base building fire alarm system was upgraded after the 1993 bombing. Therefore, this manual did not always reflect the most current fire protection systcm configuration ${ }^{4}$.

Operation of the smoke management system for WTC 1 and WTC 2 could be achieved by aligning the equipment within the individual MERs or at a central control panel located in the Operations Control Center (OCC) located on the B1 level of WTC 2. At either location, building personnel had to perform two distinct operations:

1. Aligning the HVAC systems in smoke purge

2. Starting the appropriate HVAC fans

Operation of the purge switch simply aligned all dampers that served as part of that quadrant's HVAC systems in a 100 percent outdoor air configuration. Supply and spill dampers would be fully open, and return dampers would be closed.

To achieve the smoke purge, it was up to the operator of the systems to turn on those fans necessary to achieve system operation. It would be equally possible to initiate an exhaust only type sequence as outlined in the fire safety plan, the core pressurization sequence (supply and exhaust operating) reportedly initiated during the 1975 fire, or the sequence stated by the Port Authority as the smoke purge sequence in effect on September 11, 2001. Alignment of the system would be up to the understanding of the operator as to the proper function of the smoke purge sequence, when called upon to initiate this sequence.

With regard to the use of the smoke purge function to aid in active smoke management during a fire event versus during post-fire cleanup operations, it would be up to the responding fire department personnel to initiate system operation. Depending on the type of fire event, it is possible that the system could have been used either during the fire or after it was extinguished.

For the purposes of this report, the function of the smoke purge system documcnted by the Port Authority ${ }^{1}$ was assumed to be in effect on September 11, 2001. It was also assumed that the system was to be used after the fire was extinguished, at the discretion of the responding fire department personnel.

4 E-mail communication from the Port Authority to NIST, dated February 18, 2004, responding to questions posed by NIST. 


\subsubsection{Applicable Code Requirements}

Individual code requirements of the BCNYC that pertain to smoke management are discussed in Sec. 3.2 of this report. At the time the buildings were constructed, the ability to provide a smoke purge from each HVAC zone was the only smoke management system provided in the buildings. Local Law No. 5 retroactively imposed the requirements for smoke shafts for existing high-rise buildings when it was enacted in 1973. In lieu of such smoke shaft(s), stair pressurization systems could be provided.

In order to respond to the requirements of Local Law No. 5, the Port Authority initiated a pilot study into the requirements for pressurizing the exit stairs in WTC 1 and WTC 2. This pilot study is discussed in Sec. 5.3.1. Stair pressurization was examined as a means of meeting the requirements of Local Law No. 5 since the smoke shaft requirements would have been prohibitive for a building the size of WTC 1 and WTC 2. The smoke shaft requirements contained in reference standard Reference Standard 5-17 called for the capability of providing 60 air changes per hour in the largest compartment served, which would have required the capacity to exhaust $300,000-400,000 \mathrm{ft}^{3} / \mathrm{min}$ from each floor of the towers being exhausted. This was clearly outside the capabilities of the existing ventilation systems.

Existing buildings that were sprinklered throughout were exempt from the smoke shaft and optional stair pressurization requirement by Local Law No. 86 (enacted in 1979). A decision was made at some subsequent time to fully sprinkler the WTC buildings. Therefore, the Port Authority did not move forward with the stair pressurization option. Because WTC 1 and WTC 2 were fully retrofitted with automatic sprinklers, smoke and heat venting and/or stair pressurization was not required in WTC 1 and WTC 2 on September 11, 2001.

WTC 1 and WTC 2 were equipped throughout with fire dampers at duct penetrations into vertical shafts. Combination fire/smoke dampers were not required by the code to be provided in existing buildings. Since tenant retrofit projects generally connected to the existing base building systems, fire/smoke dampers at HVAC shafts were not generally provided during tenant retrofits. This was verified by examining the mechanical drawings for the Marsh \& McLennan tenant retrofit in WTC 1, considering this retrofit occurred in the years just prior to the events on September 11, 2001.

\subsubsection{Emergency Power}

Emergency power was provided subsequent to the 1993 bombing for WTC 1 and WTC 2, serving all emergency systems (lighting, fire alarm system, etc.) and the building elevators. While one account summarizing the building restoration activities following the 1993 bombing (Corcoran 1993) purported that emergency power was provided for smoke purge fans, no other sources were found to corroborate this assertion. According to the Port Authority, ${ }^{5}$ emergency power was not provided to WTC 1 and WTC 2 base building smoke purge fans. However, the MERs were equipped with redundant power sources from different substations.

No other redundant features were identified with respect to the HVAC systems used to accomplish the smoke purge functions. No back-up systems or emergency power was provided.

\footnotetext{
E-mail communication from the Port Authority to NIST, dated February 18, 2004, responding to questions posed by NIST.
} 


\subsubsection{Fire/Smoke Dampers}

According to the Port Authority, ${ }^{6}$ all of the base building duct penetrations through firc rated partitions wcre equipped with fire dampers. Therc were no smoke dampers in the base building HVAC system, except for those within the air handling unit serving the Windows on the World restaurant in WTC 1. The smoke dampers were designed to segregate the restaurant from tenant floors below.

\section{$6.2 \quad$ WTC 7}

WTC 7 was equipped with a dedicated smoke management system (a smoke purge system) that utilized dedicated HVAC equipment that served only a smoke management function. This type of system differed from that used in WTC 1 and WTC 2, which used the HVAC systems that provided normal ventilation to the buildings to perform the smoke purge function. The smoke purge sequence for WTC 7 is discussed in detail in Sec. 6.2.1 of this report.

The HVAC systems serving WTC 7 are summarized in Chapter 4 of this report. As stated in Chapter 4, dedicated smoke exhaust fans/dampers could be manually aligned at the fire command center to provide smoke purge from a specified floor within the building. Since the smoke purge function could be provided on a floor-by-floor basis, each floor of the building constituted an individual smoke control zone.

\subsubsection{Sequence of Operations}

The WTC 7 fire safety plan (PANYNJ 1988a) specifies the sequence for emergency exhausting of heat and smoke as follows:

Heat and smoke exhausted from the building by activation of smoke purge and related air handling upon report of fire.

The fire safety plan does not identify the responsibility for activating the smoke purge system, the means for activating the system, or the location from which it was to be activated. However, the building was provided with a Class E fire alarm signal center (BCNYC Reference Standard 17-3A), which required fan control to be provided at the Fire Command Station, which was located in the 3rd floor main lobby in WTC 7 (PANYNJ 1988a).

The building operations manual for WTC 7 (PANYNJ 1988b) specifics three alarm modes pertaining to operation of the building HVAC systems. ALARM-1 initiated shutdown of HVAC equipment based on duct smoke detection. ALARM-2 initiated smoke purgc on the affected floor. ALARM-3 specified the smoke purge sequence for non-affected floors. The smoke management sequence pertaining to the smoke purge function involved exhausting the fire floor and pressurizing the remaining floors with supply air. The documented sequences (PANYNJ 1988b) are shown in Fig. 6-2.

\footnotetext{
6 E-mail communication from the Port Authority to NIST, dated February 18, 2004, responding to questions posed by NIST.
} 


\section{WTC 7}

Smoke Detection, etc., (ALARM-I)

1. Upon an alarm condition, system will completely shut-down. Dampers will close.

Smoke Purge-Affected Floor (ALARM-2)

1. When fans are operating, system will slow to $15 \%$.

a. Heating coils will de-energize.

b. Cooling System will stop.

c. Economizer coil valves will close "fully" to supply all condenser water to economizer coils.

d. Supply air dampers will remain fully open.

e. Minimum outside air dampers and smoke damper will open.

f. Maximum outside air dampers and return air dampers will remain closed.

g. VAV terminal box dampers will open fully.

1. When fans are off, fans will start and run at $15 \%$.

ALARM-2 is functional in "manual" mode and overrides ALARM-1.

Smoke Purge - Non-Affected Floors (ALARM-3)

1. When fans are operating, system will run at $100 \%$.

a. Heating coils will de-energize.

b. Cooling System will stop.

c. Economizer coil valves will close "fully" to supply all condenser water to economizer coils.

d. Supply air dampers will remain fully open.

e. Minimum outside air dampers and maximum outside air dampers will open.

f. Smoke exhaust dampers and return air dampers will remain closed.

g. VAV terminal box dampers will open fully.

2. When fans are off, fans will start and run at $100 \%$.

3. ALARM-3 is functional in "manual" mode and overrides ALARM-1 and ALARM-2.

Source: PANYNJ 1988b. Reproduced with permission of The Port Authority of New York and New Jersey.

Figure 6-2. Documented smoke management sequence, WTC 7.

\subsubsection{Applicable Code Requirements}

Individual code requirements of the Building Code of the City of New York (BCNYC) are discussed in Sec. 3.3 of this report. Local Law No. 16 required that all buildings in occupancy group E (business) be provided a manual override capability to be capable of exhausting one floor at a time at a rate of six air changes per hour, or $1 \mathrm{cfm} / \mathrm{ft}^{2}$, whichever is greater. WTC 7, having a footprint area of approximately $48,000 \mathrm{ft}^{2}$. would require an exhaust capacity of at least $48,000 \mathrm{ft}^{3} / \mathrm{min}\left(81,552 \mathrm{~m}^{3} / \mathrm{h}\right)$ to be consistent with the code. As documented in Chapter 4 of this report, the base building system serving the lower floors of the building provided a smoke exhaust capacity of $36,000 \mathrm{ft}^{3} / \mathrm{min}\left(61,164 \mathrm{~m}^{3} / \mathrm{h}\right)$, which was not consistent with the minimum value specified by code. An $84,000 \mathrm{ft}^{3} / \mathrm{min}\left(142,716 \mathrm{~m}^{3} / \mathrm{h}\right)$ exhaust fan was provided for the SSB floors during the tenant retrofit, which exceeded the capacity required by code.

WTC 7 was sprinklered throughout and was, therefore, exempted from the requirement for stair pressurization systems. The building was provided with a Class E fire alarm system per code, was provided with emergency power serving all emergency systems, and was equipped throughout with fire dampers at duct penetrations into vertical shafts, consistent with the BCNYC. 


\subsection{REFERENCES}

BCNYC (Building Code of the City of New York). 1973. Fire Safety Requirements and Controls -Local Law No. 5 of the City of New York. New York, NY, January.

BCNYC (Building Code of the City of New York). 1979. Dates for Compliance with the Local Laws Enacted for Fire Safety Requirements and Controls in Certain Buildings -Local Law No. 86 of the City of New York. New York, NY, December.

BCNYC (Building Code of the City of New York). 1984. Local Laws of the City of New York for the Year 1984 -Local Law No. 16 of the City of New York. New York, NY, March.

Corcoran, D. 1993. Fire Prevention and Building Restoration Activities. In The World Trade Center Bombing: Report and Analysis. Fire Engineering. Manning, W. A. ed. Vol. 146, No. 12. December.

Lathrop, J. K. 1975. World Trade Center Fire New York, New York. Fire Journal. July.

McAllister, T., ed. 2002. World Trade Center Building Performance Stmdy: Data Collection, Preliminary Observations, and Recommendations. FEMA 403. Federal Emergency Management Agency.

Washington, DC, May.

PANYNJ (Port Authority of New York and New Jersey). 1986. World Trade Center Instrnction Manual No. 23: Operation \& Maintenance of Fire Protection System. New York, NY, February.

PANYNJ (Port Authority of New York and New Jersey). 1988a. Fire Safety Plan, 7 World Trade Center. New York, NY, April.

PANYNJ (Port Authority of New York and New Jersey). 1988b. World Trade Center 7 Operations Mamal. New York, NY.

PANYNJ (Port Authority of New York and New Jersey). 1999. World Trade Center Fire Safety Plan: One World Trade Center, Two World Trade Center, Condensed Version. New York, NY, January.

Powers, W. R., Superintendent. 1975. Ore World Trade Center Fire New York, NY, February 13, 1975. NYBFU (New York Board of Underwriters), New York, NY. 


\section{Chapter 7 \\ Evaluation of System Performance on September 11, 2001}

As discussed in Chapter 1 of this report, expected system performance was evaluated for postulated design fires in business occupancies, as well as documentation of the expected performance of fully functional smoke management systems in World Trade Center (WTC) 1 and WTC 2.

Evaluation of hypothetical design fires. smoke management modes, and building configurations is documented in Chapter 8 of this report. First, the expected function of the installed smoke management systems, given the actual events on September 11, 2001, was evaluated.

As discussed in Chapter 6, the smoke management systems in WTC 1 and WTC 2 were designed to provide a manual smoke purge function. Given the design and intended operation of the smoke management systems, two key questions must be answered to approximate the performance of the system on September 11, 2001:

1. Was manual operation of the smoke purge systems in either WTC 1 or WTC 2 initiated by emergency response personnel?

2. Were the systems capable of operating given the damage caused by the aircrafts impacting each building?

In order to answer the second question, damage to both the building electrical and mechanical systems must be evaluated. It must first be determined whether electrical power was available to the building mechanical systems subsequent to impact so that they were capable of operating. Then, potential damage to heating, ventilating, and air conditioning (HVAC) system components must be evaluated to determine if the systems were capable of performing as designed.

\subsection{ACTIONS OF EMERGENCY RESPONSE PERSONNEL}

The events of September 11,2001, clearly represented an extreme challenge, both to emergency response personnel and to the installed building systems. The damage caused by an aircraft impact into a building is outside the range of typical design considerations for the design of most building systems, including fire protection systems. In addition. from a fire department perspective, a fire involving multiple floors of the uppermost portion of WTC 1 or WTC 2, or worse in both buildings simultaneously, represents a difficult operational environment.

A comprehensive accounting of New York City Fire Department (FDNY) policies, procedures, and performance in connection with the events on September 11,2001, was assembled by Howard Safir, the former commissioner of FDNY and the New York City Police Department (NYPD) (Safir 2002). Safir's report reflects findings from interviews with FDNY personnel and analysis of publicly available sources. Dennis Smith's book Report From Ground Zero (Smith 2002) also documents fire department operations on September 11, 2001. 
The battalion chief established a command post in the lobby of WTC 1. According to the Safir report, the battalion chief attempted to determine the floors of impact, which he estimated as near the 80th floor. The deputy division chicf arrived at the WTC 1 lobby command post approximately 3 min after the battalion chief and assumed command. The deputy division chief's account of the events stated that "all building services were out. The elevators weren't working; therc were no communications lines established" (Smith 2002).

According to the Safir report, upon his arrival at WTC 1 the battalion chief met the then-acting WTC fire safety director. The two worked to address the situation with the elevators and discussed the condition of water and power sources. The battalion chief, deputy division chief, and the WTC fire safety director then conferred and issued the order to evacuate WTC 2. No recommendation was given to initiate a smoke purge sequence, nor was smoke purge performed on September 11, 2001, to their knowledge ${ }^{7}$. The deputy division chief met with the WTC 1 fire safety director, who put his engineers to work to gain control of the elevators and building communications systems (Safir 2002).

Initial FDNY operations at WTC 1 were focused on dispatching fire department personnel arriving at the building to assist in rescue efforts and on responding to distress calls from people stuck at various locations within the building, including elevators. The responding FDNY officers focused on rcscue efforts rather than trying to extinguish the fire (Safir 2002).

Subsequent to the second aircraft impact into WTC 2, two other chiefs were dispatched to the lobby of WTC 2, to set up a command post there (Smith 2002). There is no record of either chief having initiated a smoke purge sequence in WTC 2. First hand accounts of their actions are not available as both chiefs perished during the collapse of WTC 2 .

Radio and phone traffic from various sources (New York City police and fire departments, the Port Authority of New York and New Jersey [PANYNJ or Port Authority] police, and WTC mcchanical/electrical/structural divisions) was reviewed in an effort to determine if any attempts were made to manipulate building ventilation systems or initiate the smoke purgc sequence locally from one of the mechanical equipment rooms (MERs) in WTC 1 or WTC 2. One reference to smoke purging was found. WTC channel 25/radio channel B was used by the WTC maintenance and electrical shops at the WTC. For a period of time from roughly 10 to $25 \mathrm{~min}$ after the aircraft impact into WTC 1, radio traffic was received from a person on radio "structural five" from "Stair A" on the 103rd floor in WTC 1. Structural five reported heavy smoke in the stairway and some time between 20 and 25 min after impact was recorded as transmitting the message "Need immediate purge." At roughly the same time, an unidentified male was recorded on the same radio channel transmitting the message "Electric, we have Staircase C (inaudible), is there any way to pump any outdoor air in?" No conversations were identified confirming use of the ventilation systems.

\subsection{DAMAGE TO SYSTEM COMPONENTS}

The exact extent of damage within individual floors of WTC 1 and WTC 2 may never be known, since the collapse of the buildings prohibited a dctailed inspection of the impact area. However, the potential

PANYNJ interview 3 (Fall 2003). 
extent of damage can be estimated based on the results of engineering analysis and based on observations recorded by people located within WTC 1 and WTC 2 at the time of the events.

Preliminary damage estimates identified damage areas based on damage to structural columns within the core of WTC 1 and WTC 2. ${ }^{8}$ These preliminary damage estimates are included in Appendix A of this report and were used to provide a first order estimate of the potential damage caused to building electrical and mechanical systems in order to estimate whether the smoke purge sequence had the potential to function properly during the events that occurred on September 11, 2001.

The National Institute of Standards and Technology (NIST) damage estimates included in Appendix A were overlaid onto representative floor plans for the impact areas in WTC 1 and WTC 2 in order to determine the potential damage to key electrical/mechanical system components located in the core spaces. Damage estimates for WTC 1 and IVTC 2 are shown in Figs. 7-1 and 7-2. respectively. In these figures, only those floors where major structural damage in the core was estimated are shown.

Figures $7-1$ and 7-2 depict damage estimates to key electrical/mechanical system components located in the core spaces. The preliminary NIST damage estimates are used to define the impact area on each of the three primary floors where the majority of core damage was expected. A hypothetical boundary is also shown for shaft damage caused by impact debris, given the fact that the shafts in the building are constructed using gypsum wallboard construction and are susceptible to impact damage.

The location of the HVAC shafts used for interior zone ventilation are shown in Figs. 7-1 and 7-2, as these are the primary HVAC systems used to accomplish the smoke purge sequence. The locations of the three electrical closets/risers providing power to the upper floors of the building are also shown. The locations of exit stairways and freight elevator 50 are also shown, as damage witnessed to these shafts can be used to verify the extent of shaft damage throughout the core.

The damage estimates shown in Figs. $7-1$ and $7-2$ can be corroborated to a certain extent using observations made by people located in various locations in the buildings after aircraft impact. The observations primarily have to do with stair shaft damage, damage to freight elevator 50 , and in some cases elevator shafts. HVAC shaft data could be corroborated using visual evidence of smoke spread seen from the exterior of the buildings. An attempt was also made to corroborate the extent of core damage using observations as to the presence of power in the buildings.

Part of the NIST WTC Investigation included an aircraft impact damage analysis of WTC 1 and WTC 2. The final results of these analyses are provided in NIST NCSTAR 1-2. Once the damage estimates were finalized, they were compared to the initial damage estimates (Figs. 7-1 and 7-2) developed that were used for the purposes of this analysis of active fire protection systems. The main areas of interest with respect to the smoke management systems are damage to vertical shafts. The debris fields of the revised damage estimates were determined to indicate damage to vertical shafts, on one floor or another, to a similar degree indicated by the preliminary damage estimates.

${ }^{8}$ Preliminary damage estimates provided by NIST (T. McAllister and F. Sadek), October 27, 2003. 


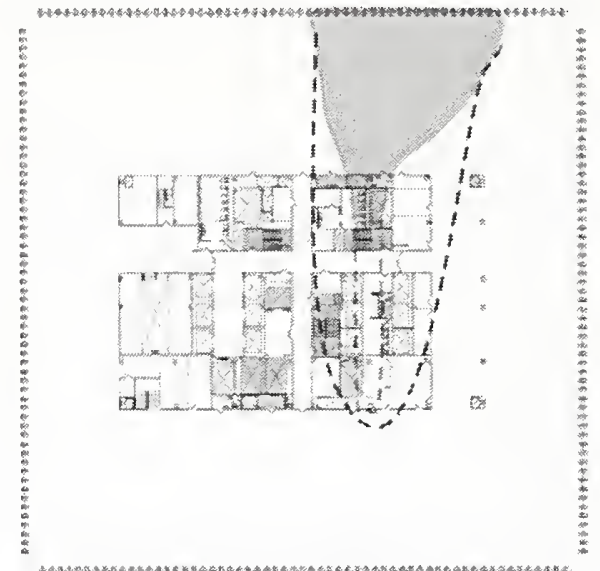

\section{4th Floor}

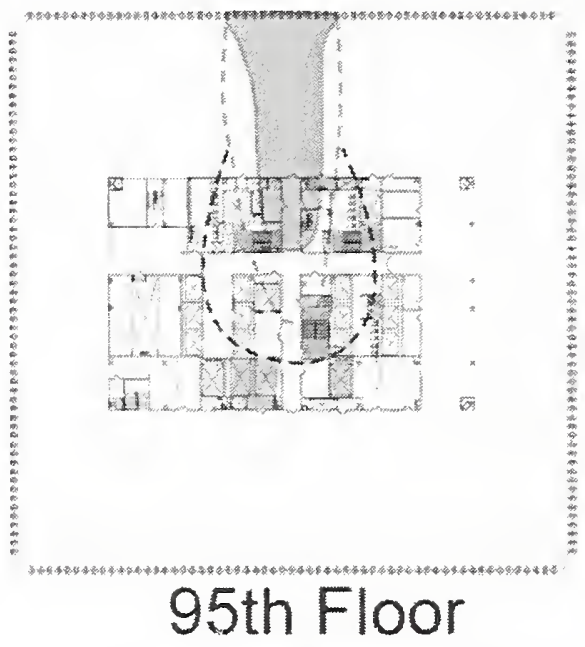

\section{WTC 1}

Probable Damage Estimate (NIST - Appendix A)

- Maximum Damage Estimate (NIST - Appendix A)

- Possible Additional Damage to Drywall Shafts

Exit Stainays

Electrical Closets HVAC Shafis

Freight Elevator 50 (full height elevator)

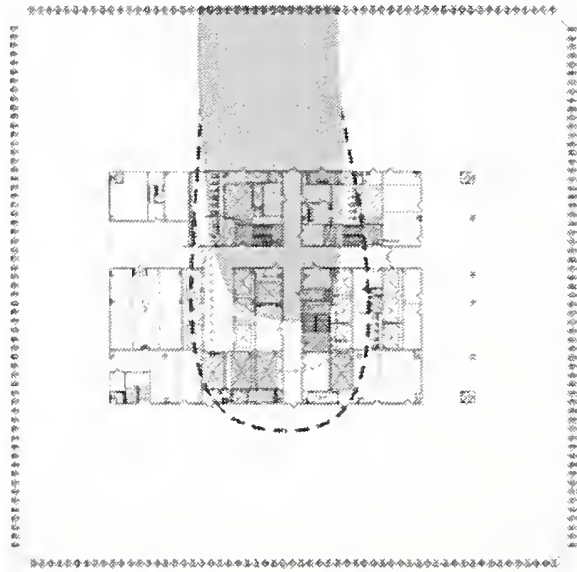

Express Elevators (full height elevators)

\section{6th Floor}

Figure 7-1. Preliminary damage estimates, WTC 1. 

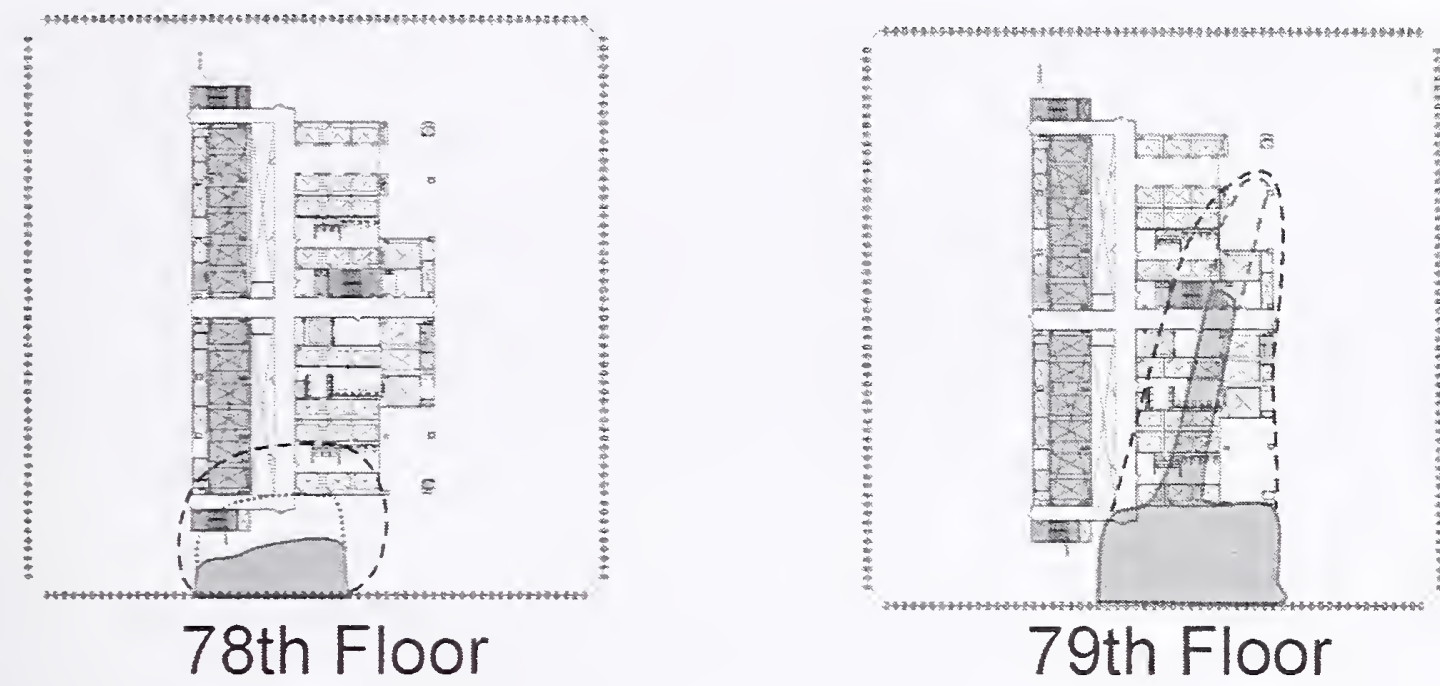

\section{9th Floor}

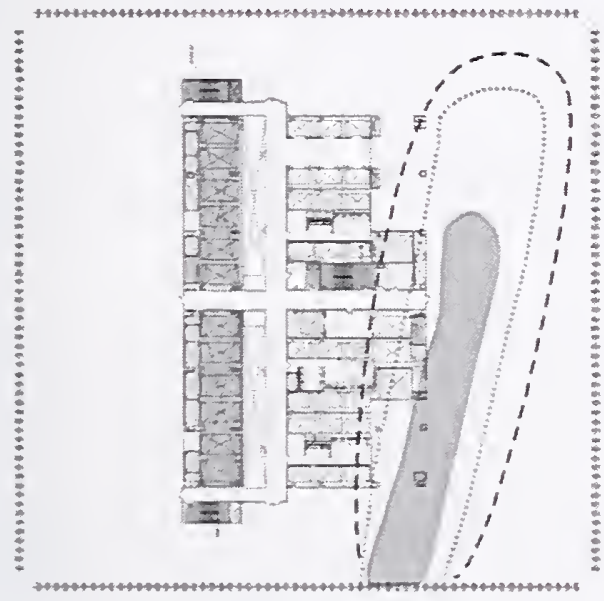

\section{0th Floor}

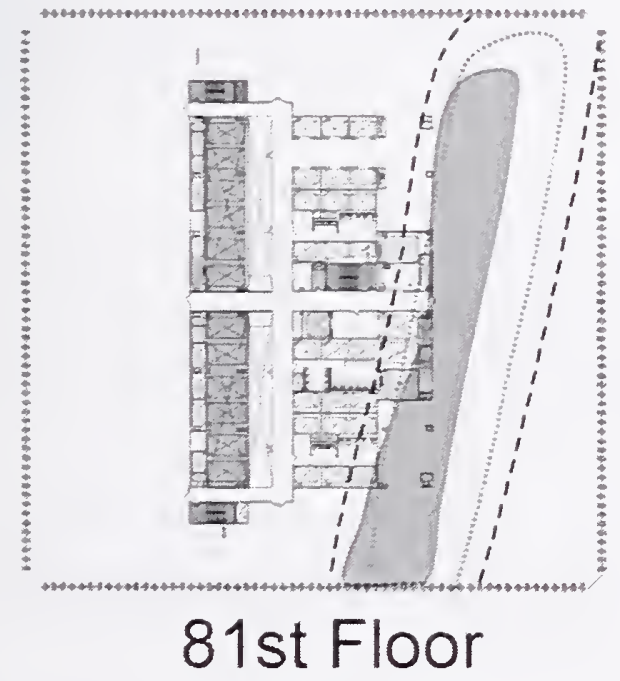

\section{WTC 2}

Probable Damage Estimate (NIST - Appendix A)

- Maximum Damage Estimate (NIST - Appendix A)

L - Possible Additional Damage to Drywall Shafts

Exit Stairways

Electrical Closets

HVAC Shafts

Freight Elevator 50 (full height elevator)

Express Elevators (full height elevators)

Figure 7-2. Preliminary damage estimates, WTC 2. 


\subsubsection{Exit Stair and Elevator Shaft Damage}

Numerous accounts were recorded of all three exit stairs in WTC 1 being blocked on the 92nd floor and above. Multiple calls received by the Port Authority police desk reported rapidly worsening smoke conditions and blocked exits from the Windows on the World restaurant, located at the top of WTC 1 (NYPD 2001). Several occupants contacted friends and family via email or cell phone from floors above the impact floors and reported heavy amounts of smoke and all exits blocked (Beyler 2002). Several employees from Carr Futures, located on the 92nd floor of WTC 1, placed calls to family and reported that the exit stairs were impassible (Cauchon 2001). Two of the three occupants that escaped from the 91 st floor reported that only two of three exit stairs were accessible due to debris in the exit corridor (Beyler 2002).

Of the two accessible stairs, one was blocked with pieces of gypsum wallboard from above. The other exit stair had some debris in the stair but was passable. A Port Authority architect located on the 88th floor of WTC 1 identified the open exit stair as "Stair C" (Murphy 2002), which, based on the description provided in his account, was the northwest exit stair (Stair 1). These accounts would tend to support the damage estimates depicted in Fig. 7-2, as far as core shaft damage enveloping the footprint of the three exit stairs. On the lower floors in the impact area, Stair 1 (the northwest stair) is furthest removed from the identified impact damage area, due to the orientation of the aircraft as it impacted the north face of the building.

The extent of damage into the core of WTC 1 is also evidenced by damage to elevator shafts in the core, particularly freight elevator 50. A notable event occurring in WTC 1 was a reported "explosion/fireball" that occurred in the lobby of WTC 1 due to jet fuel that was ignited at the base of an elevator shaft, witnessed by three survivors (Beyler 2002). This is evidence of a major opening created into one of the full height elevators in the impact zone. Freight elevator 50 and two express elevators connecting the lobby floors to the Windows on the World Restaurant on the 106th floor and observation deck were the only full height elevators in this area. The preliminary damage estimates depicted in Fig. 7-1 indicate damage as far into the core as freight elevator 50 and potentially as far as the express elevators. Since the elevator doors on the lobby level for freight elevator 50 open to a corridor within the core, and the doors to the express elevators face outward toward the exterior walls of the lobby where the "explosion/fireball" damaged the exterior walls, this is further evidence of core damage as far in as the express elevator shafts.

Damage to local elevator shafts was also evident based on survivor testimony. The base of the local elevator shafts serving the impact zone in WTC 1 was the 78th floor sky lobby. Two occupants that escaped noted fire in a vertical shaft coming out through gaps in a shaft wall as they passed through the sky lobby (Beyler 2002). The marble walls encasing the elevators on this level were also noted to have buckled and snapped (Beyler 2002). Another survivor reported jumping through large "drops" of blue flame to exit an open elevator door on the 78th floor (Beyler 2002).

Figure 7-2 depicts damage estimates for core spaces in WTC 2. Compared to WTC 1 (Fig. 7-1), damage to the core was not estimated to be quite as extensive due to the projected path of the aircraft through the building and orientation of the building's core.

In WTC 2, the core layout was such that the three exit stairs were located remotely from one another on the impact floors. As shown in Fig. 7-2, the northwest stair in the building (Stair 1) was relatively undamaged. At least four survivors were able to safely exit the building via Stair 1, from floors as high as 
the 91 st floor (Murphy 2002; Cauchon 2001). It appears that more peoplc could have escaped via Stair 1 but chose not to go down through the smoke in Stair 1 near the floors of impact or chose to try to exit by accessing the roof, but found the roof doors locked (Cauchon 2001).

As seen in Fig. 7-2, the full-height freight and express elevators were located out of the way of the postulated path of impact. Given that there were limited accounts of spread of flaming jet fuel to lower levels via the elevator shafts, unlike WTC 1, this is likely a reasonable assumption. The availability of survivor testimony for WTC 2 regarding fires in elevator shafts is not as prevalent since the primary floors of impact in WTC 2 are near the bottom of the local elevator shafts, just above the 78th floor sky lobby.

Since damage to two out of three exit stairs was substantiated by survivor testimony and significant damage was caused to the exterior walls in the northeast comer of WTC 2 caused by impact damage, the path of damage would also logically include the ventilation shafts located on the east half of the impact floors, as depicted by the damage estimates shown in Fig. 7-2.

\subsubsection{Exterior Observations}

Potential damage to the HVAC shafts was determined to some degree by examining photographic evidence depicting the exterior of the buildings after the time of aircraft impact. As was shown in Fig. 4-4, the WTC 1 impact zone was located in the uppermost HVAC zone of the building, serving the 92nd through 107th floors from the 108th floor MER, while the WTC 2 impact zone was located in the HVAC zone serving the 59th through 9lst floors from the 75th floor MER. Thus, the MER serving the impact zone was located above the impact zone in WTC 1 and below the impact zone in WTC 2.

As shown in Figs. 7-1 and 7-2, initial damage estimates support damage to the HVAC shafts in one-half of each building within the impact zone. Such damage would crcate large holes in the gypsum wallboard exhaust shafts and potentially shear off or collapse metal supply ductwork. If the HVAC shafts werc undamaged, the fire dampers at the HVAC shaft walls would have been expected to close in an intense fire, limiting the extent of airflow via the ventilation shafts. Fire dampers would not be expected to be as effective in limiting smoke spread as combination fire/smoke dampers, which are designed to bc smoketight and close earlier in the fire event due to activation of the integrated smoke detcctors installcd as part of the damper assembly.

In WTC 1, spread of large amounts of smoke via the ventilation shafts is evident in the examination of pictures of the exterior of WTC 1. after impact. Figure 7-3 depicts views of WTC 1 from the north and the west. A significant amount of smoke is observed coming out of the 108th floor MER from a localized spot on the north face of the building, and that smoke seems to exit from the MER along the length of the west face of the building. Figures 4-6 and 4-8 depict the supply and exhaust system layout in a typical MER (shown for WTC 2). At the 108th floor MER in WTC 1, the localized smoke emanating from the north face of the building corresponds to the location of the supply fan inlet for the northwest intcrior supply zone. The exhaust plenum for the northwest quadrant exhaust fans is located along the west face of the MER. The visual evidence depicted in Fig. 7-3, showing smoke exiting from the 108th floor MER, supports damage to the primary ventilation shaft serving the northwest quadrant of the impact zone, depicted in Fig. 7-1. 


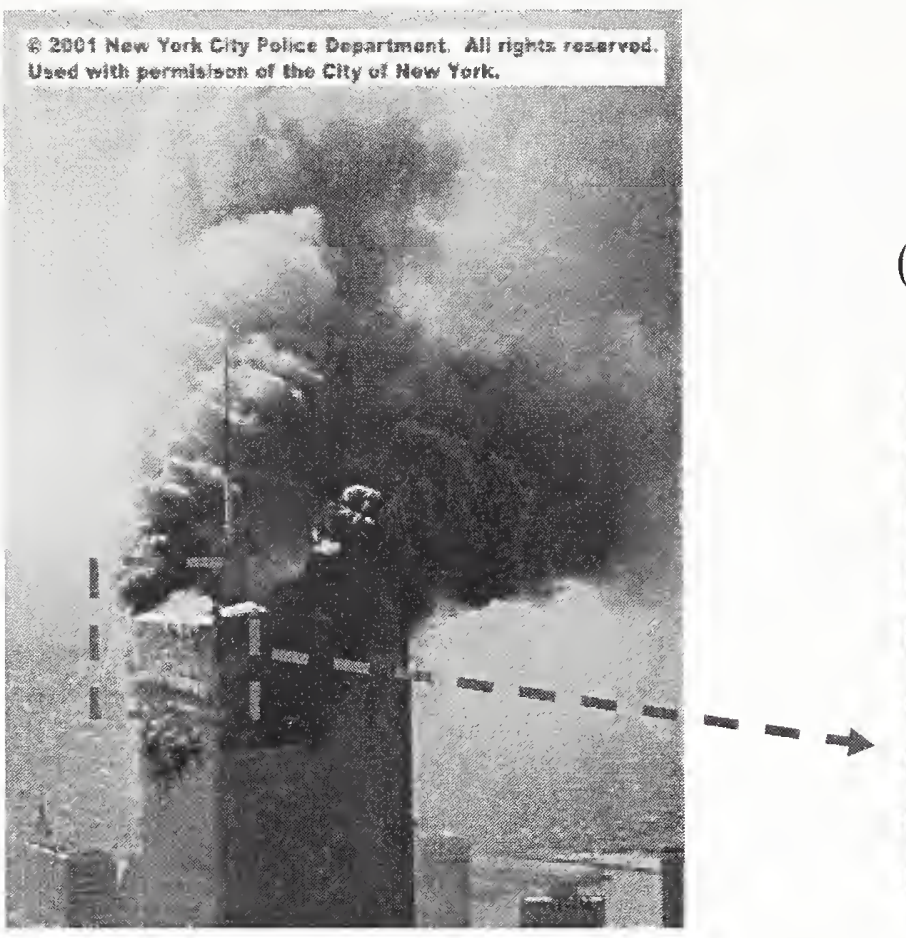

\section{North Face - WTC 1}

Smoke Exits NW Interior Ventilation Zone Supply Inlet (smoke exits at localized point)
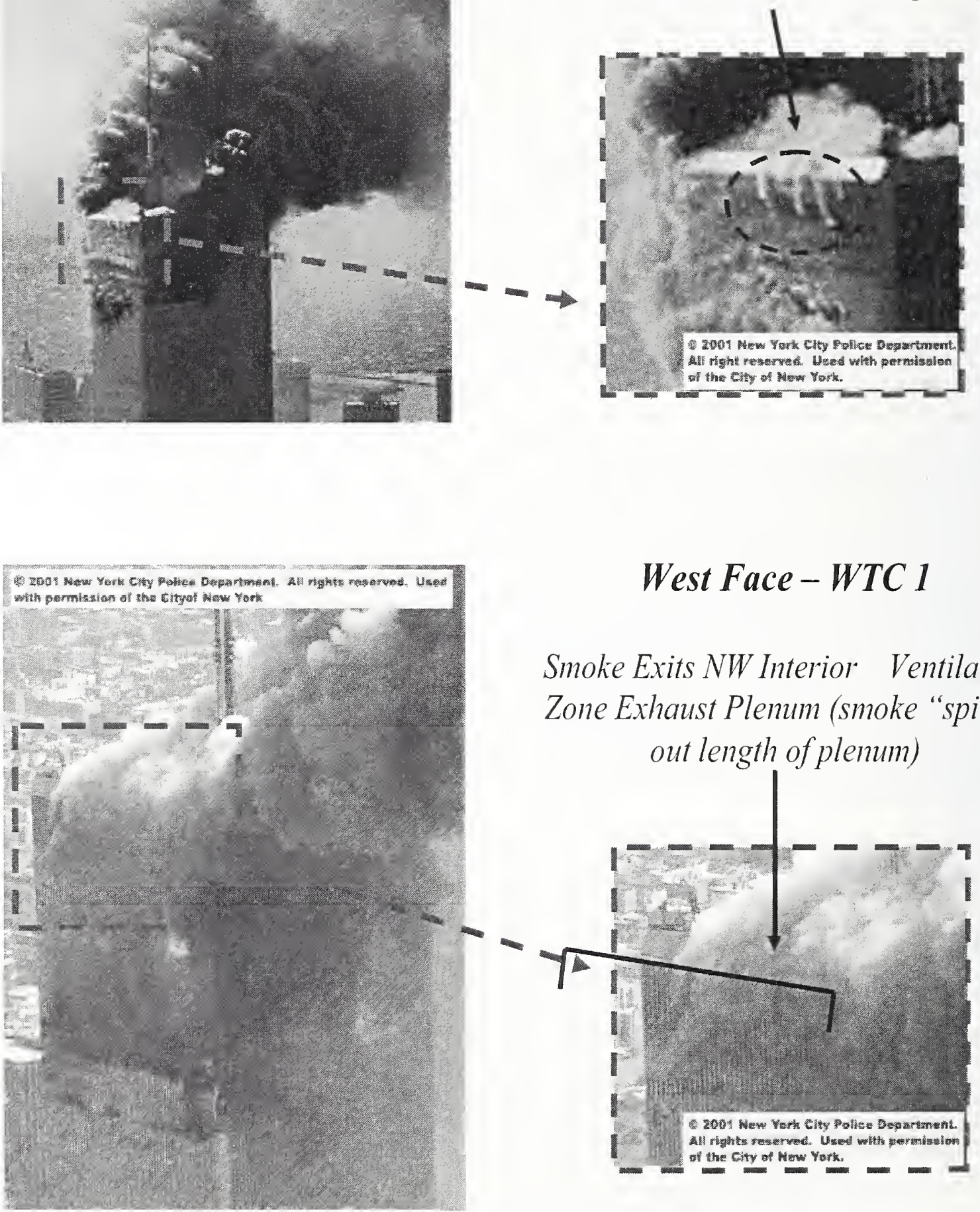

\section{West Face - WTC 1}

Smoke Exits NW Interior Ventilation Zone Exhaust Plenum (smoke "spills" out length of plenum)

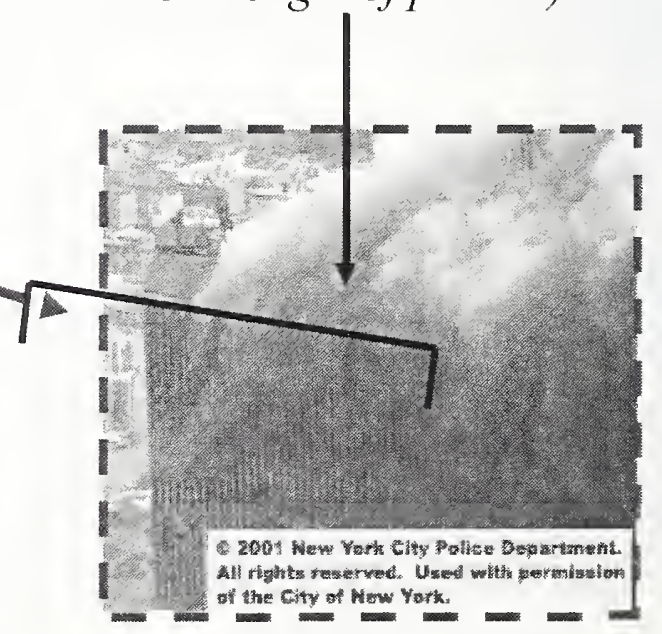

Figure 7-3. Impact damage to north and west faces of WTC 1. 
Since the damage estimate suggests similar damage to the northeast shaft, a similar pattern of smoke exiting the 108th floor MER would be expected to be seen at the northeast supply inlet and east exhaust outlets. However, due to the direction of the wind driven smoke plume from the fire toward the southeast, it is difficult to see patterns of smoke emanating from the MER at this location on the exterior of the building. Therefore, large amounts of smoke exiting supply/ventilation shafts serving the northeast quadrant of the impact zone, which would substantiate the shaft damage to the northeast quadrant ventilation shafts depicted in Fig. 7-1, could not be verified using visual observations of the exterior of the building.

Once smoke enters the ventilation ductwork, it can very quickly spread to all areas of the upper floors of the building via the air distribution plenum in the ceiling. However, smoke entering a floor via elevator doors might have to pass through multiple barriers in the core and office space to reach the perimeter offices. As a result, smoke spread via the ventilation shafts has the potential to cause a more rapid deterioration of smoke conditions in the perimeter office spaces than smoke spread via the elevator and stair shafts.

Rapid spread of smoke vertically via the ventilation shafts in WTC 1 is supported by the fact that smoke conditions became untenable (high heat/high toxicity) on the uppermost floors of WTC 1, where people were observed breaking windows to obtain outdoor air and some jumped from the building to escape the rapidly deteriorating conditions in the building. This occurred shortly after impact in WTC 1. The FDNY noted people jumping from the building shortly after their arrival in the lobby of WTC 1 (Smith 2002).

In WTC 2, shaft damage (stair/elevator/ventilation shafts) would also cause smoke to spread upward through the building. However, in WTC 2 the MER is located below the impact zone. Therefore, smoke would spread upward via the shafts to floors up to the 91 st floor and outward onto those floors. Smoke would have to spread upward into the building to floors above the 91 st floor through the other primary vertical airflow paths, which in this case were local elevator banks III-C and III-D, as depicted in Fig. 4-3.

The relatively few vertical airflow paths between the impact zone in WTC 2 and the uppermost floors of the building is supported by the length of time conditions remained tenable in some areas of the upper floors of the building. Numerous occupants of WTC 2 were trapped on the 105th floor of the building. These people decided not to go down through the smoke in Stair 1, and tried during the initial period after impact to get to the roof, but found the doors locked. Most people returned to the 105 th floor and several people called family members on their cell phones. One occupant was on the phone with his wife until the collapse of WTC 2 (Beyler 2002). The experience of occupants on the 105th floor supports the fact that spaces in the uppermost portion of WTC 2 were tenable for periods as long as 45 min after impact.

\subsubsection{Status of Power}

An attempt was made to identify the presence of power or lack thereof up to the MER floors serving the impact zones in WTC 1 and WTC 2, utilizing survivor testimony and transcripts of phone calls made by people trapped above the impact zone. Little evidence was available regarding the presence of electrical power, particularly on the upper floors of the buildings. Isolated reports were noted of "lights flickering" and going out in the buildings. These accounts also correspond to floors where ceiling collapse and other 
minor structural damage was noted. Therefore, loss of lighting could coincide with local structural damage rather than being indicative of an overall loss of electrical power.

There were two data points of note identified with regard to loss of power. A phone call recorded by the Port Authority police desk from the Windows on the World restaurant on the 106th floor of WTC 1 appears to indicate that electrical power and fire phones were out (NYPD 2001). Given the path of aircraft damage in WTC 1 (Fig. 7-1) and the relative location of the electrical closets/risers, this may be evidence of a loss of power to the upper floors of the building due to damage to the electrical risers.

In WTC 2, a survivor noted the presence of power on the 74th floor during his descent from the 84th floor (Murphy 2002). This observation may be evidence of the presence of power up to the floors of impact in WTC 2.

Despite the lack of definitive survivor testimony with regard to the presence of electrical power in WTC 1 and WTC 2, the damage estimates in Figs. 7-1 and 7-2 support damage to one or more of the electrical closets/risers in each building. In WTC 1, damage likely occurred to both the north and central electrical closets/risers. In WTC 2, damage likely occurred to at least the east electrical closet/riser.

\subsection{SUMMARY}

Examination of the available evidence provides strong indications that the smoke management systems in WTC 1 and WTC 2 played no role in the events that occurred on September 11, 2001. There is no evidence to support the fact that an attempt was made to activate the smoke purge sequence. In the chaos surrounding the events, the focus following the aircraft impacts and preceding the collapse of the buildings was on rescue operations.

Should a decision have been made to attempt to align the building ventilation systems into the smoke purge mode, it is doubtful that this would have had any impact on overall smoke conditions within the building. First, upon arriving at the scene, FDNY personnel had a difficult time determining the exact floors of impact, especially for WTC 1. Since the WTC 1 impact occurred near the boundary between ventilation zones at the $91 \mathrm{st} / 92 \mathrm{nd}$ floors, and the impact was thought to have originally occurred on floors somewhere between the 80th and 90th floors (Smith 2002), smoke purge may have been inadvertently initiated for the 59th through 91 st floor HVAC zone in WTC 1.

The aircraft impacts caused significant damage to the core spaces in both WTC 1 and WTC 2, making it unlikely that the smoke purge could have been accomplished in either building. In WTC 1, it is likely that the impact eliminated or significantly impaired electrical power on floors above the impact zone.

Therefore, because power would not have been available at the 108th floor MER, serving the zone of impact, HVAC systems would not have been operational. In addition, the ventilation shafts for at least the north half of the building were likely damaged, thus reducing the possibility for the smoke purge to function properly even if the HVAC systems had been opcrable.

In WTC 2, it is possible that electrical power may have been available to the fans located in the 75th floor MER, which was located below the impact zone in this building. Survivor testimony indicates that power may have been available up to the 75th floor. Initially, all fans would have shut down due to detection of substantial quantities of smoke by the duct smoke detectors. As shown in Fig. 7-2, the HVAC shafts utilized to accomplish smoke purging would likely have been damaged on the east side of the building, 
eliminating half of the smoke venting capacity for the floor. Even if the ventilation shafts on the west side of the building remained intact, the performance of the smoke venting system would have been reduced. This would have had a particularly detrimental impact on WTC 1, where smoke conditions deteriorated in the uppermost portions of the building at a much faster rate than WTC 2.

\subsection{REFERENCES}

Beyler, C. L. 2002. Appendix D, Witness Observations Summary. In Analysis of the Fire Aspects of the World Trade Center Terrorist Attacks: 11 September 2001. Hughes Associates, Inc. Baltimore, MD. Prepared at the direction of council Wachtell, Lipton, Rosen \& Katz, New York, NY, July 31.

Couchon, D. 2001. For many on Sept. 11, survival was no accident. USA Today, December 19.

Murphy, D. E. 2002. September 11: An Oral History. Doubleday. New York, NY, September.

NYPD (New York Police Department). 2001. World Trade Center Channel 09. Police Desk - 3541 Center. Police radio transcript, Volume 2. September 11.

Safir. 2002. Expert Report of Howard Safir. Omnicom Group, Inc., New York, NY. Prepared at the direction of council Wachtell, Lipton, Rosen \& Katz, New York, NY, August 1.

Smith, D. 2002. Report From Ground Zero: The Story of the Rescue Efforts at the World Trade Center. Viking Penguin. New York, NY. 
This page intentionally left blank. 


\section{Chapter 8 \\ EVAluation of Potential Smoke Management SYSTEM EFFECTIVENESS}

In the previous chapter it was determined that, based on the available information, the smoke purge sequence provided for the ventilation systems in World Trade Center (WTC) 1 and WTC 2 was not initiated during the events occurring on September 11,2001. It was further concluded that it is highly probable that the electrical system and heating, ventilating, and air conditioning (HVAC) system components involved in the smoke purge function were critically damaged. Even if the smoke purge sequence was initiated, it is unlikely that the smoke purge would have performed as designed.

In order to fully understand the potential impact of smoke management systems for events like those occurring on September 11,2001, it is desirable to analyze how various smoke management system configurations might have performed in WTC 1 and WTC 2, had they been available on September 11. To develop an understanding of the capabilities of the various smoke management system configurations that were evaluated it is also important to analyze their performance for other hypothetical fire scenarios in high-rise buildings, both typical/expected design scenarios and worst case scenarios.

\subsection{SMOKE MANAGEMENT SYSTEM APPROACHES}

Five distinct smoke management approaches were examined for the WTC towers. These approaches are as follows:

1. Smoke purge

2. Core pressurization

3. Building pressurization

4. Sandwich pressurization

5. Zoned smoke control with stair pressurization

Four of the five approaches evaluated are smoke management configurations that could have been achieved using the building HVAC systems as they existed prior to September 11, 2001, with little to no modification. However, unless automatic activation of a smoke management system was provided, the HVAC systems would have had to be manually aligned, requiring pre-planning of the sequence of operation to be used. The fifth approach, zoned smoke control with stair pressurization, is a smoke management system based on state of the art methods of smoke control practices on September 11. Use of this approach would have required major renovations to building systems to achieve the desired performance.

All of the smoke management system approaches modeled assumed that electrical power was available to operate the necessary HVAC systems. The CONTAM computer program was used to evaluate the 
pressure diffcrentials achieved once the system was aligned per the appropriate sequence of operations. Because automatic activation of the smoke management system is not standard practice in New York City (HAI and DCE 1996), it must be recognized that substantial smoke movement may occur prior to manual system operation, regardless of the smoke management approach adopted for the building.

\subsubsection{Smoke Purge}

The smoke purge approach is based on the documented smoke purge sequence for WTC 1 and WTC 2 as it appears in WTC 1nstruction Manual No. 23, Operation and Maintenance of Fire Protection System, dated February 1986 (PANYNJ 1986), as discussed in Chapter 6 of this report (see Fig. 6-1). The sequence involved placing the interior HVAC zone exhaust fans and core exhaust fans (toilet exhausts, elcvator machine room (EMR) exhausts) in the multi-floor ventilation zone containing the fire in 100 percent exhaust mode. HVAC systems in all other ventilation zones in the buildings were aligned in a summer normal mode. Perimeter supply fans were shut down. The sequence of operation for the smoke purge mode is summarized in Table 8-1.

Table 8-1. Smoke purge sequence of operations.

\begin{tabular}{|l|l|l|l|l|l|l|l|l|}
\hline \multirow{2}{*}{ HVAC Zone } & \multicolumn{4}{|c|}{ Fan Operation } & \multicolumn{3}{c|}{ Damper Operation } \\
\cline { 2 - 9 } & $\begin{array}{c}\text { Core } \\
\text { Supply }\end{array}$ & $\begin{array}{c}\text { Core } \\
\text { Exhaust }\end{array}$ & $\begin{array}{c}\text { Interior } \\
\text { Supply }\end{array}$ & $\begin{array}{l}\text { Interior } \\
\text { Exhaust }\end{array}$ & $\begin{array}{l}\text { Perimeter } \\
\text { Supply }\end{array}$ & $\begin{array}{l}\text { Exhaust } \\
\text { Sppill) }\end{array}$ & Return \\
\hline $\begin{array}{l}\text { Zone of Fire } \\
\text { Origin }\end{array}$ & Off & On & Off & On & Off & $\begin{array}{l}100 \% \\
\text { Open }\end{array}$ & $\begin{array}{l}100 \% \\
\text { Open }\end{array}$ & Closed \\
\hline Other Zones & $\begin{array}{l}\text { Summer } \\
\text { Normal }\end{array}$ & $\begin{array}{l}\text { Summer } \\
\text { Normal }\end{array}$ & $\begin{array}{l}\text { Summer } \\
\text { Normal }\end{array}$ & $\begin{array}{l}\text { Summer } \\
\text { Normal }\end{array}$ & $\begin{array}{l}\text { Summer } \\
\text { Normal }\end{array}$ & $\begin{array}{l}\text { Summer } \\
\text { Normal }\end{array}$ & $\begin{array}{l}\text { Summer } \\
\text { Normal }\end{array}$ & $\begin{array}{l}\text { Summer Normal } \\
\text { Normal }\end{array}$ \\
\hline
\end{tabular}

As discussed in Chapter 6, the Port Authority of Ncw York and New Jersey (PANYNJ or Port Authority) stated that a different smoke purge sequence than that documented in WTC Instruction Manual No. 23 was in place at the time of the events on September 11,2001. This sequence involved using the interior supply and return fans serving only one quadrant of a ventilation zone to purge the zone of smoke.

Because the supply and return fans would both be used, this sequence would not be expected to create a significant pressure diffcrential between the core and perimeter spaces. The purge would not be expected to greatly improve conditions within the building during the fire event.

Since the success of the smoke management approaches being evaluated is based on the pressurization method of smoke control, the sequence reported by the Port Authority (see Section 6.1.1) was not evaluated using the CONTAM model. This sequence, which involves supplying to and exhausting from a given quadrant at an equal air flow rate, would not be capable of achieving a pressure differential with respect to adjacent areas of the building.

\subsubsection{Core Pressurization}

The core pressurization approach is a slight variation of the documented smoke purge scquence for WTC 1 and WTC 2, in that the supply fans rather than the exhaust fans in the core were activated to pressurize the core in an effort to limit smoke sprcad into the core from the surrounding office spaces. As documented in Chapter 6, accounts of the 1975 fire and other sources cite this variation as being the 
"smoke purge" sequence provided for the building. The sequence of operation for the core pressurization mode is summarized in Table 8-2.

Table 8-2. Core pressurization sequence of operations.

\begin{tabular}{|l|l|l|l|l|l|l|l|l|}
\hline \multirow{2}{*}{ HVAC Zone } & \multicolumn{4}{|c|}{ Fan Operation } & \multicolumn{3}{c|}{ Damper Operation } \\
\cline { 2 - 9 } & $\begin{array}{c}\text { Core } \\
\text { Supply }\end{array}$ & $\begin{array}{c}\text { Core } \\
\text { Exhaust }\end{array}$ & $\begin{array}{c}\text { Interior } \\
\text { Supply }\end{array}$ & $\begin{array}{l}\text { Interior } \\
\text { Exhaust }\end{array}$ & $\begin{array}{l}\text { Perimeter } \\
\text { Supply }\end{array}$ & $\begin{array}{c}\text { Exhaust } \\
\text { (Spill) }\end{array}$ & Return \\
\hline $\begin{array}{l}\text { Zone of Fire } \\
\text { Origin }\end{array}$ & On & On & Off & On & Off & $\begin{array}{l}100 \% \\
\text { Open }\end{array}$ & $\begin{array}{l}100 \% \\
\text { Open }\end{array}$ & Closed \\
\hline Other Zones & $\begin{array}{l}\text { Summer } \\
\text { Normal }\end{array}$ & $\begin{array}{l}\text { Summer } \\
\text { Normal }\end{array}$ & $\begin{array}{l}\text { Summer } \\
\text { Normal }\end{array}$ & $\begin{array}{l}\text { Summer } \\
\text { Normal }\end{array}$ & $\begin{array}{l}\text { Summer } \\
\text { Normal }\end{array}$ & $\begin{array}{l}\text { Summer } \\
\text { Normal }\end{array}$ & $\begin{array}{l}\text { Summer } \\
\text { Normal }\end{array}$ & $\begin{array}{l}\text { Summer } \\
\text { Normal }\end{array}$ \\
\hline
\end{tabular}

\subsubsection{Building Pressurization}

Building pressurization is an approach that was recommended in the 1996 Hughes Associates Incorporated (HAI)/Dillon Consulting Engineers (DCE) Smoke Management Evaluation Study (HAI and DCE 1996). This approach was recommended to be used in the event of a severe fire involving a substantial portion of one floor of the building, where windows were observed to be broken out. The approach involves turning on the supply fans in the entire building and turning on the exhaust fans only in the ventilation zone of fire origin. The intent of this approach was to exhaust smoke where possible from the floor containing the fire, and to induce a substantial airflow toward the floor of fire origin to force smoke out of the broken windows. The core pressurization approach was not adopted as part of the fire safety plan for the building subsequent to the 1996 study. The sequence of operation for the building pressurization mode is summarized in Table 8-3.

Table 8-3. Building pressurization sequence of operations.

\begin{tabular}{|l|l|l|l|l|l|l|l|l|}
\hline & \multicolumn{4}{|c|}{ Fan Operation } & \multicolumn{3}{c|}{ Damper Operation } \\
\cline { 2 - 9 } HVAC Zone & $\begin{array}{c}\text { Core } \\
\text { Supply }\end{array}$ & $\begin{array}{c}\text { Core } \\
\text { Return }\end{array}$ & $\begin{array}{c}\text { Interior } \\
\text { Supply }\end{array}$ & $\begin{array}{c}\text { Interior } \\
\text { Return }\end{array}$ & $\begin{array}{c}\text { Perimeter } \\
\text { Supply }\end{array}$ & $\begin{array}{c}\text { Supply } \\
\text { (Spill) }\end{array}$ & Return \\
\hline $\begin{array}{l}\text { Zone of Fire } \\
\text { Origin }\end{array}$ & On & On & On & On & Off & $\begin{array}{l}100 \% \\
\text { Open }\end{array}$ & $\begin{array}{l}100 \% \\
\text { Open }\end{array}$ & Closed \\
\hline Other Zones & On & Off & On & Off & Off & $\begin{array}{l}100 \% \\
\text { Open }\end{array}$ & $\begin{array}{l}100 \% \\
\text { Open }\end{array}$ & Closed \\
\hline
\end{tabular}

\subsubsection{Sandwich Pressurization}

The sandwich pressurization approach was not previously examined for WTC 1 and WTC 2 in any of the engineering studies reviewed in the preparation of this report. The approach analyzed is not the classic floor-by-floor "sandwich" approach, which involves exhausting the floor of fire origin and pressurizing the floors above and below. The HVAC systems in WTC 1 and WTC 2 were not equipped with operable fire/smoke dampers; thus, it was not possible to configure the system to exhaust and supply to only single floors within a ventilation zone. Instead, an approach was examined where the sandwich was achieved by ventilation zones.

In the event of a fire, the ventilation zone of origin would have all of its exhaust fans turned on, and supply fans turned off. The ventilation zones above and below would have all supply fans activated and 
exhaust fans turned off. These actions would create a multi-floor sandwich effect in the building, with the net effect being the creation of a pressure differential between the core and perimeter spaces within the HVAC zone of fire origin. The sequence of operation for the sandwich pressurization mode is summarized in Table 8-4.

Table 8-4. Sandwich pressurization sequence of operations.

\begin{tabular}{|c|c|c|c|c|c|c|c|c|}
\hline \multirow[b]{2}{*}{ HVAC Zone } & \multicolumn{5}{|c|}{ Fan Operation } & \multicolumn{3}{|c|}{ Damper Operation } \\
\hline & $\begin{array}{c}\text { Core } \\
\text { Supply }\end{array}$ & $\begin{array}{c}\begin{array}{c}\text { Core } \\
\text { Exhaust }\end{array} \\
\end{array}$ & $\begin{array}{l}\text { Interior } \\
\text { Supply }\end{array}$ & $\begin{array}{l}\text { Interior } \\
\text { Exhaust }\end{array}$ & $\begin{array}{c}\text { Perimeter } \\
\text { Supply }\end{array}$ & Supply & $\begin{array}{c}\text { Exhaust } \\
\text { (Spill) }\end{array}$ & Return \\
\hline $\begin{array}{l}\text { Zone of Fire } \\
\text { Origin }\end{array}$ & Off & On & Off & On & Off & $\begin{array}{l}100 \% \\
\text { Open }\end{array}$ & $\begin{array}{l}100 \% \\
\text { Open }\end{array}$ & Closed \\
\hline Other Zones & On & Off & On & Off & Off & $\begin{array}{l}100 \% \\
\text { Open }\end{array}$ & $\begin{array}{l}100 \% \\
\text { Open }\end{array}$ & Closed \\
\hline
\end{tabular}

\subsubsection{Zoned Smoke Control With Stair Pressurization}

The final approach analyzed was a hypothetical approach based on best practices in smoke management system design enforced in many jurisdictions in the United States as of September 11, 2001. It was assumed that the building was retrofitted with stair pressurization systems, as required for all new highrise construction by the major building codes in the United States, and that the HVAC system was capable of exhausting on a floor by floor basis within the ventilation zone containing the fire to create the desired pressurc differential with respect to the floors above and below. Other ventilation zones were assumed to operate in the summer normal mode. It was assumed that operable fire/smoke dampers were also installed in all supply/exhaust ducts at the appropriate shaft connections and that these dampers were closed within the zone of fire origin. The sequencc of operation for the zoned smoke control with stair pressurization mode is summarized in Table $8-5$.

Table 8-5. Zoned smoke control with stair pressurization sequence of operations.

\begin{tabular}{|l|l|l|l|l|l|l|l|l|l|l|}
\hline \multirow{2}{*}{$\begin{array}{c}\text { HVAC } \\
\text { Zone }\end{array}$} & $\begin{array}{c}\text { Core } \\
\text { Supply }\end{array}$ & $\begin{array}{c}\text { Core } \\
\text { Exhaust }\end{array}$ & $\begin{array}{l}\text { Interior } \\
\text { Supply }\end{array}$ & $\begin{array}{c}\text { Interior } \\
\text { Exhaust }\end{array}$ & $\begin{array}{c}\text { Perimeter } \\
\text { Supply }\end{array}$ & Supply & $\begin{array}{c}\text { Exhaust } \\
\text { (Spill) }\end{array}$ & Return & $\begin{array}{c}\text { Interior } \\
\text { Return } \\
\text { Shaft } \\
\text { Dampers }\end{array}$ & $\begin{array}{c}\text { Other } \\
\text { HVAC } \\
\text { Shaft } \\
\text { Dampers }\end{array}$ \\
\hline $\begin{array}{l}\text { Zone } \\
\text { of Fire } \\
\text { Origin }\end{array}$ & Off & Off & Off & On & Off & $\begin{array}{l}100 \% \\
\text { Open }\end{array}$ & $\begin{array}{l}100 \% \\
\text { Open }\end{array}$ & Closed & $\begin{array}{l}\text { Open- } \\
\text { on floor } \\
\text { of fire } \\
\text { origin }\end{array}$ & Closed \\
\hline $\begin{array}{l}\text { Other } \\
\text { Zones }\end{array}$ & $\begin{array}{l}\text { Summer } \\
\text { Normal }\end{array}$ & $\begin{array}{l}\text { Summer } \\
\text { Normal }\end{array}$ & $\begin{array}{l}\text { Summer } \\
\text { Normal }\end{array}$ & $\begin{array}{l}\text { Summer } \\
\text { Normal }\end{array}$ & $\begin{array}{l}\text { Summer } \\
\text { Normal }\end{array}$ & $\begin{array}{l}\text { Summer } \\
\text { Normal }\end{array}$ & $\begin{array}{l}\text { Summer } \\
\text { Normal }\end{array}$ & $\begin{array}{l}\text { Summer } \\
\text { Normal }\end{array}$ & Open & Open \\
\hline
\end{tabular}

The capability to provide floor-by-floor exhaust could be achieved in one of two ways. The first option would be to provide variable speed drives for the interior exhaust zone fans to reduce their flow rate to provide the dcsired rate of exhaust from a single floor, with the exhaust dampers on that floor being open. The constant volume fans installed in the building provided such a high a rate of exhaust that directing all of the available exhaust from a single floor within the ventilation zone would create high pressure differentials that could lead to the creation of unacceptable door opening forces. The second option would be to provide dedicated smoke exhaust fans having the desired flow rates to pressurize a single floor. 


\subsection{DESIGN FIRE SCENARIOS}

Several different design fire scenarios were evaluated for WTC 1 and WTC 2, encompassing the range of expected fires that could be envisioned within the office spaces of the building. The fire scenarios were limited to those that could occur on the above-grade office floors of the building. Other possible fire scenarios could have resulted in smoke migration through the towers due to a fire in the sub-grade areas or adjacent spaces within the WTC complex. Several of these fire scenarios (i.e., truck dock fire, car fire in the garage, fire in the concourse) were evaluated in the $1996 \mathrm{HAI}$ /DCE study (HAI and DCE 1996). Because the focus of this report is on examining the fires that occurred on September 11, 2001 (which occurred on the uppermost floors of the building) and bounding these events with other comparable fires, it was desirable to examine only those fire scenarios on the office floors of the building. The design fire scenarios that were evaluated are as follows:

- $\quad$ Sprinklered fire

- Full-floor burnout

- Two-floor fire

- WTC 1 and WTC 2, September 11, 2001, fire scenarios (no shaft damage)

- $\quad$ WTC 1 and WTC 2, September 11, 2001, fire scenarios (shaft damage assumed)

\subsubsection{Sprinklered Fire}

By September 11,2001, WTC 1 and WTC 2 had been fully retrofitted with a full coverage automatic sprinkler system on all of the office floors of the buildings. A typical fire in a sprinklered building would typically involve only a single fuel package, or a small number of adjacent fuel packages and would either be controlled by the automatic sprinkler system or be extinguished. A simplifying assumption is to assume that the temperature in the zone of origin never exceeds the operation temperature of the sprinklers, which had an activation temperature of $165^{\circ} \mathrm{F}\left(74{ }^{\circ} \mathrm{C}\right)$ in WTC 1 and WTC 2 (NFPA 2000b). Given the large size of the majority of the office spaces in the towers, some of which encompassed an entire floor, the average temperature throughout the floor would be expected to be less than the assumed $165^{\circ} \mathrm{F}$.

The sprinklered fire scenario represents the least challenging fire scenario analyzed for WTC 1 and WTC 2. As discussed in Sec. 2.1.2, a pressurization smoke management system in a sprinklered building is only required to provide a design pressure differential of 0.05 in. $\mathrm{H}_{2} \mathrm{O}$ across the smoke zone boundary due to the reduced temperature of the smoke produced from a sprinklered fire.

\subsubsection{Full-Floor Burnout}

The full-floor burnout is a design fire scenario for a fire involving the contents of a typical office building. In a fully-sprinklered building, a full-floor burnout would only be possible in the case of a catastrophic failure of the sprinkler system, or with a fuel load that exceeds the capacity of the sprinkler system. The full-floor burnout scenario is essentially the same as the "uncontrolled fire" scenario analyzed in the $1996 \mathrm{HAI} / \mathrm{DCE}$ study (HAI and DCE 1996). The 1996 report references testing performed 
at the National Research Council Canada (NRCC) which demonstrated that mobile shelving units in an office building can overtax standard light hazard sprinkler system designs (Lougheed, Mawhinney and O’Neil 1994).

Two prominent examples of office buildings where full-floor burnout on single or multiple office floors occurred (albeit in non-sprinklered buildings) are the First Interstate Bank fire in Los Angeles (Nelson 1989) and the One Meridian Place fire in Philadelphia (Klem 1991). In each of thcse fires most of the windows broke out on the fully involved fire floor.

The full floor burnout fire scenario evaluated in this report assumed a temperature on the floor of fire origin of $1,800^{\circ} \mathrm{F}\left(1,000^{\circ} \mathrm{C}\right)$, consistent with the temperature assumed in the 1996 report for fully involved fires. This fire sccnario assumcd the break-out of 58 windows on each face (as assumed in the 1996 study) to sustain roughly a $250 \mathrm{MW}$ fire.

\subsubsection{Two-Floor Fire}

The two-floor fire scenario corresponds to a multi-floor event caused by a small explosion. The purpose of this fire scenario was to examine smoke management system performance for a multi-floor fire scenario of far less severity than the aircraft impacts that occurred on September 11, 2001. This scenario also challenges the typical floor-to-floor separation that exists in building fire scenarios with an intact floor slab.

The fire scenario assumes that a small explosion has opened up a $100 \mathrm{ft}^{2}$ hole in the floor slab at the midpoint along one of the faces of the building. The explosion does no damage to the core but causes half the windows on the near face of the building to be blown out by the blast. It is assumed that sprinkler piping may be damaged, but some sprinklers operate, to reduce the overall temperature on the two open floors of the building. The average temperature on the two floors is assumed to be identical to that of the sprinklered fire scenario, $165^{\circ} \mathrm{F}\left(74^{\circ} \mathrm{C}\right)$. Use of this temperature does not represent a worst-case twofloor scenario. Rather, in contrast to the relatively high temperatures assumed for the multi-floor WTC 1 and WTC 2 aircraft impact fire scenarios (discussed in Secs. 8.2.4 and 8.2.5), the low temperature was assumed in order to cxamine the smoke management system effectiveness where the increased exterior wall leakage and the two-floor fire are the primary challenge to the smoke management system.

\subsubsection{WTC 1 and WTC 2, September 11, 2001, Fire Scenarios (No Shaft Damage)}

A hypothetical fire scenario was envisioned in which the majority of the structural damage occurring on September 11, 2001 was modeled, but with no damage occurring to the building's core. This scenario, although unlikely, was modeled to estimate the performance of the candidate smoke managcment system approaches for a scenario involving a multi-floor fire cvent with high temperatures throughout the fire compartment and large openings in the exterior of the building.

\subsubsection{WTC 1 and WTC 2, September 11, 2001, Fire Scenarios (Shaft Damage Assumed)}

This design fire scenario was used in an attempt to model smoke management system performance under the conditions in WTC 1 and WTC 2 on September 11, 2001. Estimates of the size of the exterior 
openings after aircraft impact (McAllister 2002), including impact damage and window breakage, were used, along with the preliminary damage estimates provided by the National Institute of Standards and Technology (NIST) (Appendix A), to model the damage conditions existing within each building. A full accounting of the opening areas assumed in the models of each building is provided in Appendix B.

Where the extent of damage was unknown, the damage was estimated. The sensitivity of the model was checked to see how the results would vary for wide variations in the assumed extent of damage. For example. the size of the hole between floors within the impact zone was difficult to estimate. The models used a floor opening equal to the footprint of the impact damage depicted in the NIST damage figures, up to but not including the core. Several model runs were then conducted varying the size of the holes (larger and smaller by factors of 2) to verify that this variable did not have too great an effect on the pressure differentials predicted by the model (see Runs 55, 55b, 55c-Table 8-6c). Although the final damage estimates to the building slabs presented in NIST Special Publication 1000-7 were somewhat less than the initial estimates (Figs. 7-1 and 7-2), this analysis revealed that the resulting pressure differentials were not overly sensitive to the size of the holes in the slabs.

Several estimates of the temperature within the impact zone in the towers were made, ranging from as low as $750{ }^{\circ} \mathrm{F}\left(400{ }^{\circ} \mathrm{C}\right)$ in some areas of the impact zone (Beyler 2002$)$ to as high as $1,800^{\circ} \mathrm{F}\left(1,000^{\circ} \mathrm{C}\right)$ in the hottest areas of the impact zone (McAllister 2002). Both the lower and the higher temperature were used to model the temperature throughout the impact zone in the model runs (described in Sec. 8.4) in order to bound the range of expected performance for the candidate smoke management system approaches. For all cases the outside air temperature was modeled as $70{ }^{\circ} \mathrm{F}\left(21^{\circ} \mathrm{C}\right)$ with the wind out of the north at $11.2 \mathrm{mph}(5 \mathrm{~m} / \mathrm{s})$.

\subsection{METHODS OF ANALYSIS}

All of the smoke management approaches analyzed utilized some variation of the pressurization method of smoke management. as described in concept in Sec. 2.1.2. The pressurization method is the smoke management system design method for well-compartmented structures with low-ceiling spaces.

The performance of each of the smoke management approaches, given the postulated design fire scenarios, was evaluated using the CONTAM building airflow and contaminant dispersal model, developed by NIST. CONTAM is identified by the American Society of Heating, Refrigerating, and AirConditioning Engineers (ASHRAE), in the ASHRAE Fundamentals Handbook (ASHRAE 2001) and the ASHRAE text Principles of Smoke Managemem (Klote and Milke 2002), as well as National Fire Protection Association (NFPA) standard 92A (NFPA 2000a) as an appropriate tool for the evaluation of smoke management systems that are based on the pressurization method of smoke management. Construction of the CONTAM model used in the analysis is discussed in Appendix B of this report. Calibration of the model is discussed in Appendix C.

Although the CONTAM model used was based on architectural/mechanical drawings of WTC 1, it was used to evaluate scenarios in both WTC 1 and WTC 2 because the buildings were very similar. None of the other buildings in the WTC complex were included in the model. The $1996 \mathrm{HAI} / \mathrm{DCE}$ study determined that the buildings interacted due to their connections, with the neutral plane for the complex being located above all of the other buildings in the complex other than the towers. Therefore, CONTAM runs that evaluated stack effects on smoke management system performance are only indicative of the 
potential impaets of stack effeet on the buildings in isolation, as the impaet of the other WTC buildings was not ineluded in the model.

\subsubsection{CONTAM Building Airflow Model}

CONTAM 2.1 (Walton and Dols 2003) is the latest, Windows- based version in the CONTAM family of publie domain multi-zone building airflow and eontaminant dispersal models developed by NIST. Version 2.0 (Dols and Walton 2002) was used in this study beeause for the purposes of this study, the simulation capabilities are essentially the same.

The program eombines state-of-the-art algorithms for modeling airflow and eontaminant analysis in multi-zone buildings. Methods for using CONTAM to evaluate the performanee of smoke management systems are documented in the ASHRAE text Principles of Smoke Management (Klote and Milke 2002) and in the engineering literature (Ferreira 2002).

CONTAM utilizes a graphic SketchPad interface to create an idealized representation of a building in terms of zones that are eonneeted by airflow paths. The SketchPad illustrates the eonneetion between zones, openings between zones (i.e., flow paths), ventilation system components, and eontaminant sourees and sinks (whieh were not used for this study). The SketchPad is used to establish the geometric relationships of the relevant building features. It is not intended to produee a seale drawing of the building; rather, it is used to create a simplified model where the walls, zones, and airflow paths are topologieally similar to the actual building (Dols, Walton, and Denton 2000).

CONTAM is capable of modeling wind effeets on the building, as well as staek effeets eaused by differenees between a building's interior temperature and the exterior temperature. Simplified HVAC system models and a detailed duetwork sub-model are available to evaluate the effect of HVAC systems on eontaminant spread. The sub-model is capable of modeling re-eireulating as well as 100 pereent outdoor air ventilation systems, although in the case of smoke eontrol, re-circulating HVAC systems are seldom used. The positions of doors and windows as well as HVAC system capacities can be varied over time using the model's sehedule feature.

In order to use CONTAM to model smoke flow within a building, a number of limitations must be taken into aeeount (Ferreira 2002). First, eaeh zone is treated as a well-mixed volume. Temperature or eontaminant stratifieation within a zone, as would be the ease given a hot smoke layer, is not taken into aecount. Also, while individual temperatures ean be assigned to eaeh zone, a temperature eannot be assigned to individual eontaminants. Thus, the buoyaney-induced flow exhibited by smoke, particularly in those zones elosest to the fire, is not taken into aecount. CONTAM has been shown to provide relatively good agreement with empirieal data for airflows at or near ambient temperatures (Emmerieh 2001). Validation studies have not been performed to evaluate the use of CONTAM to model buoyant flows.

Beeause buoyaney-indueed flows have the potential to play an important role in smoke spread, the CONTAM model is best suited for those applieations where buoyaney effeets are minimized. For instance, sprinklered buildings are better suited to use of the CONTAM model than are non-sprinklered buildings. Upon sprinkler activation in the room/zone of fire origin, the sprinkler water spray cools the hot smoke and stirs the smoke layer, driving some smoke down to the floor level. Although some degree of stratifieation does oeeur, stratification is not nearly as great as with an unsprinklered fire seenario (Tamura 1994). The mixing that oeeurs better approximates CONTAM's assumption of a well-mixed 
zone, meaning that each zone is characterized by a single temperature, pressure, and contaminant concentration at any given point in time. However, pressure does vary hydrostatically with elevation within each zone. The reduced smoke temperature reduces the extent of the buoyancy-induced flow associated with the smoke.

Buildings that are highly compartmented are also better suited to using CONTAM, particularly those that are broken up into multiple compartments using smoke barriers. Confining a fire to a specific volume will aid in the development of a well-mixed volume. Smoke spread across the smoke barriers will be predominately governed by forces such as wind, stack effect, and HVAC systems operation. Smoke spread from the confined compartment due to buoyancy can also be better approximated by defining an elevated smoke temperature in the room/zone of fire origin and using this temperature as the mechanism for buoyant spread across the compartment boundaries in the model. Once smoke has migrated from the room of fire origin, it is either cool enough where the buoyant forces are minimized or additional sprinklers may activate to further aid in the creation of a well-mixed volume in the adjacent spaces.

In buildings that are not sprinklered or where individual zones are connected by large openings, such as were caused due to the events on September 11,2001, buoyancy may play a more predominant role in smoke spread. When used for modeling smoke movement where buoyant flow is expected to be the predominant factor in the spread of smoke, CONTAM is most appropriately used to examine "far-field" conditions. Far-field conditions exist in those areas of a building further from a zone containing a fire, where cold-smoke conditions prevail. Far-field smoke conditions better approximate the well-mixed zone volume assumed in the model. "Near-field" conditions exist in those areas of the building close to the fire, in which hot-smoke conditions result in buoyancy induced smoke flow.

Figure 8-1 depicts the problem with using CONTAM where buoyant flow of smoke is expected to be the primary factor in smoke spread through the building. The right side of Fig. 8-1 shows buoyant flow conditions where smoke flows from a fire compartment to another compartment at some level above, via a vertical shaft. In reality, the temperature of the smoke cools as it rises up the shaft. The temperature gradient affects the pressure differentials throughout the shaft and, ultimately, between the shaft and the upper compartment. As shown in Fig. 8-1, the flow into the upper compartment is a function of $T_{1}$ through $\mathrm{T}_{7}$. In CONTAM, the temperature of each compartment must be specified by the user. The model does not perform an energy balance to determine the temperature of the smoke as it moves throughout the building; thus, temperature is not carried along as a property of the migrating smoke. In the model, then, the flow into the upper compartment is only a function of the difference between $T_{0}$ and $T_{1}$.

In order for smoke movement behavior to be adequately modeled using CONTAM, the near-field behavior of the smoke must be accounted for using other appropriate tools. Models such as the Consolidated Fire and Smoke Transport Model (CFAST) developed by NIST can be used to approximate near-field conditions where buoyancy is a concern (Peacock, Jones and Bukowski 1993). CFAST would be used to estimate the temperature of intermediate spaces (i.e., $T_{1}$ through $T_{7}$ in Fig. 8-1). However, using CFAST as a basis for selecting inputs into CONTAM compounds the uncertainty related to combining the models. Further research is needed to quantify the uncertainty and to develop the best strategies for coupling fire models to CONTAM. 


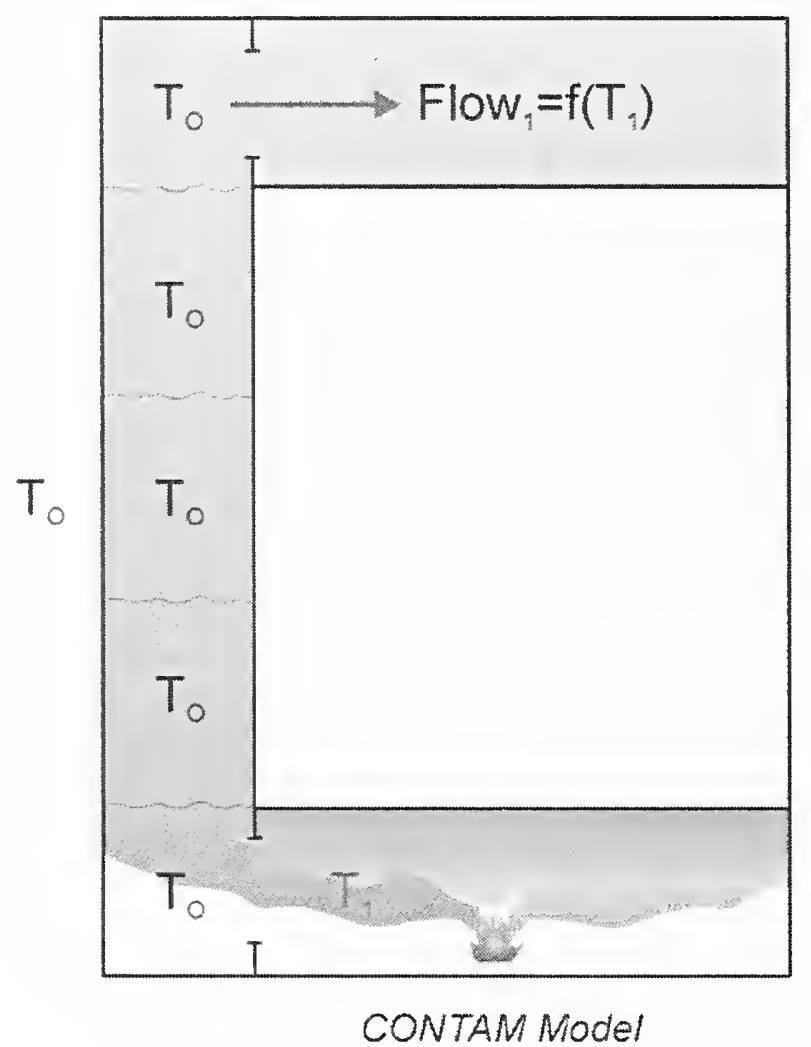

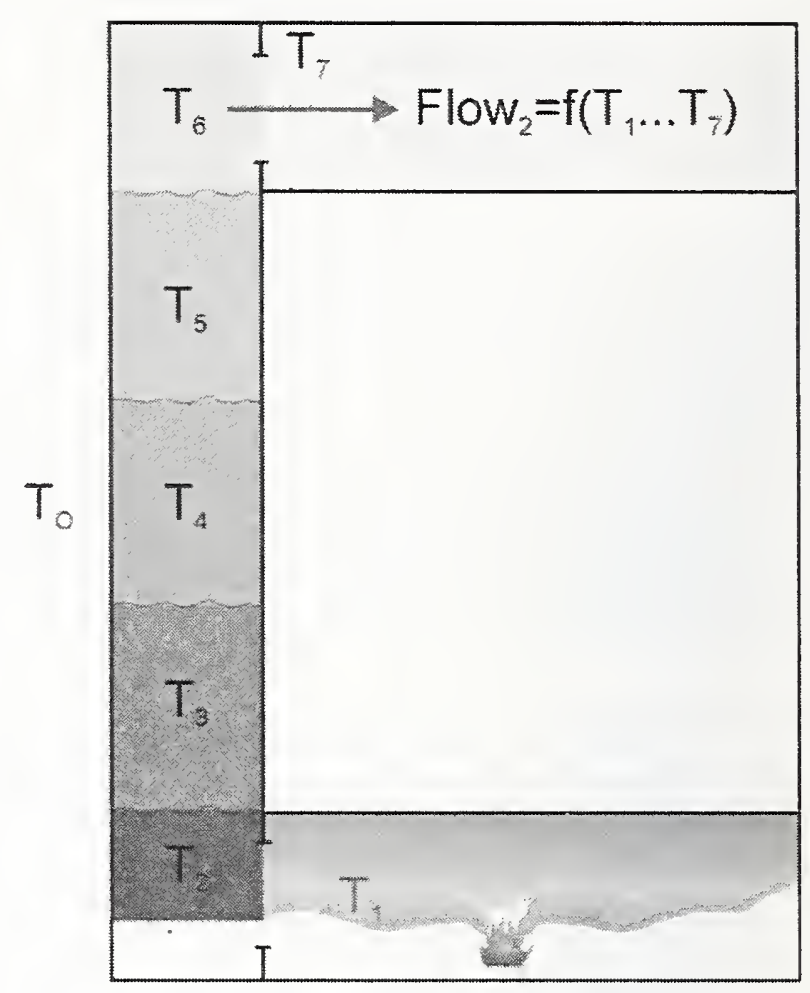

Real Flow Condition

Figure 8-1. Modeled versus real flow conditions.

Little information is available regarding the validation of CONTAM's handling of wind. However, any uncertainty inherent in the model is outweighed by uncertainties in selecting wind coefficients for the various exterior faces of a building. In the absence of detailed wind tunnel test data for a building, the coefficients used are at best rough approximations.

\subsubsection{System Performance Criteria}

The $1996 \mathrm{HAI} / \mathrm{DCE}$ smoke management study performed for WTC 1 and WTC 2 (HAI and DCE 1996) utilized not only pressure differentials, but also smoke tenability (i.e., temperature, visibility, toxicity) as system performance criteria. In some of the cases modeled in the 1996 study, smoke escaped the floor of fire origin. As long as the smoke migrating to other areas of the building did not violate pre-defined tenability criteria, the performance of the system was judged to be a success.

Based on a review of the various issues relating to the use of tenability (dilution) analysis, it was determined that the performance of the candidate smoke management approaches described in Sec. 8.1 would be evaluated based solely on the ability to provide pressure differentials consistent with the pressurization method of smoke control (see Sec. 2.1.2). Several concerns were identified related to the evaluation of whether acceptable tenability was maintained in remote areas of the building using a particular smoke management system approach.

First, as discussed in Sec. 2.1.2 of this report, use of a smoke management approach based on diluting smoke to provide a tenable environment is not recommended in the space containing the fire. In spaces 
remote from the fire, acceptable dilution of smoke may be achieved if the volume of the remote space is relatively large or the air change rate in the space is high relative to the amount of smoke migrating from the fire compartment. Several of the design fire scenarios evaluated, including the WTC 1 and WTC 2 aircraft impact scenarios, involved the creation of large openings that allowed smoke to travel to remote areas of the building above the impact region; therefore, significant airflow volumes would be necessary to accomplish dilution.

Establishing meaningful, conservative tenability criteria was also a concern given the large volumes of smoke migrating through the buildings and the nature of the primary fuel involved in the fire (jet fuel). Methods for assessing smoke tenability are discussed in the ASHRAE text Principles of Smoke Management Systems (Klote and Milke 2002) and within various chapters of the Society of Fire Protection Engineers' SFPE Handbook of Fire Protection Engineering (Mulholland 2002; Purser 2002). However, these references do not provide definitive tenability criteria to be used for assessing acceptable occupant exposure limits. Selection of appropriate tenability criteria is left up to the evaluating engineer, based on consideration of the fuel(s) involved in the fire and type(s) of occupants within the building. Furthermore, some tenability criteria such as smoke temperature and toxicity are a function of time of exposure to the smoke. Methods are available for calculating egress times (Proulx 2002; Nelson and Mowrer 2002), but calculation of egress time is a function of many factors affecting human behavior in fire that may introduce uncertainty into this type of calculation.

Finally, as discussed in Sec. 8.3.1, the CONTAM model is not well equipped to handle the modeling of scenarios where gas temperature is a primary driver of air (smoke) flow. Other methods (i.e., use of fire models) would be necessary to estimate the effects of buoyancy driven flow within the model. These methods introduce further uncertainty into the results obtained with the model.

Because of the various uncertainties involved with determining acceptable tenability in remote arcas of WTC 1 and WTC 2 using the CONTAM model, particularly for the aircraft impact scenario, smoke management system performance was evaluated based on the ability to contain smoke to the compartment of fire origin using pressure differentials. As discussed in Sec. 2.1.1, the various codes and standards that reference the use of pressurization smoke control require the provision of 0.05 in. $\mathrm{H}_{2} \mathrm{O}(12.5 \mathrm{~Pa})$ pressure differentials in sprinklered buildings and 0.1 in. $\mathrm{H}_{2} \mathrm{O}(25 \mathrm{~Pa})$ in non-sprinklered buildings to contain smoke. These pressures are measured with a building's HVAC systems placcd in smoke management mode, without the presence of a fire. The required pressure differentials are high enough to contain heated smoke were a fire to be present in sprinklered and non-sprinklered occupancies, and are used for design purposes.

The modeling performed using CONTAM includes the temperature of the fire compartment as a parameter in the model. Therefore, it is only necessary that the system maintain a positive pressure differential to contain smoke when the barrier across which the pressure is maintained is fairly tight. For barriers containing large openings, creation of a positive pressure differential may not be sufficient to contain smoke. Unless sufficient airflow velocity is applied to hold back the smoke, two-way flow will occur. Hcated smoke will flow from the fire compartment at the uppermost portion of the large opening, and pressurization air will be introduced into the fire compartment through the lower portion of the large opening.

A rough approximation of whether pressurization air may be capable of prohibiting passage of smoke from the fire compartment through a large opening may be obtained using equations pertaining to the 
airflow method of smoke control, discussed in Sec. 2.1.1. As stated in NFPA 92B (2000b), the limiting airflow velocity for sprinklered spaces is on the order of $300 \mathrm{ft} / \mathrm{min}(1.5 \mathrm{~m} / \mathrm{s})$, while the limiting airflow velocity for unsprinklered spaces is on the order of $600 \mathrm{ft} / \mathrm{min}(3 \mathrm{~m} / \mathrm{s})$.

\subsubsection{Calibration of the Model}

As part of the $1996 \mathrm{HAI} / \mathrm{DCE}$ study, a model of WTC 1 was constructed using an earlier version of CONTAM (Walton 1997). This model was used as the baseline to which modifications were made to perform the current modeling effort documented in this report. As discussed in Appendix B, many changes to the existing model (hereafter referred to as the 1996 CONTAM model) were necessary to allow it to be used for the current modeling effort. Many of the changes werc made to refiect lessons learned over the intervening years with regard to use of CONTAM to model the performance of smoke management systems in high-rise buildings. The 1996 study was one of the earliest uses of CONTAM to model smoke movement and control in large high-rise buildings.

As part of the 1996 study, calibration measurements were made of actual airflows and pressure differentials obtained at various locations in WTC 1 for different ventilation modes. At the time, a crude calibration was performed in order to develop the building model used to perform the analysis in the 1996 study.

For the current modeling effort, the 1996 calibration data was reviewed, and an attempt was made to calibrate the model to match the data. Appendix $\mathrm{C}$ documents the calibration of the model. As discussed in Appendix C, several uncertainties existed with regard to the accuracy of the reported data, and the determination of the exact configuration of the building (openings and HVAC system alignment) at the time the calibration measurements were madc.

After extensive effort, it was determined that a single building configuration could not be developed that conclusively matched the 1996 calibration data. The primary problem was the existence of too many independent variables (leakage types, wind/weather conditions, HVAC system alignments, design versus measured supply/return airflows, and unknown architectural changes to individual floor plans) to allow for a single building model that matched all of the data for the various ventilation modes.

It was determined that in order to accurately represent the uncertainty involved in the type of modeling being performed, and the potential range of results given this uncertainty, that threc separate building configurations would be carried forth in the modeling. These configurations, described in detail in Appendix B, are as follows:

- Configuration A-Best estimate of building parametcrs (i.e. leakage areas, HVAC system airflows, etc.), based on available building information.

- Configuration B-Configuration A ventilation system parameters changed in order to better match data from different ventilation modes tested.

- Configuration $C$-Configuration A assumed leakage values changed in order to better match data from different ventilation modes tested. 


\subsection{RESULTS OF ANALYSIS}

A total of 180 model runs were conducted using CONTAM to evaluate the performance of the candidate smoke management system approaches for the proposed design fire scenarios. The results of these model runs are shown in Table 8-6. The results presented in Table 8-6 are grouped in banded sets of runs for each fire scenario. Within each set of runs, each of the three potential building configurations (A, B, and C) were repeated for each fire scenario.

Tables 8-6a through 8-6d show the pressure differential achieved across key vertical and horizontal leakage paths for given smoke management mode/fire scenario combinations. Positive pressures signify airflow in a direction outward from the stairs/elevators, to the core, and into the office spaces. Thus, positive pressures mean desirable system performance with respect to conditions in the core/stairs. Negative pressures signify airflow in the opposite direction, into the core and into the vertical shafts, and indicate the probable spread of smoke to other floors of the building.

The fire floor is generally modeled as the 80th floor, which corresponds to a floor of impact in WTC 2 on September 11,2001. This floor was selected in order to provide a direct comparison to results obtained for the WTC 2 September 11 fire scenarios. The ambient temperature modeled was also generally $70^{\circ} \mathrm{F}$ $\left(21^{\circ} \mathrm{C}\right)$, the reported temperature in New York City on the morning of September 11, 2001 (McAllister 2002). Within each group of modeling runs, building configuration $\mathrm{A}, \mathrm{B}$, or $\mathrm{C}$ was sometimes repeated, with the fire floor changed to a lower floor in the building ( 15 th floor) and the ambient temperature changed to $15^{\circ} \mathrm{F}\left(-9.5^{\circ} \mathrm{C}\right)$. This was done to examine system performance under maximum stack effect conditions, as $15^{\circ} \mathrm{F}$ is the design winter temperature for New York City listed in the $A S H R A E$ Fundamentals Handbook (ASHRAE 2001).

Given the uncertainty associated with the construction of the model, it is not appropriate to examine an individual data point as an absolute indicator of whether it is possible to maintain the required pressure differential. Rather, the entire set of data should be reviewed as a whole, as an indicator of whether the candidate smoke management system would be capable of providing pressure differentials in the desired range for that fire scenario.

\subsubsection{Sprinklered Fire Scenario-Results}

The CONTAM modeling results for the sprinklered fire scenario are shown in Table 8-6a. As previously stated, the sprinklered fire scenario assumed a temperature of $165^{\circ} \mathrm{F}\left(74^{\circ} \mathrm{C}\right)$ in the zone of fire origin, which is conservative for a sprinklered fire in a large open plan office space.

The results show that all of the five candidate smoke management approaches evaluated would be capable of providing at least a positive pressure across the tenant doors on the floor of fire origin. So long as the doors remained closed, the pressure differential would be sufficient to contain smoke to the office space on the floor of fire origin.

For some of the smoke management approaches, the pressure differential provided by the system would decrease for a fire on a lower floor (15th floor) in the event of a design stack effect condition $\left(15^{\circ} \mathrm{F}[-9.5\right.$ $\left.{ }^{\circ} \mathrm{C}\right]$ ); however, positive pressure could be maintained for building configuration $\mathrm{A}$. 
It is important to note that for all of the approaches except for the zoned smoke control with stair pressurization, the pressure differentials become negative at one or more of the exit stairways. In each of the other approaches, the stairways are not pressurized; thercfore, air from other portions of the building pressurizing the core on the fire floor may cause the flow direction to be into one or more stairways on the fire floor. This means that if smoke should enter the corc during the fire, due to a tcnant door being blocked open or some other means, smoke could be forced into the exit stairways.

Stair 3 gencrally maintains a positive pressure in all of the smoke control modes cxcept for core pressurization mode under extrcme stack effect conditions (Run 8). As scen in Fig. 4-3, this stair only has onc interruption via a transfer corridor as it rises vertically through the building, as opposed to five transfer corridors in Stairs 1 and 4 transfer corridors in Stair 2. This lack of interruption allows more supply air to enter the stair on other floors and effectively pressurize Stair 3 in the various smoke management modes modeled.

\subsubsection{Full-Floor Burnout Scenario-Results}

The CONTAM modeling results for the full-floor burnout case are shown in Table 8-6b. A temperature of $1,800^{\circ} \mathrm{F}\left(1,000^{\circ} \mathrm{C}\right)$ in the zone of fire origin was assumed for this fire scenario (as in the $1996 \mathrm{HAI} / \mathrm{DCE}$ study).

The results show that for the case of a full-floor burnout, the buoyancy driven pressure differentials ovcrcome the ability of the smoke purge and core pressurization configurations to maintain adequate pressure differentials $\left(0.05 \mathrm{in} . \mathrm{H}_{2} \mathrm{O}\right.$ [12.5 Pa]). Flow direction is into the core via the tenant doors, and then into freight elevator 50 and the three exit stairs. This would likely result in smoke spread to other floors via the stairs/elevator shafts.

For the building pressurization smoke management approach, significant pressure differentials are created due to the fact that the supply air provided throughout the entire building flows to the fire floor and exits the building via the windows assumed to be broken out by the fire. For all building configurations, the simulated pressure differentials across tenant doors and stair doors were well in excess of the 0.36 in. $\mathrm{H}_{2} \mathrm{O}$ maximum pressure differential that would result in the $30 \mathrm{lb}_{\mathrm{f}}$ maximum allowable door opening force (for use in a means of egress) recommended by NFPA 92A (2000a), assuming a $3 \mathrm{ft}$ by $7 \mathrm{ft}(0.91 \mathrm{~m}$ by $2.13 \mathrm{~m}$ ) standard door dimension. This is consistent with observations made during the 1996 study, which is why one of the rccommendations of the $1996 \mathrm{HAI} / \mathrm{DCE}$ study was not to use building pressurization unless it was verified that all occupants had exited the building.

Both the zoned smoke control and sandwich pressurization approaches are successful in maintaining positive pressures across the tcnant doors. The success of both approaches is aided by the ability to pressurize the core, using stair pressurization in the zoned approach and airflow via the elevator shafts from other ventilation zones in the building in the sandwich approach. However, as documented by run 32, the zoned approach is sensitive to stack effect as ncgative prcssures in freight elevator 50, Stair 3 , and other vertical shafts cause the core space to become negatively pressurized, resulting in negative pressure across the tenant doors.

The zoned smoke control approach involves exhausting the zone of fire origin to create the desired pressure differentials, which also has the positive result of rcmoving smoke from the zone of fire origin. While this approach was demonstrated to be successful for the sprinklercd fire sccnario, where barrier 
integrity is expected to be maintained, the ability of this approach to maintain a pressure differential is greatly impeded when large openings are created in the exterior boundary of the zone, as is the case due to window break-out in the full-floor fire scenario.

\subsubsection{Two-Floor Fire Scenario-Results}

The CONTAM modeling results for the two-floor fire case are shown in Table 8-6b. A temperature of $165^{\circ} \mathrm{F}\left(74^{\circ} \mathrm{C}\right)$ in the zone of fire origin was assumed for this fire scenario. The intent of modeling this fire scenario was to examine the effect of moderate openings in the exterior of the building, as well as an increase in the effective volume of the zone of fire origin, due to the postulated opening in the floor slab, on smoke management system effectiveness.

The results show that the smoke purge and core pressurization configurations were not capable of maintaining adequate pressures to contain smoke $\left(0.05\right.$ in. $\mathrm{H}_{2} \mathrm{O}$ [12.5 Pa]). Flow direction is into the core via the tenant doors, and then into freight elevator 50 and the three exit stairs. The reversal in flow direction is caused by the fact that for each approach, the floors in the multi-floor ventilation zone containing the fire are at a net-negative pressure. The openings created on the two fire floors in the exterior of the building result in the interior exhaust pulling air directly from the outside. Therefore, the other non-fire floors within the zone become more negative than the floors of fire origin, resulting in the flow of air into the vertical shafts and then out onto the other floors within the ventilation zone. This would result in smoke spread throughout the building.

For the building pressurization smoke management approach, significant pressure differentials are again created due to the fact that the supply air provided throughout the entire building travels to the fire floor and is then able to exit the building via the windows broken out by the fire. The pressure differentials across tenant doors and stair doors are well in excess of the 0.36 in. $\mathrm{H}_{2} \mathrm{O}$ maximum pressure differential that would result in the $30 \mathrm{lb}_{\mathrm{f}}$ maximum allowable door opening force, and would be expected to impede occupant egress from the building.

The zoned smoke control and sandwich pressurization approaches both are successful in maintaining positive pressures across the tcnant doors. As prcviously stated, the success of both approaches is aided by the ability to pressurize the core, using stair pressurization in the zoned approach and airflow via the elevator shafts from other ventilation zones in the sandwich approach. Again, the zoned approach is sensitive to stack effect as negative pressures in freight elevator 50, Stair 3, and other vertical shafts cause the core space to become negatively pressurized, resulting in negative pressure across the tenant doors.

\subsubsection{WTC 1 and WTC 2, September 11, 2001, Fire Scenarios (No Shaft Damage)- Results}

Table 8-6c shows the results for the WTC 1 and WTC 2 fire scenarios that model the extent of damage due to the aircraft impacts into each building on September 11,2001. It was assumed that no damage occured to the core and that the damage to the exterior and floor slabs was consistent with the impact damage described in Appendixes $\mathrm{A}$ and $\mathrm{B}$ of this report.

The intent of the no shaft damage simulations was to determine whether a smoke management system might be effective given a multi-floor fire zone heated to an elevated temperature, but where the integrity of the core is maintained. It is recognized that maintaining the integrity of the core after an aircraft impact 
into the building would be difficult, regardless of the building materials that were used in constructing the core. The purpose of this scenario is to evaluate whether core damage would be the primary contributing factor to the success or failure of a candidate smoke management system approach.

In order to evaluate the results of the September 11, 2001, fire scenarios, it is important to note that the aircraft impact created a large, multi-floor zone with openings to the outside via damage to the building envelope and openings to the interior core spaces. The temperature throughout the impact zone is assumed to be uniform, at either $750{ }^{\circ} \mathrm{F}\left(400{ }^{\circ} \mathrm{C}\right)$ or $1,800^{\circ} \mathrm{F}\left(1,000^{\circ} \mathrm{C}\right)$. The temperature within the multi-floor zone creates a buoyant airflow due to localized stack effect within the zone caused by the high temperature. This phenomenon is shown in Fig. 8-2.
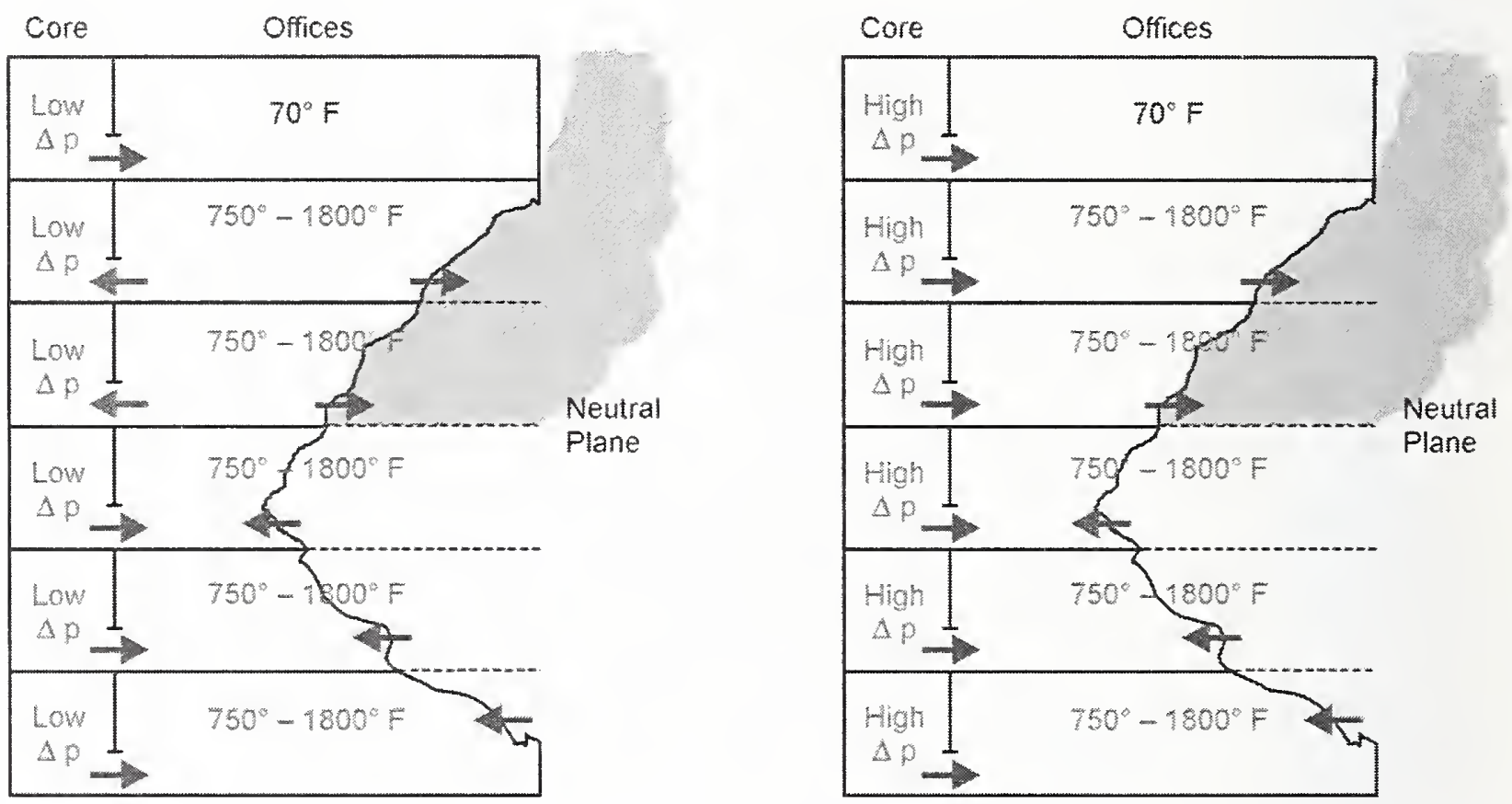

Figure 8-2. Effect of core pressure on airflows in impact zones.

As shown in Fig. 8-2, air flows into the impact zone on lower floors and out of the impact zone on higher floors. Only when the positive pressure in the core is high enough can sufficient pressure be maintained on all floors of the impact zone.

Columns in Table 8-6c list the high and low pressures achieved across tenant doors, with the floor the pressure occurs on listed next to the pressure differential in brackets. Table $8-6 \mathrm{c}$ shows that for the smoke purge, core pressurization, and zoned smoke control approaches, in both WTC 1 and WTC 2, pressure is positive (out of the core) on the lower floors of the zone and negative (into the core) on the upper floors of the impact zones. The core pressurization approach does maintain very low positive pressures for several model configuration/temperature combinations. However, given that negative pressures occur in other cases and due to the uncertainty inherent in the model, this smoke management system approach was determined to be unable to contain smoke to the impact zone on all floors.

The results differ between buildings for the building pressurization and sandwich pressurization approaches. For WTC 1, positive pressure is maintained on all floors. For WTC 2, adequate pressure is not maintained for the uppermost floors of the impact zone. The reason for the disparity in results 
between the two buildings is the difference in location of the aircraft impacts into the two buildings relative to the mechanical rooms that served the impact zones. As shown in Fig. 4-4, the mechanical equipment room (MER) serving the impact zone was located above the impact zone in WTC 1 and was located below the impact zone in WTC 2 .

Both the building pressurization and sandwich pressurization approaches make use of supply air from the other ventilation zones as part of each smoke management approach. For the building pressurization mode, both the supply and exhaust ventilation are operated in the zone of fire origin, but only supply is operated in the other zones. Since the supply and exhaust ventilation in the zone of fire origin were assumed to cancel each other out from a pressure standpoint, a higher net positive pressure is achieved within the building when the uppermost ventilation zone served by the 108th floor MER is the zone of fire origin.

A similar effect occurs in the sandwich pressurization mode. This approach involves exhausting the ventilation zone of fire origin and supplying air to the other zones. When large openings are present to the exterior on the fire floor(s), the exhaust ventilation is able to pull air directly from the outside, and therefore, does not contribute to the pressure differential across the core/office barrier. Positive pressure must be achieved from the core relative to the office spaces via supply air coming from the rest of the building. Again, the building is at a higher net positive pressure when the floors served by the 108th floor MER are the floors of fire origin; thus, the difference in performance noted between WTC 1 and WTC 2 in Table 8-6c.

\subsubsection{WTC 1 and WTC 2, September 11, 2001, Fire Scenarios (Shaft Damage Assumed)-Results}

Table 8-6d shows the results for the WTC 1 and WTC 2 fire scenarios that model the extent of damage due to the aircraft impacts into each building on September 11, 2001, assuming shaft damage occurred, as postulated. The extent of core/shaft damage is discussed in Sec. 8.2.4 (and Appendixcs A and B).

As previously stated, it is important to note from a multi-zone modeling perspective that the aircraft impact created a large, multi-floor zone with openings to the outside via damage to the exterior wall and openings to the interior core spaces. As shown in Fig. 8-2, air flows into the impact zone on lower floors and out of the impact zone on higher floors. Only when the positive pressure in the core is high enough can sufficient pressure be maintained on all floors of the impact zone.

In Table 8-6d, columns list the high and low pressures achieved across tenant doors, with the floor on which the pressure occurs listed next to the pressure differential in brackets. Table 8-6d shows that for the smoke purge, core pressurization, and zoned smoke control approaches, in both WTC 1 and WTC 2, pressure is positive (out of the core) on the lower floors of the zone and negative (into core) on the upper floors of the impact zones. These smoke management system approaches fail to contain smoke to the impact zone on all floors.

As with the results for the undamaged core scenarios discussed in Sec. 8.4.4, the results differ between buildings for the building pressurization and sandwich pressurization approaches. For WTC 1, positive core pressure is maintained relative to the office spaces on all floors. For WTC 2, adequate pressure is not maintained between the core and perimeter office spaces for the uppermost floors of the impact zone. As 
previously discussed, the reason for the disparity in results between the two buildings is the relative location of the aircraft impacts into the two buildings.

Due to the shaft damage, the positive pressure diffcrentials maintained by the building pressurization and sandwich pressurization approaches in WTC 1 are very low on the upper floors of the impact zone, less than $0.01 \mathrm{in} . \mathrm{H}_{2} \mathrm{O}(2.5 \mathrm{~Pa})$. Airflows across the large openings in the model were found to be lcss than $150 \mathrm{ft} / \mathrm{min}(0.75 \mathrm{~m} / \mathrm{s})$ at this low pressure differential. This is far less than the limiting airflow velocity of $600 \mathrm{ft} / \mathrm{min}(3 \mathrm{~m} / \mathrm{s})$ nceded to keep smoke from entering the shaft, discussed in Sec. 8.3.2. Therefore, smoke would be expected to enter the core and migrate to other areas of the building via the damaged shafts, albeit at a lesser ratc than if no smoke management was provided.

\subsection{SUMMARY OF ANALYSIS}

Five candidate smoke management system approaches were evaluated to determine whether each of these approaches could provide adequate pressurization to contain smoke to the zone of fire origin for five postulated fire scenarios.

The snoke punge approach and the core pressurization approach were shown to create adequate pressure differentials for only the sprinklered fire scenario. Substantial negative pressure differentials, indicating flow of smoke from the zone of fire origin into the core, occurred for each of the other fire scenarios.

The building pressurization approach created high pressure differentials from the core to the perimeter office spaces for all fire scenarios except the multi-floor September 11, 2001, aircraft impact scenarios. Positive pressures were demonstrated for both the undamaged core and shaft damage September 11 scenarios in WTC 1, but sufficient airflow velocity was not created to prohibit smoke spread via large openings in ventilation shafts and in the core/office space boundaries resulting from aircraft impact damage. Use of the building pressurization method could potentially create excessive door opening forces that could hinder or prohibit the egress of building occupants. The magnitude of the door opening forces is a function of the fire scenario, size of interior and extcrior openings, and location of the floor(s) of fire origin relative to the location of the MER.

The zoned smoke control with stair pressurization approach was shown to be effective for the sprinklered fire scenario, the full-floor burnout, and the two-floor fire. For each of these fire scenarios, however, stack effect was shown to have a substantial impact on the performance of the system, in some cases causing airflow from the floor of fire origin into the core. Therefore, this approach might not be effective using a single speed fan, or set airflow quantity. It is likely that fan speed would have to be adjusted based on differential pressure readings to ensure the success of a smoke management system using this approach. Because the zoned smoke control method involves exhausting from a single floor of the building, it was not effective for the multi-floor aircraft impact scenarios. In addition, stair pressurization did not prohibit smoke spread into the stairs when large openings in the stairway walls were present due to aircraft impact damage.

The sandwich pressurization approach was determined to be effective for the sprinklered fire, full-floor burnout, and two-floor fire scenarios, even in the presence of stack effect. Positive pressures were demonstrated in the model scenarios for both the undamaged core and shaft damage September 11 scenarios in WTC 1, but sufficient airflow velocity was not created to prohibit smoke spread via large openings into ventilation shafts or the core resulting from aircraft impact damage. 


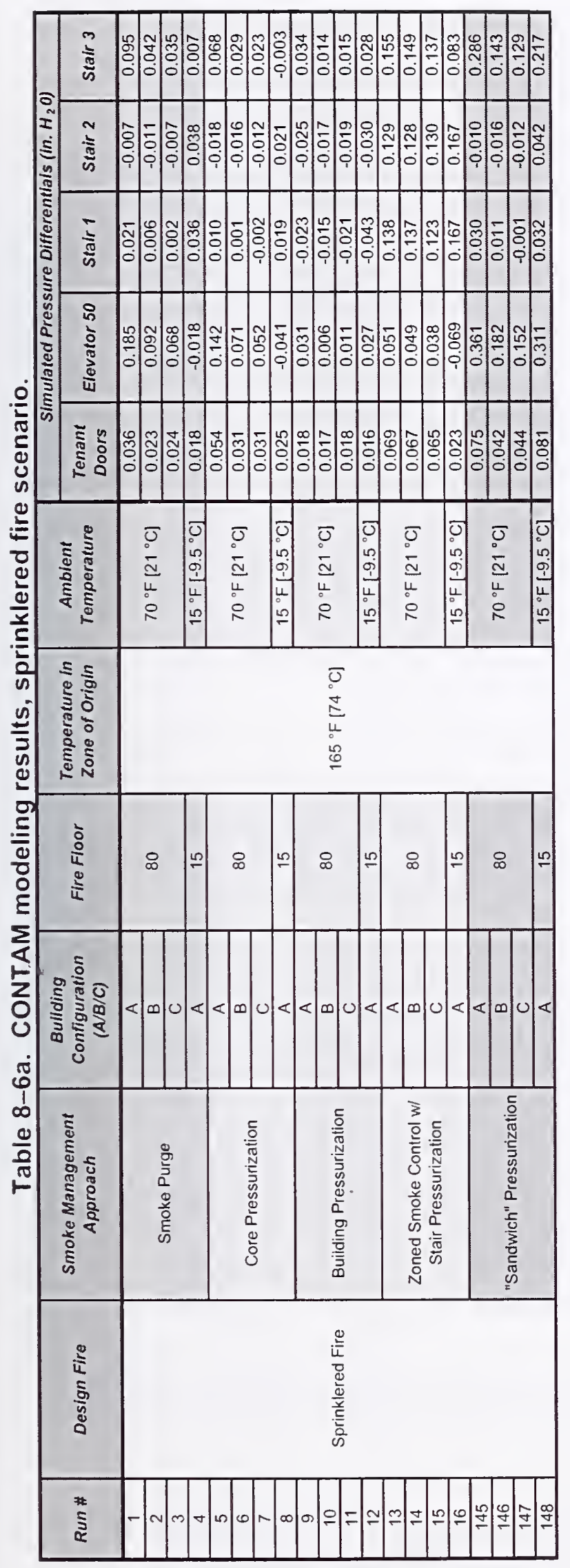




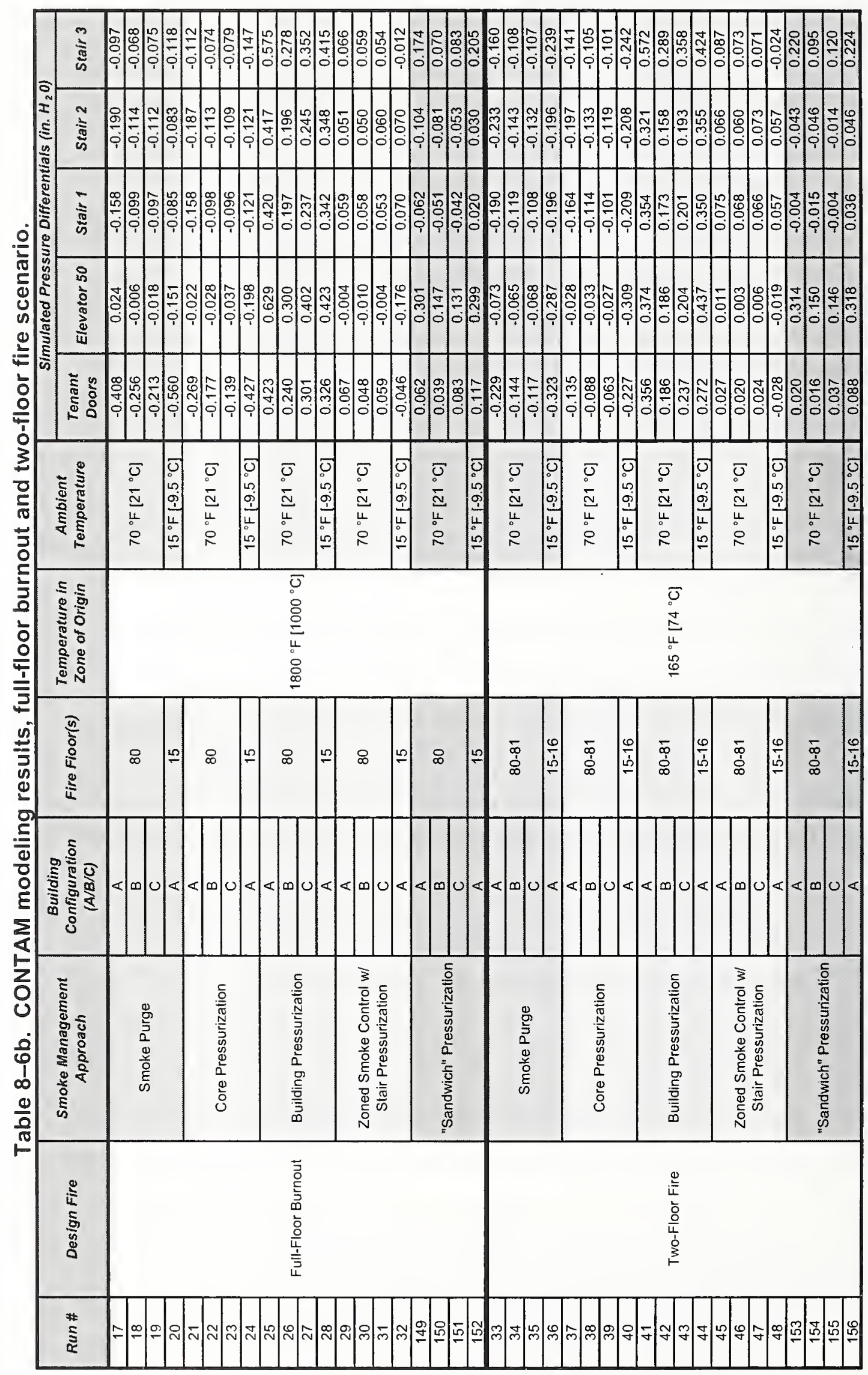




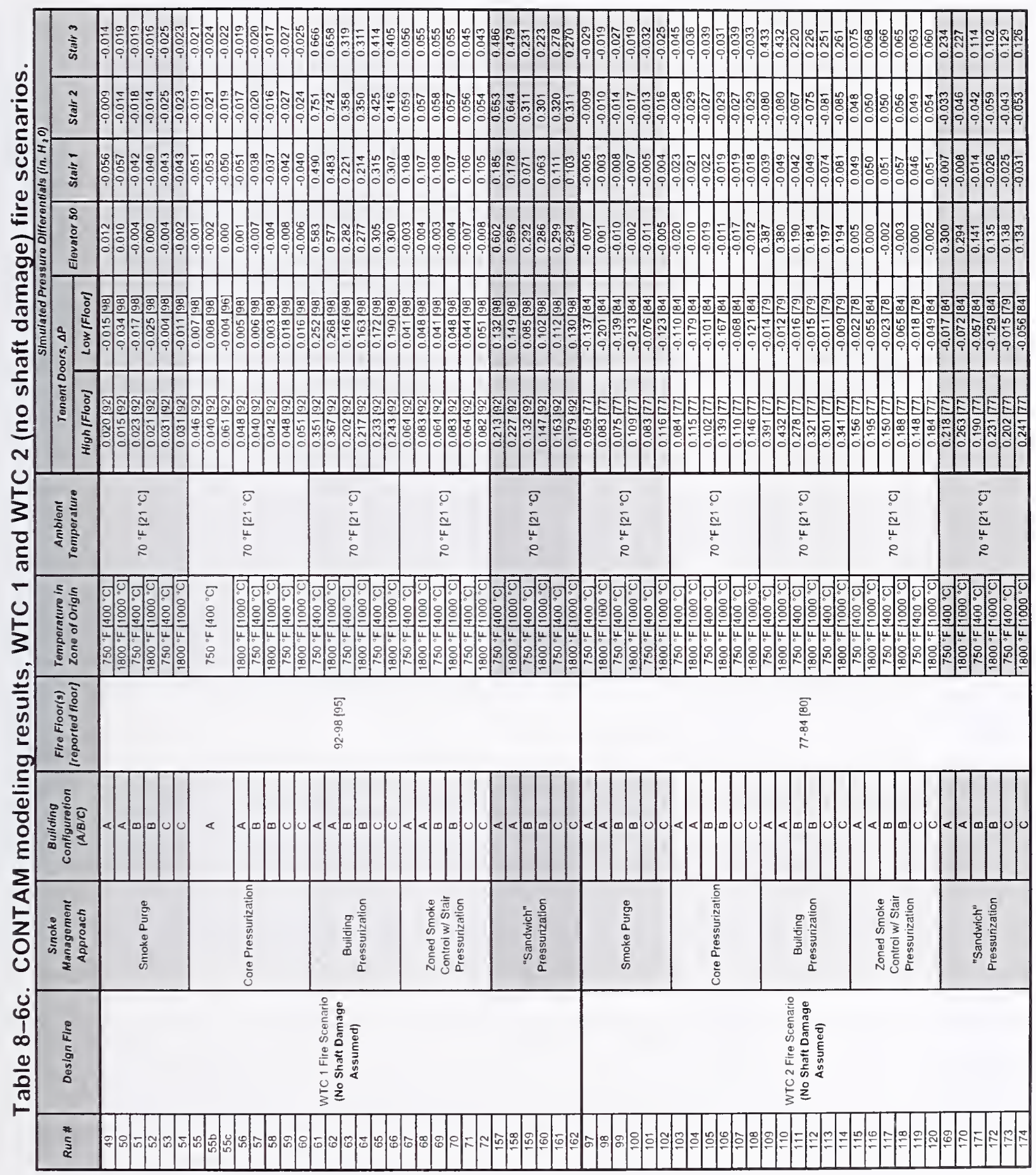




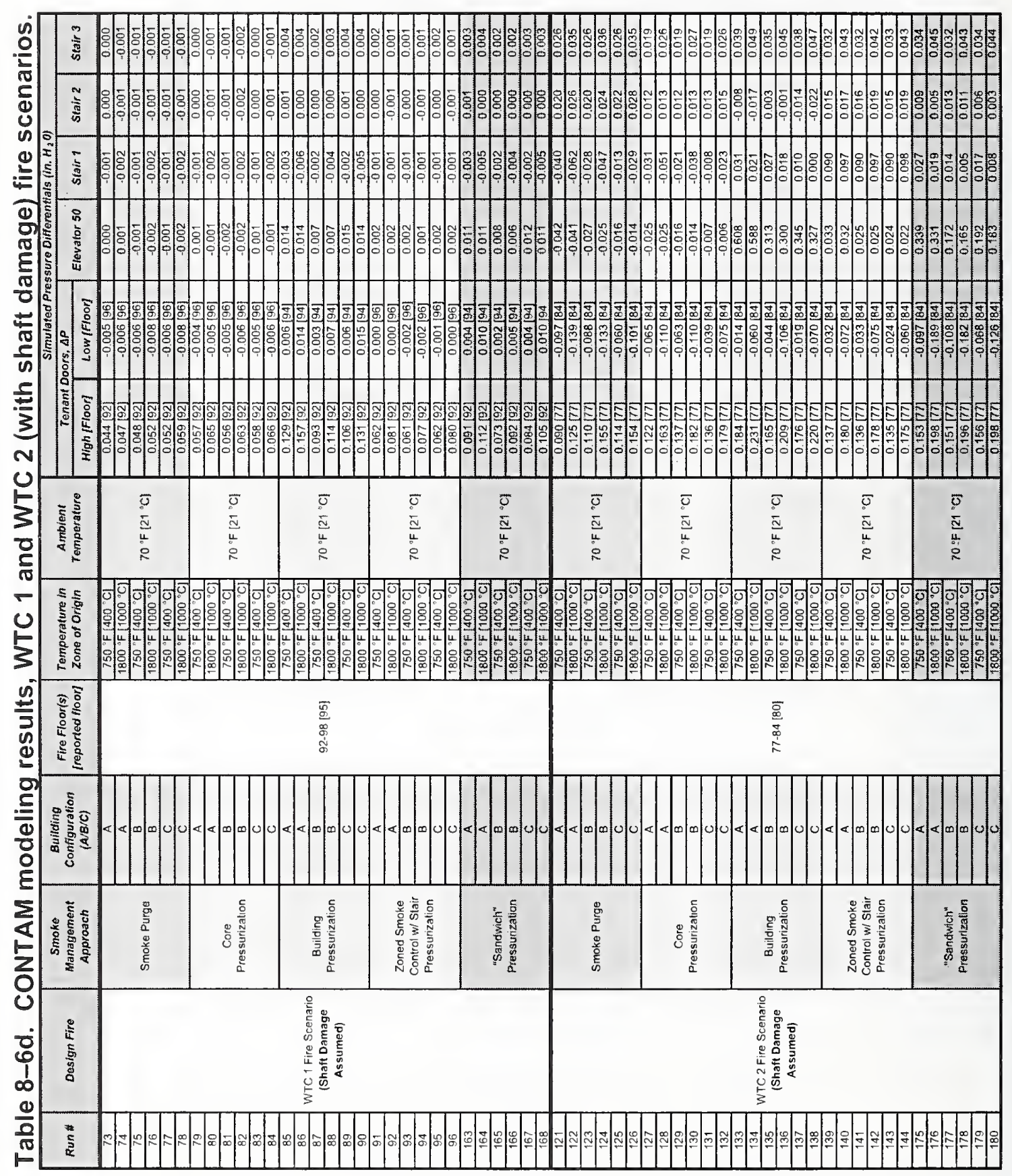




\subsection{REFERENCES}

ASHRAE (American Society of Heating, Refrigeration and Air-Conditioning Engineers). 2001. ASHRAE Fundamentals Handbook. ASHRAE, Atlanta, GA.

Beyler, C. L. 2002. Analysis of the Fire Aspects of the World Trade Center Terrorist Attacks:

11 Septeniber 2001. Hughes Associates, Inc. Baltimore, MD. Prepared at the direction of council Wachtell, Lipton, Rosen \& Katz, New York, NY, July 31.

Dols, W. S., G. N. Walton, and K. R. Denton. 2000. CONTAMW 1.0 User Manual: Multizone Wirflow and Contaminant Transport Analysis Software. NISTIR 6476 (National Institute of Science and Technology-Interagency Report). U.S. Department of Commerce, Washington, DC.

Dols, W. S., and G. N. Walton. 2002. CONTAM 2.0 User Manual: Multizone airflow and contaminant transport analysis software. NISTIR 6921 (National Institute of Science and Technology-Interagency Report). U.S. Department of Commerce, Washington, DC.

Emmerich, S. J. 2001. Validation of multizone IAQ modeling of residential-scale buildings: A review. ASHRAE Transactions. Vol. 107, Part 2. American Society of Heating Refrigeration and Air-Conditioning Engineers, Atlanta, GA, 2001.

Ferreira, M. J. 2002. Use of multi-zone modeling for high-rise smoke control system design. ASHRAE Transactions. Vol. 108, Part 2. American Society of Heating, Refrigeration and Air-conditioning Engineers, Atlanta, GA.

HAI (Hughes Associates, Inc.) and DCE (Dillon Consulting Engineers). 1996. Smoke Management Evaluation Study of The World Trade Center Complex Excluding the Concourse and Plaza. Prepared for the PANYNJ (Port Authority of New York and New Jersey). New York, NY.

Klem, T. J. 1991. Preliminary Investigative Report: One Meridian Plaza, Philadelphia, PA, February 23, 1991, Three Firefighter Fatalities. NFPA (National Fire Protection Association), Quincy, MA.

Klote, J. H., and J. A. Milke. 2002. Principles of Smoke Management. American Society of Heating Refrigeration and Air-conditioning Engineers (ASHRAE). Atlanta, GA.

Lougheed, G. D., J. R. Mawhinney, and J. O'Neill. 1994. Full-scale fire tests and the development of design criteria for sprinkler protection of mobile shelving units. Fire Technology. Vol. 30.

McAllister, T., ed. 2002. World Trade Center Building Performance Study: Data Collection, Preliminary Observations, and Recommendations. FEMA 403. Federal Emergency Management Agency. Washington, DC, May.

Mulholland, G. W. 2002. Smoke Production and Properties. SFPE Handbook of Fire Protection Engineering. 3rd Edition. Chapter 13, Section 2. DiNenno, P. J., Drysdale, D., Beyler, C. L. Walton, W. D., eds.. NFPA (National Fire Protection Association), Quincy, MA. 
Nclson, H. E. 1989. An Engineering View of the Fire of May 4, 1988 in the First Interstate Bank Building Los Angelcs, Califomia. NISTIR 89-4061 (National Institute of Standards and TechnologyInteragency Report). U.S. Dept. of Commerce, Washington, DC, March.

Nelson, H. E., and F. W. Mowrer. 2002. Emergency Movement. The SFPE (Society of Fire Protection Engineers) Handbook of Fire Protection Engineering, $3 r d$ Ed. DiNenno, P. J., Drysdale, D., Beyler, C. L. Walton, W. D., eds. National Fire Protection Association, Quincy, MA.

NFPA (National Fire Protection Association). 2000a. Recommended Practice for Smoke-Control Systems. NFPA 92A, Quincy, MA.

NFPA (National Fire Protection Association). 2000b. Guide for Smoke Management Systems in Malls, Atria, and Large Areas. NFPA 92B, Quincy, MA.

PANYNJ (Port Authority of New York and New Jersey). 1986. World Trade Center Instrnction Manual No. 23: Operation \& Maintenance of Fire Protection System. New York, NY, February.

Peacock, R. D., W. W. Jones, and R. W. Bukowski. 1993. Verification of a Model of Fire and Smoke Transport. Fire Safety Jourmal. Vol. 21, No. 2.

Proulx, G. 2002. Movement of People: The evacuation timing. The SFPE (Society of Fire Protection Engineers) Handbook of Fire Protection Engineering, 3rd Ed. DiNenno, P. J., Drysdale, D., Beyler, C. L. Walton, W. D., eds. National Fire Protection Association, Quincy, MA.

Purser, D. A. 2002. Toxicity Assessment of Combustion Products. The SFPE (Society of Fire Protection Engineers) Handbook of Fire Protection Engineering, 3rd Ed. DiNenno, P. J., Drysdale, D., Beyler, C. L. Walton, W. D., eds. National Fire Protection Association, Quincy, MA.

Tamura, G. T. 1994. Smoke movement and control in high rise buildings. National Fire Protection Agency, Quincy, MA.

Walton, G. N. 1997. CONTAM96: User Manual. NISTIR 6056 (National Institute of Science and Technology-Interagency Report). U.S. Department of Commerce, Washington, DC, September.

Walton, G. N., and W. S. Dols. 2003. CONTAM 2.1 Supplemental User Guide and Program Documentation. NISTIR 7049 (National Institute of Science and Technology-Interagency Report). U.S. Department of Commerce, Washington, DC. 


\section{Chapter 9 \\ SUMMARY}

The objective of this effort was to evaluate the design, installation, and performance of the smoke management systems installed in World Trade Center (WTC) 1,2, and 7. The National Institute of Standards and Technology (NIST) documented the design and installation of the smoke management systems in WTC 1.2, and 7 and compared the systems to requirements in applicable codes and standards. The effort also included the documentation of the normal operation of fully functional smoke management systems on smoke conditions in WTC 1 and WTC 2 on September 11, 2001.

In order to complete Tasks 1 and 2, it was necessary to answer several questions to fully understand the potential impact of smoke management systems on the events occurring on September 11, 2001:

- Were other smoke management system design approaches available for WTC 1 and WTC 2 that might have had a substantial impact on smoke conditions in the buildings on September 11, 2001?

- Is it reasonable to expect that an alternate smoke management system configuration could have been provided for WTC 1 and WTC 2 given the prevailing codes and standards and building practices in the United States?

- What factors could have contributed to the success or failure of a smoke management system given the aircraft impact scenarios that occurred on September 11, 2001?

\subsection{EVALUATION OF SMOKE MANAGEMENT SYSTEMS AVAILABLE ON SEPTEMBER 11, 2001}

WTC 1 and WTC 2 were provided with a manual smoke purge system that was capable of exhausting smoke by quadrant for a multi-floor heating, ventilating, and air conditioning (HVAC) zone. WTC 1 and WTC 2 were designed to meet the requirements contained in the 1968 Building Code of the City of New York (BCNYC). Changes were made to the buildings to meet the retroactive provisions of various local laws enacted subsequent to the time of building construction. Local Law No. 5, enacted in 1973, required retroactive provision of a smoke shaft for smoke venting or stair pressurization in high-rise building. Local Law No. 86, enacted in 1979, later omitted these requirements for existing buildings provided with automatic sprinklers throughout. The Port Authority of New York and New Jersey (PANYNJ or Port Authority) initially investigated the provision of stair pressurization in a pilot study conducted in WTC 1 over a period of time between 1976 and 1979. This approach was not implemented because a program for retrofitting the buildings with automatic sprinklers was adopted. WTC 1 and WTC 2 were also equipped with fire dampers in HVAC ductwork at the shaft walls on each floor. No requirement existed for retroactive provision of fire/smoke dampers in the buildings.

Documentation of the sequence of operations pertaining to smoke purge in WTC 1 and WTC 2 differed in the available sources consulted in the preparation of this report. Building operations and maintenance 
manuals, not updated since 1986, referred to a smoke purge mode as exhausting the HVAC zone containing the fire using the interior zone exhaust fans. No supply ventilation fans were referenced in the documented sequence. Port Authority personnel noted that the current sequence of operations in place on September 11,2001, involved using both the interior supply and exhaust serving one of the four interior sub-zones to purge the zone of smoke. The New York City Fire Department (FDNY) had the potential to utilize additional fans as they saw fit to respond to the conditions of a particular fire event.

The smoke purge system for WTC 1 and WTC 2 were designed to be used for post-fire cleanup of smoke, although smoke purge was shown to have been used during a fire occurring in 1975 in WTC 1 during a fire event in an effort to control smoke spread. Smoke purge was initiated by the FDNY, but operated by building operations and maintenance personnel.

From an examination of the available evidence, it was determined that the smoke management (smoke purge) systems in WTC 1 and WTC 2 played no role in the events that occurred on September 11, 2001. No record was found of the smoke purge sequence being initiated in WTC 1 or WTC 2 by the FDNY or building operations and maintenance personnel. Had an attempt been made to initiate the smoke purge sequence it is unlikely the system would have functioned as designed, due to loss of electrical power and/or damage to the HVAC shafts and other structural elements in the impact zone. Even if the systems were in some way fully functional, they would not be capable of substantially reducing the extent of smoke spread through the building, as dcmonstrated by the analysis performed within this study.

WTC 7 was provided with a zoned smoke management system that was capable of exhausting smoke manually on a floor-by-floor basis. Local Law No. 16 amended the 1968 BCNYC to require that all buildings in occupancy group $\mathrm{E}$ (business) be provided a manual override capable of exhausting one floor at a time at a rate of 6 air changes per hour, or $1 \mathrm{cfm} / \mathrm{ft}^{2}$, whichever is greater. For WTC 7, with a footprint area of approximately $48,000 \mathrm{ft}^{2}$, this would require an exhaust capacity of at least $48,000 \mathrm{ft}^{3} / \min \left(81,552 \mathrm{~m}^{3} / \mathrm{h}\right)$. As documented in Chapter 4 of this report, the base building system serving the lower floors of the building provided a smoke exhaust capacity of $36,000 \mathrm{ft}^{3} / \mathrm{min}\left(61,164 \mathrm{~m}^{3} / \mathrm{h}\right)$, which is not consistent with the minimum value specified by code. An $84,000 \mathrm{ft}^{3} / \mathrm{min}\left(142,716 \mathrm{~m}^{3} / \mathrm{h}\right)$ exhaust fan was provided for the Salomon Smith Barney floors during the tenant retrofit. WTC 7 was sprinklered throughout and was therefore exempted from the requirement for stair pressurization systems. The building was provided with a Class E firc alarm system per code and with emergency power serving all emergency systems, and was equipped throughout with fire dampers at duct penetrations into vertical shafts.

\subsection{ALTERNATE MEANS OF SMOKE MANAGEMENT}

\subsubsection{Design Requirements in Prevailing Codes and Standards}

As discussed in Sec. 2.2, the earliest work pertaining to what we now would consider smoke management systems in buildings occurred in the late 1960s and early 1970s, right around the time that WTC 1 and WTC 2 were being constructed. Design requirements for engineered smoke management systems matured in the late 1980s and early 1990s, with the publication of National Fire Protection Association (NFPA) 92A and 92B, the American Society of Heating, Refrigerating and Air-Conditioning Engineers (ASHRAE) design texts, and updates to requirements in the model building codes in the United States. These advances in smoke management system design occurred well after the construction of WTC 1 and 
WTC 2. As such. the definition of what was considered state-of-the-art smoke management system design changed over the life of the building.

Various national and local building codes in the United States required provision of zoned smoke management systems in the 1980s and 1990s. Requirements predating the publication of NFPA 92A most often based the design on fixed air change rates such as six air changes per hour. After publication of NFPA 92A the codes most often based the design on provision of a specified pressure differential. Current codes. such as the International Building Code (IBC) and NFPA 5000 have removed the requirement of zoned smoke management for sprinklered high-rise buildings. The current codes are consistent with regard to the requirement of stair pressurization systems in high-rise buildings and combination fire/smoke dampers in HVAC system ductwork.

\subsubsection{Past Recommendations for Changes to Smoke Management Systems}

Subsequent to the 1993 bombing, two separate studies were initiated by the Port Authority to cxamine the impact of smoke management systems in WTC 1 and WTC 2. The first study, performed by Rolf Jensen \& Associates (RJA), modeled smoke movement through the buildings given the conditions at the time of the bombing. The study also examined the effects of stair venting, elevator hoistway venting, and stair pressurization on smoke spread through the buildings. The study concluded that of the approaches analyzed, stair pressurization had the potential to improve conditions for occupants exiting the building. However, the study concluded that the stair pressurization system design must consider the impact of stack effect, which greatly impacts the pressures obtained within the stairways. The study also concluded that stair pressurization would have little to no effect when a large number of doorways were open into the stairways, as is the case during an event involving a building-wide evacuation. There is no evidence indicating that provisions were made to provide stair pressurization in WTC 1 and WTC 2 as a result of the RJA study.

The second study. performed in 1996 by Hughes Associates, Inc. (HAI) in conjunction with Dillon Consulting Engineers (DCE), cxamined the use of the existing building HVAC systems to accomplish smoke management in the buildings. Several major recommendations resulted from this study, including that smoke management systems be activated automatically using smoke detectors. The study specified use of a core pressurization approach, activated automatically by the detectors. The study further recommended manual alignment of the HVAC systems in a building pressurization mode in the event of a full-floor-burnout where flames were visible via broken windows on a fire floor.

The recommendations for automatic initiation of smoke management from the 1996 study were not implemented in WTC 1 and WTC 2, as manual initiation of smoke management system was required in New York City. The sequence of operations for the existing manual smoke purge system was not updated to reflect use of a core pressurization approach. Procedures were not put in place for use of the building pressurization approach, as numerous decisions would have to be made that had the potential to create adverse door opening forces in the building.

\subsubsection{Summary of Potential Changes}

New York City differs from many jurisdictions in the extent that new code provisions are retroactively enforced. Many provisions of the various local laws enacted since the 1968 BCNYC were retroactively 
applied to existing high-rise buildings. Building codes typically do not retroactively apply requirements to retrofit existing buildings with smoke management systems. Retrofits of existing buildings are often difficult to achieve, and are costly to the building owners. WTC 1 and WTC 2 were retrofitted with automatic sprinkler systems, but no retrofit was done to provide additional smoke management systems for the buildings. Retrofit of WTC 1 and WTC 2 with stair pressurization and/or smoke dampers in HVAC ductwork would have been a substantial undcrtaking. Automatic initiation of smoke management systems was not implemented, as manual initiation of smoke management is the general practice in New York City.

Based on the 1996 study, the Port Authority could have chosen to change the sequence of operations pertaining to the smoke purge to reflect use of a core pressurization approach. This arrangemcnt would have performed adequately for typical building fires if the system was used as an active fire protection system during a fire event. However, such a change would have had little or no impact relative to the events that occurred on September 11,2001.

\section{$9.3 \quad$ EVALUATION OF SMOKE MANAGEMENT SYSTEM PERFORMANCE}

Based on the modeling of smoke management system performance for the candidate systems evaluated in this report, it can be concluded that smoke management systems would not have been effective in confining smoke to the zone of fire origin given the events of September 11, 2001.

All of the candidate approaches evaluated failed to provide sufficient pressure differentials to confine smoke for the postulated Scptembcr 11, 2001, building damage scenarios. Considering the fact that the availability of power was questionable due to impact damage, and that damage would have affected the intended pattern of air distribution within the zone of fire origin, successful system operation is even further in doubt.

An assumption critical to the provision of smoke management systems designed to provide life safety protection for building occupants is that the system be operated automatically via approved automatic initiating devices, such as smoke detectors. Even if it was determined that a candidate smoke management system approach had the potential to provide adequate pressure differentials for a given fire scenario, substantial amounts of smoke could migrate through a building prior to activation of the system via manual means. This is particularly true for the extreme fire scenarios occurring as a result of the September 11,2001, aircraft impacts. Manual operation of smoke management systems is specified by New York City regulations.

On September 1 1, 2001, the aircraft impacts into both WTC 1 and WTC 2 affected floors that were entirely within only one ventilation zone, the 108th floor mechanical equipment room (MER) in WTC 1 , and the 75 th floor MER in WTC 2. If an aircraft were to have impacted the 91 st/92nd floors, a large opening would have been created connecting two HVAC zones. Operation of a smoke management system in this scenario could have adversely impacted conditions in the building, depending on the smoke management system approach used. Also, an aircraft impact directly onto an MER floor, such as the 75th floor, could directly damage HVAC systems used for smoke management and cause smoke movement to all connected floors via the HVAC shafts.

The prevailing national codes for new building construction in effect on September 11, 2001, specified the provision of stair pressurization systems and combination fire/smoke dampers in HVAC system 
ductwork for new high-rise buildings equipped throughout with automatic sprinkler systems. No other active smoke management systems were required. Although the effectiveness of these measures was analyzed using the CONTAM model for the zoned smoke control with stair pressurization approach to determine if smoke containment via pressurization could be achieved, the modeling did not address whether provision of stair pressurization or smoke dampers could have improved smoke conditions within the buildings (i.e. tenability analysis). However, conclusions can be made with regard to the potential impact of these provisions in WTC 1 and WTC 2 on September 11, 2001, as discussed in the following sections.

\subsubsection{Impact of Stair Pressurization Systems}

Provision of stair pressurization systems in WTC 1 and WTC 2 would have been difficult, due to the fact that the stainvays extended 110 stories and changed location within the building at several locations via horizontal transfer corridors.

It was shown in the RJA study that provision of stair pressurization systems would require pressure relief mechanisms within the stairs to relieve excessive overpressure conditions due to stack effect. The study further demonstrated that the effectiveness of stair pressurization was expected to be minimal when large numbers of doors were open, as would be the case in a full building evacuation scenario. The stair pressurization pilot study performed by the Port Authority in WTC 1 demonstrated that stair pressurization was achievable given a small number of doors open, but also demonstrated that excessive door opening forces were created under certain stack effect conditions during testing.

During the events occurring on September 11, 2001, stair pressurization using typical existing design criteria would have been ineffective in improving conditions for occupants trying to exit the buildings. In the initial stages of the event, a full-building evacuation occurred from all floors that were not significantly affected by the aircraft impacts. This would have reduced the pressure differential within the stairs to the point where the required pressure differential was no longer achieved.

In addition, substantial damage occurred to the stairway within the impact zone, causing smoke to migrate directly into the stairs. Stair pressurization is designed to prohibit smoke entry into a stairway. Supply air provided into the stair to achieve pressurization would be ineffective in diluting large amounts of smoke entering the stair. As with all HVAC systems in the building, it is unlikely that stair pressurization systems would have been fully operable on September 11, 2001, even if they had been installed, as damage to the building's electrical and HVAC systems may have prevented proper operation of the systems.

\subsubsection{Smoke Dampers}

As discussed in Chapter 7 of this report, significant smoke spread occurred within WTC 1 and WTC 2 via HVAC system ductwork. Combination fire/smoke dampers would likely have reduced the extent of smoke spread through the building by reducing smoke spread through damper openings on the upper floors of the building. Smoke dampers are generally powered open and are designed to fail closed upon loss of power. Thus. they would have been capable of closing despite a loss of electrical power. The primary effect of smoke damper operation would likely have been to slow the development of hazardous smoke conditions on the uppermost floors of the building. 


\subsection{SUMMARY OF RESULTS}

The following findings are bascd on the information and analysis documented in this report:

- The smoke management systems in WTC 1 and WTC 2, which provided the capability for a manual smoke purge within an individual HVAC zone on a quadrant-by-quadrant basis, were not initiated on September 11,2001.

- Had the smoke purge sequence been initiated in WTC 1 or WTC 2, it is unlikely the system would have functioned as designed, duc to loss of electrical power and/or damage to the HVAC shafts and other structural elements in the impact zone.

- Provision of active smoke management systems and/or combination fire/smoke dampers was not required by the $1968 \mathrm{BCNYC}$ or retroactive provisions in the various local laws enacted aftcr WTC 1 and WTC 2 were constructed for existing high-rise buildings provided with automatic sprinklers throughout.

- None of the potential smoke management system configurations evaluated in this report would have provided sufficient pressure differentials to contain smoke for the postulated aircraft impact damage scenarios, even if these systems were capable of operation after the building sustained damage from the aircraft impact.

- The smoke purge sequence in existence on or before September 11, 2001, would have been expected to be capable of limiting the spread of smoke from the zone of fire origin only for fire scenarios in which the sprinkler system was operational and controlled the fire. Other smoke management strategies capable of being implemented using the existing WTC 1 and WTC 2 ventilation systems may also have been capable of controlling smoke from the postulated full-floor burnout and two-floor fire scenarios evaluated in this report had these strategies been identified and implemented in the sequence of operations.

- During the events occurring on September 11, 2001, stair pressurization likely would have been ineffective in improving conditions for occupants trying to exit the building.

- Installation of combination fire/smoke dampers in HVAC ductwork, which was not required in WTC 1 or WTC 2, would have actcd to slow the development of hazardous conditions on the uppermost floors of the building, but would likely not have had a significant effect on the ability of occupants to egress the building due to the impassibility of the exit stairways. 


\section{Appendix A \\ NIST PRELIMINARY Damage Estimates}

The analysis of smoke management system performance on September 11, 2001, discussed in Chapter 7 of this report, considered preliminary aircraft damage estimates dated October 27, 2003, developed under the National Institute of Standards and Technology (NIST) World Trade Center (WTC) Investigation. This information was used to create the estimates of core damage summarized in Figs. 7-1 and 7-2.

The preliminary damage estimates predate more current estimates that were not available at the time that the analyses of the smoke management system were performed. The revised damage estimates are presented in NIST NCSTAR 1-2. The damage estimated to have occurred to the drywall partitions within the building cores is of particular interest in the analyscs of the smokc management systems, because the stair and heating, ventilating, and air conditioning shafts were made up of these types of partitions. The debris fields shown on the revised damage estimates were determined to indicate damagc to vertical shafts to a similar degree shown on the preliminary damage estimates, for both WTC 1 and WTC 2 . Therefore, the effects of implementing the revised estimates on the analyses of WTC 1 and WTC 2 would be minimal, as the preliminary and revised damage estimates were very similar with respect to vertical shaft damage.

\section{A.1 WTC 1 PRELIMINARY DAMAGE ESTIMATES}

Preliminary damage estimates for WTC 1 are shown in Figs. A-1 through A-6. The figurcs summarize the estimated aircraft damage to core and exterior columns on floors 94 through 98 of the building. Each figure depicts a shaded region (likely damage) and a rcgion bounded by a dotted linc (potential damage). 


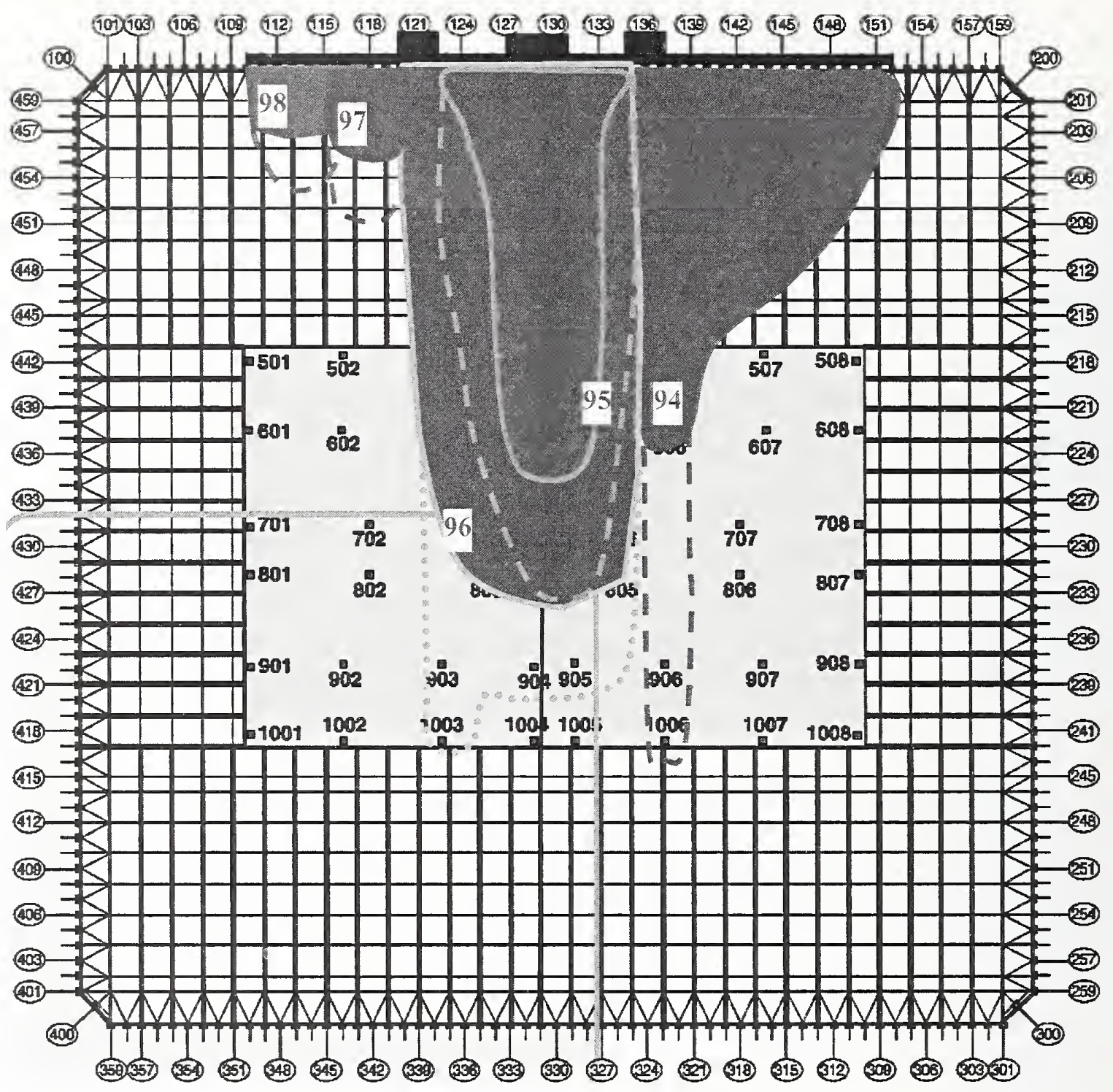

Source: Adapted from McAllister 2002.

Figure A-1. Preliminary damage estimates, all floors, WTC 1. 


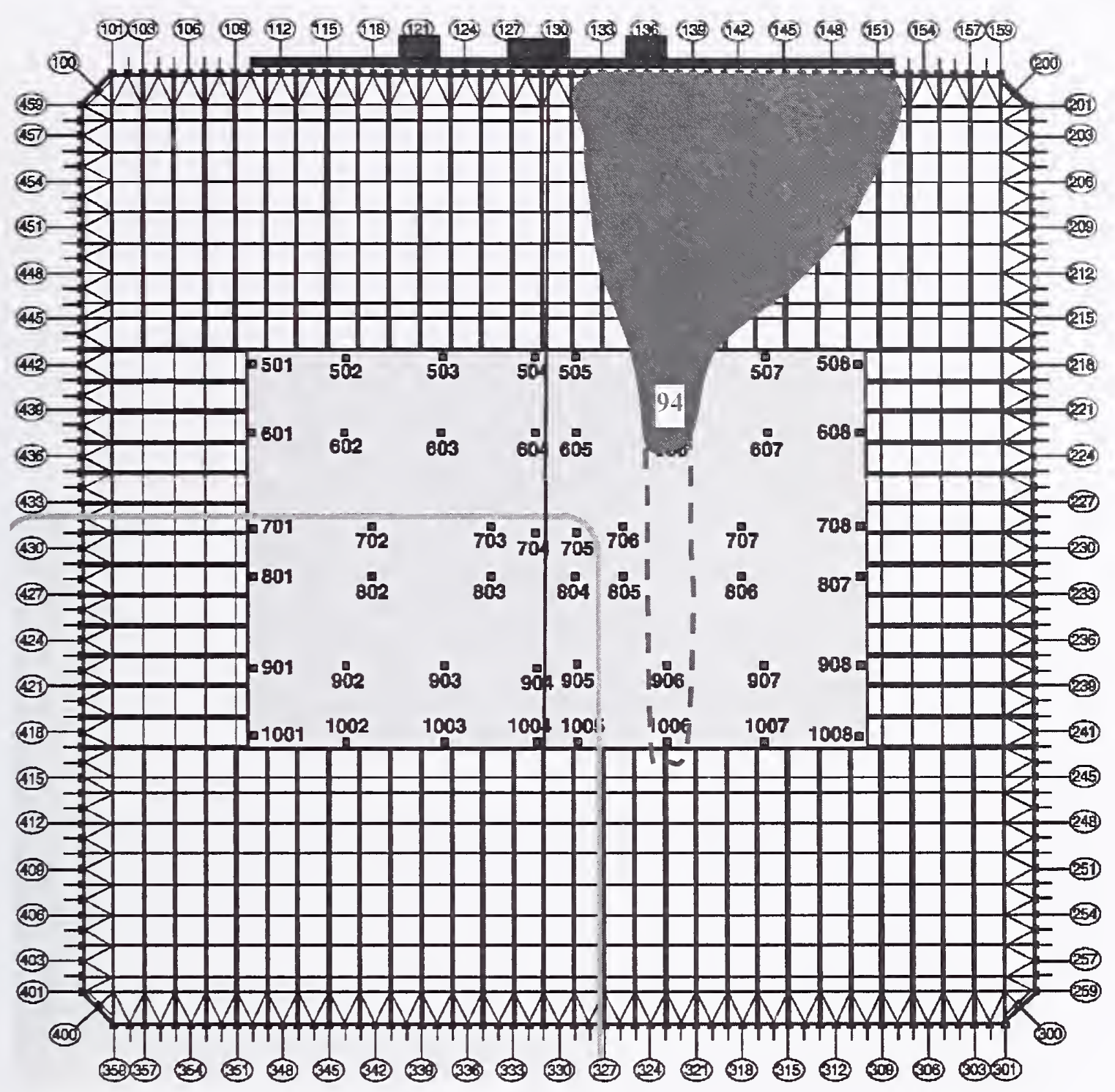

Source: Adapted from McAllister 2002.

Figure A-2. Preliminary damage estimates, 94th floor, WTC 1. 


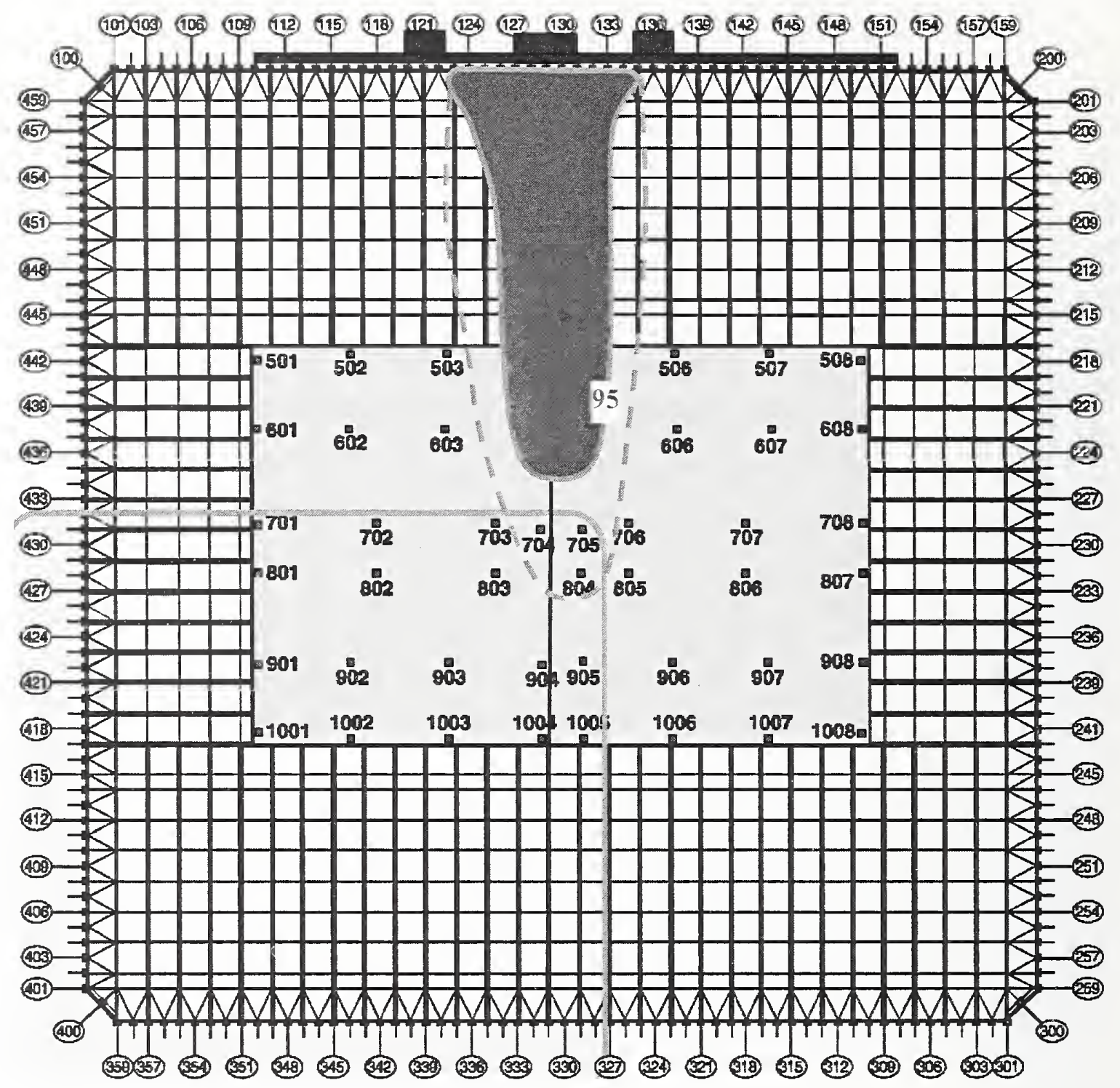

Source: Adapted from McAllister 2002.

Figure A-3. Preliminary damage estimates, 95th floor, WTC 1. 


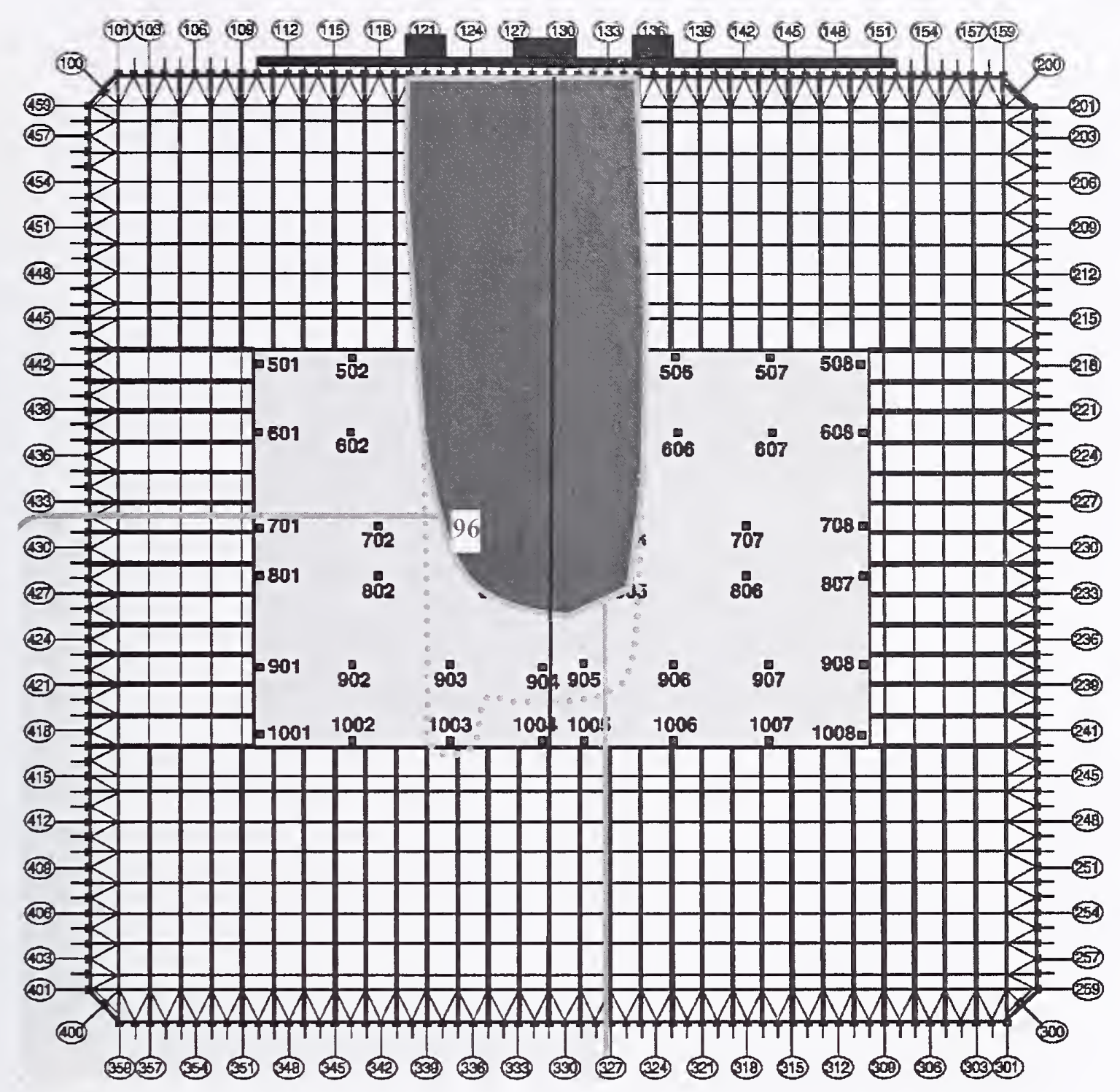

Source: Adapted from McAllister 2002.

Figure A-4. Preliminary damage estimates, 96th floor, WTC 1. 


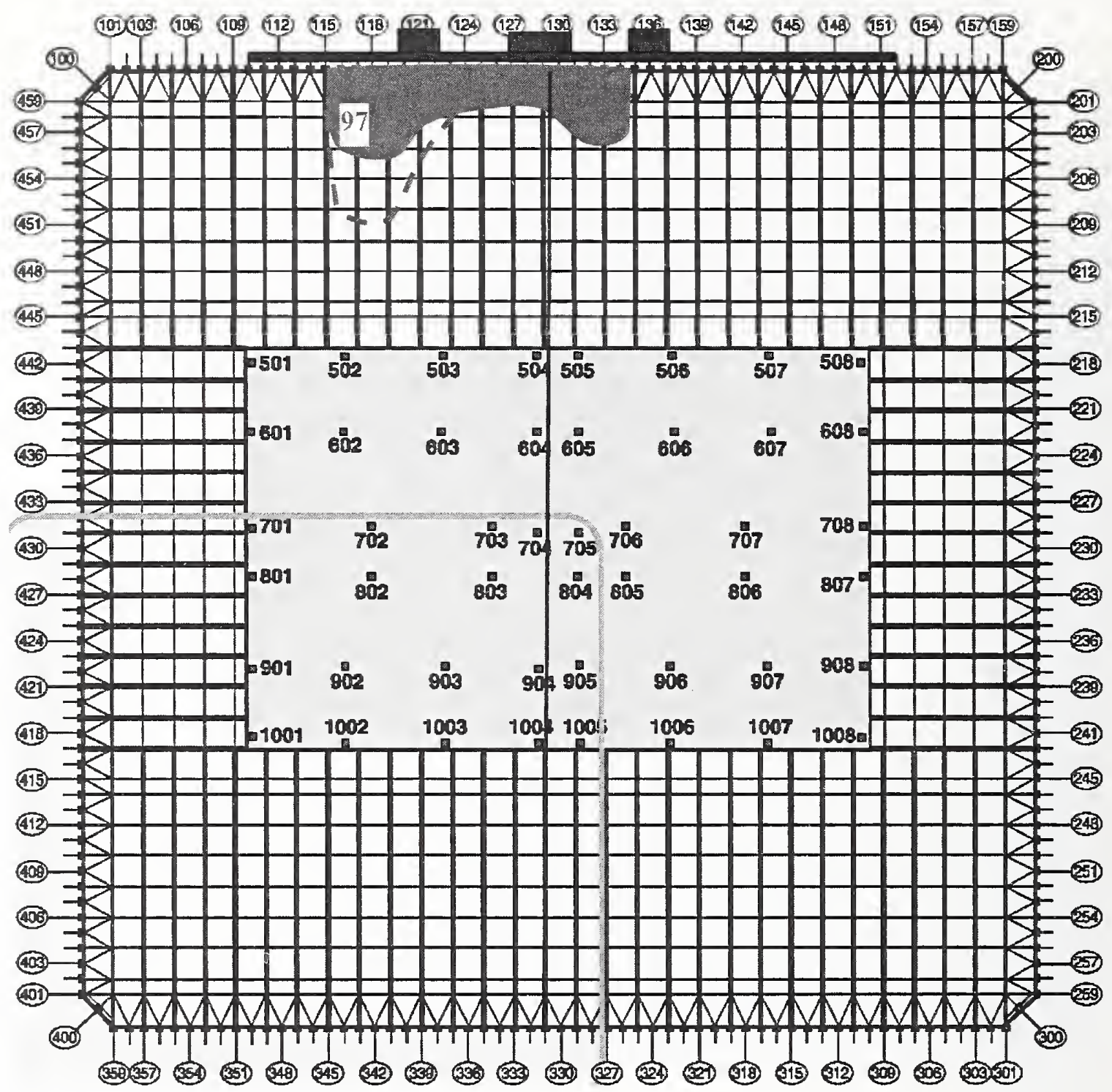

Source: Adapted from McAllister 2002.

Figure A-5. Preliminary damage estimates, 97th floor, WTC 1. 


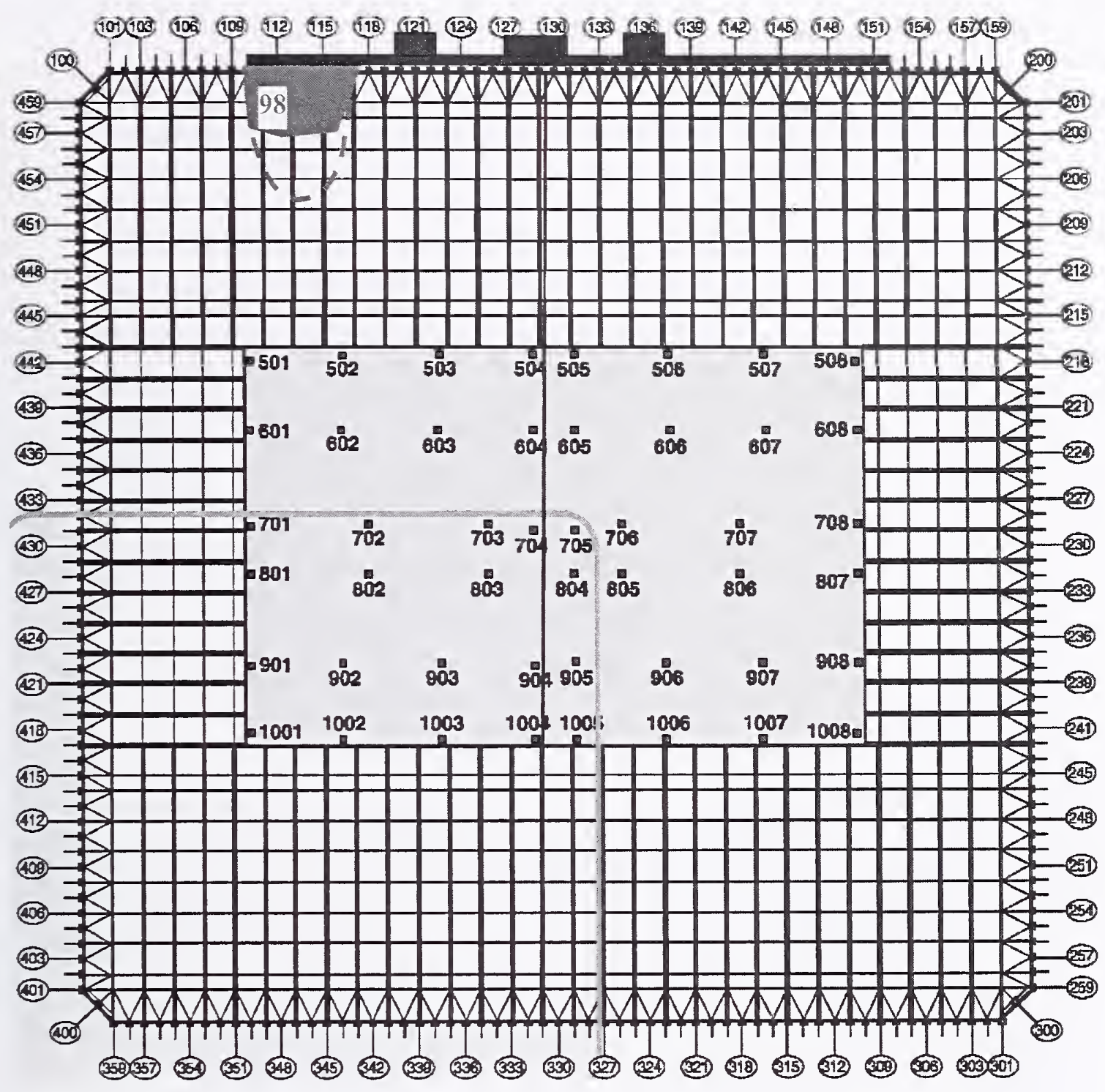

Source: Adapted from McAllister 2002.

Figure A-6. Preliminary damage estimates, 98th floor, WTC 1. 


\section{A.2 WTC 2 PRELIMINARY DAMAGE ESTIMATES}

Preliminary damage estimates for WTC 2 are shown in Figs. A-7 through A-14. The figures summarize the estimated aircraft damage to core and exterior columns on floors 78 through 84 of the building. Each figure depicts a shaded region (likely damage) and a region bounded by a dotted line (potential damage).

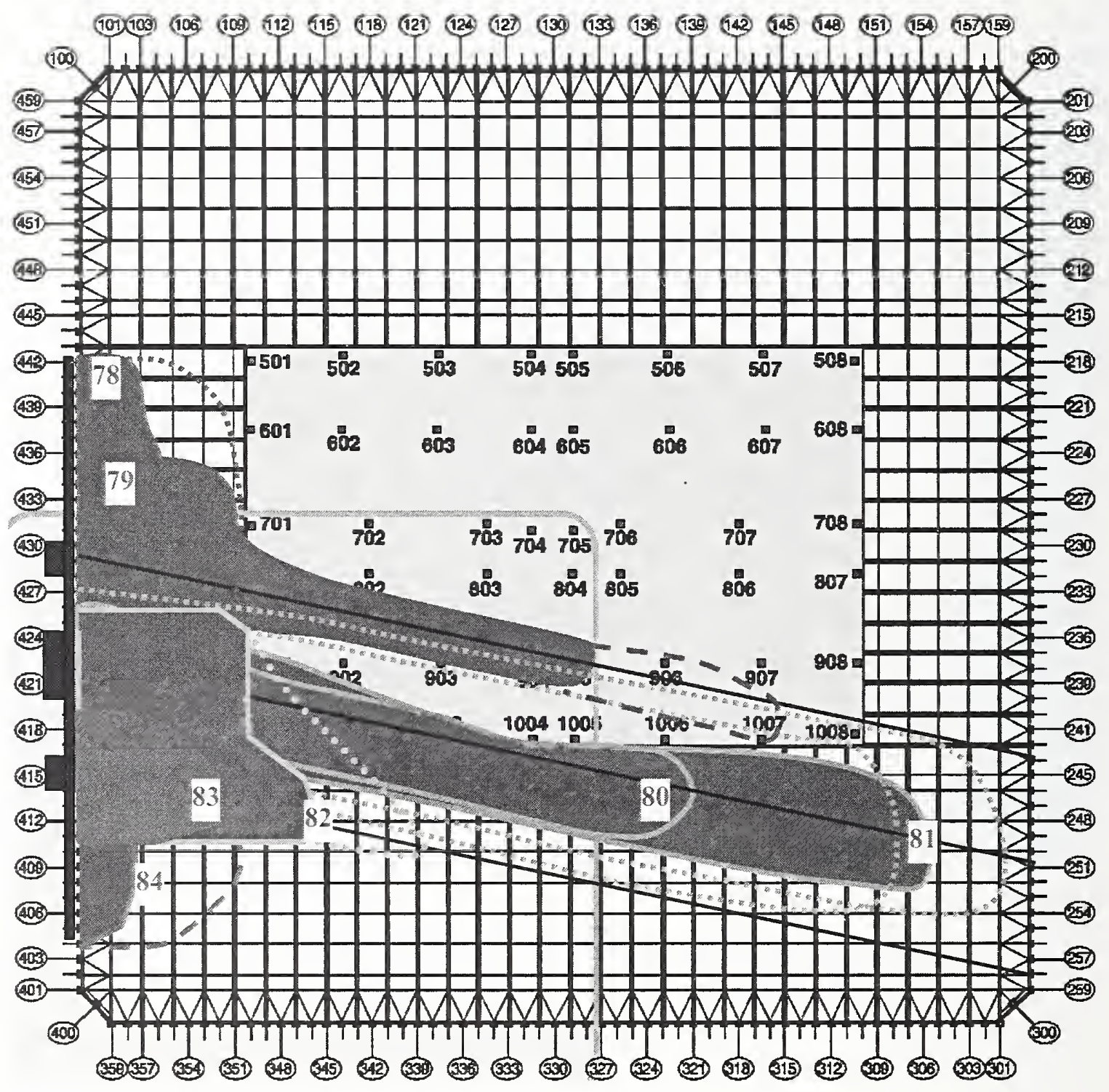

Source: Adapted from McAllister 2002.

Figure A-7. Preliminary damage estimates, all floors, WTC 2. 


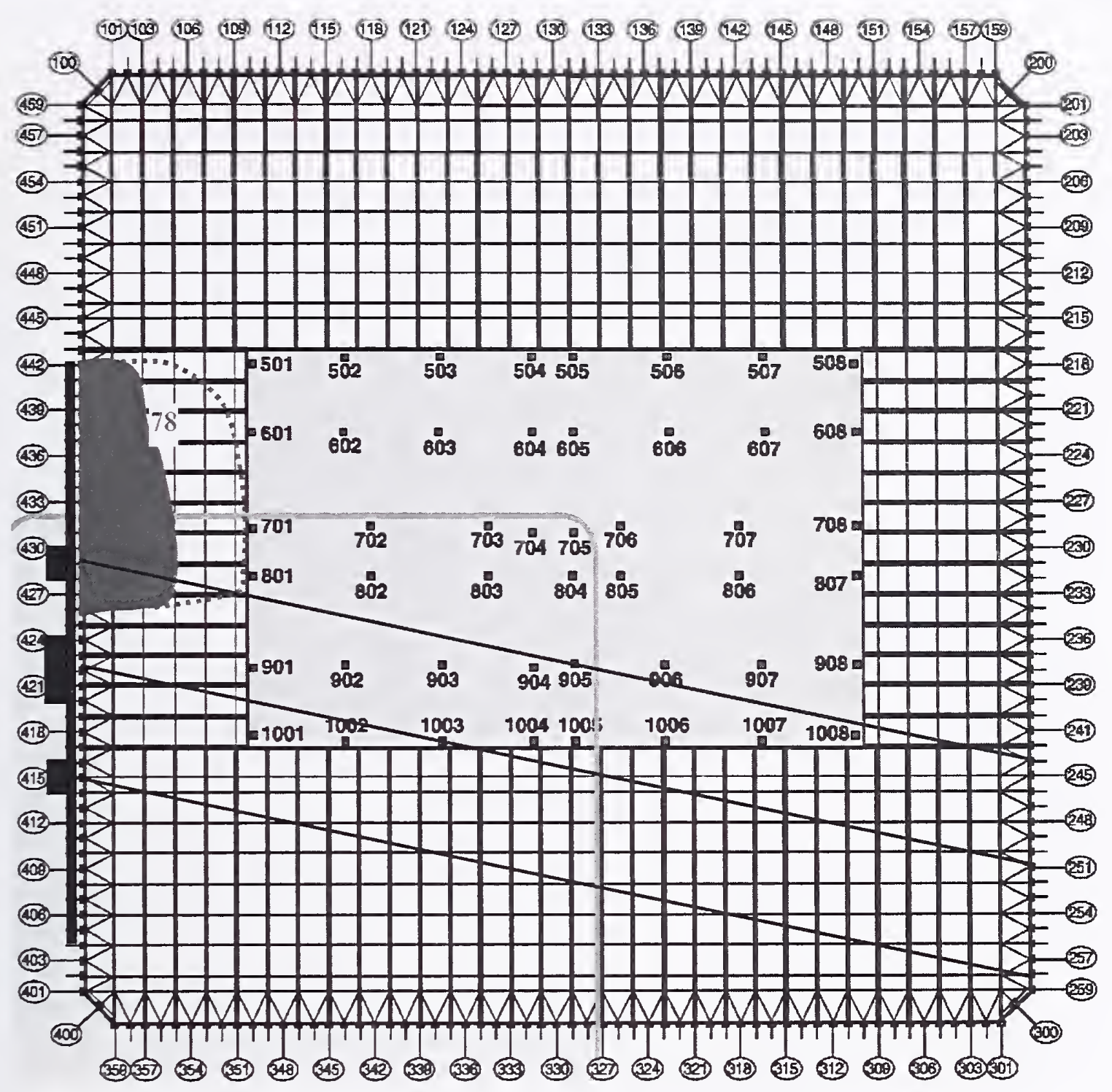

Source: Adapted from McAllister 2002.

Figure A-8. Preliminary damage estimates, 78th floor, WTC 2. 


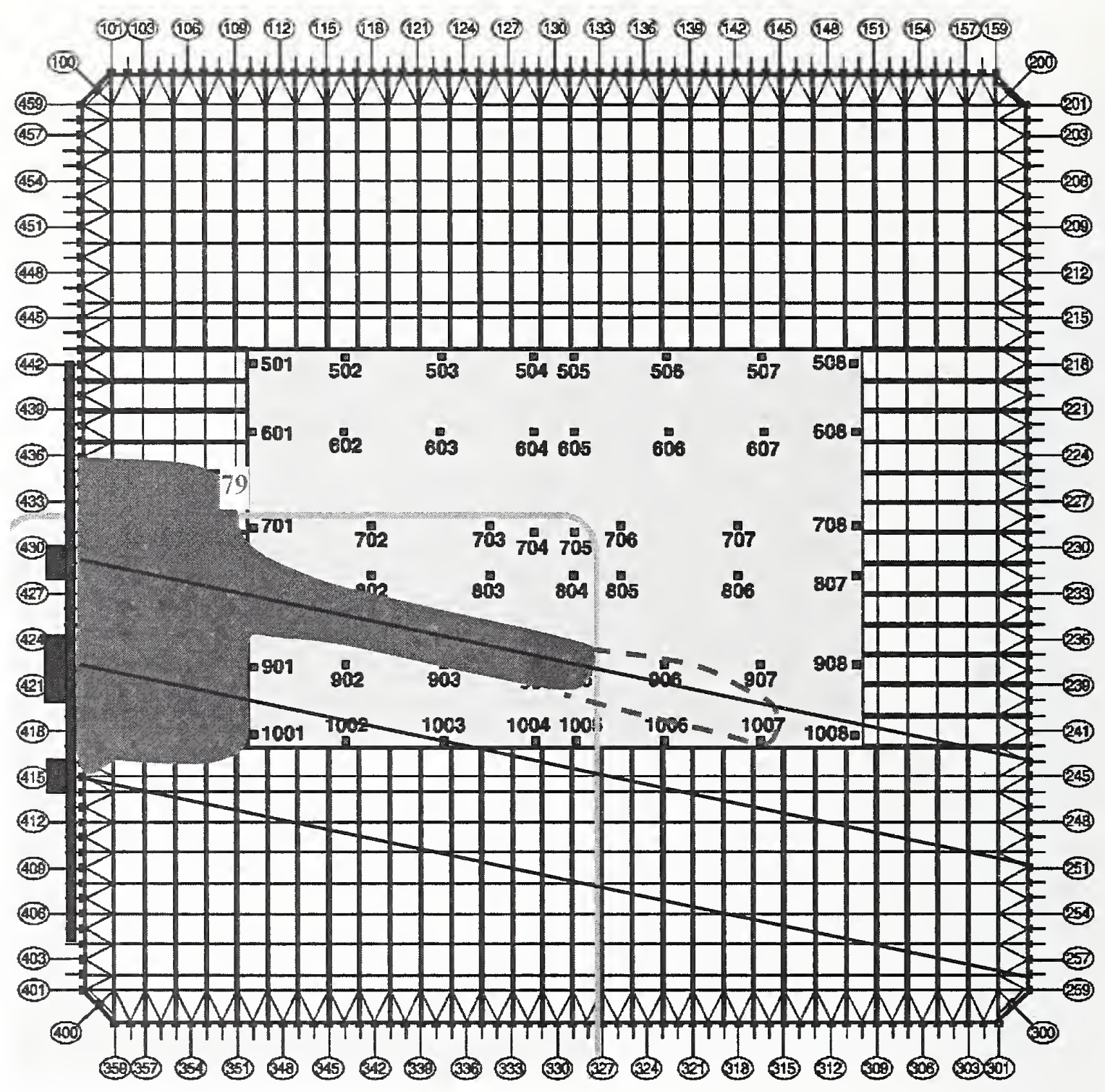

Source: Adapted from McAllister 2002.

Figure A-9. Preliminary damage estimates, 79th floor, WTC 2. 


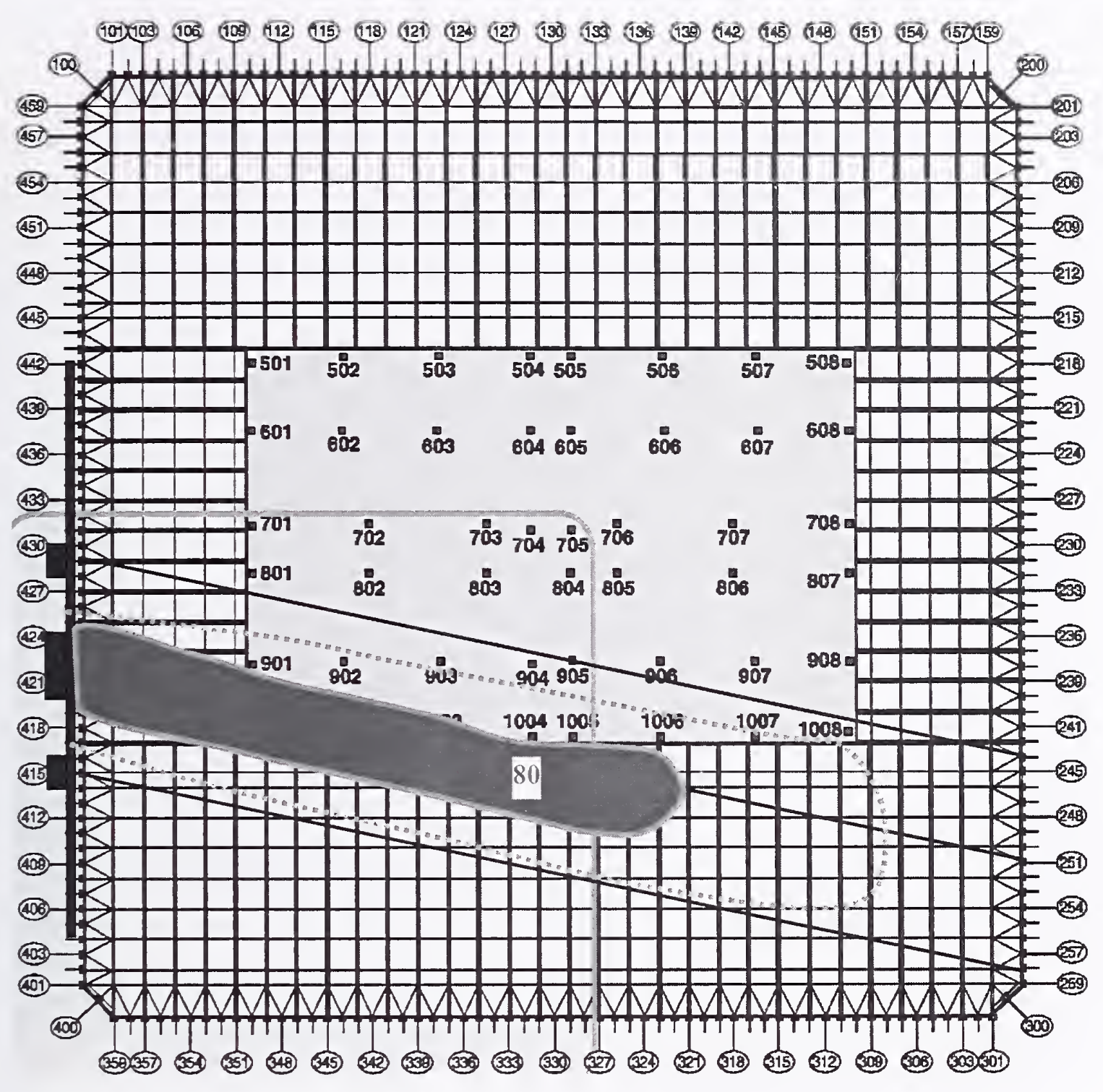

Source: Adapted from McAllister 2002.

Figure A-10. Preliminary damage estimates, 80th floor, WTC 2. 


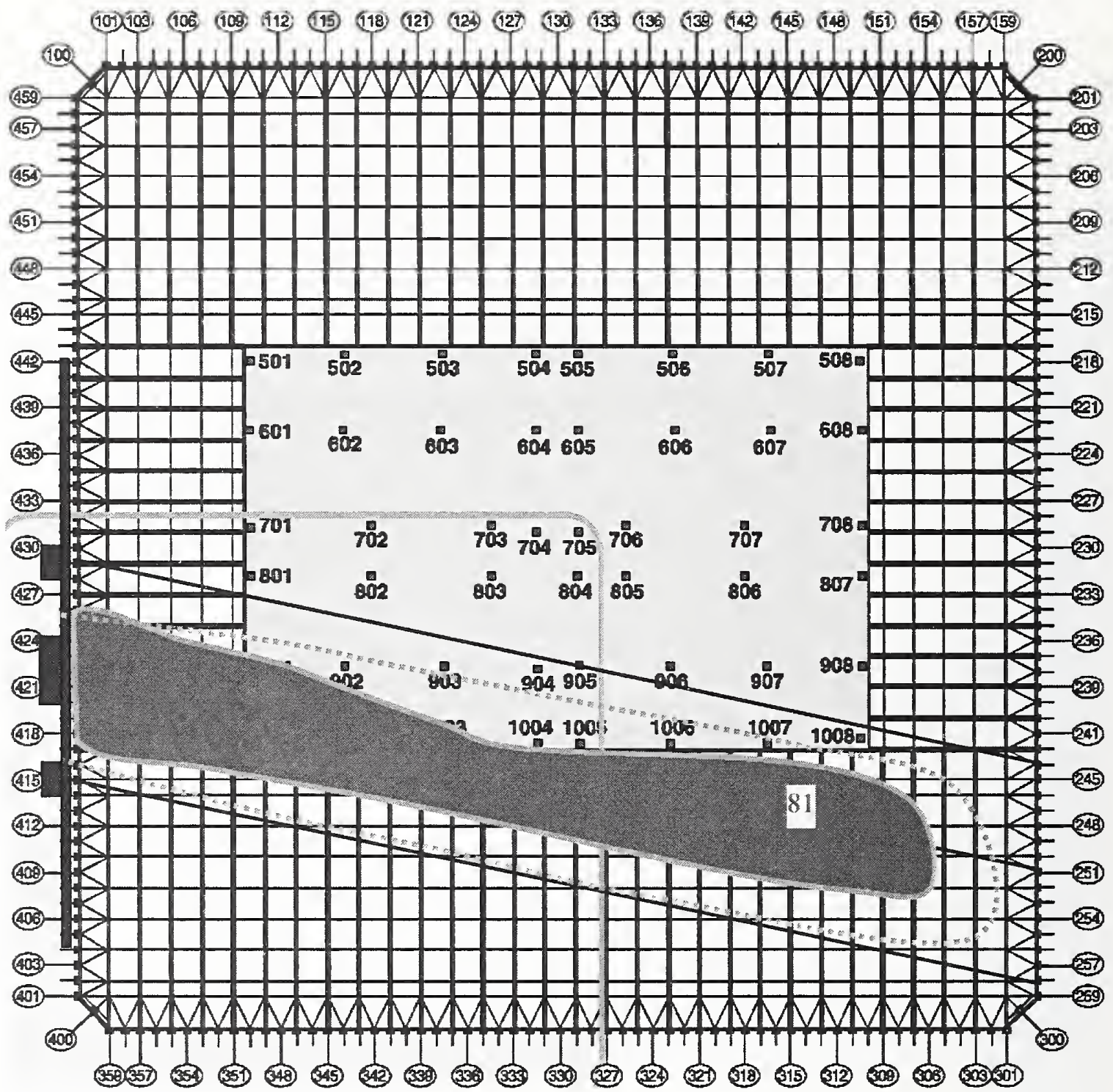

Source: Adapted from McAllister 2002.

Figure A-11. Preliminary damage estimates, 81st floor, WTC 2. 


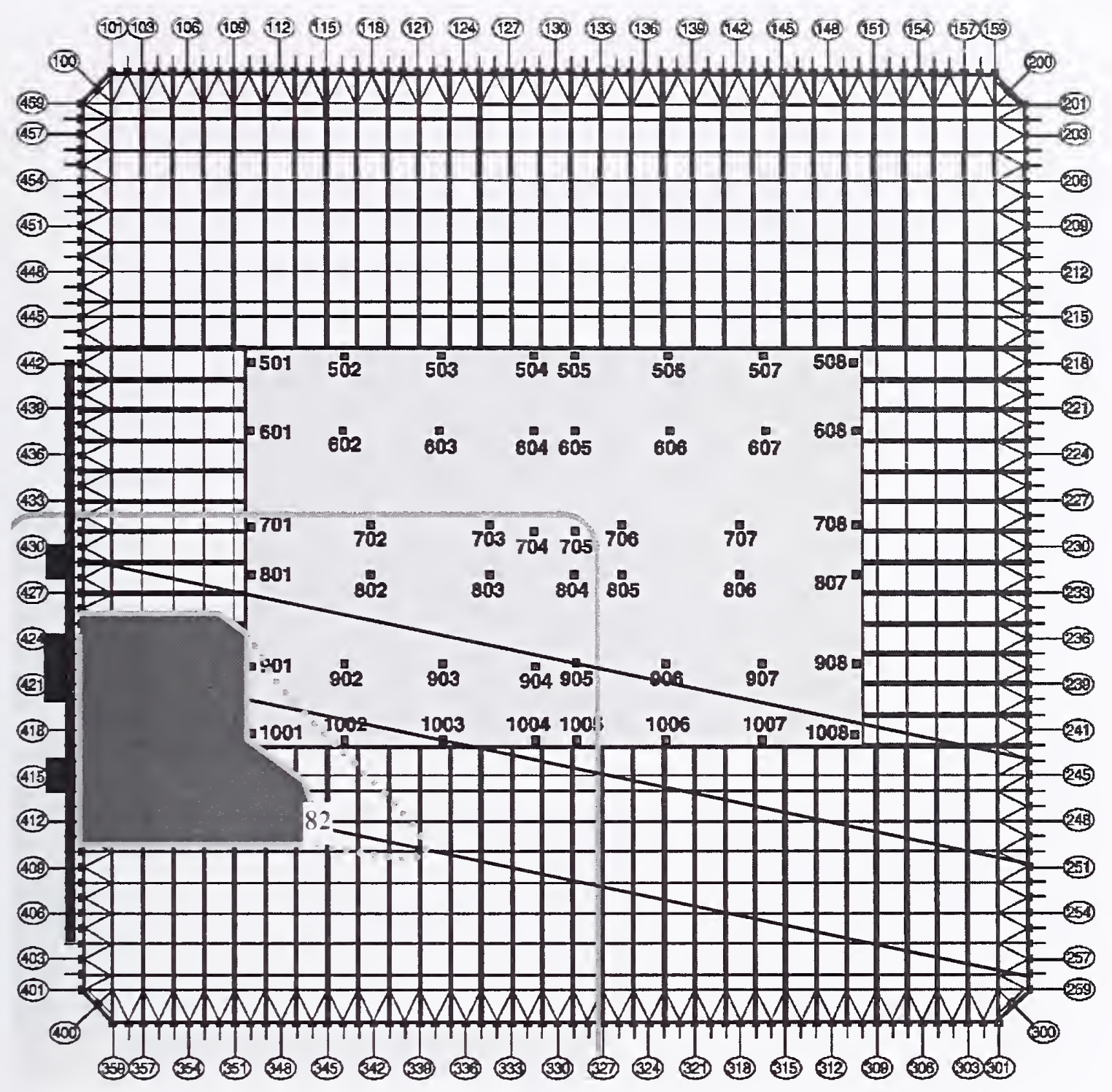

Source: Adapted from McAllister 2002.

Figure A-12. Preliminary damage estimates, 82nd floor, WTC 2. 


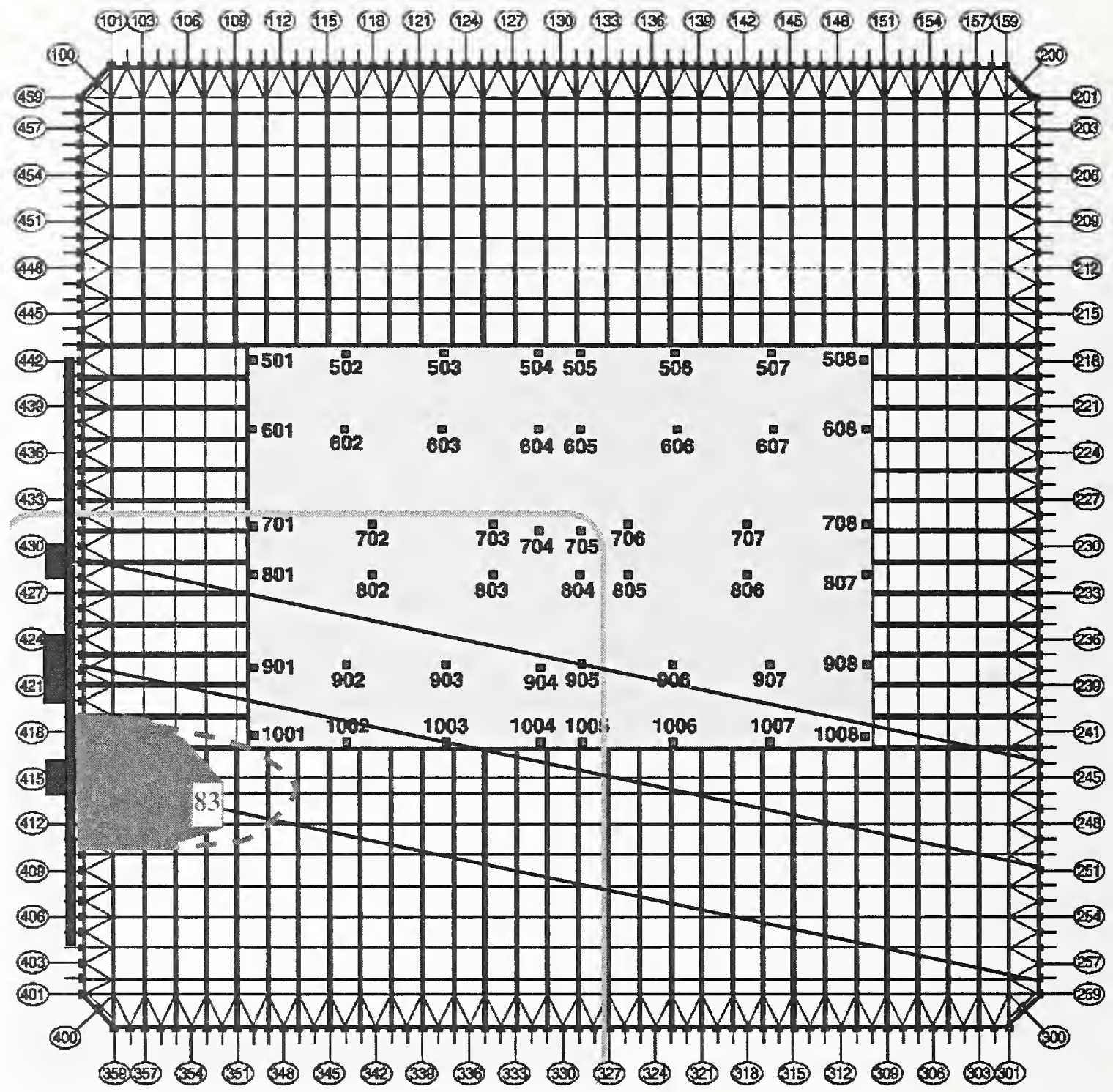

Source: Adapted from McAllister 2002.

Figure A-13. Preliminary damage estimates, 83rd floor, WTC 2. 


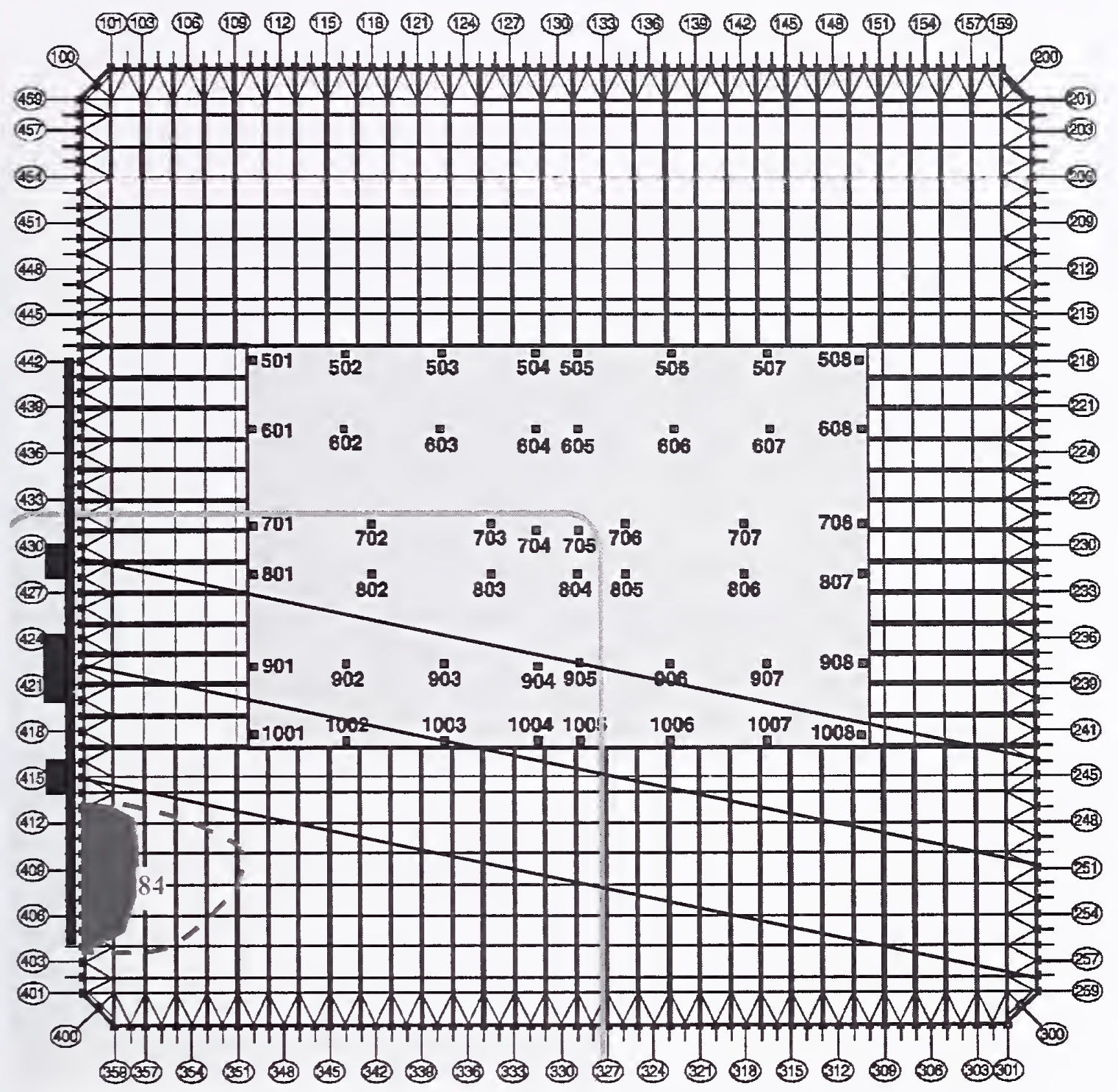

Source: Adapted from McAllister 2002.

Figure A-14. Preliminary damage estimates, 84th floor, WTC 2. 
This page intentionally left blank. 


\section{Appendix B \\ CONTAM MODEL CONSTRUCTION}

As discussed in Chapter 8 of this report. the CONTAM building airflow and contaminant dispersal model was used to evaluate the performance of candidate smoke management system approaches for various fire scenarios postulated for World Trade Center (WTC) 1 and 2.

A model of WTC 1 was constructed using a baseline computer model created to support the analysis included in the 1996 Hughes Associates Incorporated (HAI)/Dillon Consulting Engineers (DCE) study. This model was utilized to evaluate scenarios in both WTC 1 and WTC 2 due to the similarity between the two buildings. Individual damage models were constructed simulating the effect of the aircraft impacts into the two buildings on September 11, 2001.

Only WTC 1 was included in the model. Other buildings in the WTC complex wcre not modeled. As a result, simulations that evaluate the impact of stack effect on smoke management system performance do not consider the impact of the other buildings in the complex on the magnitude of the stack effect in a single tower or the position of the neutral plane in the building.

This appendix summarizes the inputs included in the 1996 model, and the changes that werc madc to thc model to perform the analysis included in this report.

\section{B.1 1996 WTC CONTAM MODEL}

The 1996 WTC CONTAM model was used as a starting point for the construction of the 2004 WTC CONTAM model. The physical dimensions, geographical relationship of the spaces, airflow paths, and the heating, ventilating, and air conditioning (HVAC) setup used in the 1996 WTC CONTAM modcl are discussed in the 1996 study report (HAI and DCE 1996).

The network model CONTAM 96 (Walton 1997), a DOS-based precursor to the CONTAC 2.0 model, was used to analyze the movement of smoke in the WTC complex. The CONTAM 96 model is an interactive network model designed for analyzing air movement and air quality in multi-zonc buildings. The equations are derived from Bernoulli's equation for airflow and conservation equations for the spread of contaminants. Further discussion of the theory behind the CONTAM model is discusscd in Chaptcr 8 of this report.

\section{B.1.1 CONTAM SketchPad and Building Zones}

CONTAM 96 and CONTAM 2.0 provide a SketchPad feature that can be uscd to cstablish the geomctric relationships of building spaces and openings. The SketchPad is not intended to produce a scale drawing of the building, but rather to provide a spatial representation of the relative locations of zones and flow paths. Zones only need to be constructed in order to have the proper interconnections between them. The shape and size of the zoncs as drawn are not important. 
A zone, as defined in the CONTAM model, represents a volume of air with uniform temperature and contaminant concentration. Thus, individual geometric peculiarities are not important. Figure B-1 provides an illustration of the 95th floor of WTC 1 and the corresponding CONTAM SketchPad representation of that floor, highlighting the major types of zones within the building including, Stairs 1 through 3, local stairs, freight elevator 50, convenience stairs, local elevators, express elevators, HVAC shafts, and electrical closets.

Because each tower has a large number of shafts and flow paths, it proved easiest to sketch the layout of each level by exaggerating the size of the shafts and other vertical openings, and shrinking the size of the tenant (interior) space, so that all flow elements could be shown on the SketchPad. This does not imply that any of the results are dependent on geometric features of the individual zones shown on the sketches. As far as the model is concerned, results will be identical for flow into a long corridor or square room, as long as the zone volume and temperature and other openings into the zone remain constant.

One hundred and sixteen levels were used in the construction of the tower model, including levels B-6 through floor 110. The base model contained more than 3,200 discrete zones and more than 14,000 flow paths between various zones. Each zone is given a zone name that, when tied to the floor level, gives it a discrete identification from every other zone in the model. A naming convention was used to facilitate record keeping, and is shown in Table B-1. 


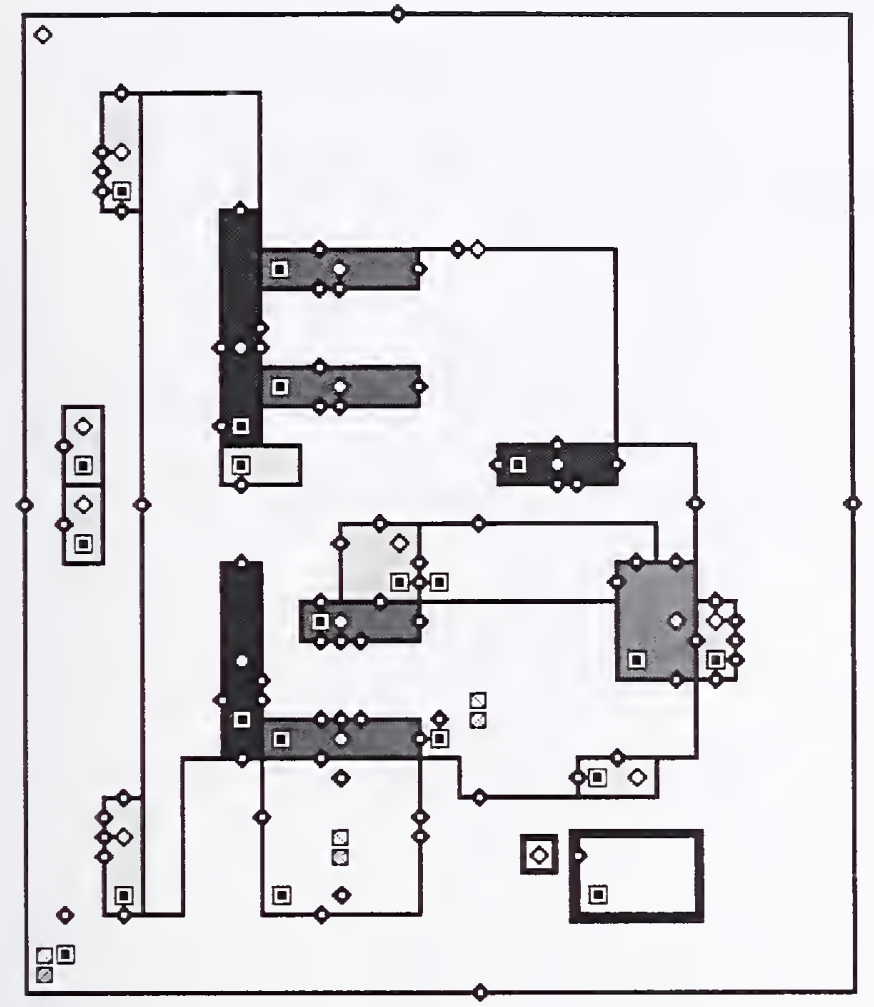

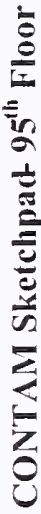

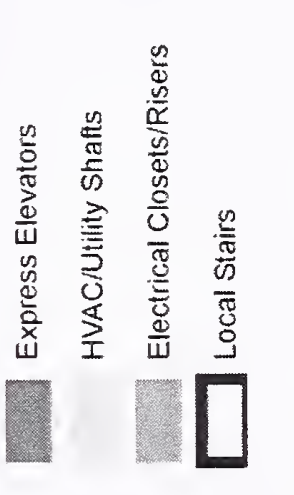

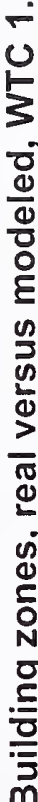

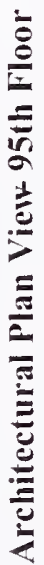
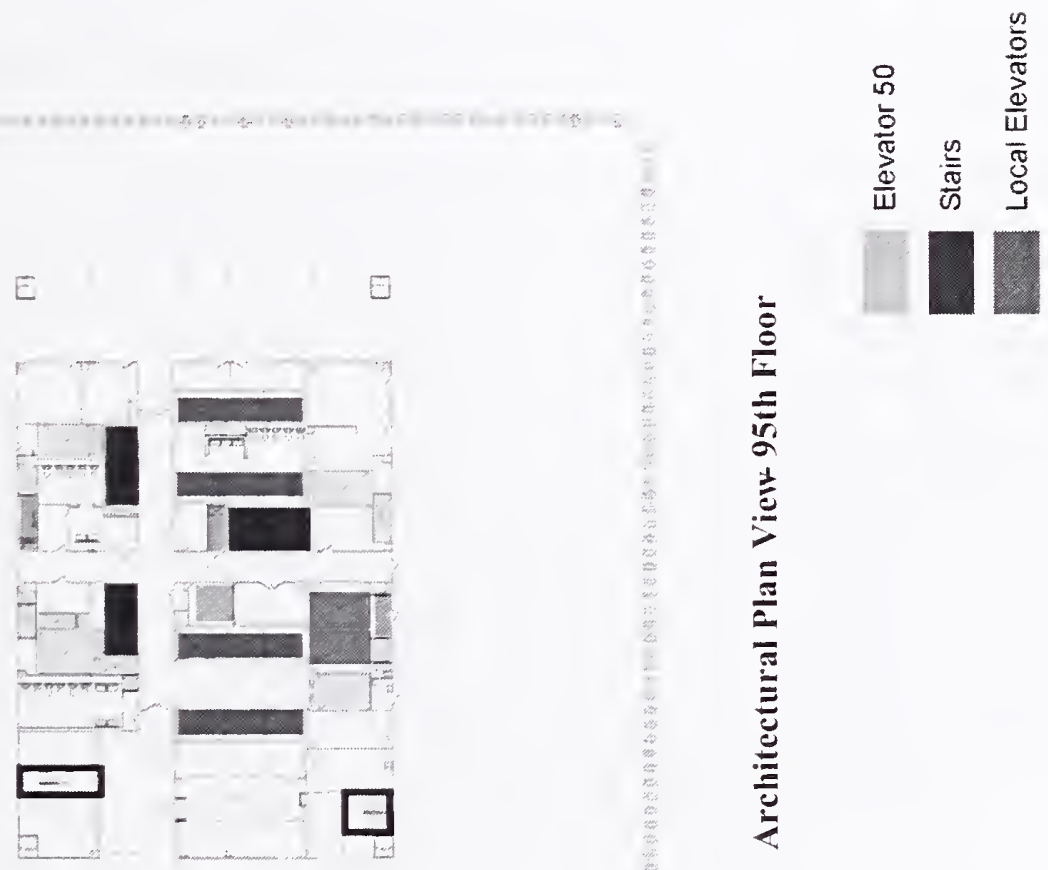

亩 
Table B-1. Tower model zone naming convention.

\begin{tabular}{|c|c|c|c|c|}
\hline $\begin{array}{c}\text { Zone } \\
\text { Designation }\end{array}$ & $x$ (Number) & $y$ (Number) & $w$ (Letter) & Description \\
\hline $80 \mathrm{E} x$ & ID Number & $\mathrm{NA}$ & NA & Elevator Machine Room \\
\hline AIRw & NA & NA & Special ID & Loading Dock Air Lock Entrances \\
\hline ATR & NA & NA & NA & Atrium Space \\
\hline CORE & NA & NA & $\mathrm{NA}$ & Core Space \\
\hline DOC & NA & NA & NA & Loading Dock Space \\
\hline ELCL & NA & NA & NA & Building Services Space Adjacent to Elevators \\
\hline FxM & Car Number & NA & NA & Elevator Machine Room \\
\hline$F x V$ & Car Number & NA & NA & Elevator Machine Room Exit Vestibule \\
\hline $\mathrm{MECH}$ & NA & NA & NA & Mechanical Room \\
\hline OS & NA & NA & $\mathrm{NA}$ & Occupant Space, Tenant Area \\
\hline PARK & NA & $\mathrm{NA}$ & $\mathrm{NA}$ & Parking Garage Space \\
\hline PExM & NA & NA & NA & Elevator Machine Room Vestibule \\
\hline $\mathrm{P} x \mathrm{M}$ & NA & NA & NA & Elevator Machine Room \\
\hline SRVC & NA & NA & NA & Misc. Service Area \\
\hline STJ4 & NA & NA & NA & Stair $\mathbf{J}-4$ \\
\hline SV1 & NA & NA & $\mathrm{NA}$ & Service Elevator Lobby \\
\hline SVJ4 & NA & NA & $\mathrm{NA}$ & Exit Vestibule for Stair $\mathbf{J}-4$ \\
\hline SVx & ID Number & NA & NA & Stair Vestibules in Basement \\
\hline $\mathrm{TX} 1$ & NA & NA & NA & Duct Reserved for Toilet Exhaust from Core Space \\
\hline$x \mathrm{D} y$ & Tower Number & ID Number & NA & Duct Space \\
\hline$x \mathrm{E}$ & Floor Number & NA & NA & Elevator Machine Room \\
\hline$x \mathrm{EM}$ & Floor Number & NA & NA & Elevator Machine Room \\
\hline$x F y$ & Tower Number & Car Number & NA & Freight Elevator \\
\hline$x \mathrm{M}$ & Floor Number & NA & NA & Elevator Machine Room \\
\hline$x \mathrm{Py}$ & Tower Number & Car Number & NA & Passenger Elevator \\
\hline$x \mathrm{~S} y$ & Tower Number & Stair Number & NA & Stairway \\
\hline$x \mathrm{Sy} y$ & Tower Number & Stair Number & NA & Stair Exit Vestibule \\
\hline$x$ Syw & Tower Number & Stair Number & ID Letter & Special Stair Section, i.e., Crossovers, Hallways, etc \\
\hline$Z x-C$ & Zone Number & NA & NA & Reserved Zoned Duct Space for Core \\
\hline $\mathrm{Zx}-\mathrm{R}$ & Zone Number & NA & NA & Reserved Zoned Duct Space for OS Returns \\
\hline$Z x-S$ & Zone Number & $\mathrm{NA}$ & $\mathrm{NA}$ & Reserved Zoned Duct Space for OS Supply \\
\hline
\end{tabular}




\section{B.1.2 Openings and Leakage Paths}

Large openings were modeled as ASCOS openings in the model. These openings follow a simple power law opening relationship (Klote and Milke 1992):

$$
\mathrm{Q}=\mathrm{K}_{0} \mathrm{CA} \sqrt{\frac{2 \Delta \mathrm{P}}{\rho}}
$$

where:

$$
\begin{aligned}
& Q=\text { volumetric flow rate }\left(\mathrm{ft}^{3} / \mathrm{min}\right) \\
& C=\text { dimensionless flow coefficient }(0.6) \\
& A=\text { flow area (leakage area) }\left(\mathrm{ft}^{2}\right) \\
& \Delta P=\text { pressure difference, in } \mathrm{m} . \mathrm{g} . \\
& \rho=\text { density of air }\left(0.075 \mathrm{lb} / \mathrm{ft}^{3}\right) \\
& K_{0}=\text { unit conversion factor }(776)
\end{aligned}
$$

A number of smaller openings were also included in the model. These consisted of elevators, stairs, doors, walls, and floor leakages. Both elevators and stairs were modeled as ASCOS openings, governed by equation 1. Flow though smaller leakage areas was modeled using the power law equation:

$$
\mathrm{Q}=c(\Delta \mathrm{p})^{\mathrm{n}}
$$

In this equation, $\Delta p$ is the pressure difference across the opening in in. of $\mathrm{H}_{2} \mathrm{O}$, and $\boldsymbol{Q}$ is the mass flow across the opening in $\mathrm{ft}^{3} / \mathrm{min}$, and $\mathrm{n}$ is the power law exponent. The value of $c$, the flow coefficient, is determined using the following equation:

$$
c=K_{0} C_{D} L\left(\frac{2}{\rho}\right)^{0.5}\left(\Delta p_{r}\right)^{0.5-n}
$$

where:

$$
\begin{aligned}
& c=\text { flow coefficient } \\
& n=\text { power law exponent } \\
& \Delta p_{r}=\text { reference pressure at which leakage factor was determined }\left(\mathrm{in} . \mathrm{H}_{2} \mathrm{O}\right) \\
& K_{\theta}=\text { unit of conversion factor }(776) \\
& A=\text { density of air }\left(0.075 \mathrm{lb} / \mathrm{ft}^{3}\right)
\end{aligned}
$$




$$
\begin{aligned}
& \boldsymbol{L}=\text { leakage area determined at reference pressure }\left(\mathrm{ft}^{2}\right) \\
& C_{D}=\text { discharge coefficient }
\end{aligned}
$$

In order for CONTAM to calculate flow through an opening using the "leakage area" approach, a flow coefficient, reference pressure difference, and power law exponent are required to be input for each opening type. For different types of openings, the values listed in Table B-2 were used.

Table B-2. Leakage area parameters.

\begin{tabular}{|l|l|c|c|c|}
\hline Opening Type & \multicolumn{1}{|c|}{ Size } & Coefficient & $\begin{array}{c}\text { Reference } \Delta \mathbf{P} \\
\text { (in. } \mathbf{H}_{2} \mathbf{O} \text { ) }\end{array}$ & Exponent \\
\hline Floor & $0.008 \mathrm{in}^{2} / \mathrm{ft}^{2}$ & 0.65 & 0.1 & 0.5 \\
\hline Exterior wall & $0.03 \mathrm{in}^{2} / \mathrm{ft}$ & 1.0 & 0.3 & 0.65 \\
\hline Interior wall & $2 \mathrm{in}^{2} / \mathrm{ft}$ & 0.65 & 0.3 & 0.5 \\
\hline Doorway & see Table B-3 & 0.65 & 0.3 & 0.5 \\
\hline Large opening & \multicolumn{1}{|c|}{-} & 0.82 & 0.3 & 0.5 \\
\hline
\end{tabular}

Entrances to openings can be characterized as intruding, flush, or well-rounded inlets. Exits can be characterized in the same manner. Entrance conditions can be characterized as either plenum or pipeflow, self-generated eddies caused by stagnation or separation can occur based on the angle of attack of the airflow. Virtually all of the opening areas in the WTC complex can be reasonably approximated by use of an orifice discharge coefficient, $C_{D}$, equal to 0.65 . This coefficient is well documented and applicable to virtually all of the flow conditions where the Reynolds number, Re, is fully turbulent, i.e., greater than 10,000 .

Some of the very large areas with very low velocities are not well characterized by this same $C_{D}$. In these instances, it is more appropriate to use values observed by F.C. Lea (Lea 1942) and those of Newell. These two works lead to the conclusion that for these conditions a number lying between 0.74 and 0.91 is more appropriate. Given that the experimental data reported has a spread of nearly 15 percent, the value of 0.82 was selected for $C_{D}$ to characterize these openings. The parameters for the various leakage paths in the model are shown in Table B-2. Leakage areas for the various doors in the model are shown in Table B-3. 
Table B-3. Door leakage areas.

\begin{tabular}{|l|c|c|c|}
\hline \multicolumn{1}{|c|}{ Description/Use } & Type & $\begin{array}{c}\text { Average } \\
\text { Measured } \\
\text { Leakage Area } \\
\left(\mathrm{ft}^{2}\right)\end{array}$ & $\begin{array}{c}\text { Corrected } \\
\text { Leakage Area } \\
\text { (ft }^{2} \text { ) }\end{array}$ \\
\hline $\begin{array}{l}\text { Side hinged single leaf door } \\
\text { (stairs. tenant space. etc.) }\end{array}$ & $\mathrm{A}$ & 0.1688 & 0.20 \\
\hline $\begin{array}{l}\text { Center parting double leaf doors (tenant space, } \\
\text { escalator cut-off, etc.) }\end{array}$ & $\mathrm{A}$ & 0.3376 & 0.081 \\
\hline $\begin{array}{l}\text { Center parting "single speed" elevator doors } \\
\text { (freight elevators) }\end{array}$ & $\mathrm{B}$ & 0.4017 & 0.4017 \\
\hline $\begin{array}{l}\text { Center parting "double speed" elevator doors } \\
\text { (freight elevators) }\end{array}$ & $\mathrm{C}$ & 0.7885 & 0.7885 \\
\hline $\begin{array}{l}\text { Center parting "single speed" elevator doors } \\
\text { (local passenger elevators) }\end{array}$ & $\mathrm{B}$ & 0.5673 & 1.00 \\
\hline $\begin{array}{l}\text { Center parting "double speed" elevator doors } \\
\text { (shuttle passenger elevators) }\end{array}$ & $\mathrm{C}$ & 1.2014 & 1.2014 \\
\hline Freight elevator door & $\mathrm{D}$ & 1.2500 & 1.25 \\
\hline Tenant doors & $\mathrm{A}$ & 0.3866 & 2.60 \\
\hline Elevator pit doors & $\mathrm{A}$ & 0.63 & 0.63 \\
\hline Mechanical room door & $\mathrm{A}$ & 1.00 & 1.00 \\
\hline Automatic closing dock door & & 1.00 & 1.00 \\
\hline Rolling steel dock doors & & $6 \mathrm{in}{ }^{2} / \mathrm{ft}^{2}$ & $6 \mathrm{in}^{2}{ }^{2} / \mathrm{ft}^{2}$ \\
\hline Rubber door at dock & & 1.00 & 1.00 \\
\hline
\end{tabular}

a. 1996 WTC model.

\section{B.1.3 1996 CONTAM HVAC System}

Air handling systems in the 1996 CONTAM model were simulated by using CONTAM's Simple Air Handling System feature. A simple air handling system consists of two implicit airflow nodes (supply and return), three implicit flow paths (recirculation, outdoor, and exhaust air), and multiple supply and return points, each with specified airflows, in the building zones. Outside air supply to a system is set either by definition, as a fixed percentage, by profile, or by calculation. If the sum of supply flows cxceeds the sum of return flows, the balance is made up from outside air. Excess rcturn flow is cxhausted. The modcl does not require that both supply and return points be defined for a system.

To facilitate the various scenarios and cases that were simulated, four simple air handling systems were constructed for each HVAC zone in the tower: Interior space supply, interior space return, core supply, and core return. (The perimeter and interior systems were combined into a single system in the model). Additional systems were constructed for the elevator machine room (EMR) exhausts, the mechanical equipment room (MER) exhausts, the sub-grade transfer fans, and the garage and truck dock systems.

Supply and return points for each system were added to the appropriate zones in the model. The flow for each point was derived from a careful study of the HVAC plans for the building. The fan schedules and riser diagrams were reviewed, and the supply and return flow for each zone was determined. To simulate actual operating efficiency (based on building engineer estimates), the simulations were conducted using 
85 percent of the design flow to each floor. Tables B-4a through B-4e show the HVAC flows used in the WTC 1 model.

Table B-4a. HVAC system flows in tower model.

\begin{tabular}{|c|c|c|c|}
\hline Fan & Service & Schedule Flow & $\begin{array}{c}\text { Design Flow } \\
\text { (85\% of Schedule) }\end{array}$ \\
\hline \multicolumn{4}{|c|}{ Supplies to Sub-Grade } \\
\hline VS-S5-3 & MER Ventilation & 30,030 & 25,526 \\
\hline VS-S5-7 & MER Ventilation & 38.200 & 32,470 \\
\hline \multicolumn{4}{|c|}{ Supplies to B-1-B-6 } \\
\hline \multirow[t]{4}{*}{ ACS-S5-1 } & B-1 & 6,100 & 5,185 \\
\hline & B-2 & 5,015 & 4,263 \\
\hline & B-2 & 5,470 & 4,650 \\
\hline & Fan Total & 19,340 & 16,439 \\
\hline ACS-S5-2 & Electrical sub station on B-1 & 13,800 & 11,730 \\
\hline ACS-S5-3 & B-1 & 12,940 & 10,999 \\
\hline \multirow[t]{6}{*}{ ACS-S5-5 } & B-1 & 7,145 & 6,073 \\
\hline & B-1 & 2,400 & 2,040 \\
\hline & B-2 & 4,430 & 3,766 \\
\hline & B-2 & 3,340 & 2,839 \\
\hline & B-2 & 6,000 & 5,100 \\
\hline & Fan Total & 37,625 & 31,981 \\
\hline \multirow[t]{11}{*}{ VS-S5-4 } & Tenant Storage B-4 & 4,940 & 4,199 \\
\hline & Tenant Storage B-3 & 4,670 & 3,970 \\
\hline & Tenant Storage B-2 & 3,320 & 2,822 \\
\hline & Tenant Storage B-4 & 6,980 & 5,933 \\
\hline & Tenant Storage B-3 & 6,410 & 5,449 \\
\hline & Tenant Storage B-4 & 7,265 & 6,175 \\
\hline & Tenant Storage B-3 & 6,580 & 5,593 \\
\hline & Tenant Storage B-4 & 5,290 & 4,497 \\
\hline & Tenant Storage B-3 & 4,670 & 3,970 \\
\hline & Tenant Storage B-2 & 7,740 & 6.579 \\
\hline & Fan total & 49,720 & 42,262 \\
\hline
\end{tabular}


Table B-4b. HVAC system flows in tower model.

\begin{tabular}{|c|c|c|c|}
\hline Fan & Service & Schedule Flow & $\begin{array}{c}\text { Design Flow } \\
(85 \% \text { of Schedule })\end{array}$ \\
\hline \multirow[t]{3}{*}{ ACR-S5-1 } & B-1 & 5,875 & 4,994 \\
\hline & B-2 & 7,740 & 6,579 \\
\hline & Fan Total & 13.615 & 11.573 \\
\hline ACR-S5-2 & Electrical sub station on B-1 & 13.800 & 11,730 \\
\hline \multirow[t]{5}{*}{ ACR-S5-5 } & B-1 & 8,100 & 6,885 \\
\hline & B-1 & 5,500 & 4,675 \\
\hline & B-2 & 8.200 & 6,970 \\
\hline & B-2 & 3,400 & 2,890 \\
\hline & Fan Total & 26,185 & 22,257 \\
\hline \multicolumn{4}{|c|}{ MER Exhaust to Garage } \\
\hline E-S5-7 & To Garage on B-4 & 24,000 & 20,400 \\
\hline E-S5-8 & To Garage on B-4 & 44,000 & 37,400 \\
\hline \multicolumn{4}{|c|}{ Transfer Fans from Tower A to Garage } \\
\hline T-S3-1 & From B-4 thru north wall & 24.470 & 20.800 \\
\hline $\mathrm{T}-\mathrm{S} 2-1$ & From B-3 thru north wall & 7,000 & 5,950 \\
\hline $\mathrm{T}-\mathrm{S} 2-2$ & $\begin{array}{l}\text { From B-3 thru north wall on } \\
\text { B-4 }\end{array}$ & 14,910 & 12,674 \\
\hline T-Sl-1 & From B-2 thru north wall & 3,320 & 2,822 \\
\hline \multicolumn{4}{|c|}{ Garage Exhausts } \\
\hline E-S3-S3 & & 90,500 & 76,925 \\
\hline E-S2-S4 & & 92.000 & 78,200 \\
\hline E-S2-S5 & & 92,000 & 78,200 \\
\hline E-S1-S1 & & 90,500 & 76,925 \\
\hline E-S1-S2 & & 90,500 & 76,925 \\
\hline E-S1-S3 & & 90,500 & 76,925 \\
\hline E-S1-S4 & & 101,000 & 85,850 \\
\hline E-S1-S5 & & 101,000 & 85,850 \\
\hline E-S1-S6 & & 101,000 & 85,850 \\
\hline E-S1-S7 & & 101,000 & 85,850 \\
\hline
\end{tabular}


Table B-4c. HVAC system flows in tower model (100 percent).

\begin{tabular}{|c|c|c|c|c|c|c|c|c|}
\hline Floor & Core Supply & $\begin{array}{c}\text { Core } \\
\text { Return }\end{array}$ & $\begin{array}{l}\text { Interior } \\
\text { Supply }\end{array}$ & $\begin{array}{c}\text { Interior } \\
\text { Return }\end{array}$ & LMRS & LMRX & SMRS & SMRX \\
\hline B-4 & 55,630 & 68,000 & 0 & 0 & 0 & 0 & 0 & 0 \\
\hline B-3 & 28,794 & 28,765 & 0 & 0 & 0 & 0 & 0 & 0 \\
\hline $\mathrm{B}-2$ & 26,271 & 21,985 & 0 & 0 & 0 & 0 & 0 & 0 \\
\hline B-1 & 26.486 & 12.420 & 0 & 0 & 0 & 0 & 0 & 0 \\
\hline Service & 204,451 & 23,245 & 0 & 0 & 0 & 0 & 0 & 0 \\
\hline 1 & 8,200 & 2,500 & 219,000 & 200,100 & 0 & 0 & 0 & 0 \\
\hline 2 & 985 & 985 & 0 & 0 & 0 & 0 & 0 & 0 \\
\hline 3 & 3,820 & 3,880 & 0 & 0 & 0 & 0 & 0 & 0 \\
\hline 4 & 3,820 & 3,880 & 0 & 0 & 0 & 0 & 0 & 0 \\
\hline 5 & 3,880 & 3,880 & 0 & 0 & 0 & 0 & 0 & 0 \\
\hline 6 & 1,680 & 1,620 & 0 & 0 & 0 & 0 & 0 & 0 \\
\hline 9 & 2,140 & 1,785 & 26,060 & 23,320 & 0 & 0 & 0 & 0 \\
\hline 10 & 2,140 & 1,785 & 26,060 & 23,320 & 0 & 0 & 0 & 0 \\
\hline 11 & 2,140 & 1,785 & 26,060 & 23,320 & 0 & 0 & 0 & 0 \\
\hline 12 & 2,140 & 1,785 & 26,060 & 23,320 & 0 & 0 & 0 & 0 \\
\hline 13 & 2,140 & 1,785 & 26.060 & 23,320 & 0 & 0 & 0 & 0 \\
\hline 14 & 2,140 & 1,785 & 26,060 & 23,320 & 0 & 0 & 0 & 0 \\
\hline 15 & 2,140 & 1,785 & 26,060 & 23,320 & 0 & 0 & 0 & 0 \\
\hline 16 & 2,245 & 1.595 & 26,060 & 23,320 & 0 & 0 & 0 & 0 \\
\hline 17 & 2,000 & 1,675 & 26,060 & 23,320 & 4,530 & 4,530 & 0 & 0 \\
\hline 18 & 2,005 & 1,675 & 26,060 & 23,320 & 2,270 & 2,270 & 0 & 0 \\
\hline 19 & 2,380 & 1,785 & 26,060 & 23,755 & 0 & 0 & 0 & 0 \\
\hline 20 & 2,380 & 1,785 & 26,060 & 23,755 & 0 & 0 & 0 & 0 \\
\hline 21 & 2,130 & 1,785 & 26.560 & 23,425 & 0 & 0 & 0 & 0 \\
\hline 22 & 2,130 & 1,785 & 26,560 & 23,755 & 0 & 0 & 0 & 0 \\
\hline 23 & 2,130 & 1,785 & 26,560 & 23,755 & 0 & 0 & 0 & 0 \\
\hline 24 & 2.335 & 1,565 & 26.360 & 23,755 & 0 & 0 & 0 & 0 \\
\hline 25 & 2,105 & 1,565 & 26,365 & 23,585 & 5,930 & 5,930 & 0 & 0 \\
\hline 26 & 2,175 & 1,565 & 26,060 & 23,320 & 2,970 & 2,970 & 0 & 0 \\
\hline 27 & 1.855 & 1,565 & 27,500 & 24,570 & 0 & 0 & 0 & 0 \\
\hline 28 & 1,855 & 1,565 & 27,500 & 24,570 & 0 & 0 & 0 & 0 \\
\hline 29 & 1.855 & 1,565 & 27,500 & 24,570 & 0 & 0 & 0 & 0 \\
\hline 30 & 1,855 & 1,565 & 27,500 & 24,570 & 0 & 0 & 0 & 0 \\
\hline 31 & 1,855 & 1,565 & 27,500 & 24,570 & 0 & 0 & 0 & 0 \\
\hline 32 & 2,105 & 1,565 & 27,190 & 24,570 & 0 & 0 & 0 & 0 \\
\hline 33 & 1,855 & 1,565 & 27,190 & 24,300 & 6,670 & 6,670 & 0 & 0 \\
\hline 34 & 1,855 & 1,565 & 27,190 & 24,300 & 3,330 & 3,330 & 0 & 0 \\
\hline
\end{tabular}




\begin{tabular}{|l|c|c|c|c|c|c|c|c|}
\hline Floor & Core Supply & $\begin{array}{c}\text { Core } \\
\text { Return }\end{array}$ & $\begin{array}{c}\text { Interior } \\
\text { Supply }\end{array}$ & $\begin{array}{c}\text { Interior } \\
\text { Return }\end{array}$ & LMRS & LMRX & SMRS & SMRX \\
\hline 35 & 1,845 & 1,565 & 28,030 & 25,025 & 0 & 0 & 0 & 0 \\
\hline 36 & 1,845 & 1,565 & 28,030 & 25,025 & 0 & 0 & 0 & 0 \\
\hline 37 & 1,845 & 1,565 & 28,030 & 25,025 & 0 & 0 & 0 & 0 \\
\hline 38 & 1,845 & 1,565 & 28,030 & 25,025 & 0 & 0 & 0 & 0 \\
\hline 39 & 1,845 & 1,565 & 28,030 & 25,025 & 0 & 0 & 0 & 0 \\
\hline 40 & 12,950 & 12,350 & 24,945 & 21,661 & 0 & 0 & 0 & 0 \\
\hline 44 & 1,600 & 2,315 & 17,390 & 11,650 & 0 & 0 & 0 & 0 \\
\hline
\end{tabular}

Key: LMRS/X. Elevator Machine Room Supply/Exhaust; SMRS/X, Machine Room Supply/Exhaust. 
Table B-4d. HVAC system flows in tower model (100 percent).

\begin{tabular}{|c|c|c|c|c|c|c|c|c|}
\hline Floor & Core Supply & $\begin{array}{c}\text { Core } \\
\text { Return }\end{array}$ & $\begin{array}{l}\text { Interior } \\
\text { Supply }\end{array}$ & $\begin{array}{l}\text { Interior } \\
\text { Return }\end{array}$ & LMRS & LMRX & SMRS & SMRX \\
\hline 45 & 2,585 & 2,210 & 25,710 & 23,010 & 0 & 0 & 0 & 0 \\
\hline 46 & 2,830 & 1,785 & 25,710 & 23,010 & 0 & 0 & 0 & 0 \\
\hline 47 & 1,925 & 1,785 & 25,710 & 23,010 & 0 & 0 & 14,300 & 14,700 \\
\hline 48 & 2,100 & 1,785 & 25,500 & 22,830 & 0 & 0 & 0 & 0 \\
\hline 49 & 1,895 & 1,785 & 27,900 & 24,760 & 0 & 0 & 0 & 0 \\
\hline 50 & 1,895 & 1,785 & 27,900 & 24,920 & 0 & 0 & 0 & 0 \\
\hline 51 & 1,895 & 1,785 & 27,900 & 24,920 & 0 & 0 & 0 & 0 \\
\hline 52 & 1,895 & 1,785 & 27,900 & 24,920 & 0 & 0 & 0 & 0 \\
\hline 53 & 1,895 & 1,785 & 27,900 & 24,920 & 0 & 0 & 0 & 0 \\
\hline 54 & 2,130 & 1,785 & 27,900 & 24,920 & 0 & 0 & 0 & 0 \\
\hline 55 & 1,760 & 1,785 & 27,745 & 24,620 & 3,160 & 3,160 & 0 & 0 \\
\hline 56 & 1,760 & 1,785 & 27,745 & 24,620 & 1,590 & 1,590 & 0 & 0 \\
\hline 57 & 1,760 & 1,785 & 28,575 & 25,505 & 0 & 0 & 0 & 0 \\
\hline 58 & 1,760 & 1,785 & 28,575 & 25,505 & 0 & 0 & 0 & 0 \\
\hline 59 & 1,835 & 1,785 & 28,640 & 25,270 & 0 & 0 & 0 & 0 \\
\hline 60 & 1,670 & 1,785 & 28,315 & 25,280 & 0 & 0 & 0 & 0 \\
\hline 61 & 2,310 & 1,825 & 27,890 & 25,500 & 0 & 0 & 0 & 0 \\
\hline 62 & 1,765 & 1,785 & 28,225 & 25,200 & 4,430 & 4,430 & 0 & 0 \\
\hline 63 & 1,760 & 1,785 & 28,575 & 25,215 & 2,220 & 2,220 & 0 & 0 \\
\hline 64 & 1,665 & 1,565 & 29,290 & 26,130 & 0 & 0 & 0 & 0 \\
\hline 65 & 1,665 & 1,565 & 29,310 & 26,145 & 0 & 0 & 0 & 0 \\
\hline 66 & 1,665 & 1,565 & 29,175 & 26,145 & 0 & 0 & 0 & 0 \\
\hline 67 & 2,010 & 1,565 & 38,755 & 37,195 & 0 & 0 & 0 & 0 \\
\hline 68 & 1,580 & 1,565 & 28,910 & 25,760 & 4,750 & 4,750 & 0 & 0 \\
\hline 69 & 1,510 & 1,565 & 29.085 & 26.445 & 2,400 & 2,400 & 0 & 0 \\
\hline 70 & 1,525 & 1,565 & 29,905 & 26,660 & 0 & 0 & 0 & 0 \\
\hline 71 & 1,525 & 1,565 & 29,905 & 26,660 & 0 & 0 & 0 & 0 \\
\hline 72 & 1,525 & 1,565 & 29,800 & 26,570 & 0 & 0 & 0 & 0 \\
\hline 73 & 1,525 & 1,565 & 29,650 & 26,570 & 0 & 0 & 0 & 0 \\
\hline 74 & 1,525 & 1,565 & 24,005 & 26,240 & 0 & 0 & 0 & 0 \\
\hline 77 & 2,460 & 2,335 & 26,795 & 23,115 & 0 & 0 & 0 & 0 \\
\hline 78 & 6,350 & 1,320 & 37,040 & 32,660 & 0 & 0 & 0 & 0 \\
\hline 79 & 2,535 & 1,735 & 26,845 & 23,995 & 0 & 0 & 0 & 0 \\
\hline 80 & 2,470 & 1,735 & 27,125 & 24,240 & 0 & 0 & 0 & 0 \\
\hline 81 & 1,780 & 1,735 & 27,125 & 24,250 & 0 & 0 & 19,000 & 19,000 \\
\hline 82 & 2,205 & 1,785 & 26,915 & 24,060 & 0 & 0 & 0 & 0 \\
\hline 83 & 1,600 & 1,755 & 30,730 & 27,375 & 0 & 0 & 0 & 0 \\
\hline
\end{tabular}




\begin{tabular}{|l|c|c|c|c|c|c|c|c|}
\hline Floor & Core Supply & $\begin{array}{c}\text { Core } \\
\text { Return }\end{array}$ & $\begin{array}{c}\text { Interior } \\
\text { Supply }\end{array}$ & $\begin{array}{c}\text { Interior } \\
\text { Return }\end{array}$ & LMRS & LMRX & SMRS & SMRX \\
\hline 84 & 1,600 & 1,755 & 30,730 & 27,375 & 0 & 0 & 0 & 0 \\
\hline 85 & 1,600 & 1,755 & 30,730 & 27,375 & 0 & 0 & 0 & 0 \\
\hline 86 & 1,600 & 1,755 & 30,730 & 27,375 & 0 & 0 & 0 & 0 \\
\hline 87 & 1,605 & 1,755 & 30,385 & 26,845 & 3,160 & 3,160 & 0 & 0 \\
\hline
\end{tabular}

Key: LMRS/X, Elevator Machine Room Supply/Exhaust; SMRS/X, Machine Room Supply/Exhaust. 
Table B-4e. HVAC system flows in tower model (100 percent).

\begin{tabular}{|c|c|c|c|c|c|c|c|c|}
\hline Floor & Core Supply & $\begin{array}{c}\text { Core } \\
\text { Return }\end{array}$ & $\begin{array}{l}\text { Interior } \\
\text { Supply }\end{array}$ & $\begin{array}{l}\text { Interior } \\
\text { Return }\end{array}$ & LMRS & LMRX & SMRS & SMRX \\
\hline 88 & 1,605 & 1,755 & 30,365 & 26,825 & 1,590 & 1,590 & 0 & 0 \\
\hline 89 & 1,605 & 1,755 & 31,300 & 27,870 & 0 & 0 & 0 & 0 \\
\hline 90 & 1,605 & 1,755 & 31,300 & 27,870 & 0 & 0 & 0 & 0 \\
\hline 91 & 1,605 & 1,755 & 31,300 & 27,872 & 0 & 0 & 0 & 0 \\
\hline 92 & 1,605 & 1,655 & 31,300 & 27,870 & 0 & 0 & 0 & 0 \\
\hline 93 & 1.575 & 1.585 & 31,300 & 27,870 & 0 & 0 & 0 & 0 \\
\hline 94 & 1,445 & 1,585 & 30,525 & 27,270 & 4,430 & 4,430 & 0 & 0 \\
\hline 95 & 1,445 & 1,585 & 30,525 & 26,995 & 2,220 & 2,220 & 0 & 0 \\
\hline 96 & 1,445 & 1,585 & 31,275 & 27,850 & 0 & 0 & 0 & 0 \\
\hline 97 & 1,445 & 1.585 & 31,275 & 27,850 & 0 & 0 & 0 & 0 \\
\hline 98 & 1,445 & 1,585 & 31,275 & 27,850 & 0 & 0 & 0 & 0 \\
\hline 99 & 1,445 & 1,685 & 31,275 & 27,850 & 0 & 0 & 0 & 0 \\
\hline 100 & 1,665 & 1,685 & 31,275 & 27,850 & 0 & 0 & 0 & 0 \\
\hline 101 & 1,555 & 1,685 & 31,275 & 27,850 & 4,750 & 4,750 & 0 & 0 \\
\hline 102 & 1,555 & 1,685 & 31.275 & 27,850 & 2,400 & 2,400 & 0 & 0 \\
\hline 103 & 1,465 & 1,765 & 31.500 & 28,145 & 0 & 0 & 0 & 0 \\
\hline 104 & 1,465 & 1,765 & 29,585 & 25,335 & 0 & 0 & 0 & 0 \\
\hline 105 & 1.465 & 1,685 & 28.215 & 28,065 & 0 & 0 & 0 & 0 \\
\hline 106 & 1,640 & 1,825 & 34,011 & 30,513 & 0 & 0 & 0 & 0 \\
\hline 107 & 0 & 0 & 5.250 & 0 & 0 & 0 & 0 & 0 \\
\hline 110 & 5,000 & 5,000 & 0 & 0 & 0 & 0 & 14,000 & 14,000 \\
\hline
\end{tabular}

Key: LMRS/X, Elevator Machine Room Supply/Exhaust; SMRS/X, Machine Room Supply/Exhaust.

\section{B.1.4 1996 Site Survey and Physical Testing}

As part of the 1996 study, a site survey and physical testing of the WTC complex was conducted. The site survey was performed on June 28-July 2, 1996 with a follow up visit on July 23, 1996. The physical testing was conducted on June 30, between 1:00 a.m. and 3:00 p.m. Temperatures early in the morning were nominally $60^{\circ} \mathrm{F} \pm 5^{\circ} \mathrm{F}$, and the wind was fairly constant at $2 \mathrm{mph}$ (HAI and DCE 1996). The National Oceanic and Atmospheric Administration reported a New York City temperature range of $60^{\circ} \mathrm{F}-75^{\circ} \mathrm{F}$ on June $30,1996$.

The purpose of the testing that was conducted was to determine the performance of the building's air movement pathways as well as the various barriers to air movement. Pressure measurements were taken at various locations through the building under various HVAC modes. The HVAC modes included:

- Mode 1-All fans on

- Mode 2-Fans set on summer normal 
- Mode 3-Fans set for core pressurization for the full height of WTC 1

- Mode 4-Floors 59 through 91 set on core pressurization and all other floors set on 100 percent purge

Site survey pressure measurement results, for HVAC Modes 1 through 4, are listed in Tables B-5 through B-8.

Measurements of the leakage areas of several types of door assemblies were also taken during the site survey. Survey measurements are presented in two tables:

1. Table B-9 is the raw data recorded during the site survey.

2. Table B-10 is the adjusted data with outlying measurements discarded.

Table B-11 lists the adjusted average leakage areas proposed to be used for the various types of leakage paths by the $1996 \mathrm{HAI} / \mathrm{DCE}$ study (HAI and DCE 1996). 

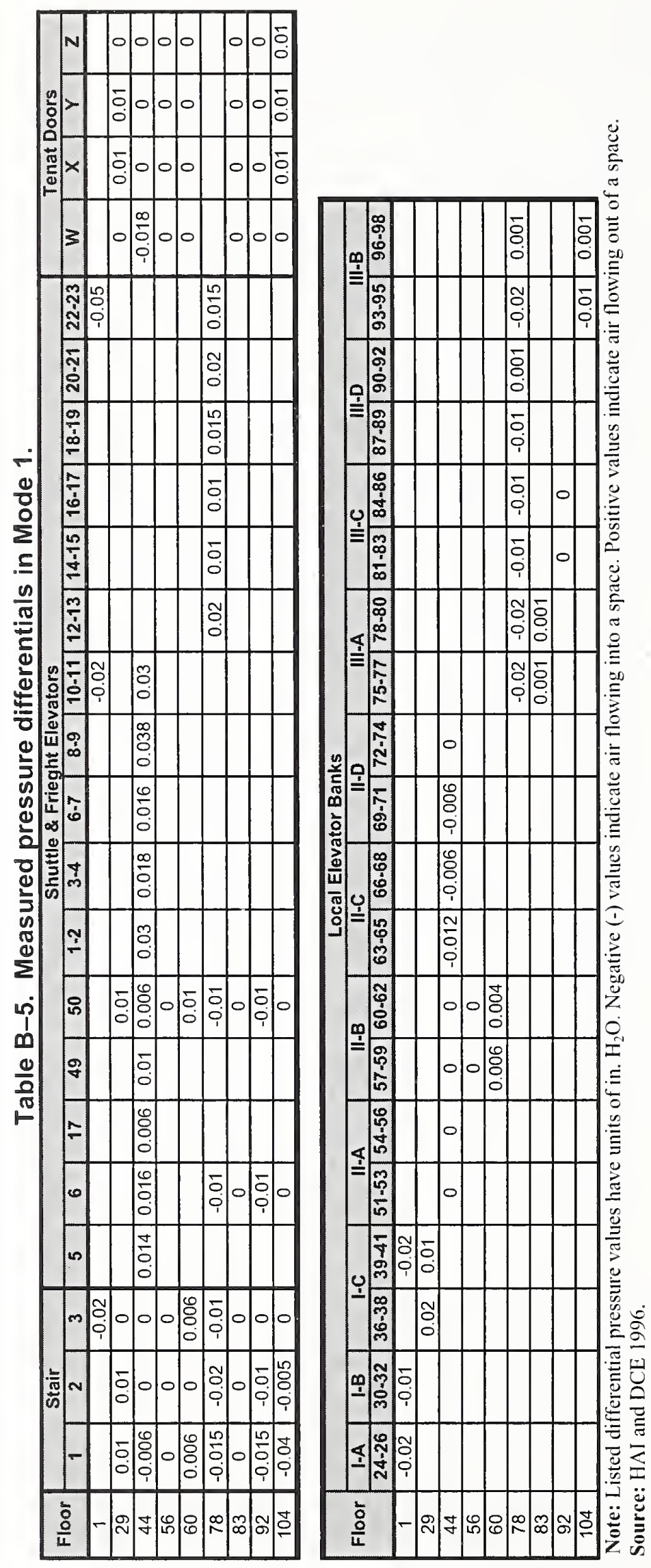


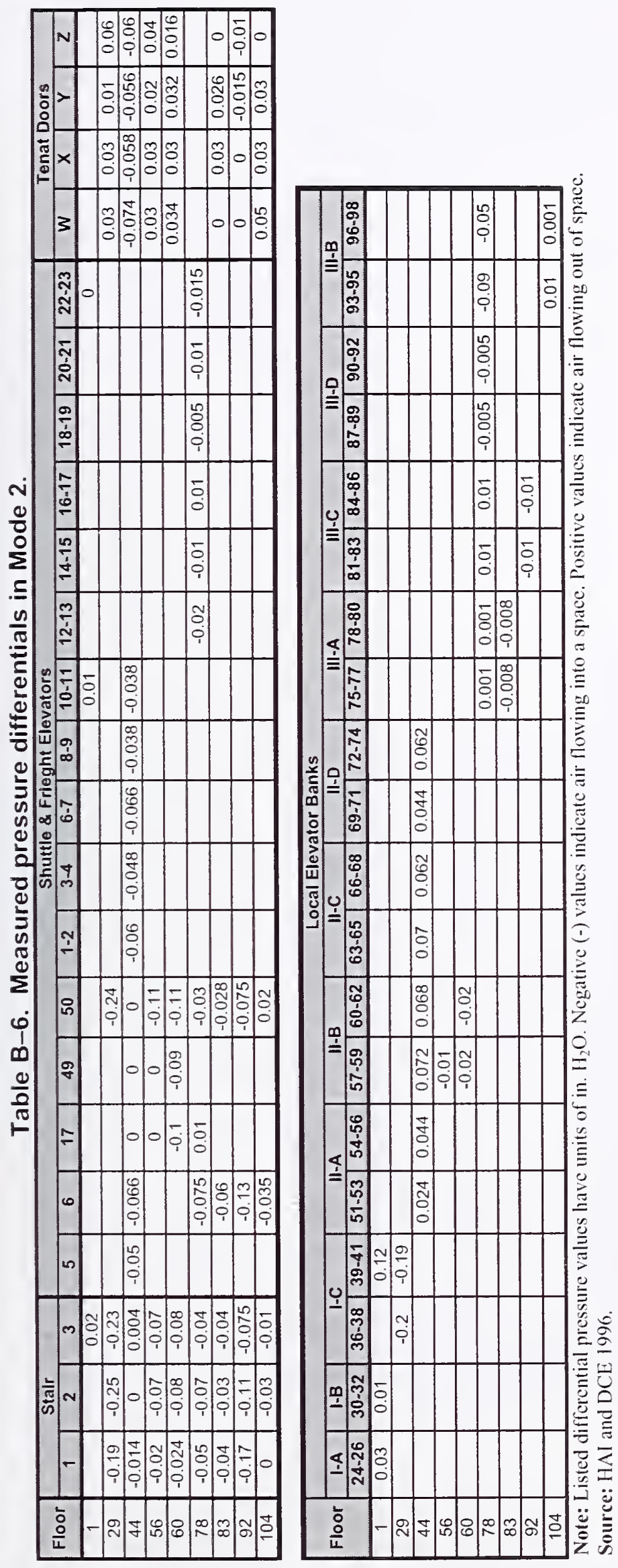



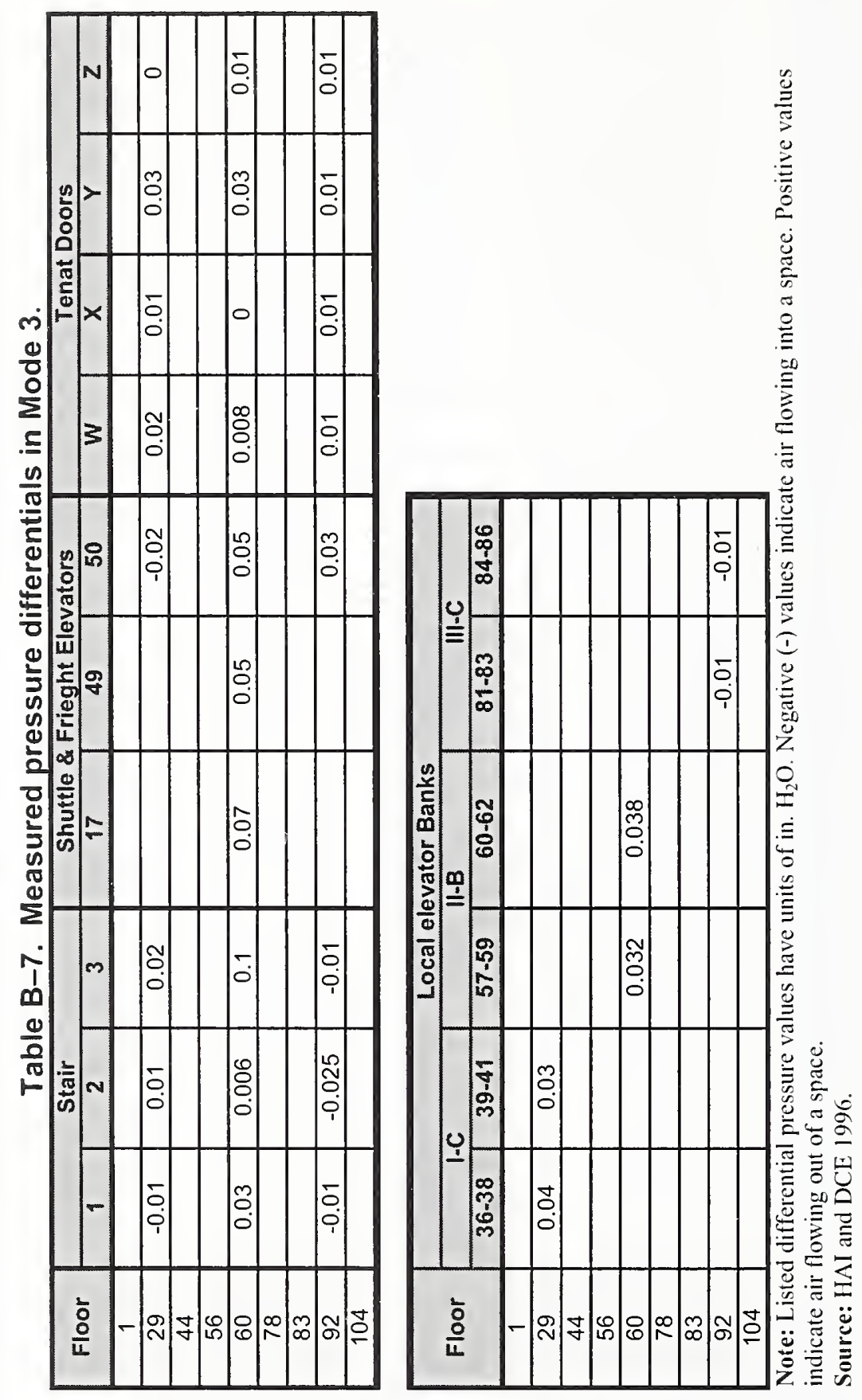

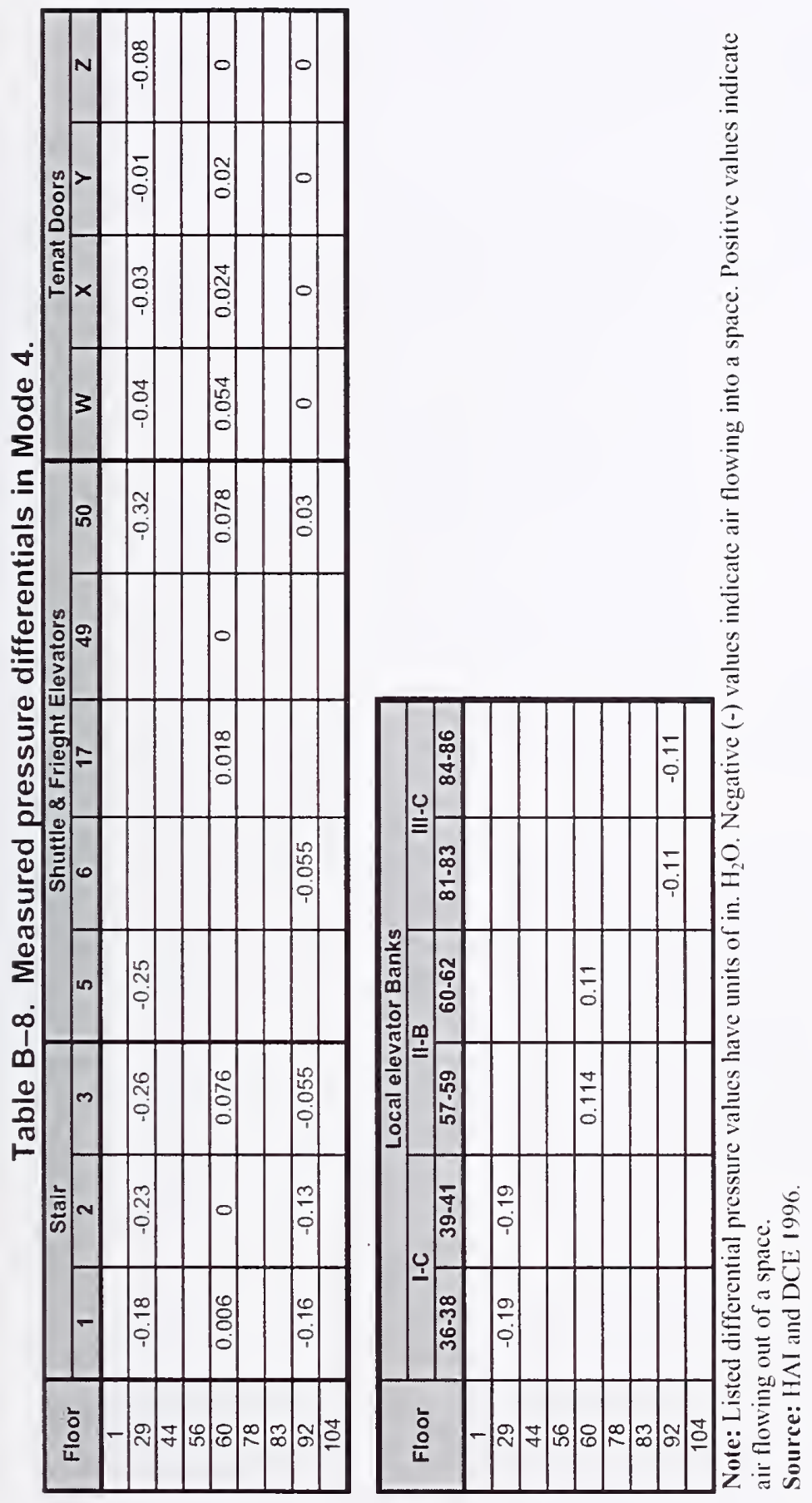
Table B-9. Door leakage path measurements (raw data).

\begin{tabular}{|c|c|c|c|c|c|c|c|c|c|c|c|c|c|c|}
\hline \multirow[t]{2}{*}{ Evilding } & \multirow[t]{2}{*}{ Floor } & \multirow{2}{*}{\multicolumn{2}{|c|}{ Shatt I Type }} & \multirow{2}{*}{$\begin{array}{l}\text { Width } \\
\text { (t) }\end{array}$} & \multirow{2}{*}{$\begin{array}{c}\text { Height } \\
\text { (ft) }\end{array}$} & TOP 1E & Botnom! & Lett & Rioht I & Center-L I & Center-C & Center-RIL & Leakane Are & \\
\hline & & & & & & (in) & (in) 1 & (in) & (in) & (in) & (in) & (in) & $\left(\mathrm{in}^{2}\right)$ & (iti) \\
\hline & & & & & & & & & & & & & & \\
\hline Freight Elev & vators D & Doors & & & & & & & & & & & & \\
\hline 11 & 29 & $1 F 50$ & $B$ & 5.17 & 7 & & & 0.125 & 0.344 & & & & 39.375 & 0.2734 \\
\hline 11 & 60 & $1 F 50-1$ & $B$ & 4.5 & 7.5 & 0.25 & 0.125 & 0.25 & 0.25 & 0063 & & & 70.875 & 0.4922 \\
\hline 11 & 60 & $1 F 50-2$ & $B$ & 45 & 7.5 & 0.25 & 0.125 & 0.375 & 0.375 & 0.063 & & & $9 \overline{3.375}$ & 0.6484 \\
\hline 11 & 77 & 1750 & $B$ & 45 & 7.5 & \begin{tabular}{|l|}
0.438 \\
\end{tabular} & 0144 & 0.219 & 0.219 & 0438 & & & 110.142 & 0.7649 \\
\hline 9 & 92 & $1 F 50$ & $\mathrm{~B}$ & 4.5 & 7.5 & 0.25 & 0.25 & 0.25 & 0.25 & & & & 72 & 0.5000 \\
\hline 9 & 104 & $9 F 50$ & $B$ & 4.5 & 7.5 & 0.29 & 0.25 & 0.125 & 0.188 & & & & 52.965 & 0.3678 \\
\hline & Average & & & & & & & & & & & & 87.7464 & 0.6094 \\
\hline & Deviatc & & & & & & & & & & & & 25.815 & 0.1793 \\
\hline & & & & & & & & & & & & & & \\
\hline Cargo Eleva & ator Doo & ors & & & & & & & & & & & & \\
\hline II & 60 & $11 \mathrm{P}^{16}$ & C & 5.17 & 7.5 & 0.25 & 0.125 & 0.25 & 0.25 & 0.063 & 0.125 & 0.000 & 96.39 & 0.6694 \\
\hline 1 & 77 & $1 P 7$ & C & 5.17 & 7.5 & 0.313 & 0.25 & 0.188 & 0.313 & 0.250 & 0.000 & 0.250 & 117875 & 0.8186 \\
\hline 1 & 92 & 197 & C & 5.17 & 7.5 & 0.3751 & 0.25 & 0.375 & 0.375 & 0.000 & 0.375 & 0.375 & 197.04 & 1.3683 \\
\hline 11 & 104 & $1 \mathrm{P7}$ & $\mathrm{C}$ & 5.17 & 7.5 & 0.4211 & 0.25 & 0.25 & 0.188 & 0.000 & 0.188 & 0.188 & \begin{tabular}{|c|}
126.3863 \\
\end{tabular} & 0.8777 \\
\hline & Average & & & & & & & & & & & & 179.2304 & 1.2447 \\
\hline & Devatic & & & & & & & & & & & & 43.611 & 0.3029 \\
\hline & & & & & & & & & & & & & & \\
\hline 4 & 5 & & $D$ & 8 & 8 & 0.375 & 0.75 & 0.375 & 0.375 & & & & 180 & 9.2500 \\
\hline & & & & & & & & & & & & & & \\
\hline Express Ele & evators & Doors & & & & & & & & & & & & \\
\hline 1 & 78 & T1P13 & $C$ & 5.17 & 7.5 & 0.25 & 0.125 & 0.25 & 0.25 & 0.063 & 0.125 & 0.000 & 96.39 & 0.6694 \\
\hline 11 & 78 & I & C & 5.17 & 75 & 0.25 & 0.25 & 0.375 & 0.375 & 0.000 & 0.375 & 0.375 & 189.285 & 1.3145 \\
\hline 1 & 78 & & C & 5.17 & 7.5 & 0.25 & 0.21 & 0.375 & 0.375 & 0.1251 & 0.313 & 0.313 & 182.3055 & 1.2660 \\
\hline II & 78 & & C & 5.17 & 7.5 & 0.25 & 0.29 & 0.188 & 0.313 & 0.063 & 0.250 & 0.375 & 147.4284 & 1.0238 \\
\hline & Average & & & & & & & & & & & & 205.1363 & 1.4248 \\
\hline & Deviatu & & & & & & & & & & & & 42.459 & 0.2949 \\
\hline & & & & & & & & & & & & & & \\
\hline Local Eleva & ators Do & oone & & & & & & & & & & & & \\
\hline 11 & 60 & 1924 & $B$ & 4 & 7.5 & 0.25 & 0.375 & 0.25 & 0.25 & 0.063 & & & 80.625 & 0.5599 \\
\hline 1 & 60 & 1929 & $B$ & 4 & 7.5 & 0.25 & 0.375 & 0.25 & 0.25 & 0.063 & & & 80.625 & 0.5599 \\
\hline 11 & 92 & 19936 & $B$ & 4 & 7.5 & 0.25 & 0.375 & 0.176 & 0.268 & 0.063 & & & 75.585 & 0.5249 \\
\hline 1 & \begin{tabular}{|l|}
92 \\
\end{tabular} & $11 P 49$ & $B$ & 4 & 7.5 & 0.25 & 0.375 & 0.25 & 0.25 & 0.063 & & & 80.625 & 0.5599 \\
\hline 1 & 104 & 1930 & $B$ & 4 & 7.5 & 0.375 & 0.375 & 0.25 & 0.375 & 0.000 & & & 92.25 & 0.6406 \\
\hline 1 & 104 & 1 P35 & $B$ & 4 & 7.5 & 0.25 & 0.375 & 0.25 & 0.25 & 0.060 & & & 80.4 & 0.5583 \\
\hline & Average & & & & & & & & & & & & 81.685 & 0.5673 \\
\hline & d. Deviat & $110 n$ & & & & & & & & & & & 5.547 & 0.0385 \\
\hline & & & & & & & & & & & & & & \\
\hline Stainway De & oors & & & & & & & & & & & & & \\
\hline 1 & 29 & 151 & A & 3 & 775 & \begin{tabular}{|l|}
0.145 \\
\end{tabular} & 0.5313 & 0.086 & 0.094 & & & & 41.06175 & 0.2852 \\
\hline 1) & 60 & 159 & A & 2.85 & 7.75 & 0.0631 & 0.1875 & 0.063 & 0.063 & & & & 20.175 & 0.1401 \\
\hline I) & 60 & 152 & $A$ & 2875 & 7.75 & 0.063 & 0.375 & 0.063 & 0.063 & & & & 27.375 & 0.1901 \\
\hline 1 & 60 & 153 & A & 3.61 & 7.75 & 0063 & 0.375 & 0.063 & 0.063 & & & & 30.5775 & 0.2123 \\
\hline 1 & 83 & 151 & $A$ & 2.87 & 7.75 & 0.063 & 0.1875 & 0.063 & 0.063 & & & & 20.235 & 0.1405 \\
\hline 9 & 83 & 152 & A & 2.87 & 7.75 & \begin{tabular}{|l|}
0.063 \\
\end{tabular} & 0.1875 & 0.063 & 0.063 & & & & 20.235 & 0.1405 \\
\hline I & 83 & 153 & $A$ & 3.58 & 7.75 & \begin{tabular}{|l|}
0.063 \\
\end{tabular} & 0.375 & 0.063 & $\begin{array}{ll}0.063 \\
\end{array}$ & & & & 30.42 & 0.2113 \\
\hline 1) & 92 & 151 & A & 3 & 7.75 & \begin{tabular}{|l|}
0.035 \\
\end{tabular} & 0.25 & 0.076 & 0.058 & & & & 22.722 & 0.1578 \\
\hline 1 & 92 & 152 & $\bar{A}$ & 3 & 7.75 & \begin{tabular}{|l|l|}
0.097 \\
\end{tabular} & 0.25 & 0.067 & 0.035 & & & & 21.978 & 0.1526 \\
\hline 1 & 92 & 153 & $A$ & 3 & 7.75 & 0.066 & 0.176 & 0.067 & 0.067 & & & & 21.174 & 0.1470 \\
\hline 11 & 104 & 151 & $A$ & 2.85 & 7.75 & 0.12 & 0.25 & 0.014 & \begin{tabular}{|l|}
0.014 \\
\end{tabular} & & & & 15.258 & 0.1060 \\
\hline 1 & 104 & $1 \mathrm{S2}$ & A & 3.61 & 7.75 & 0.1 & 0.375 & 0.25 & 0.25 & & & & 67.077 & 0.4658 \\
\hline 1 & 104 & 153 & $\bar{A}$ & 2.85 & 7.75 & 0.25 & 0.25 & 0.014 & 0.25 & & & & 41.652 & 0.2893 \\
\hline 1 & B-2 & 153 & A & 3 & 7.75 & 0.063 & 0.375 & 0.063 & 0.063 & & & & 27.375 & 0.1901 \\
\hline & Average & & & & & & & & & & & & 29.094 & 0.2020 \\
\hline & o. Devat & iton & & & & & & & & & & & 13.403 & 0.0931 \\
\hline & & & & & & & & & & & & & & \\
\hline Tenant Doc & ons & & & & & & & & & & & & & \\
\hline 11 & 29 & 2 & A & 6 & 7.75 & & 0.5313 & 0.068 & 0.127 & 0.173 & & & 72.381 & 0.5026 \\
\hline 1 & 60 & ww & $A$ & 5 & 7.75 & 0.063 & 0.25 & 0.063 & 0.063 & & & & 30.375 & 0.2109 \\
\hline 1 & 60 & $x$ & $A$ & 3 & 7.75 & 0.125 & 1.125 & 0.125 & 0.125 & & & & 68.25 & 04740 \\
\hline 9 & 60 & $y$ & $\bar{A}$ & 6 & 7.75 & 0.063 & 1.125 & 0.063 & 0.063 & 0.125 & & & 108.75 & 0.7552 \\
\hline 1 & 104 & $w$ & $\bar{A}$ & 5 & 7.75 & 0.11 & 1] & 0.035 & 0.035 & & & & 72.51 & 0.5035 \\
\hline 1 & 104 & $x$ & $A$ & 6 & 7.75 & 0.06 & 0.75 & 0.067 & \begin{tabular}{|l|}
0.067 \\
\end{tabular} & 0.150 & & & 84.732 & 0.5884 \\
\hline 1 & 104 & $Y$ & $A$ & 3 & 7.75 & 0.25 & 0.5 & 0.07 & 0.06 & & & & 39.09 & 0.2715 \\
\hline 1] & 104 & $\sqrt{2}$ & A & 3 & 7.75 & \begin{tabular}{|l|}
0.188 \\
\end{tabular} & 1 & 0.25 & 0.25 & & & & 89.25 & 0.6198 \\
\hline 1] & B.2 & $w$ & $A$ & 3 & 7.75 & 0.063 & 0.25 & 0.063 & \begin{tabular}{|l|}
0.063 \\
\end{tabular} & & & & \begin{tabular}{|l|l|}
22.875 \\
\end{tabular} & 0.1589 \\
\hline 1 & 8.2 & $x$ & A & 3 & 7.75 & \begin{tabular}{|l|}
0.125 \\
\end{tabular} & 1.125 & 0.125 & 0.125 & & & & 68.25 & 0.4740 \\
\hline 1 & B-2 & IY & $A$ & 45 & 7.5 & 0.25 & 0.125 & 0.375 & 0.375 & 0.063 & & & 93.375 & 06484 \\
\hline T) & $\mathrm{B}-2$ & $\frac{1}{2}$ & A & 3 & 7.75 & \begin{tabular}{|l|}
0.063 \\
\end{tabular} & 1] & 0.063 & 0.063 & & & & 49.875 & 0.3464 \\
\hline & Average & & & & & & & & & & & & 6664275 & 04628 \\
\hline & id. Deviat & & & & & & & & & & & & -26.405 & 0.1834 \\
\hline
\end{tabular}

Source: HAI and DCE 1996. 
Table B-10. Adjusted door leakage path measurements.

\begin{tabular}{|c|c|c|c|c|c|c|c|c|c|c|c|c|c|c|}
\hline Lullung! & Floor & Snat: & Type & Wiath & meront & TOD & Eotom I & Left & Rignt I & Center-LI & Center-C & Center-R 11 & Leakage Are & ea \\
\hline 1 & & 1 & & (fi) & (t) & (in) 1 & (in) & (in) & (in) 1 & (in) & (in) & (in) & $\left(\operatorname{in}^{2}\right)$ & $\left(\mathrm{ft}^{2}\right)$ \\
\hline I & & 1 & & & & & & & & 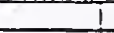 & I & & & \\
\hline \multicolumn{15}{|c|}{ Peicht Elevators Doors } \\
\hline T1 & 29 & 19750 & $E$ & 5.17 & 7 & & & 0.125 & 0.344 & & i & & & 0.0000 \\
\hline 11 & 60 & $19550-1$ & $B$ & 45 & 7.5 & 0.25 & 0.125 & 0.25 & 0.251 & 0.0631 & $t$ & & 70.875 & 0.4922 \\
\hline II & 60 & $11 F 50-2$ & E & 4.5 & 75 & 0.25 & 0.125 & 0.375 & 0.375 & 0.063 & & & 93.3751 & 0.6484 \\
\hline 71 & 77 & 19550 & 8 & 4.5 & 7.5 & $0438 !$ & 0144 & 0.219 & 0.219 & 0438 & & & & 00000 \\
\hline 1) & $\$ 2$ & 19550 & B & 4.5 & 7.5 & 0.251 & 0.251 & 0.25 & 0.251 & & & & 72 & 0.5000 \\
\hline 1 & 104 & $11 F 50$ & B & 4.5 & 7.5 & 0.21 & 0.25 & 0.125 & 0.188 & & & & 52.965 & 0.3678 \\
\hline & Average & & & & & 1 & & & & & & & 57.843 & 0.4017 \\
\hline & Deviat & & & & & $I$ & & & & & & & 16.534 & 0.2741 \\
\hline I & & $I$ & & & & 1 & & & & & & & E & \\
\hline \multicolumn{3}{|c|}{ Caroo Elevator Doors } & & & & & & & & & & & & \\
\hline 11 & 60 & $19 P 16$ & $\bar{C}$ & 5.17 & 7.5 & 0251 & 0.125 & 0.251 & 0251 & 0.063 & 0125 & 0.000 & 96.39 & 0.6694 \\
\hline 11 & 77 & $19 P 7$ & C & 5.17 & 7.5 & 0.313 & 0.25 & 0.188 & $0.313 \mid$ & 0.250 & 0000 & 0.2501 & 197.875 & 0.8186 \\
\hline it & 92 & 197 & $c$ & 5.17 & 7.5 & 0.3751 & 0.25 & 0.375 & 0.375 & 0.000 & 0.375 & 0.375 & & 0.0000 \\
\hline 1 & 104 & 197 & C & 5.17 & 7.5 & 0.4211 & 0.25 & 0.25 & 0.188 & 0.000 & 0.188 & 0.188 & 126.3863 & 0.8777 \\
\hline \multicolumn{3}{|c|}{ Average! } & & & & & 1 & & & & & & 113.5504 & 0.7885 \\
\hline \multicolumn{3}{|c|}{ Sid. Devation } & & & & & & & & & & & 15.459 & 0.4038 \\
\hline \multirow{3}{*}{41} & & $T$ & & & & & & & & & & & & \\
\hline & 5 & I & $D$ & 8 & 8 & 0.375 & 0.75 & 0.375 & 0.375 & & & & 180 & 1.2500 \\
\hline & & 1 & & & & & & & & & & & & \\
\hline Express Ele & evators & Doors & & & & & & & & & & & & \\
\hline 11 & 78 & $11 P 13$ & $\mathrm{C}$ & 5.17 & 7.5 & 0.25 & 0.925 & 0.25 & 0.25 & 00631 & 0.125 & 0.000 & & 0.0000 \\
\hline 1) & 78 & $i$ & C & 5.17 & 75 & 025 & 0.251 & 0.3751 & 0.3751 & 00001 & 0.3751 & 0.375 & 189285 & 1.3145 \\
\hline 31 & 78 & & $c$ & 5.17 & 7.5 & 0.251 & 0.2 & 0.375 & 0.375 & 0.125 & 0313 & 0.313 & 182.3055 & 1.2660 \\
\hline 1 & 78 & & $c$ & 5.17 & 7.5 & 0.25 & 0.21 & 0.188 & 0.313 & 0.063 & 0.250 & 0.375 & 1474284 & 1.0238 \\
\hline & Average & & & & & & & & & & & & 173.0063 & 1.2014 \\
\hline & Deviat & & & & & & & & & & & & 22.424 & 0.6140 \\
\hline 1 & & $T$ & & & & & & & & & & & & \\
\hline Local Eleva & ators Do & 200 & & & & & & & & & & & & \\
\hline 1 & 60 & 11924 & E & 4 & 7.5 & 0.25 & 0.375 & 0.25 & 0.25 & 0.063 & & & 80.625 & 0.5599 \\
\hline 1 & 60 & Tि29 & E & 4 & 7.5 & 0.25 & 0.375 & 0.25 & 0.25 & 0.063 & & & 80.625 & 0.5599 \\
\hline 1 & 92 & 1936 & $B$ & 4 & 7.5 & 0.25 & 0.375 & 0.176 & 0.268 & 0.063 & & & 75.585 & 0.5249 \\
\hline 1 & 92 & $11 P 41$ & $E$ & 4 & 7.5 & 0.25 & 0.3751 & 0.25 & 0.25 & 0.063 & & & 80.625 & 0.5599 \\
\hline 1 & 102 & 11930 & 8 & 4 & 7.5 & 0.375 & 0.375 & 0.25 & 0.375 & 0000 & & & 92.25 & 0.6406 \\
\hline 9 & 104 & $11 \mathrm{P35}$ & $\bar{B}$ & 4 & 7.5 & 0.25 & 0.375 & 0.25 & 0.25 & 0.060 & & & 80.41 & 0.5583 \\
\hline & Average & & & & & & & & & & & & 81.685 & 0.5673 \\
\hline & d. Devat & & & & & & & & & & & & 5.547 & 0.0385 \\
\hline & & & & & & & & & & & & & & \\
\hline Staitway D & oors & & & & & & & & & & & & & \\
\hline 11 & 29 & 1959 & E & 3 & 7.75 & 0.1451 & 0.53925 & 0.086 & 0.054 & & & & 41.06175 & 0.2852 \\
\hline 91 & 60 & 151 & A & 2.85 & 7.75 & 0.063 & 0.1875 & 0.063 & 0.063 & & & & 20175 & 0.1401 \\
\hline 9 & 60 & 1952 & A & 2.875 & 7.75 & 0.063 & 0.375 & 0.063 & 0.063 & & & & 27.375 & 01901 \\
\hline 1 & 60 & 1153 & F & 369 & 7.75 & 0063 & 0.375 & 0.063 & 0.0631 & & & & 30.5775 & 0.2123 \\
\hline 11 & 83 & 1959 & A & 2.87 & 7.75 & 00631 & 0.18751 & 0.063 & 0.063 & & & & \begin{tabular}{|l|l|}
20.235 \\
\end{tabular} & 0.1405 \\
\hline 11 & 83 & 1152 & A & 2.87 & 7.75 & 0.063 & 01875 & 0.063 & 0.063 & & & & 20.235 & 0.1405 \\
\hline 1 & 83 & 153 & A & 3.58 & 7.75 & 0.063 & 0.375 & 0.063 & 0.063 & & & & 30.42 & 0.2113 \\
\hline 9 & 52 & 1151 & $A$ & 3 & 7.75 & 0035 & 0.25 & 0.0761 & 0058 & & & & 22.722 & 0.1578 \\
\hline 1 & 92 & 152 & $A$ & 3 & 7.75 & 0.0971 & 0.25 & 0.067 & 0.035 & & & & 21.978 & 0.1526 \\
\hline 9 & 92 & 1153 & A & 3 & 7.75 & 0.066 & 0.176 & 0.067 & 0.067 & & & & 21.174 & 0.9470 \\
\hline 1 & 104 & 1159 & A & 2.85 & 7.75 & 0.12 & 0.25 & 0.014 & 0.014 & & & & 15.258 & 0.1060 \\
\hline 1 & 104 & 152 & A & 3.61 & 7.75 & 0.1 & 0.375 & 0.25 & 0.25 & & & & & 0.0000 \\
\hline 9 & 104 & 153 & $A$ & 2.85 & 7.75 & 0.25 & 0.25 & 0.014 & 0.25 & & & & 41.6521 & 0.2893 \\
\hline 1 & E-2 & 153 & A & 3 & 7.75 & 0.063 & 0.375 & 0.063 & 0.063 & & & & 27.375 & 0.1901 \\
\hline & Average & & & & & & & & & & & & 24.303 & 0.1688 \\
\hline & d. Devat & & & & & & & & & & & & 8.071 & 0.0725 \\
\hline & & & & & & & & & & & & & & \\
\hline Tenan: Doo & & & & & & & & & & & & & & \\
\hline 11 & 29 & 12 & $A$ & 6 & 775 & & 0.53125 & 0.068 & 0.127 & 0.173 & & & \begin{tabular}{|l|}
72.381 \\
\end{tabular} & 0.5026 \\
\hline 1 & 60 & Tw & A & 5 & 7.75 & 0.063 & 0.25 & 0.053 & 0.0631 & & & & 30.375 & 0.2109 \\
\hline 1) & 60 & $i x$ & $A$ & 3 & 7.75 & 0.125 & 9.125 & 0.125 & 0.125 & & & & 68.25 & 0.4740 \\
\hline T & 60 & Ty & A & 6 & 7.75 & 0.063 & 9.125 & 0.063 & 0.063 & 0.125 & & & & 0.0000 \\
\hline 1 & 104 & iw & A & 5 & 7.75 & 0.1 & T & 0.035 & 0.035 & & & & 72.51 & 0.5035 \\
\hline 1 & 104 & $x$ & $A$ & 6 & 7.75 & 0.06 & 0.75 & 0.067 & 0.067 & 0.150 & & & \begin{tabular}{|l|}
84.732 \\
\end{tabular} & 0.5884 \\
\hline 1 & 104 & IY & A & 3 & 7.75 & 0.25 & 0.5 & 0.07 & 0.06 & & & & 39.09 & 0.2715 \\
\hline T) & 104 & 12 & A & 3 & 7.75 & 0188 & 1 & 0.25 & 0.25 & & & & 89.25 & 0.6198 \\
\hline 1 & $B-2$ & IN & $A$ & 3 & 7.75 & 0.063 & 0.25 & 0.063 & 0.063 & & & & & 0.0000 \\
\hline 1 & $B-2$ & $x$ & A & 3 & 7.75 & 0.125 & 1.125 & 0.125 & 0.125 & & & & 68.25 & 0.4740 \\
\hline 11 & $8-2$ & Ty & $A$ & 45 & 7.5 & 0.25 & 0.125 & 0.375 & 0.375 & 0.063 & & & 93.375 & 0.6484 \\
\hline 1 & B.2 & 12 & A & 3 & 7.75 & 0.063 & 11 & 0.063 & 0.063 & & & & 49.875 & 0.3464 \\
\hline & Averaos & & & & & & & & & & & & 55.674 & 0.3866 \\
\hline & Id Devial & & & & & & & & & & & & 21.031 & 0.2238 \\
\hline
\end{tabular}

Source: HAI and DCE 1996. 
Table B-11. Door leakage areas.

\begin{tabular}{|c|c|c|c|}
\hline Description/Use & Type & $\begin{array}{c}\text { Average }^{\mathrm{a}} \\
\text { Measured } \\
\text { Leakage Area } \\
\left(\mathrm{ft}^{2}\right)\end{array}$ & $\begin{array}{c}\text { Corrected }^{\mathrm{b}} \\
\text { Leakage } \\
\text { Area }\left(\mathrm{ft}^{2}\right)\end{array}$ \\
\hline $\begin{array}{l}\text { Side hinged single leaf door } \\
\text { (stairs, tenant space, etc.) }\end{array}$ & A & 0.1688 & 0.20 \\
\hline $\begin{array}{l}\text { Center parting double leaf doors } \\
\text { (tenant space, escalator cut-off, etc.) }\end{array}$ & A & 0.3376 & 0.081 \\
\hline $\begin{array}{l}\text { Center parting "single speed" elevator doors } \\
\text { (freight elevators) }\end{array}$ & B & 0.4017 & 0.4017 \\
\hline $\begin{array}{l}\text { Center parting "double speed" elevator doors } \\
\text { (freight elevators) }\end{array}$ & $\mathrm{C}$ & 0.7885 & 0.7885 \\
\hline $\begin{array}{l}\text { Center parting "single speed" elevator doors } \\
\text { ("local" passenger elevators) }\end{array}$ & B & 0.5673 & 1.00 \\
\hline $\begin{array}{l}\text { Center parting "double speed" elevator doors } \\
\text { ("shuttle" passenger elevators) }\end{array}$ & $\mathrm{C}$ & 1.2014 & 1.2014 \\
\hline Freight elevator door & $\mathrm{D}$ & 1.2500 & 1.25 \\
\hline Tenant doors & $\mathrm{A}$ & 0.3866 & 2.60 \\
\hline Elevator pit doors & A & 0.63 & 0.63 \\
\hline Mechanical room door & A & 1.00 & 1.00 \\
\hline Automatic closing dock door & & 1.00 & 1.00 \\
\hline Rolling steel dock doors & & 6 in. $^{2} / \mathrm{ft}^{2}$ & $6 \mathrm{in}^{2} / \mathrm{ft}^{2}$ \\
\hline Rubber door at dock & & 1.00 & 1.00 \\
\hline
\end{tabular}

a. Door leakage areas used in 2004 WTC CONTAM model.

b. Door leakage areas used in 1996 WTC CONTAM model.

\section{B.1.6 1996 WTC CONTAM Model Calibration}

The pressure measurements obtained during the site survey were used to validate the 1996 WTC CONTAM model. In order to fine tune the model, the leakage path areas for stair doors, passenger elevators, and selected other doors were increased. These increases lumped together as part of the stair and elevator door openings other construction leakages that may have existed, such as penetrations in elevator/stair shaft walls. Therefore, the leakage areas used may appear higher than that typically associated with stair doors or elevator doors. The corrected leakage path areas used in the 1996 WTC CONTAM model are listed in Table B-11.

\section{B.2 2004 WTC CONTAM MODEL}

The construction process of the 2004 WTC CONTAM model was guided by efforts to provide a better calibration of the model to the actual pressure measurements taken within the building. Details of this calibration process are discussed in Appendix C. The following section outlines the final version(s) of the 2004 WTC CONTAM model, including aircraft impact damage models for WTC 1 and WTC 2. 


\section{B.2.1 Leakage Areas}

The leakage areas used in the 2004 WTC CONTAM model for the various building construction elements and their associated tightness classification are listed in Table B-12, for model configurations $\mathrm{A} / \mathrm{B}$ and $\mathrm{C}$. As is discussed in Appendix $\mathrm{C}$, there were several potential building configurations, representing combinations of assumed leakages and ventilation system parameters that provide relatively good agreement with the calibration data.

Configuration A represents a best approximation of the various leakages and ventilation system parameters that existed in the towers on September 11,2001. Configuration B uses the same leakage areas assumed for configuration $\mathrm{A}$. The only difference between model configurations $\mathrm{A}$ and $\mathrm{B}$ is that configuration $\mathrm{A}$ assumes 85 percent fan efficiency, while configuration $\mathrm{B}$ assumes 60 percent fan efficiency. Tightness classifications are based on typical leakage area measurements of walls and floors in commercial buildings (see Table B-12) (Klote and Milke 2002).

Several architectural features were added to the 2004 WTC CONTAM model. Wall transfers grills, which were observed during the 1996 site survey, were added to the model. A perimeter leakage was added, intended to model floor slab penetrations for the high-pressure perimeter air system, discussed in Chapter 4. Given the building's approximate $800 \mathrm{ft}$ perimeter, a perimeter leakage of $8 \mathrm{ft}^{2}$ and $16 \mathrm{ft}^{2}$ correlates to a $1 / 8 \mathrm{in}$. and $1 / 4 \mathrm{in}$. perimeter gap respectively.

Table B-12. Leakage area parameters used in 2004 WTC model.

\begin{tabular}{|c|c|c|c|c|}
\hline \multirow[b]{2}{*}{ Construction Elements } & \multicolumn{2}{|c|}{ Model Configuration A/B } & \multicolumn{2}{|c|}{ Model Configuration $\mathrm{C}$} \\
\hline & Leakage Area & $\begin{array}{c}\text { Tightness } \\
\text { Classification }\end{array}$ & Leakage Area & $\begin{array}{c}\text { Tightness }^{a} \\
\text { Classification }\end{array}$ \\
\hline Floor & $0.00095 \mathrm{in.}^{2} / \mathrm{ft}^{2}$ & Tight & $0.00095 \mathrm{in}^{2} / \mathrm{ft}^{2}$ & Tight \\
\hline Exterior walls & 0.02 in. $^{2} / \mathrm{ft}^{2}$ & Average-Tight & 0.03 in. $^{2} / \mathrm{ft}^{2}$ & Average \\
\hline Stair walls ${ }^{b}$ & 0.6 in. $^{2} / \mathrm{ft}^{2}$ & Loose & $1.0 \mathrm{in}^{2} / \mathrm{ft}^{2}$ & Very Loose \\
\hline Shaft walls ${ }^{b}$ & $1.5 \mathrm{in}^{2} / \mathrm{ft}^{2}$ & Average & $3.1 \mathrm{in}^{2} / \mathrm{ft}^{2}$ & Loose \\
\hline Wall transfer grills & $6 \mathrm{in.}^{2} / \mathrm{ft}^{2}$ & $\mathrm{NA}$ & $10 \mathrm{ft}^{2}$ & NA \\
\hline HVAC louvers & $0.3 \mathrm{in}^{2} / \mathrm{ft}^{2}$ & $\mathrm{NA}$ & $0.3 \mathrm{in}^{2} / \mathrm{ft}^{2}$ & NA \\
\hline Floor slab perimeter & $8 \mathrm{ft}^{2}$ & NA & $16 \mathrm{ft}^{2}$ & NA \\
\hline Doorway $^{c}$ & \multicolumn{4}{|c|}{ Average Measured Areas (see Table B-1 1) } \\
\hline
\end{tabular}

a. Tightness classifications are based on typical leakage area measurements of walls and floors in commercial building (Klote and Milke 2002).

b. Listed wall leakages are per linear $\mathrm{ft}$ of wall based on a $12 \mathrm{ft}$ slab-to-slab height.

c. Modeled doorway leakage areas were based on average measured leakage areas.

Key: NA, not applicable.

In the 1996 CONTAM model only one wall leakage type was used, termed "interior wall." Variations in wall leakage were taken into account by lumping extra leakage area into stair and elevator leakage paths. This methodology presents problems in trying to keep track of the effect of the various leakage parameters used.

The 2004 CONTAM model added several new leakage path types to provide unique leakage paths for the various interior wall types (stairs, elevators, tenant/core separations). Leakage areas for doors (elevator, stair, tenant) were reset to correspond to the actual measured values, as shown in Table B-11. 


\section{B.2.2 2004 CONTAM HVAC System}

The basic framework of the HVAC modeling approach used in the 1996 WTC CONTAM model (discussed in Sec. B.1.3) remained the same for the 2004 WTC CONTAM model. However, several additions were made in the 2004 model, which had a sizeable impact on simulated pressurcs. The additions to the 1996 HVAC modeling approach included:

- Added schedules to the vcrtical shaft openings, which allowed the user to easily open and close the shafts when necessary. When both supply and exhaust fans are turned off, the ventilation shafts are modeled open in CONTAM. This is done to model the passive pathway created when no air is being mechanically driven within the ventilation ducts. Conversely, when both supply and exhaust fans are turned on, as in the case of summer normal mode, ventilation shafts are modeled closed. This is done to model the mechanically driven air, which eliminates the passive pathway for air transport via the ventilation ducts.

- Dampers were added to core and tenant ventilation shafts. Damper dimensions wcre taken from WTC mechanical riser diagrams.

- Outdoor air louvers, connected to each ventilation unit/shaft, where added on each MER level. Modeling the outdoor air louvers provided additional pressure relief to the building. Outdoor air louver dimensions were taken from WTC mechanical riser diagrams.

In the 2004 WTC CONTAM model, configurations A and C assume that air is supplied and returned at 85 percent of listed capacities, while configuration $B$ assumes that air is supplied and returned at 60 percent of listed capacities (see Tables B-4a through B-4e for details). It is important to note that in all threc configurations $(\mathrm{A}-\mathrm{C}$ ) the ratio between supply and return air remains constant (as listed in Tables B-4a through B.4e). The ratio between supply and return air can have a substantial effect on building pressures.

\section{Zoned Smoke Control With Stair Pressurization}

As discussed in Sec. 8.1.5 of this report, the state of the art smoke management approach referred to as "Zoned Smoke Control With Stair Pressurization" was analyzed. This smoke management approach consisted of pressurizing Stairs 1-3, while exhausting air within the tenant (interior) space on the fire floor. Theoretical fans sizes for stair pressurization and tenant space exhaust were determined based on providing 0.05 in. $\mathrm{H}_{2} \mathrm{O}$ across the stair and tenant doors under the following HVAC configuration:

- Supply and exhaust fans are turned off in the multi-floor ventilation zone containing the fire. For example, if a fire occurs on the 80th floor (served by MER 75), interior and core (supply and exhaust) fans on floors 59 through 91 are turned off. As previously discussed, when both supply and exhaust fans are turned off (within a ventilation zone), the ventilation shafts are modeled open in CONTAM. This is done to model the passive pathway created when no air is being mechanically driven within the ventilation ducts.

- Supply and exhaust fans in ventilation zones not containing the fire are set to summer normal mode. In summer normal mode, both supply and exhaust fans are running and therefore a passive pathway for air movement is eliminated. Under summer normal mode, ventilation 
shafts are modeled in CONTAM as being closed to address the mechanically driven air within the ventilation ducts.

- Class-II smoke dampers activate in the multi-floor ventilation zone containing the fire, as smoke dampers would typically be provided in a state-of-the-art smoke management system. Class-II leakage rated smoke dampers (UL 555S) were modeled in CONTAM by multiplying the flow area of each ventilation shaft damper by a leakage area ratio of $0.6 \mathrm{in}^{2} / \mathrm{ft}^{2}$ (Klote and Milke 2002).

Some smoke control designers limit the height of single-injection stairways to 8 stories; however, other designers feel this limit can be extended to 12 stories (Klote and Milke 2002). Given the height of the WTC stairways (40 or more stories within each stair section), a multiple-injection point system was used. A multi injection point stair pressurization system was modeled in CONTAM using the Simple Air Handling System feature. Supply (injection) points were placed approximately five stories apart within each stairway. CONTAM schedules were added to each supply point, which allowed the user to adjust the amount of air supplied to each stair section. Stair sections were determined by the location of the horizontal transfer corridors.

Stair 1 and Stair 2 consists of three sections:

- Section 1: Floors 2 through 42

- Section 2: Floors 43 through 75

- Section 3: Floors 75 to Roof

Stair 3 consists of two sections:

- Section 1: Floors 1 through 75

- Section 2: Floors 75 through 107

Through an iterative simulation proccss using CONTAM, the stair pressurization fan size required to achieve 0.05 in. $\mathrm{H}_{2} \mathrm{O}$ across the stair doors for each stair section was determincd. Stair pressurization fan sizes were determined for both model configurations $\mathrm{A} / \mathrm{B}$ and $\mathrm{C}$ (as discussed in Sec. 8.3.3). Model configurations $\mathrm{A}$ and $\mathrm{B}$ assumed identical leakage areas for the various building construction elemcnts and therefore the stair pressurization fan sizes required were the same. Modeling rcsults for the stair pressurization fan sizes required to achieve 0.05 in. $\mathrm{H}_{2} \mathrm{O}$ across stair doors are shown in Table $\mathrm{B}-13$. The listed fan capacities in Table B-13 assume that all stair doors, stair transition doors, elcvator doors, and tenant doors were closed. 
Table B-13. Stair pressurization system fan sizes.

\begin{tabular}{|c|c|c|c|c|}
\hline \multirow{2}{*}{$\begin{array}{c}\text { Model } \\
\text { Configuration }\end{array}$} & $\begin{array}{c}\text { Stair } \\
\text { Sections }\end{array}$ & Stair 1 & Stair 2 & Stair 3 \\
\cline { 2 - 5 } & $1^{*}$ & 19,200 & 17,600 & 21,000 \\
\cline { 2 - 5 } & 2 & 10,500 & 9,600 & 7,800 \\
\cline { 2 - 5 } & 3 & 13,300 & 15,400 & - \\
\cline { 2 - 5 } & Total & 43,000 & 42,600 & $\mathbf{2 8 , 8 0 0}$ \\
\hline \multirow{4}{*}{$C$} & $1^{*}$ & 22,400 & 20,800 & 27,000 \\
\cline { 2 - 5 } & 2 & 14,100 & 12,600 & 10,200 \\
\cline { 2 - 5 } & 3 & 17,500 & 19,600 & - \\
\cline { 2 - 5 } & Total & $\mathbf{5 4 , 0 0 0}$ & $\mathbf{5 3 , 0 0 0}$ & 37,200 \\
\hline
\end{tabular}

The listed fan capacities for Stairs 1 and 2 in stair section 1 (floors 2 through 42), do not achieve $0.05 \mathrm{in}$. $\mathrm{H}_{2} \mathrm{O}$ across the stair doors on floors 2 through 6 . Floors 2 through 6 are unique in that a stair vestibule is located between the core space and stairway. As shown in Table B-13 the fan size needed to pressurize the stairway in model configuration $\mathrm{C}$ are considerably higher due to the relative looseness of the building construction elements compared to model configuration $\mathrm{A} / \mathrm{B}$.

In conjunction with stair pressurization, an iterative simulation process was used in CONTAM to determine the interior zone exhaust fan size required to achieve 0.05 in. $\mathrm{H}_{2} \mathrm{O}$ and 0.1 in. $\mathrm{H}_{2} \mathrm{O}$ across the tenant doors for both model configurations $\mathrm{A} / \mathrm{B}$ and $\mathrm{C}$. Modeling results for interior exhaust fan sizes required to achieve 0.05 in. $\mathrm{H}_{2} \mathrm{O}$ and 0.1 in. $\mathrm{H}_{2} \mathrm{O}$ across tenant doors are shown in Table $\mathrm{B}-14$.

Table B-14. Calculated interior exhaust fan sizes.

\begin{tabular}{|c|c|c|}
\hline \multirow{2}{*}{$\begin{array}{c}\text { Model } \\
\text { Configuration }\end{array}$} & \multicolumn{2}{|c|}{ Tenant Doors } \\
\cline { 2 - 3 } & $0.0 \mathbf{H}^{\prime \prime} \mathrm{H}_{2} \mathrm{O}$ & $\mathbf{0 . 1} \mathrm{H}_{\mathbf{2}} \mathrm{O}$ \\
\cline { 2 - 3 } & $(\mathrm{cfm})$ & (cfm) \\
\hline $\mathrm{A} / \mathrm{B}$ & 29,100 & 39,500 \\
\hline $\mathrm{C}$ & 51,000 & 73,000 \\
\hline
\end{tabular}

The listed fan capacities in Table B-14 assume that all stair doors, stair transition doors, elevator doors, and tenant doors are closed.

\section{B.3 DAMAGED WTC CONTAM MODELS}

A "damaged" CONTAM model, for both WTC 1 and WTC 2, was developed from the 2004 WTC baseline CONTAM model (discussed in Sec. B.2). The damaged models reflect the aircraft impact damage to a tower's exterior walls, concrete floor slabs, core walls, and shafts (elevator and stairs) due to the events on September 11, 2001.

For the damaged models, a northerly wind was modeled in CONTAM at a velocity of $11.2 \mathrm{mph}(5 \mathrm{~m} / \mathrm{s})$ and a direction of 328 degrees, depicting wind conditions on September 11, 2001. In the CONTAM model, the wall azimuth angle (reference point) for the top wall on the SketchPad is defined as 0 degrees. A 0 degree wind modeled in CONTAM would be directly perpendicular to the north face of WTC 1 . As shown in Fig. B-2, a northerly wind is approximately 32 degrees off the perpendicular, equaling a wind direction of 328 degrees. The outside temperature was modeled in CONTAM as $70^{\circ} \mathrm{F}$, depicting temperature conditions on September 11. 




Figure B-2. Illustration of a northerly wind modeled in CONTAM at 328 degrees.

\section{B.3.1 Damaged WTC 1 CONTAM Model}

The top of the CONTAM SketchPad represents the north face of the building; where as the bottom of the SketchPad represents the south face of the building. The impact damage to each exterior face of the building, discussed below, was modeled accordingly. This was to done to ensure that the effects of a northerly wind across the large exterior (damage) openings were modeled properly.

Table B-15 shows the estimated impacted damage to the exterior walls of WTC 1 . The impact damage was added in CONTAM to the external walls as two-way flow openings. The estimated impacted damage to exterior walls is based on the World Trade Center Building Performance Study performed by the Federal Emergency Management Agency (FEMA) (McAllister 2002). 
Table B-15. Estimated impact damage to exterior walls, WTC 1.

\begin{tabular}{|c|c|c|c|c|}
\hline Floor & $\begin{array}{c}\text { North } \\
\left(\mathbf{f t}^{2}\right)\end{array}$ & $\begin{array}{c}\text { South } \\
\left(\mathbf{f t}^{2}\right)\end{array}$ & $\begin{array}{c}\text { East } \\
\left(\mathbf{f t}^{2}\right)\end{array}$ & $\begin{array}{c}\text { West } \\
\left(\mathbf{f t}^{2}\right)\end{array}$ \\
\hline 92 & 743 & 0 & 1,572 & 0 \\
\hline 93 & 958 & 0 & 1,356 & 0 \\
\hline 94 & 592 & 54 & 1,163 & 0 \\
\hline 95 & 1,055 & 54 & 0 & 420 \\
\hline 96 & 797 & 151 & 0 & 1,518 \\
\hline 97 & 926 & 151 & 0 & 1,798 \\
\hline 98 & 1,335 & 0 & 0 & 0 \\
\hline
\end{tabular}

Table B-16 shows the estimated impact damage to the concrete floor slabs and core walls of WTC 1 . The impact damage was added in CONTAM to the floors in the tenant area and to the core walls as a two-way flow opening. The estimated impact damage is based on the National Institute of Standards and Technology (NIST) preliminary impact estimates shown in Appendix A. The floor slab damage is based on the solid lines up to the core area in Figs. A-1 through A-6. The core wall damage is based on the dotted lines across the core area walls in Figs. A-1 through A-6.

Table B-16. Estimated impact damage to floor slabs and core walls, WTC 1.

\begin{tabular}{|c|c|c|}
\hline \multirow{2}{*}{ Floor } & $\begin{array}{c}\text { Floor Slab } \\
\text { Damage }\end{array}$ & $\begin{array}{c}\text { Core Wall } \\
\text { Damage }\end{array}$ \\
\cline { 2 - 3 }$\left(\mathrm{ft}^{2}\right)$ & $\left(\mathrm{ft}^{2}\right)$ \\
\hline 94 & 2,800 & 216 \\
\hline 95 & 1,650 & 432 \\
\hline 96 & 2,830 & 588 \\
\hline 97 & 870 & 0 \\
\hline 98 & 330 & 0 \\
\hline
\end{tabular}

Table B-17 shows the estimated impact damage to the stair and elevator shafts in WTC 1 . The impact damagc was added in CONTAM to the associated shaft wall as a two-way flow opening. The estimated impact damage is based on the NIST impact estimates shown in Appendix A. The stair and elevator damage is based on the dotted lines in Figs. 7-1 and 7-2.

Table B-17. Estimated impact damage to stairlelevator shafts, WTC 1.

\begin{tabular}{|c|c|c|c|c|c|c|c|}
\hline \multirow{3}{*}{ Floor } & \multicolumn{3}{|c|}{ Stairs } & \multicolumn{2}{c|}{ Express \& Freight Elevators } & \multicolumn{2}{c|}{ Local Elevators } \\
\cline { 2 - 8 } & $\mathbf{1}$ & $\mathbf{2}$ & $\mathbf{3}$ & $\mathbf{5 0}$ & $\mathbf{6 - 7}$ & $\mathbf{9 0 - 9 2}$ & $\mathbf{9 3 - 9 5}$ \\
\cline { 2 - 8 } & $\left(\mathrm{ft}^{2}\right)$ & $\left(\mathrm{ft}^{2}\right)$ & $\left(\mathrm{ft}^{2}\right)$ & $\left(\mathrm{ft}^{2}\right)$ & $\left(\mathrm{ft}^{2}\right)$ & $\left(\mathrm{ft}^{2}\right)$ & $\left(\mathrm{ft}^{2}\right)$ \\
\hline 94 & 192 & 0 & 0 & 0 & 0 & 0 & 0 \\
\hline 95 & 480 & 120 & 120 & 468 & 0 & 0 & 0 \\
\hline 96 & 288 & 576 & 576 & 708 & 672 & 864 & 864 \\
\hline
\end{tabular}

\section{B.3.2 Damaged WTC 2 CONTAM Model}

Similar to the damaged WTC 1 model, the damaged WTC 2 model considers the north face of the building as the top of the SketchPad. The impact damage to each exterior face of the building, discussed below, was modeled accordingly. This was to done to ensure the effects of a northerly wind across the large exterior (damage) openings were modeled properly for the different orientations of WTC 1 and WTC 2. It should be noted, however, that the WTC 2 model does not consider the impact of WTC 1 on 
wind driven flow around the building, which is important since WTC 1 was directly in the path of the prevailing wind on September 11, 2001.

The impact damage to the core walls of WTC 2 were rotated by 90 degrees with respect to WTC 1 (see Fig. B-3). This was done to correctly account for the different core orientation in WTC 2 versus WTC 1 with respect to the point of aircraft impact. Since the CONTAM model considers the interior office space as one large open zone, the core can be effectively rotated by placing damage openings in the proper locations, rather than physically rotating the location of the core zones on the CONTAM SketchPad.
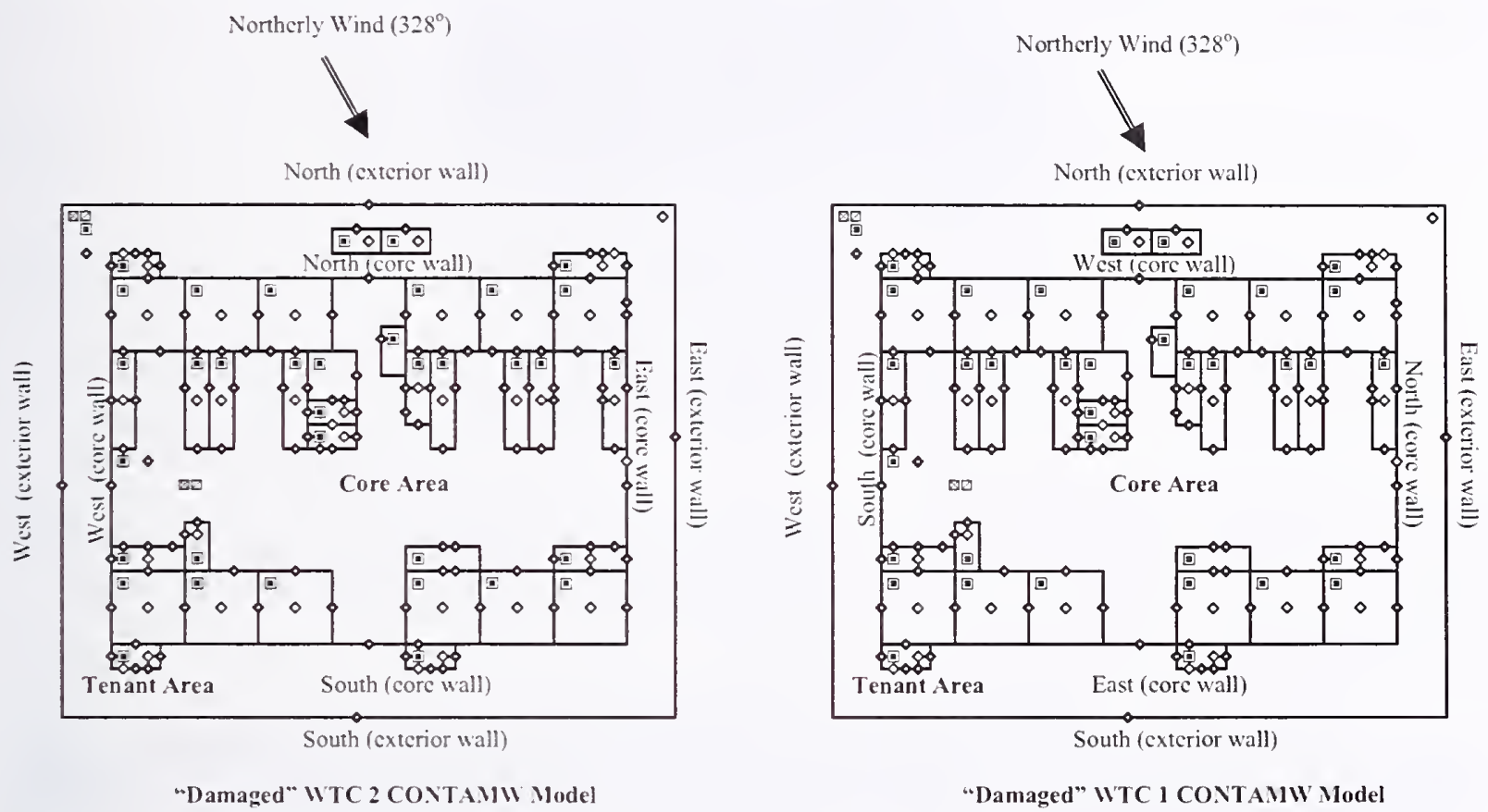

\section{Figure B-3. CONTAM SketchPad, floor 15, exterior and core wall directional orientations for damaged CONTAM models.}

Table B-18 shows the estimated impacted damage to the exterior wall of WTC 2. The impact damage was added in CONTAM to the external walls as two-way flow openings. The estimated impacted damage to the south exterior wall of WTC 2 is based on Fig. 2-27 in the FEMA report (McAllister 2002).

Impacted damage to the north and east exterior walls of WTC 2 are based on video data showing postimpact window damage (Custer 2002).

Table B-18. Estimated impact damage to exterior walls, WTC 2.

\begin{tabular}{|c|c|c|c|c|}
\hline \multirow{2}{*}{ Floor } & North & South & East & West \\
\cline { 2 - 5 } & $\left(\mathrm{ft}^{2}\right)$ & $\left(\mathrm{ft}^{2}\right)$ & $\left(\mathrm{ft}^{2}\right)$ & $\left(\mathrm{ft}^{2}\right)$ \\
\hline 78 & 0 & 360 & 0 & 0 \\
\hline 79 & 0 & 550 & 0 & 0 \\
\hline 80 & 24 & 472 & 690 & 0 \\
\hline 81 & 119 & 824 & 690 & 0 \\
\hline 82 & 143 & 415 & 690 & 0 \\
\hline 83 & 95 & 241 & 0 & 0 \\
\hline 84 & 0 & 97 & 0 & 0 \\
\hline
\end{tabular}


Table B-19 shows the estimated impact damage to the concrete floor slabs and core walls of WTC 2 . The impact damage was added in CONTAM to the floors in the tenant zone and to the core walls as a twoway flow opening. The estimated impact damage is based on NIST preliminary impact estimates shown in Appendix A. The floor slab damage is based on the solid line up to the core are in Figs. A-7 through $\mathrm{A}-12$. The core wall damage is based on the dotted lines across the core area walls in Figs. A-7 through $\mathrm{A}-12$.

Table B-19. Estimated impact damage, floor slabs
\begin{tabular}{|c|c|c|}
\hline and core walls, WTC 2. \\
\hline \multirow{2}{*}{ Floor } & $\begin{array}{c}\text { Floor Slab } \\
\text { Damage }\end{array}$ & $\begin{array}{c}\text { Core Wall } \\
\text { Damage }\end{array}$ \\
\cline { 2 - 3 } & $\left(\mathrm{ft}^{2}\right)$ & $\left(\mathrm{ft}^{2}\right)$ \\
\hline 78 & 830 & 0 \\
\hline 79 & 2,210 & 240 \\
\hline 80 & 650 & 265 \\
\hline 81 & 910 & 265 \\
\hline 82 & 1,685 & 265 \\
\hline 83 & 600 & 0 \\
\hline 84 & 240 & 0 \\
\hline
\end{tabular}

Table B-20 shows the estimated impact damage to the stair and elevator shafts in WTC 2. The impact damage was added in CONTAM to the associated shaft walls as a two-way flow opening. The estimated impact damage is based on the NIST impacts estimates shown in Appendix A. The stair and elevator damage is based on the dotted lines in Figs. 7-1 and 7-2.

Table B-20. Estimated impact damage, stair and elevators, WTC 2.

\begin{tabular}{|c|c|c|c|c|c|c|c|c|}
\hline \multirow{3}{*}{ Floor } & \multicolumn{2}{|c|}{ Stairs } & Express Elevator & \multicolumn{5}{c|}{ Local Elevators } \\
\cline { 2 - 8 } & $\mathbf{2}$ & $\mathbf{3}$ & $\mathbf{6 - 7}$ & $\mathbf{8 1 - 8 3}$ & $\mathbf{8 4 - 8 6}$ & $\mathbf{8 7 - 8 9}$ & $\mathbf{9 0 - 9 2}$ & $\mathbf{9 3 - 9 5}$ \\
\cline { 2 - 8 } & $\left(\mathrm{ft}^{2}\right)$ & $\left(\mathrm{ft}^{2}\right)$ & $\left(\mathrm{ft}^{2}\right)$ & $\left(\mathrm{ft}^{2}\right)$ & $\left(\mathrm{ft}^{2}\right)$ & $\left(\mathrm{ft}^{2}\right)$ & $\left(\mathrm{ft}^{2}\right)$ & $\left(\mathrm{ft}^{2}\right)$ \\
\hline 78 & 288 & 0 & 0 & 0 & 0 & 0 & 0 & 0 \\
\hline 79 & 120 & 120 & 300 & 432 & 432 & 432 & 264 & 84 \\
\hline 80 & 0 & 0 & 468 & 144 & 120 & 84 & 0 & 0 \\
\hline 81 & 0 & 0 & 468 & 144 & 120 & 84 & 0 & 0 \\
\hline
\end{tabular}




\section{B.3.3 REFERENCES}

Custer, R. L. P. 2002. World Trade Center Expert Report: Documentation and analysis of fire spread in World Trade Center events of September 11, 2001. Arup Fire, New York, NY, August.

HAI (Hughes Associates, Inc.) and DCE (Dillon Consulting Engineers). 1996. Smoke Management Evaluation Study of The World Trade Center Complex Excluding the Concourse and Plaza. Prepared for the PANYNJ (Port Authority of New York and New Jersey). New York, NY.

Klote. J. H., and J. A. Milke. 1992. Design of Smoke Management Systems. Amcrican Society of Heating, Refrigerating and Air-Conditioning Engineers (ASHRAE). Atlanta, GA.

Klote, J. H., and J. A. Milke. 2002. Principles of Smoke Management. American Society of Heating Refrigeration and Air-Conditioning Engineers (ASHRAE). Atlanta, GA.

LEA, F. C. 1942. Hydraulics for Engineers and Engineering Students: Sixth edition. London, UK.

McAllister, T., ed. 2002. World Trade Center Building Performance Study: Data Collection, Preliminary Observations, and Recommendations. FEMA 403. Federal Emergency Management Agency. Washington, DC, May.

UL (Underwriters Laboratories). 2003b. Standard for Safety Leakage Rated Dampers for Use in Smoke Control Systems. UL Standard 555S. Northbrook, IL.

Walton, G. N. (1997). “CONTAM96 User Manual," NISIR 6065, National Institute of Standards and Technology. 
This page intentionally left blank. 


\section{Appendix C \\ CONTAM MODEL CALIBRATION}

As part of the 1996 Hughes Associates Incorporated (HAI)/Dillon Consulting Engineers (DCE) study, measurements were made of actual airflows and pressures at various locations in World Trade Center (WTC) 1 for different ventilation modes. At the time, a limited model calibration was performed in order to perform the analysis in the 1996 study.

To complete the modeling summarized in this report, many changes were made to the model (summarized in Appendix B) to add building features not present in the 1996 model and to add additional leakage path types to provide additional degrees of freedom in performing the simulations. As such, it was desired to revisit the calibration of the model in order to attempt to provide better agreement between the model and the measured data.

This appendix discusses the efforts that went into the recalibration of the model, and the relative agreement between the actual WTC pressure measurements (see Tables B-2 through B-5) and pressures simulated using the 2004 WTC CONTAM model. Calibration efforts were conducted for the four different ventilation modes (Modes 1 through 4), discussed in Appendix B.1.4.

\section{C.1 PRE-CALIBRATION EFFORTS}

The 2004 WTC CONTAM model was constructed using the 1996 WTC CONTAM model as a starting point. Changes were made to the model to add building features that were identified as missing from the 1996 model and to reflect lessons learned over the intervening years with regard to the use of CONTAM to model the performance of smoke management systems in high-rise buildings. This knowledge was applied to the calibration process and construction of the 2004 WTC model.

The first step in the 2004 WTC CONTAM model construction involved setting all of the corrected door leakage areas used in 1996 model back to the values measured during the 1996 WTC site visit. Measured door leakage areas are given in Appendix B, Table B-11. Since the door leakage values (core, elevator, and stair doors) reflect actual measured values, these leakages remained fixed during the calibration process.

The leakage areas of several key construction elements were not included as individual elements during the 1996 study and therefore needed to be estimated. The non-measured construction elements included:

- Exterior walls

- Stair walls

- Elevator walls

- Floors 
Leakage area estimates for these construction elements wcre kept within the bounds of tightness typically observed in commercial buildings (Klote and Milke 2002). Typical leakage areas of walls and floors of commercial buildings are listed in Table $\mathrm{C}-1$.

Table C-1. Typical leakage areas of walls and floors in commercial buildings.

\begin{tabular}{|c|c|c|}
\hline Construction Element & Tightness & Leakage Area Ratioa \\
\hline \multirow{4}{*}{$\begin{array}{l}\text { Exterior Building Walls } \\
\text { (included construction cracks and cracks } \\
\text { around windows and doors) }\end{array}$} & Tight & $0.01 \mathrm{in}^{2} / \mathrm{ft}^{2}$ \\
\hline & Average & 0.03 in. $^{2} / \mathrm{ft}^{2}$ \\
\hline & Loose & 0.06 in. $^{2} / \mathrm{ft}^{2}$ \\
\hline & Very Loose & $0.19 \mathrm{in}^{2} / \mathrm{ft}^{2}$ \\
\hline \multirow{3}{*}{$\begin{array}{l}\text { Stairway Walls } \\
\text { (includes construction cracks but not cracks } \\
\text { around windows or doors) }\end{array}$} & Tight & $0.02 \mathrm{in.}^{2} / \mathrm{ft}$ \\
\hline & Average & $0.19 \mathrm{in}^{2} / \mathrm{ft}$ \\
\hline & Loose & $0.61 \mathrm{in}^{2} / \mathrm{ft}$ \\
\hline \multirow{3}{*}{$\begin{array}{l}\text { Elevator Shaft Walls } \\
\text { (includes construction cracks but not cracks } \\
\text { around doors }\end{array}$} & Tight & $0.31 \mathrm{in}^{2} / \mathrm{ft}$ \\
\hline & Average & $1.45 \mathrm{in.}^{2} / \mathrm{ft}$ \\
\hline & Loose & $3.11 \mathrm{in.}^{2} / \mathrm{ft}$ \\
\hline \multirow{3}{*}{$\begin{array}{l}\text { Floors } \\
\text { (includes construction cracks and gaps around } \\
\text { penetrations) }\end{array}$} & Tight & 0.00095 in. $^{2} / \mathrm{ft}^{2}$ \\
\hline & Average & 0.00749 in. $^{2} / \mathrm{ft}^{2}$ \\
\hline & Loose & 0.02448 in. $^{2} / \mathrm{ft}^{2}$ \\
\hline
\end{tabular}

a. For the stairway and elevator shaft walls, the leakage area ratio is the area of the leakage through the wall per linear $\mathrm{ft}$ based on a $12 \mathrm{ft}$ slab-to-slab height.

Measurements made by Tamura and Shaw (Klote and Milke 2002) show stairway walls to be approximately one order of magnitude tighter than elevator shaft walls (see Table $\mathrm{C}-1$ for details). In the 1996 WTC CONTAM model, elevator shaft walls and stairway walls were combined together as one building construction element for simplicity. In the 2004 WTC CONTAM model, elevator shafts and stairway walls were modeled as two separate construction elements (airflow elements), to account for their considerable difference in tightness. This allowed the modeler to independently vary the leakage areas for the elevator shaft walls and stairway walls.

\section{C.2 CALIBRATION EFFORTS}

Initial calibration efforts involved matching simulated data with measured data under Mode 2, where all fans are set to summer normal. The heating, ventilating, and air conditioning (HVAC) system within CONTAM was set up to depict ventilation Mode 2, where all fans were running at 85 percent of design capacity. Using an iterative process, leakage areas for the non-measured construction elements were varied until simulated results were in reasonable agreement with measured values. Under Mode 2, simulated results showed the best agreement with measured values when:

- Exterior walls were set to tight

- Elevator shaft wall were set to tight 
- Stairway walls were set to average

- Floors were set to tight

This tightness configuration for the non-measured construction elements also produced a reasonable agreement under Mode 1.

The iterative process also involved varying outside temperature and wind velocities. CONTAM simulations, running under Mode 2, showed that outside temperature differences of up to $10^{\circ} \mathrm{F}$ and wind velocity variation of up to $20 \mathrm{mph}$ produced relatively small changes in simulated pressures, as illustrated in Figs. C-21 through C-30. Mode 1 was calibrated using an outside temperature of $63^{\circ} \mathrm{F}$ and Modes 2 through 4 were calibrated using an outside temperature of $70^{\circ} \mathrm{F}$. The temperatures used were based on measurements made during the site survey (see Sec. B.1.4) and the sequence in which the four different HVAC modes were conducted, as outside temperature would have risen during the day from the early morning to late morning period in which the pressure tests were performed.

The next calibration step involved testing the tightness configuration that produced a reasonable agreement under Modes 1 and 2, for Modes 3 and 4. When the CONTAM model was set up for Mode 3 (core pressurization for the full height of the tower), using the tightness configuration used to match Modes 1 and 2, the model simulations produced very high positive pressures across the tenant doors. Simulated pressures across the tenant door were greater than $1.0 \mathrm{in} . \mathrm{H}_{2} \mathrm{O}$. These high pressures across the tenant doors would have been apparent during the site survey, because the doors would have been pinned shut due to the substantial overpressure. In actuality, under the core pressurization configuration (Modes 3 and 4), positive pressures were measured between 0.01 in. $\mathrm{H}_{2} \mathrm{O}$ and 0.05 in $\mathrm{H}_{2} \mathrm{O}$ (see Tables B-5 through $\mathrm{B}-8)$.

At this point in the calibration process the results showed that the 2004 CONTAM model agreed reasonably well with Modes 1 and 2. but not with Modes 3 and 4. Because this study involved analyzing the effectiveness of various smoke management approaches, including the core pressurization mode, Modes 3 and 4 were used to calibrate the final version(s) of the 2004 WTC CONTAM model. Principally, the positive pressures measured across the tenant doors and elevator 50 during core pressurization (Modes 3 and 4) were used to calibrate the final version(s) of the 2004 WTC CONTAM model.

\section{C.2.1 Architectural and Mechanical Building Features Added}

The initial simulation results for Modes 3 and 4 warranted further investigation into the building's architecture and HVAC system. Investigation of the building's ventilation system led to modeling shaft dampers and mechanical equipment room (MER) outdoor air louvers located in WTC 1. This modification dramatically reduced pressures across the tenant doors in Modes 3 and 4, by adding additional pressure relief from the core and interior space to the exterior of the building. Investigation of the building's architecture lead to modeling the wall transfer grills located over many of the tenant doors, providing an additional airflow path between the core and interior space. Leakage around the perimeter of the tenant space due to ventilation penetrations for the high-pressure air was also modeled in CONTAM. As stated in Appendix B, perimeter gaps of $1 / 8$ in. and $1 / 4$ in. correlate to total perimeter leakages of $8 \mathrm{ft}^{2}$ and $16 \mathrm{ft}^{2}$, respectively, given the approximate $800 \mathrm{ft}$ perimeter of the building. 
After the architectural and mechanical building features described above were added to the 2004 WTC model, leakage values for the non-measured construction elements were set based on the construction characteristics of each element. The construction characteristics of each element are as follows:

- Floors-Floor construction typically consisted of 4 in. of lightweight concrete on $11 / 2$ in., 22 gauge non-composite steel deck (McAllister 2002). In the core area, slab thickness was $5 \mathrm{in}$. Based on this construction, the floor leakage was set and held at "tight" $\left(0.00095 \mathrm{in}^{2} / \mathrm{ft}^{2}\right)$.

- Exterior Walls-Construction of the building's exterior walls consisted of closely spaced built-up box columns. A total of 59 perimeter columns were present along each flat face of the building. The columns were built up by welding four plates together to form an approximately $14 \mathrm{in}$. spare section, spaced at 3-4 in. on center. This column spacing resulted in relatively small window sizes, approximately $2 \mathrm{ft}$ wide. Based on this construction, leakage areas for the exterior wall were set between "average" $\left(0.03 \mathrm{in.}^{2} / \mathrm{ft}^{2}\right)$ and "tight" $\left(0.01 \mathrm{in.}{ }^{2} / \mathrm{ft}^{2}\right)$.

- Elevator Shaft Walls-Elevator shaft walls were constructed of taped drywall. Using drywall greatly reduced the natural weight load of the building. Based on this construction, leakage areas were set between "average" $\left(1.45 \mathrm{in.}^{2} / \mathrm{ft}\right)$ and "loose" $\left(3.11 \mathrm{in}^{2} / \mathrm{ft}\right)$.

- Stairway Walls-Stairway walls were constructed of taped drywall. Using drywall greatly reduced the natural weigh load of the building. Stairway walls contained various types of penetrations, adding leakage. Based on this construction, leakage areas were set between "loose" $\left(0.6 \mathrm{in}^{2} / \mathrm{ft}\right)$ and "very loose" $\left(1.0 \mathrm{in} .{ }^{2} / \mathrm{ft}\right)$.

\section{C.2.2 Model Configurations}

Three different model configurations were used in order to represent the uncertainty involved with this type of modeling. These three model configurations attempt to bracket the estimated leakage rates for the various building construction elements, as well as the efficiency of the HVAC system. The model configurations include:

- Configuration A-This model configuration is based on best estimates of building variables. The HVAC efficiency is set at 85 percent based on WTC building engineer estimates (HAI and DCE 1996). Door leakage areas are set to measured leakage values (Appendix B, Table B-11). Non-measured building construction elements are set to expected leakage values based on the construction type of each element, as discussed in Sec. C.2.1. A complete summary of leakage areas for this configuration is given in Appendix B, Table B-12.

- Configuration B-Same leakage areas as configuration $A$. This model configuration reduces the HVAC efficiency from 85 to 60 percent, and results in an overall reduction of pressure within the building.

- Configuration $C$-This model configuration increases the leakage areas (i.e., loosens) of configuration A. The HVAC efficiency is held at 85 percent. A complete summary of leakage areas for this configuration is given in Appendix B, Table B-12. 


\section{C.3 CALIBRATION RESULTS}

A summary of the simulated pressures verses the measured pressures, under HVAC Modes 1 through 4, are shown in Table $\mathrm{C}-1$ (Sec. C.3.1). The simulation results for model configurations $\mathrm{A}-\mathrm{C}$ under HVAC Modes 1 through 4 are shown in Tables $\mathrm{C}-2$ through $\mathrm{C}-12$ (Sec. C.3.2). Graphical comparisons between simulated and measured pressures, for HVAC Modes 1 through 4, are shown in Figs. C-1 through C-20 (Sec. C.3.3). Temperature effects are shown in Figs. C-21 through $\mathrm{C}-25$ (Sec. C.3.4). Wind effects are shown in Figs. C-26 through C-30 (Sec. C.3.5).

\section{C.3.1 Summary of Results}

The values listed in Table $\mathrm{C}-1$ are the minimum and maximum pressures under HVAC Modes 1 through 4 , observed versus predicted, for the full height of the building, across the tenant doors or within a given group of shafts. Shaft types included the following:

- Stairs: Stair 1, 2, and 3

- Elevator 50: Elevator 50 only

- Shuttle and freight elevators: Elevator 5, 6, 17, 49, 1-2, 3-4, 6-7, 8-9, 10-11, 12-13, 14-15, $16-17,18-19,20-21$, and 22-23

- Local elevators: Elevator 24-26, 30-32, 36-38, 39-41, 51-53, 54-56, 57-59, 60-62, 63-65, $66-68,69-71,72-74,75-77,78-80,81-83,84-86,87-89,90-92$, and 93-95

Table C-1. Comparison of measured and simulated pressures for HVAC Modes 1 through 4.

\begin{tabular}{|c|c|c|c|c|c|c|c|c|c|c|c|}
\hline \multirow{2}{*}{$\begin{array}{c}\text { HVAC } \\
\text { Configuration }\end{array}$} & \multirow{2}{*}{ Data Description } & \multicolumn{2}{|c|}{ Stairs } & \multicolumn{2}{|c|}{ Elevator 50} & \multicolumn{2}{|c|}{ Shuttle Elev. } & \multicolumn{2}{|c|}{ Local Elev. } & \multicolumn{2}{|c|}{ Tenant Doors } \\
\hline & & Min & Max & Min & Max & Min & Max & Min & Max & Min & Max \\
\hline \multirow{3}{*}{ Mode 1} & Measured & -0.04 & 0.01 & -0.01 & 0.01 & -0.05 & 0.04 & -0.02 & 0.02 & -0.02 & 0.01 \\
\hline & Configuration $A / B$ & -0.04 & 0.02 & -0.02 & 0.05 & -0.04 & 0.05 & -0.04 & 0.03 & 0.00 & 0.00 \\
\hline & Configuration $\mathrm{C}$ & -0.03 & 0.02 & -0.01 & 0.03 & -0.03 & 0.04 & -0.03 & 0.02 & 0.00 & 0.00 \\
\hline \multirow{4}{*}{ Mode 2} & Measured & -0.25 & 0.02 & -0.24 & 0.02 & -0.07 & 0.01 & -0.20 & 0.12 & -0.07 & 0.06 \\
\hline & Configuration $\mathrm{A}$ & -0.01 & 0.01 & -0.01 & 0.00 & -0.01 & 0.00 & 0.00 & 0.01 & -0.01 & 0.00 \\
\hline & Configuration B & -0.01 & 0.01 & -0.01 & 0.00 & 0.00 & 0.00 & 0.00 & 0.01 & 0.00 & 0.00 \\
\hline & Configuration $\mathrm{C}$ & -0.01 & 0.00 & 0.00 & 0.00 & 0.00 & 0.00 & 0.00 & 0.00 & 0.00 & 0.00 \\
\hline \multirow{4}{*}{ Mode 3} & Measured & -0.03 & 0.10 & -0.02 & 0.05 & 0.05 & 0.07 & -0.01 & 0.04 & 0.00 & 0.03 \\
\hline & Configuration A & 0.00 & 0.05 & -0.01 & 0.05 & 0.01 & 0.02 & -0.01 & 0.04 & 0.01 & 0.02 \\
\hline & Configuration B & 0.00 & 0.03 & 0.00 & 0.02 & 0.00 & 0.01 & 0.00 & 0.01 & 0.00 & 0.01 \\
\hline & Configuration C & 0.00 & 0.01 & 0.00 & 0.02 & 0.00 & 0.01 & 0.00 & 0.01 & 0.00 & 0.01 \\
\hline \multirow{4}{*}{ Mode 4} & Measured & -0.26 & 0.08 & -0.32 & 0.08 & -0.25 & 0.02 & -0.19 & 0.11 & -0.08 & 0.05 \\
\hline & Configuration $\mathrm{A}$ & -0.05 & 0.14 & -0.12 & 0.15 & -0.02 & 0.11 & -0.07 & 0.15 & -0.01 & 0.05 \\
\hline & Configuration $\mathrm{B}$ & -0.04 & 0.08 & -0.07 & 0.08 & -0.02 & 0.05 & -0.04 & 0.08 & 0.00 & 0.03 \\
\hline & Configuration C & -0.02 & 0.07 & -0.05 & 0.07 & 0.00 & 0.05 & -0.04 & 0.08 & 0.00 & 0.02 \\
\hline
\end{tabular}


For Mode 1, the 2004 WTC CONTAM model agreed fairly wcll with measured pressures. Maximum stairs pressure agreed by a factor of 1.7 , elevator 50 by 2.5 , shuttle and freight elevators by 1.2 , local elevators by 1.4 , and tenant doors by 2.5 . Tenant doors agreement factors are high because simulated pressures were very close to zero.

For Mode 2, the 2004 WTC CONTAM model agreed poorly with measured pressures. Simulated agreement factors were between 3.1 and 85.7. These agreement factors are high because simulated pressures were close to zero. Simulated pressure in Mode 2 is close to zero for two main reasons:

1. Non-measured building construction elements were loosened to better match Modes 3 and 4 .

2. The ventilation system modeled assumed a relative air balance between the supply and return air.

Supply and return air rates were modeled based on mechanical drawings, as shown in Tables B-4a through $\mathrm{B}-4 \mathrm{e}$, and not on actual measured ventilation rates. Tenant changes on individual floors to the ventilation system were not known nor modeled. As shown Tables B-6 and B-8, relatively high negative pressures were measured on floors 29 and 92 under Modes 2 and 4. Mode 4 is similar to Mode 2 on floors 29 and 92 in that the ventilation is set to summer normal. The pressures measured on floor 29 and 92 are over an order of magnitude greater than the other measured floors. These abnormally high pressures may be attributed to tenant changes to the ventilation system on these floors (or neighboring floors). Tenant changes to the ventilation system on an individual floor would not only alter the pressures on that floor, but could alter the entire network of pressures within the WTC complex. These abnormally high pressures may also be attributed to unique architectures on these floor or neighboring floors, as discussed in Sec. C.2.3. It should be noted that in many cases, the floors directly above/below floors 29 and 92 had fairly good agrecment with measured data for these floors, indicating that pressures were in the correct range for that area of the building.

For Mode 3, the 2004 WTC CONTAM model agreed reasonably well with measured pressures. Maximum stair pressures agreed by a factor of 2.1 , elevator 50 by 1.0 , shuttle and freight elevators by 3.2 , local elevators by 1.0, and tenant doors by 1.7. As previously discussed, calibration of the 2004 WTC CONTAM model depended heavily on the positive pressures measured during the site survey across the tenant doors and elevator 50, under Modes 3 and 4 (core pressurization). These principal measured pressures are highlighted in Table $\mathrm{C}-1$. As shown in Table $\mathrm{C}-1$, simulated pressures agree very well with the principal measured pressures across the tenant doors and elevator 50 .

For Mode 4, the 2004 WTC CONTAM model agreed reasonably well with measured pressures. Maximum stair pressures agreed by a factor of 1.1 , elevator 50 by 1.0 , shuttle and freight elevators by 2.5 , local elevators by 1.3 , and tenant doors by 1.1 .

\section{C.3.2 Simulated Results for Modes 1 through 4}

The simulation results for model configurations $A$ through $C$ under HVAC Modes 1 through 4 are shown in Tables $\mathrm{C}-2$ through $\mathrm{C}-12$. The measured data is summarized in Tables B-5 through B-8 (Appendix B) as well as the calibration measurements taken during the $1996 \mathrm{HAI} / \mathrm{DCE}$ study. The figurcs discussed in Sec. C.3.3 provide a comparison between the two sets of data. 


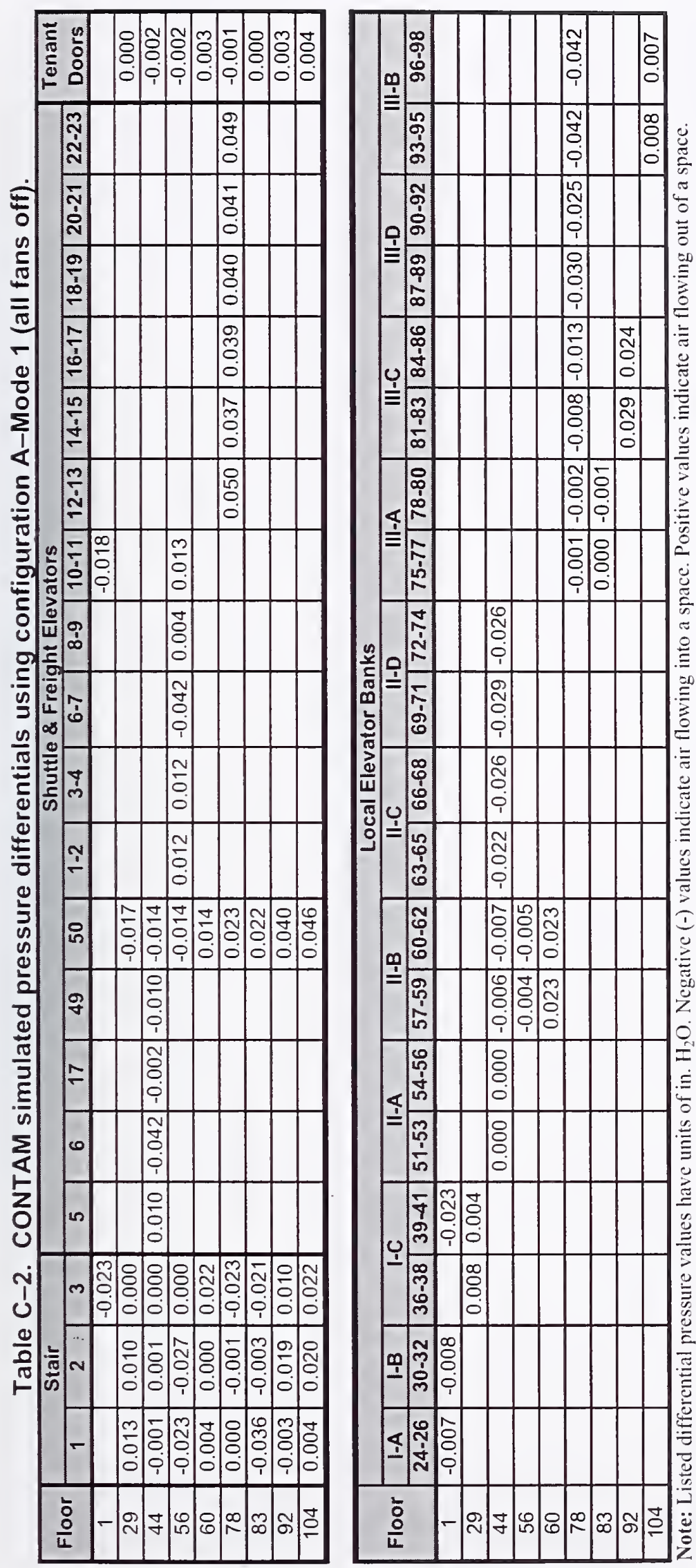



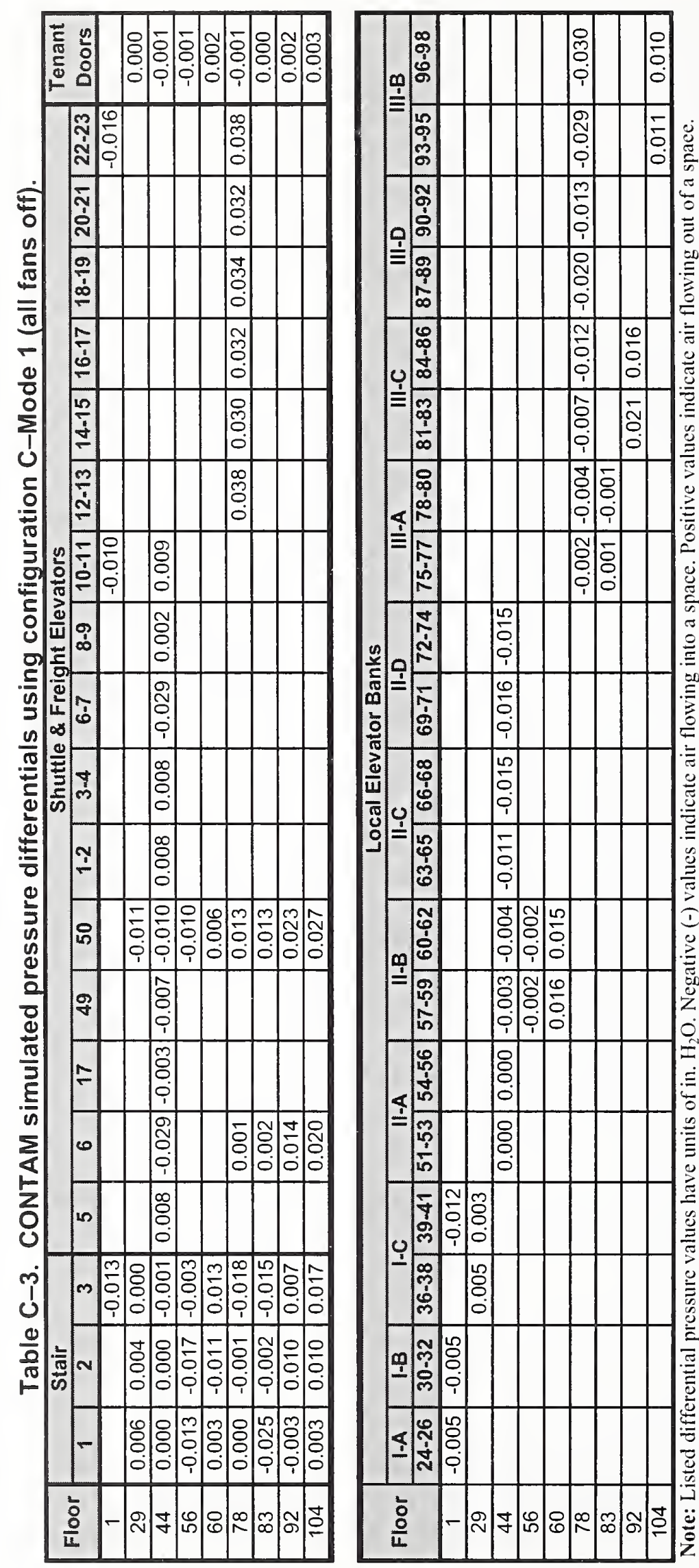


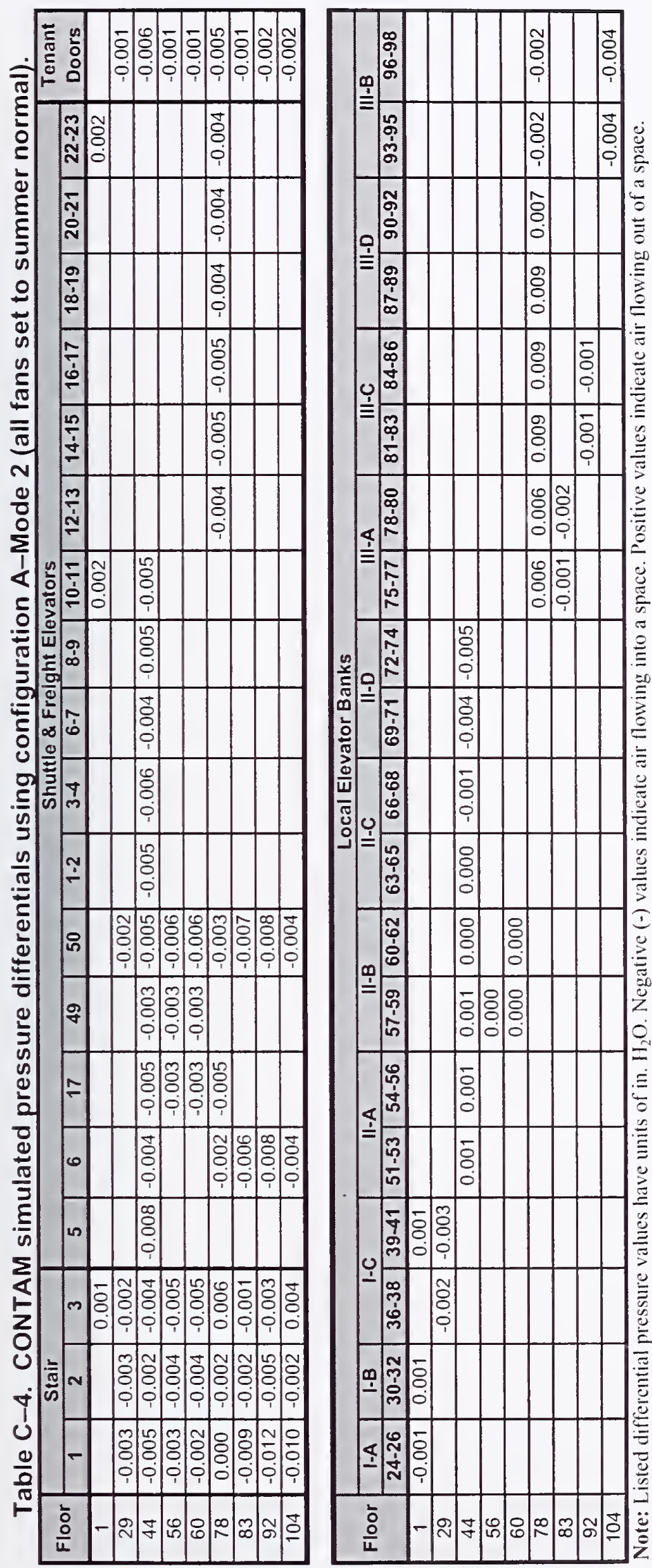




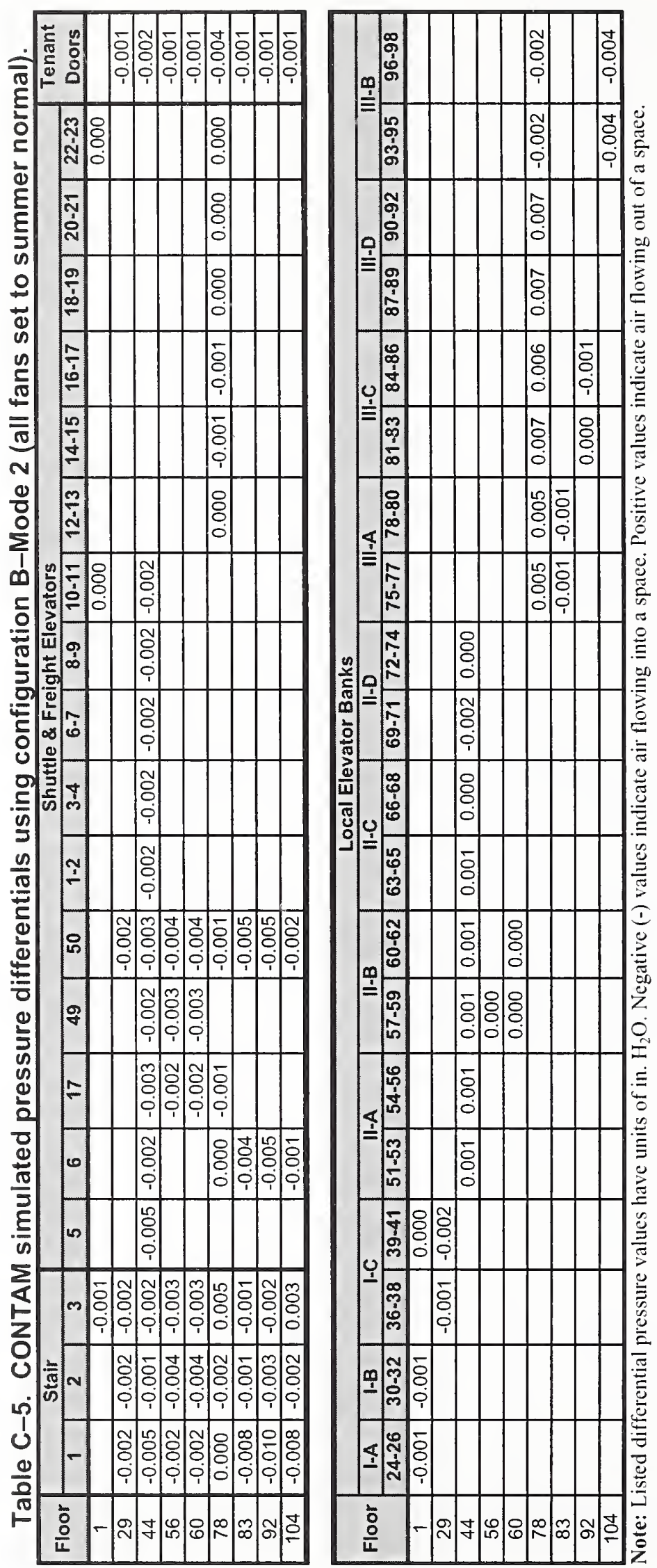



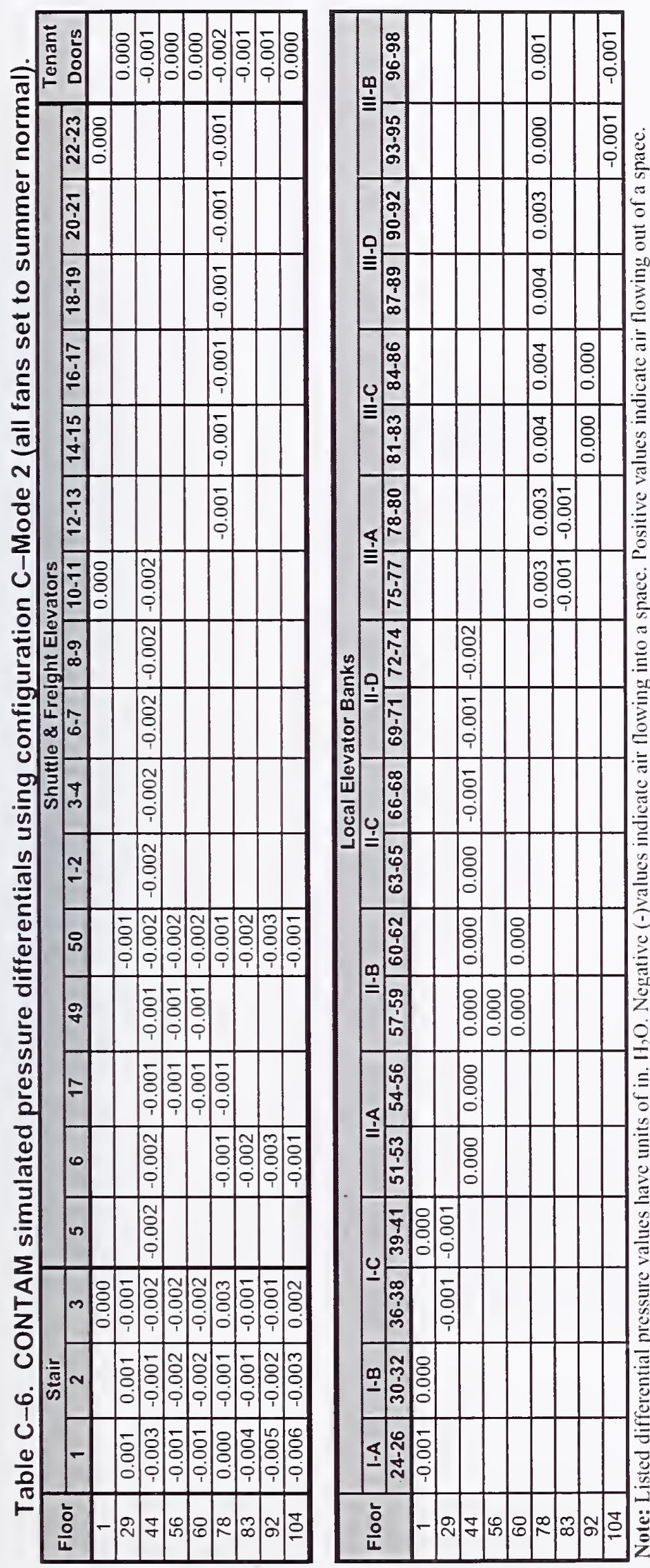

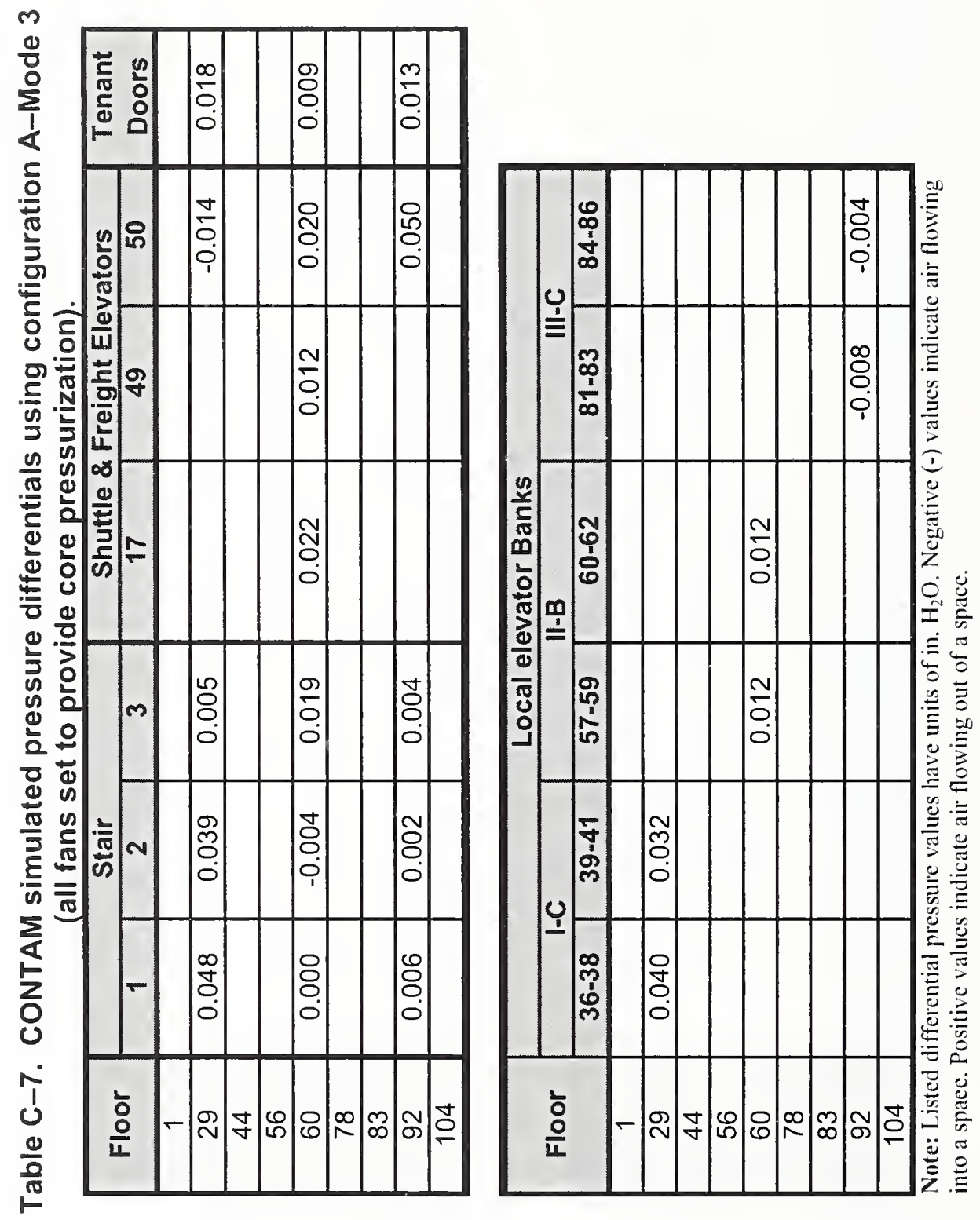

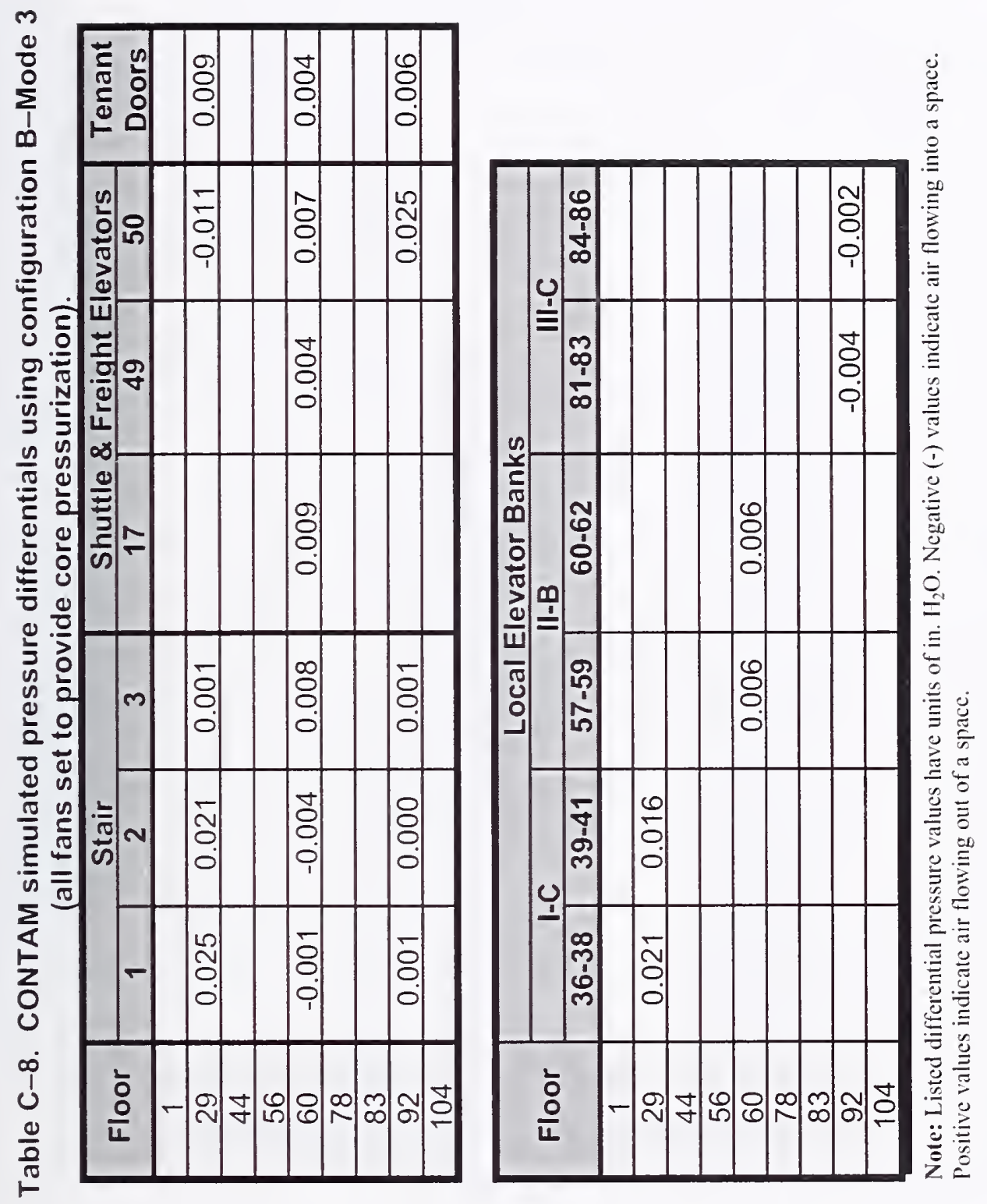

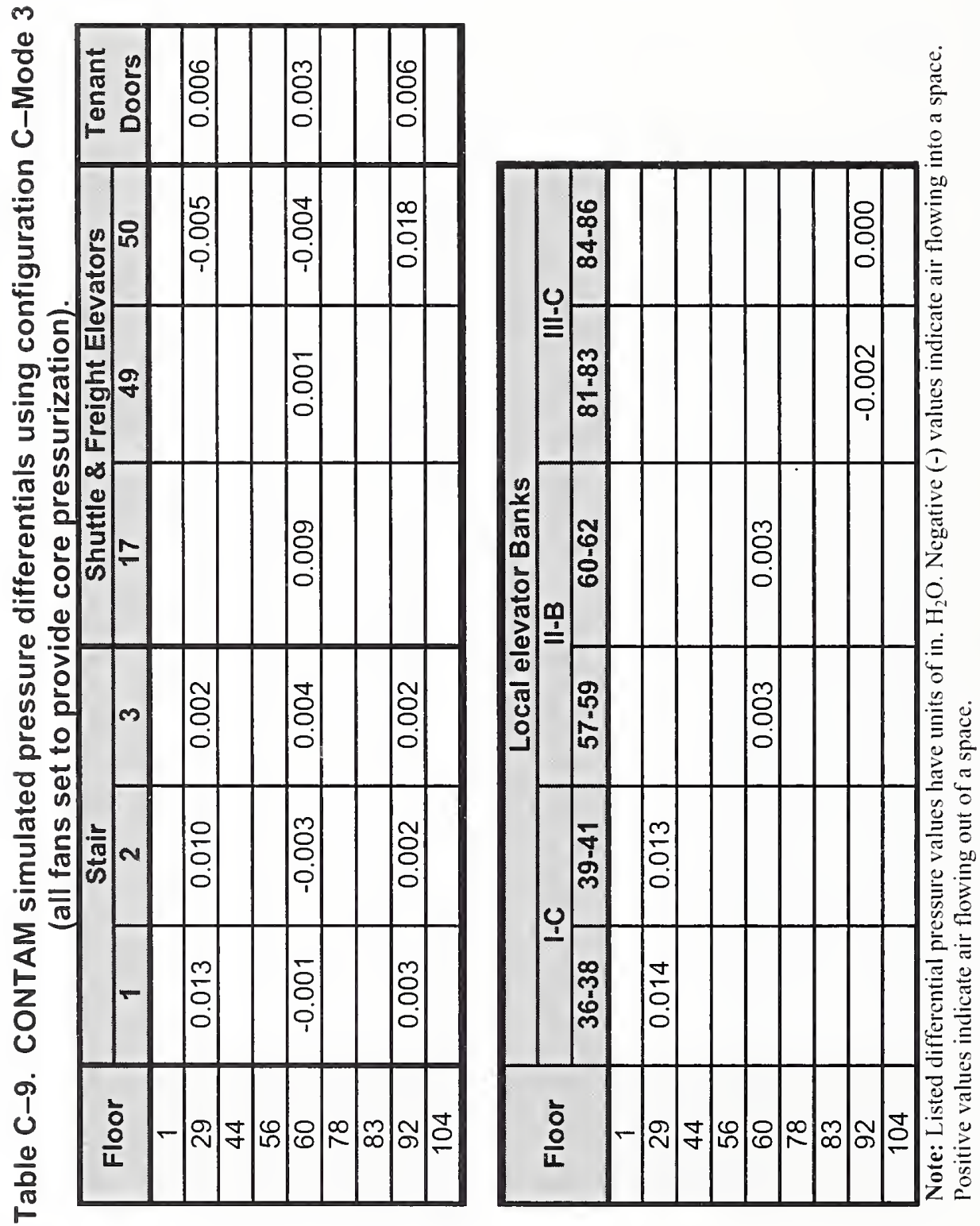


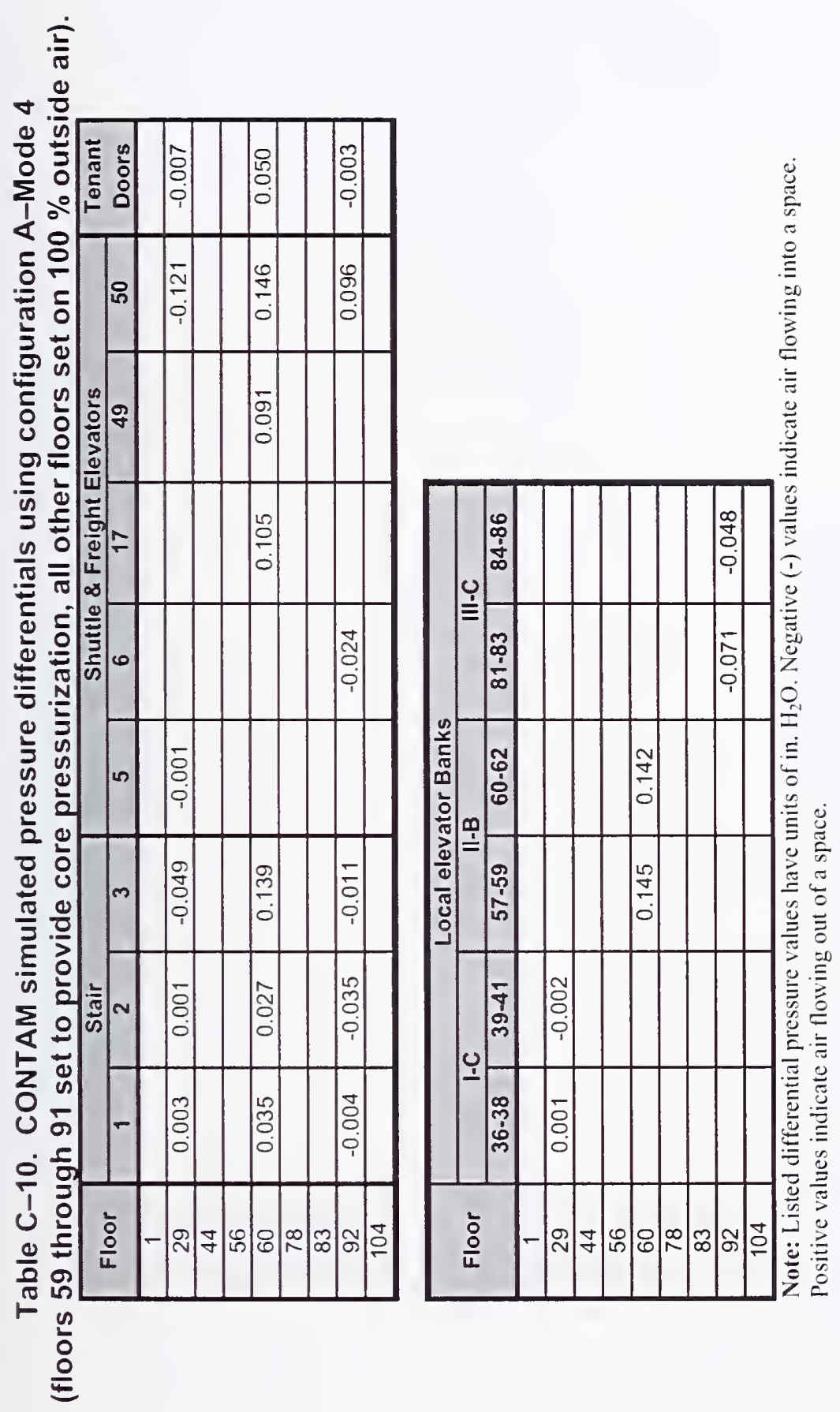




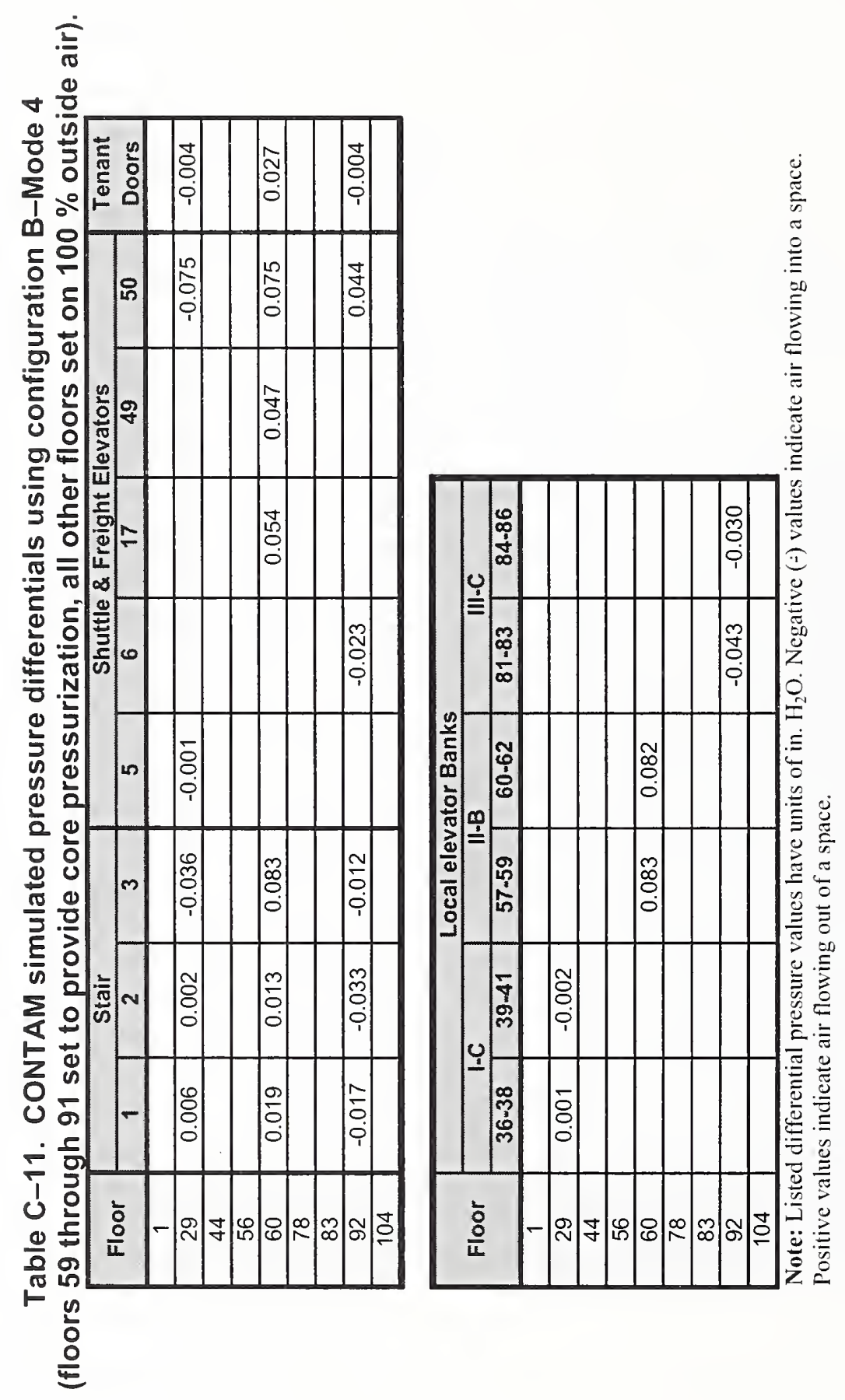




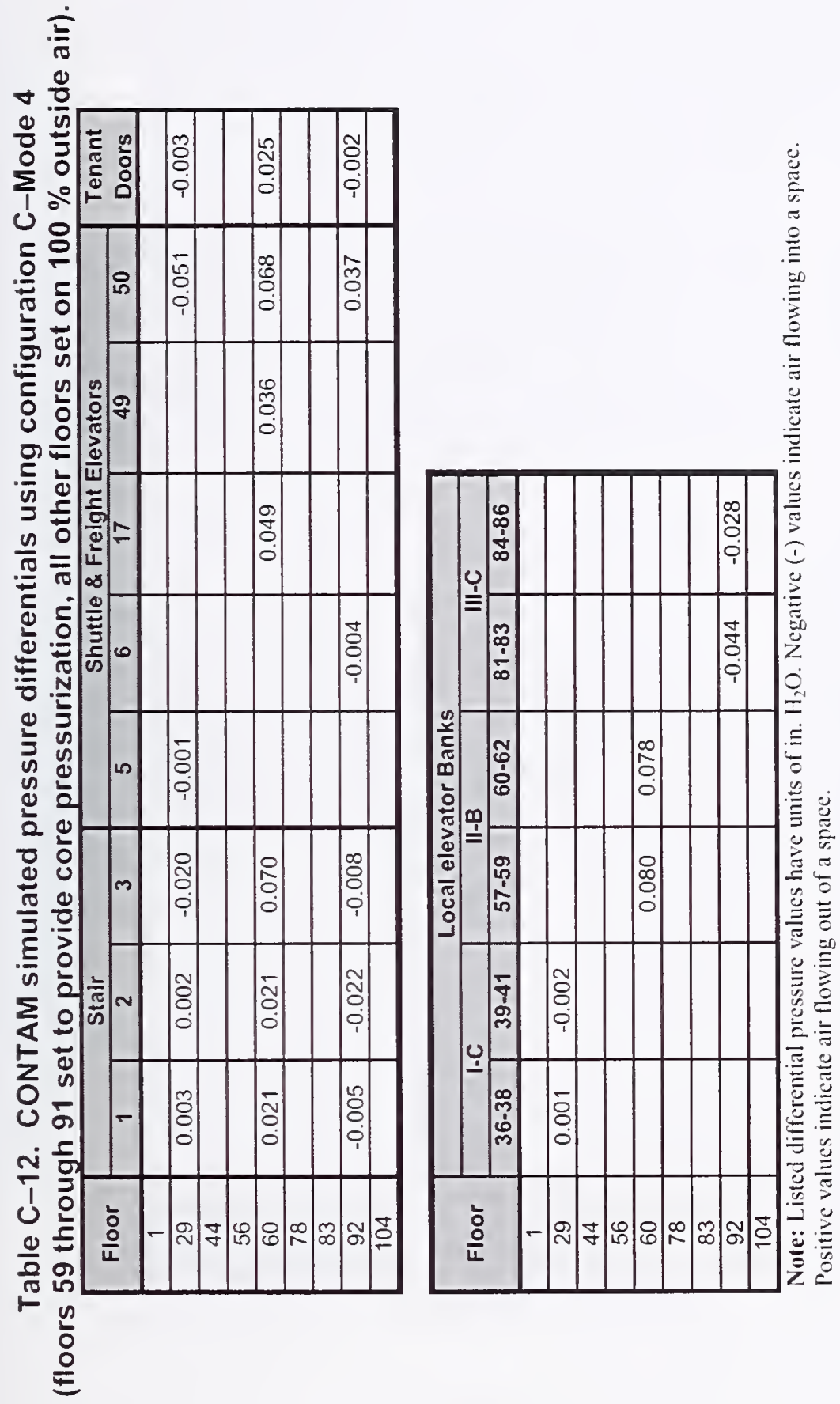




\section{C.3.3 Comparison of Results-Measured versus Predicted}

Graphical comparisons between measured and predicted pressure differentials, for HVAC Modes 1 through 4 , are shown in Figs. C-1 through C-20. When considering these figures it would appear that in some cases the agreement between measured and predicted values appears quite good and in some cases measured and predicted values vary substantially. Since measured pressures were often in the range of 0.01 in. $\mathrm{H}_{2} \mathrm{O}$ to $0.2 \mathrm{in} . \mathrm{H}_{2} \mathrm{O}$, the overall agreement between measured and predicted values was good, off by a factor of 1-2 rather than an order of magnitude. Differences between measured and predicted values are due to uncertainties and simplifications in the model, as discussed in Sec. C.3.4.

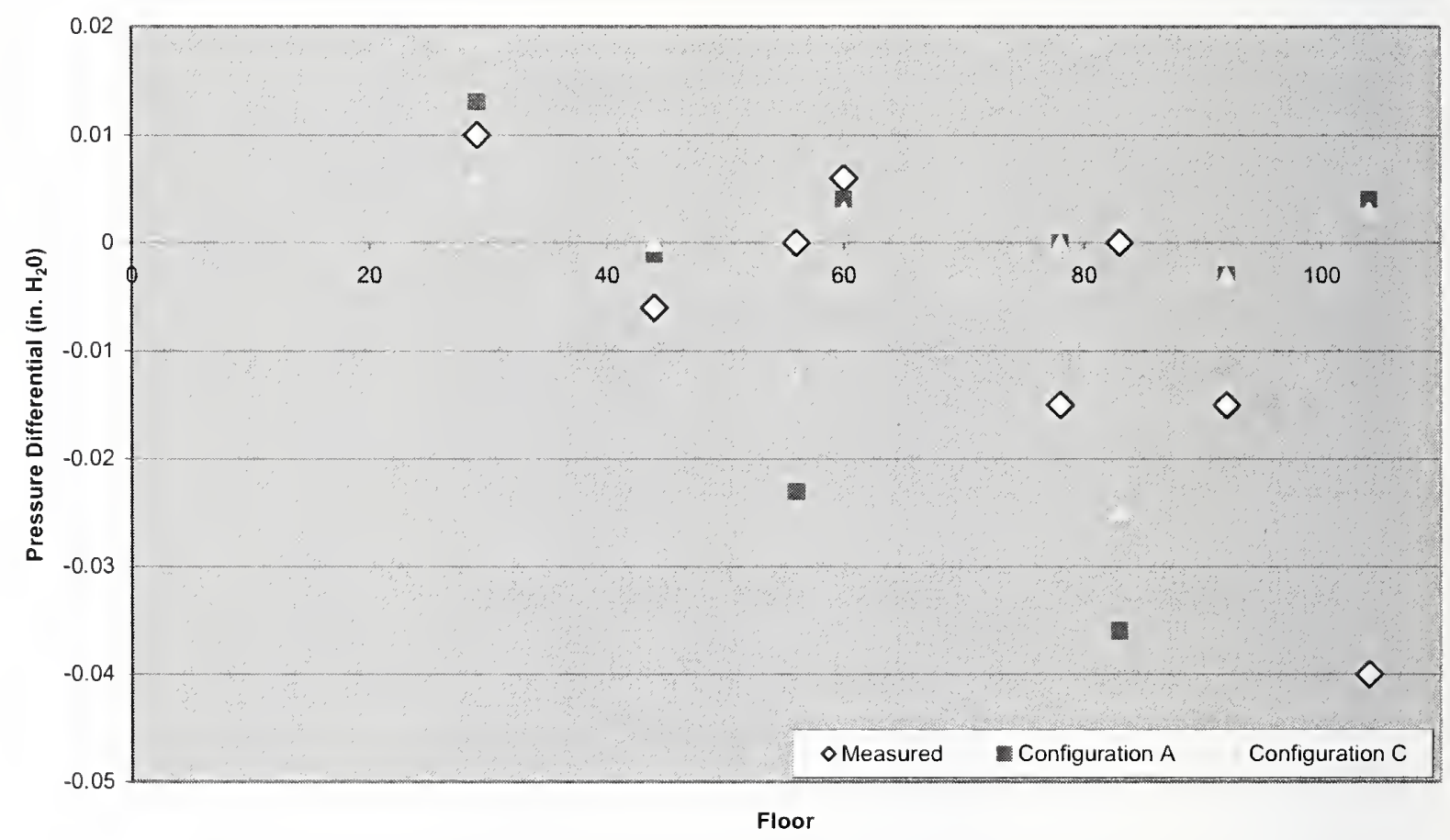

Figure C-1. Mode 1, all fans off, stair 1. 


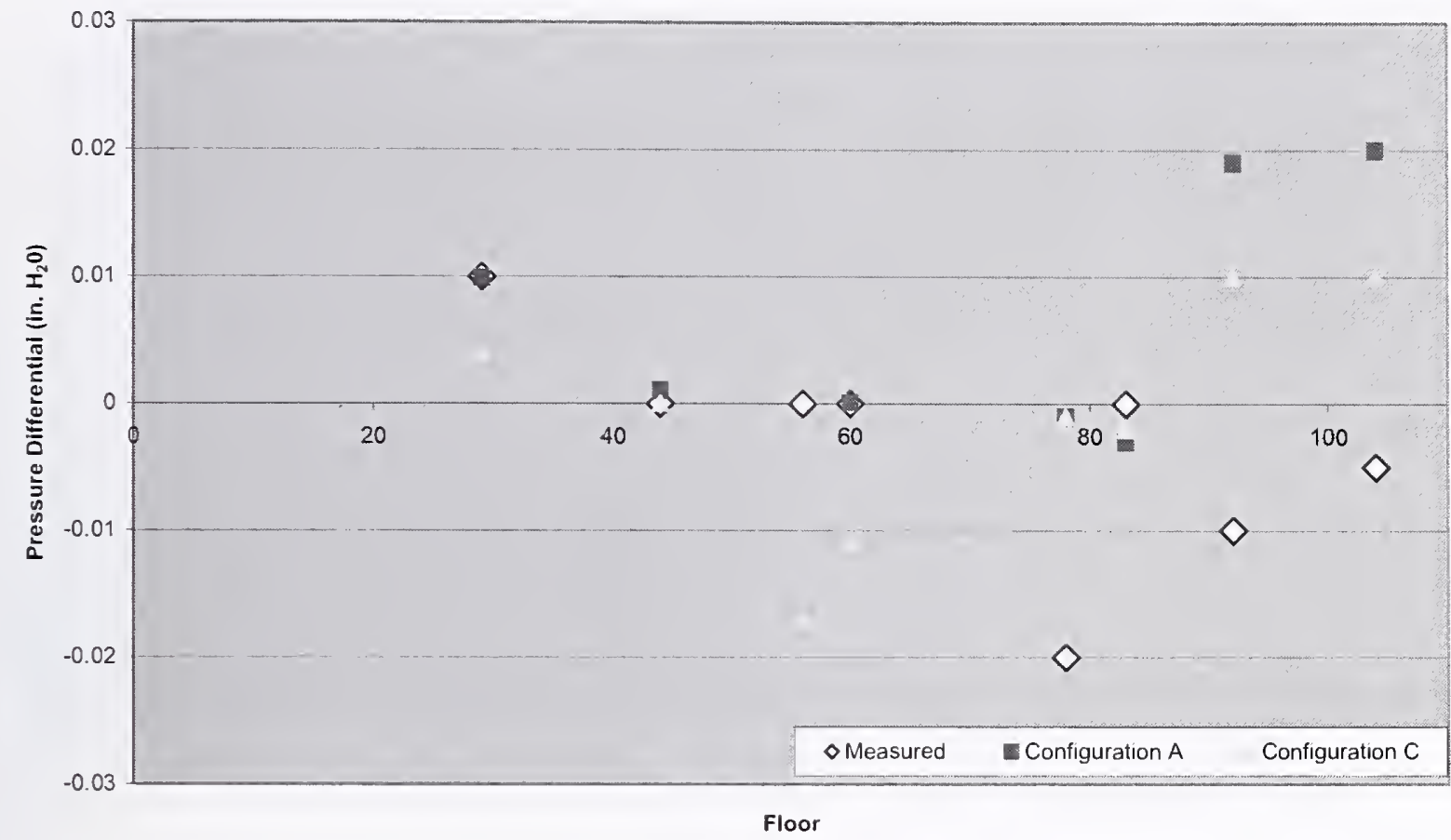

Figure C-2. Mode 1, all fans off, stair 2.

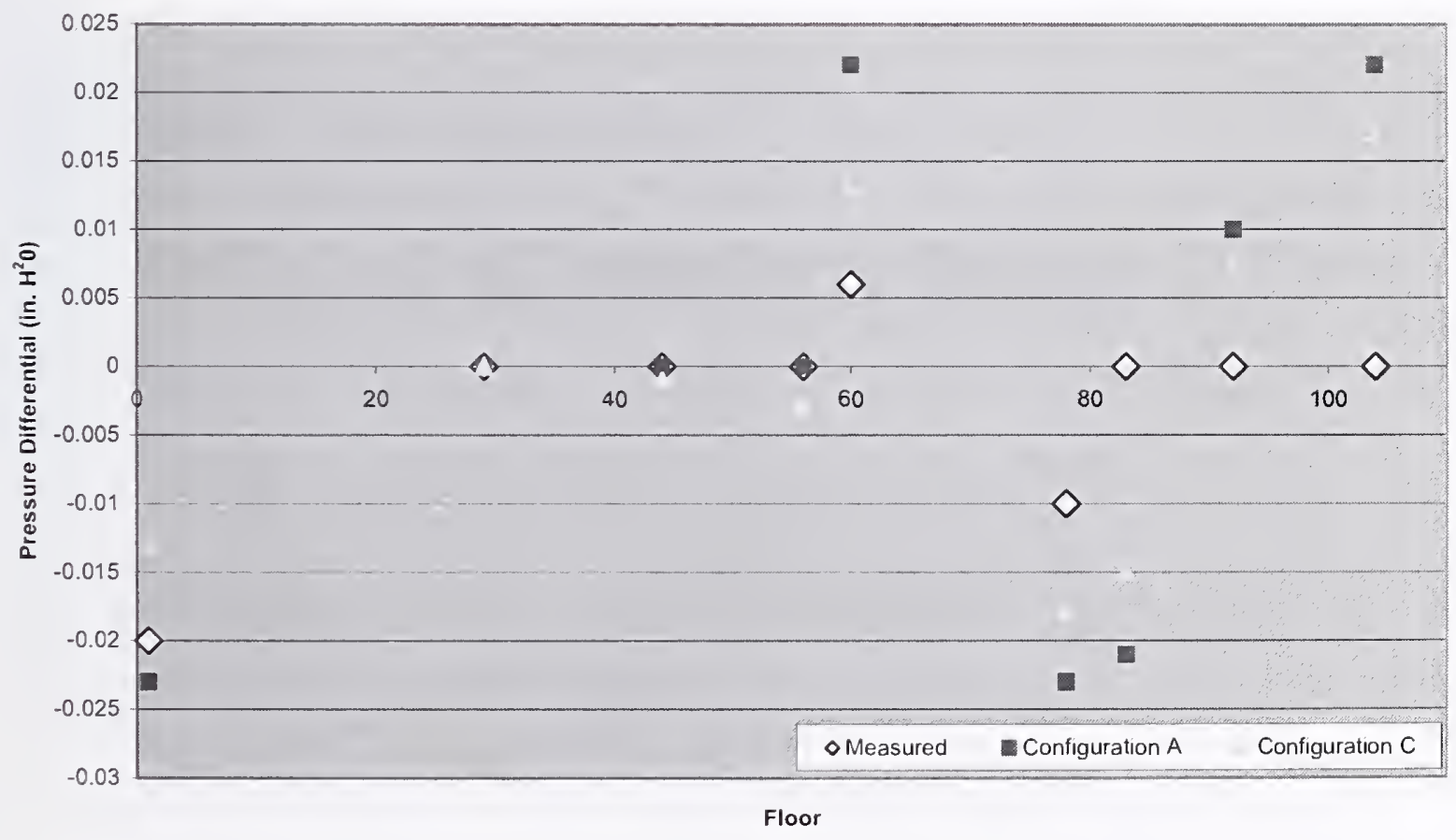

Figure C-3. Mode 1, all fans off, stair 3. 


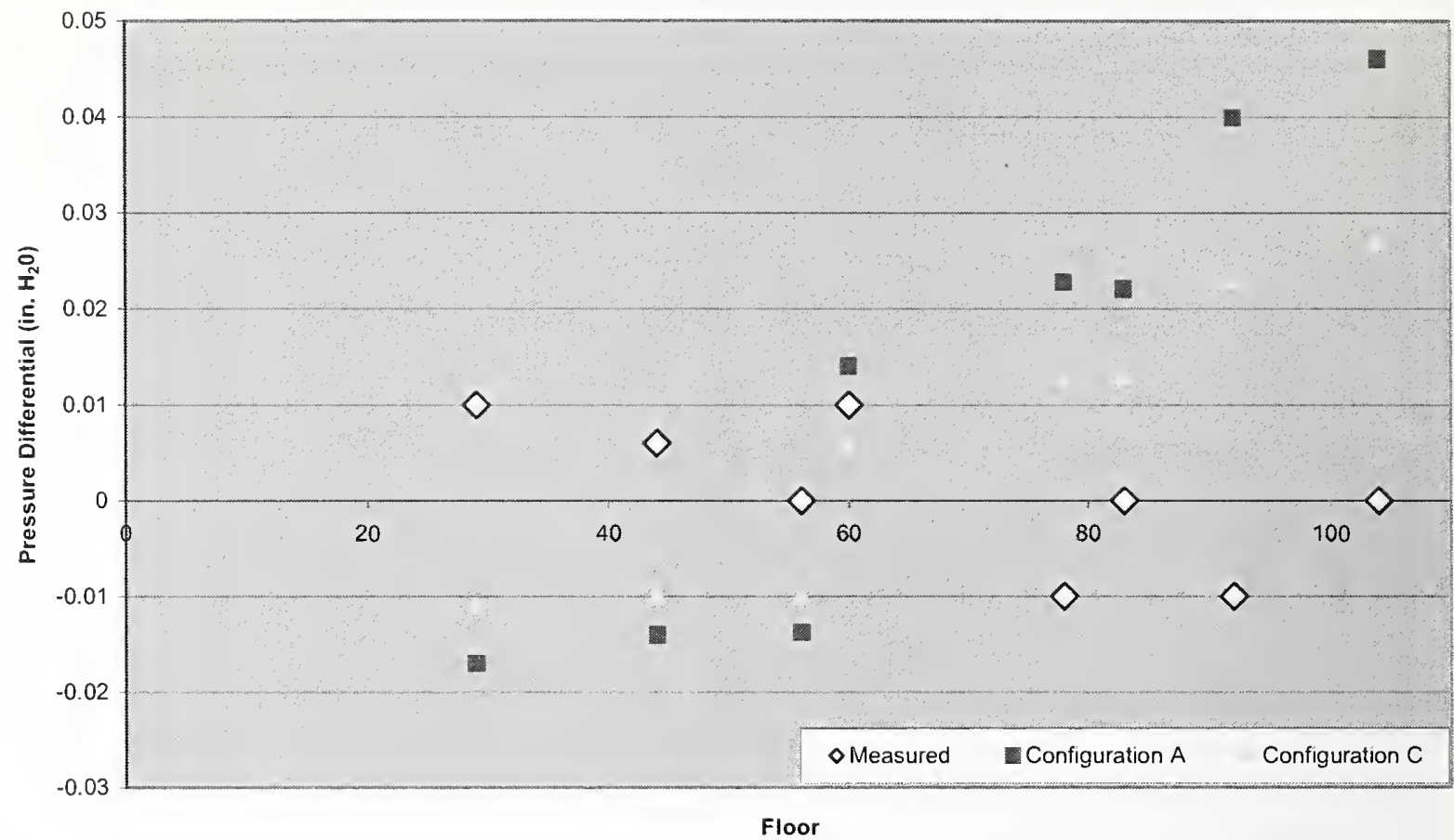

Figure C-4. Mode 1, all fans off, elevator 50.

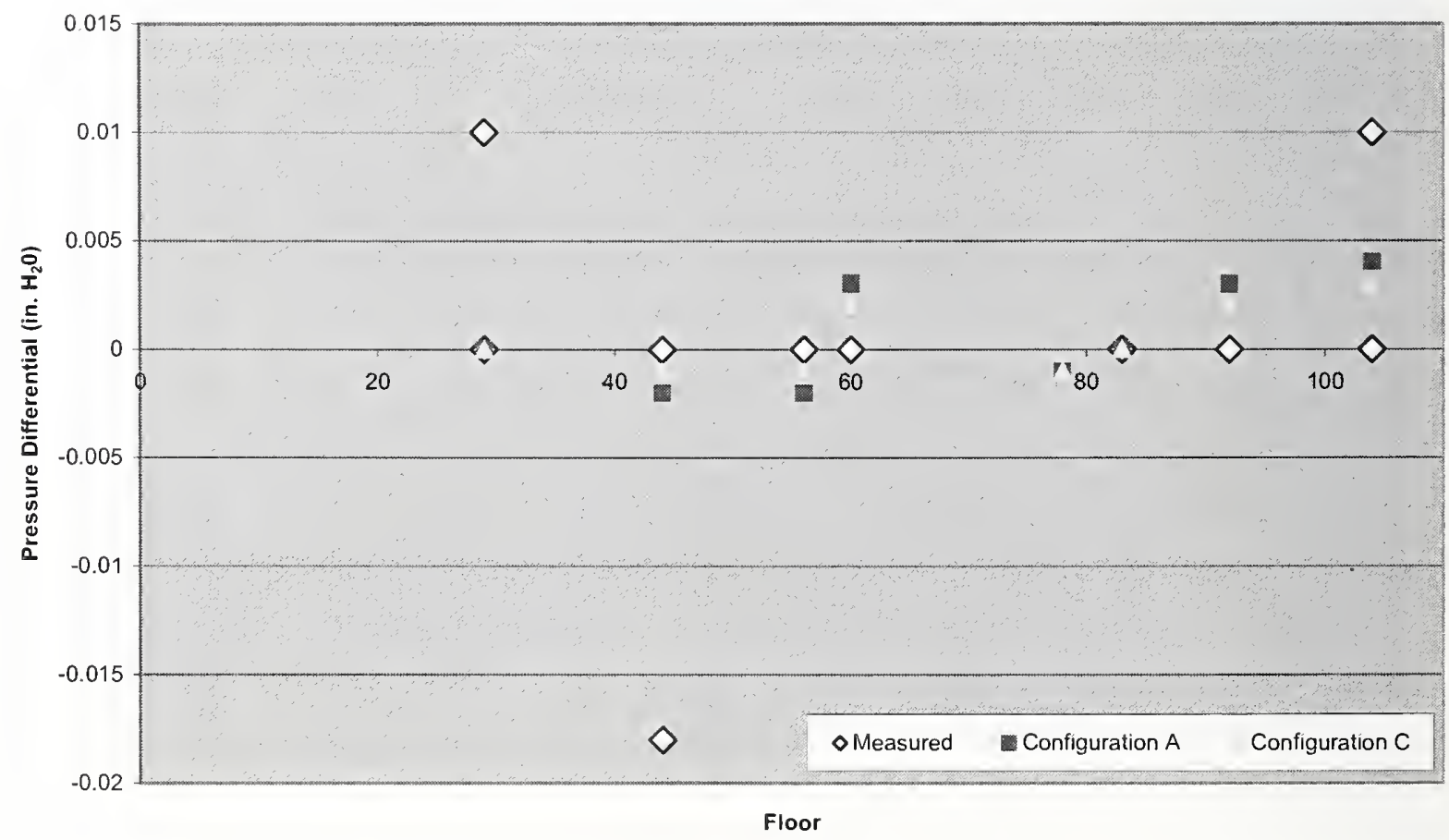

Figure $\mathrm{C}-5$. Mode 1, all fans off, tenant doors. 


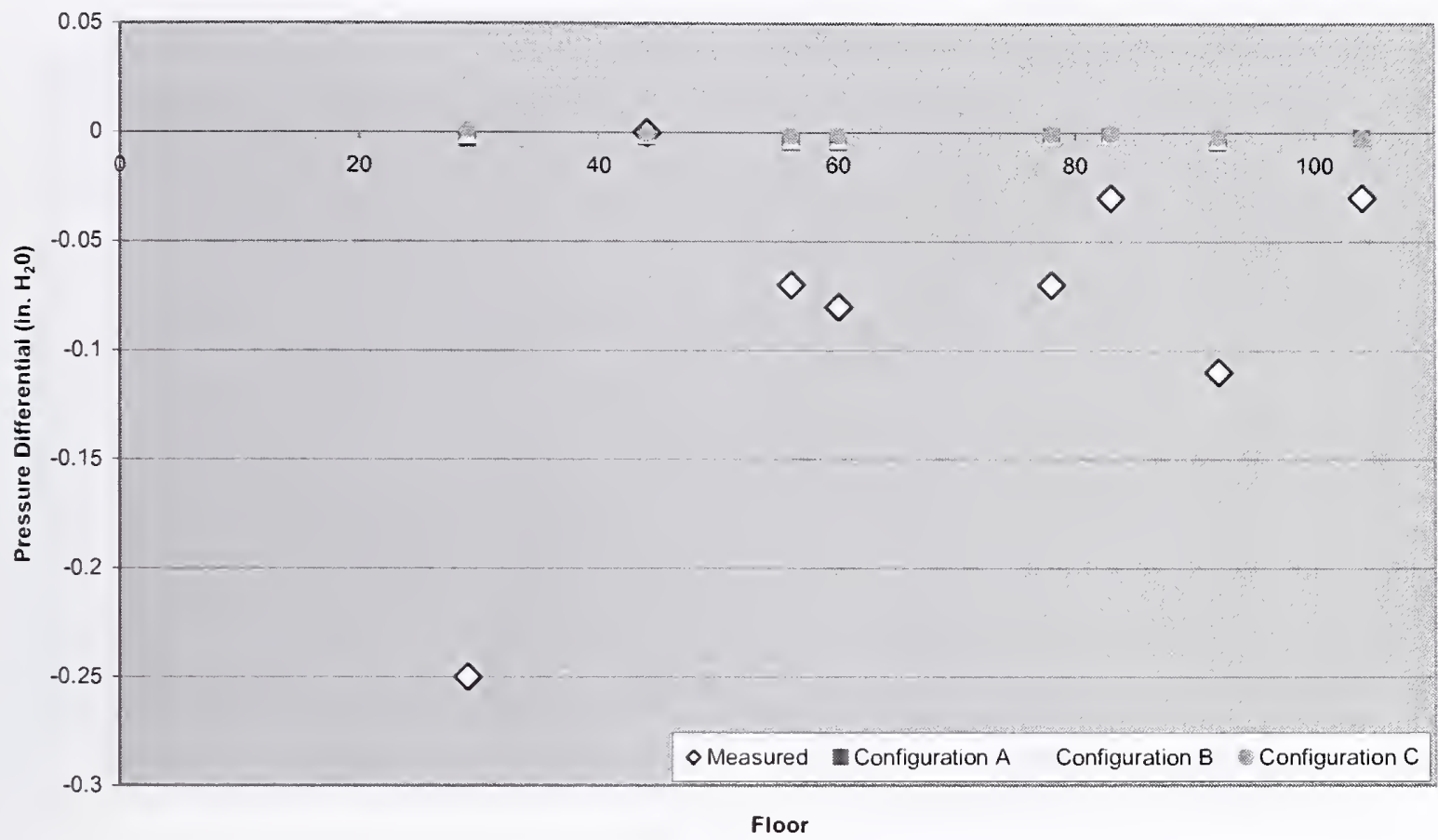

Figure C-6. Mode 2, all fans set to summer normal, stair 1 .

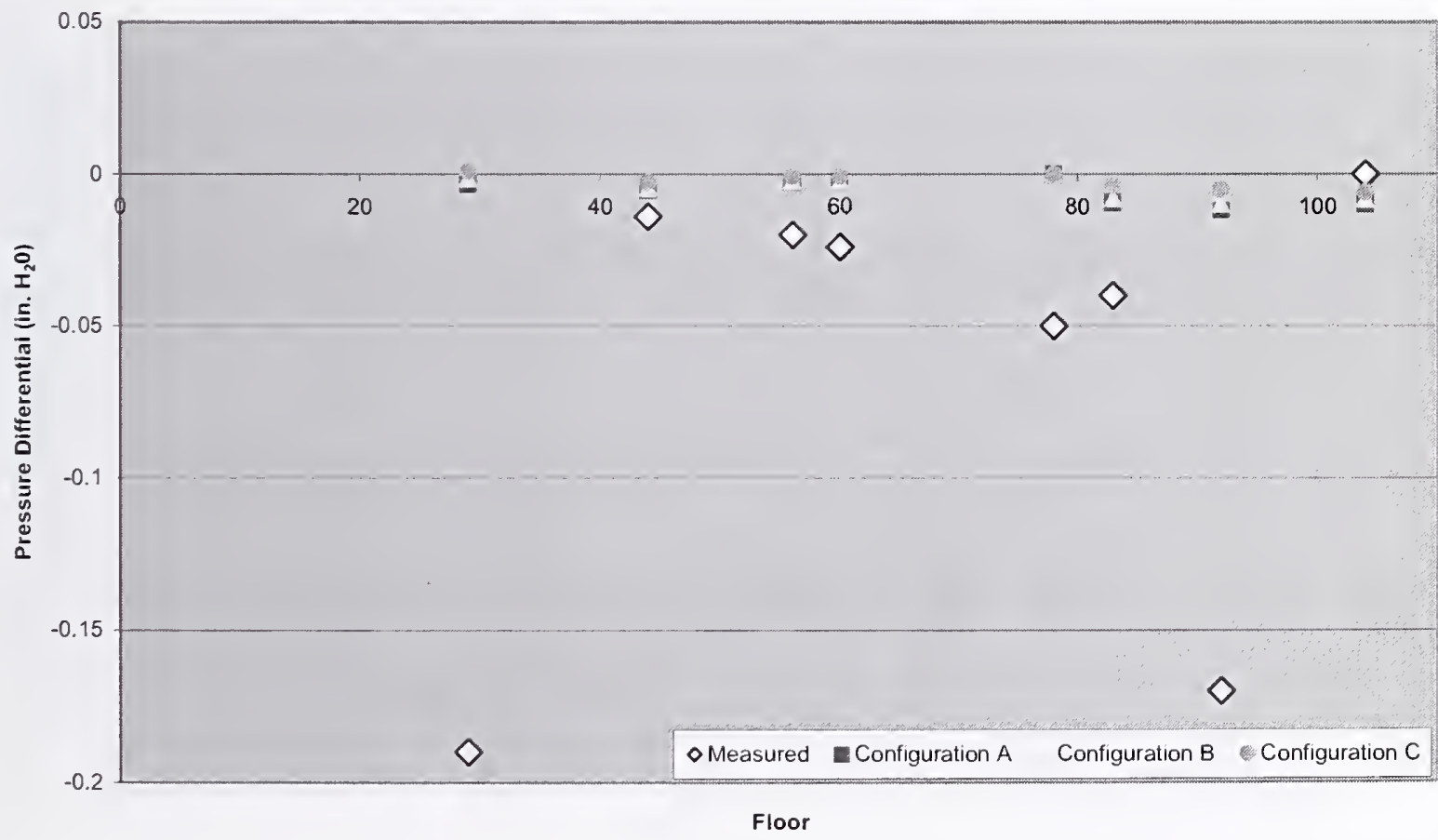

Figure C-7. Mode 2, all fans set to summer normal, stair 2. 


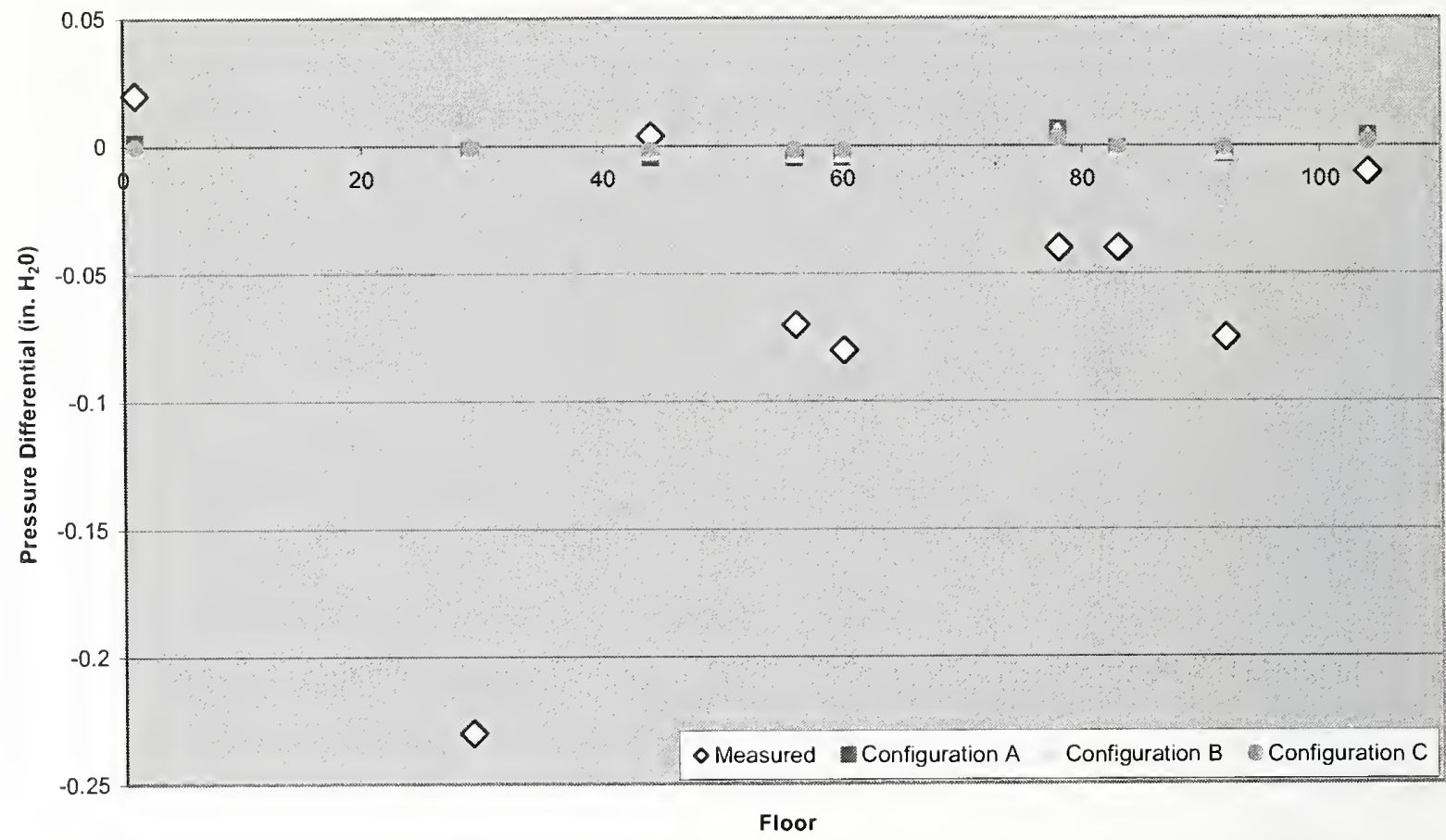

Figure C-8. Mode 2, all fans set to summer normal, stair 3.

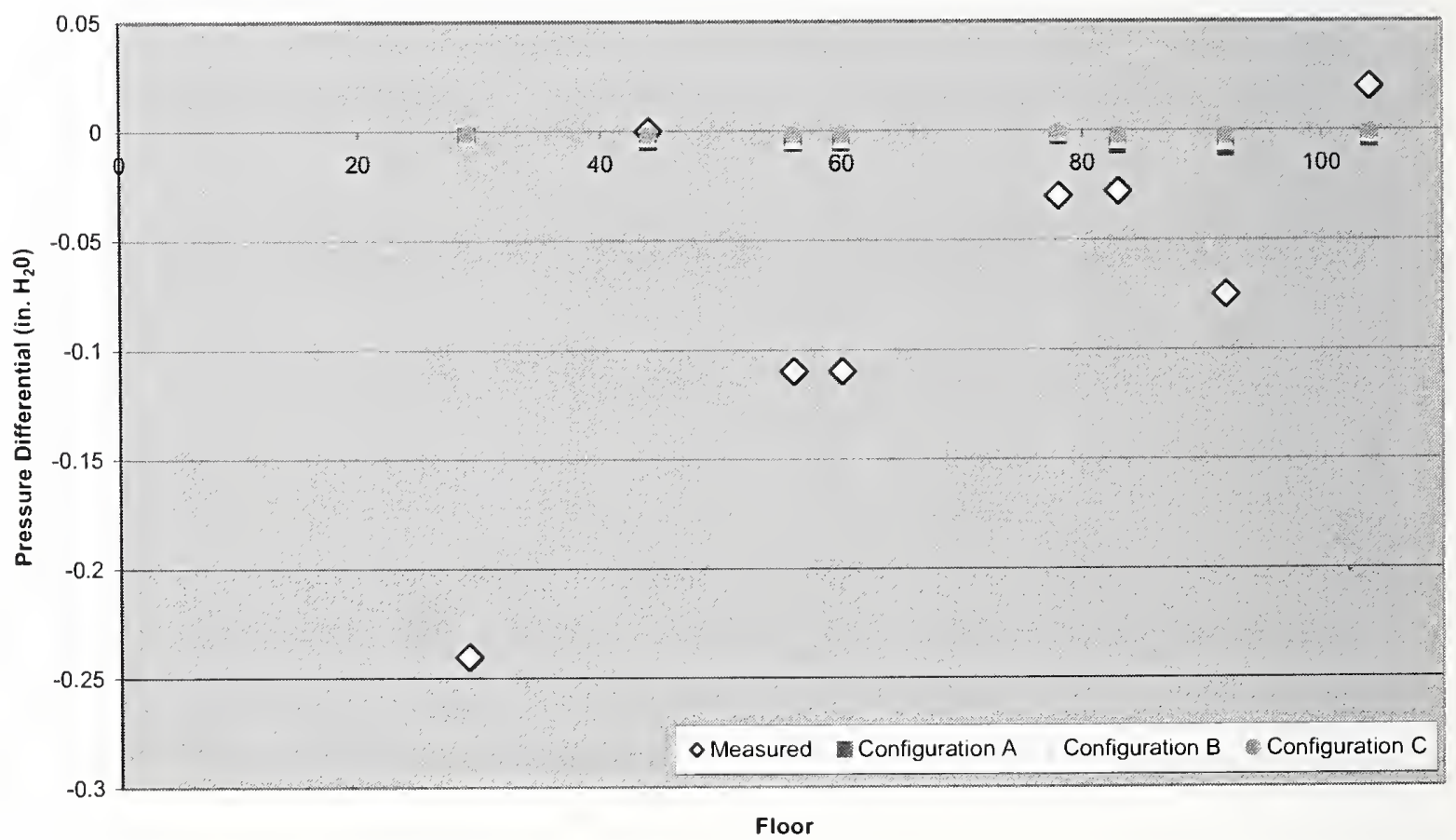

Figure C-9. Mode 2, all fans set to summer normal, elevator 50. 


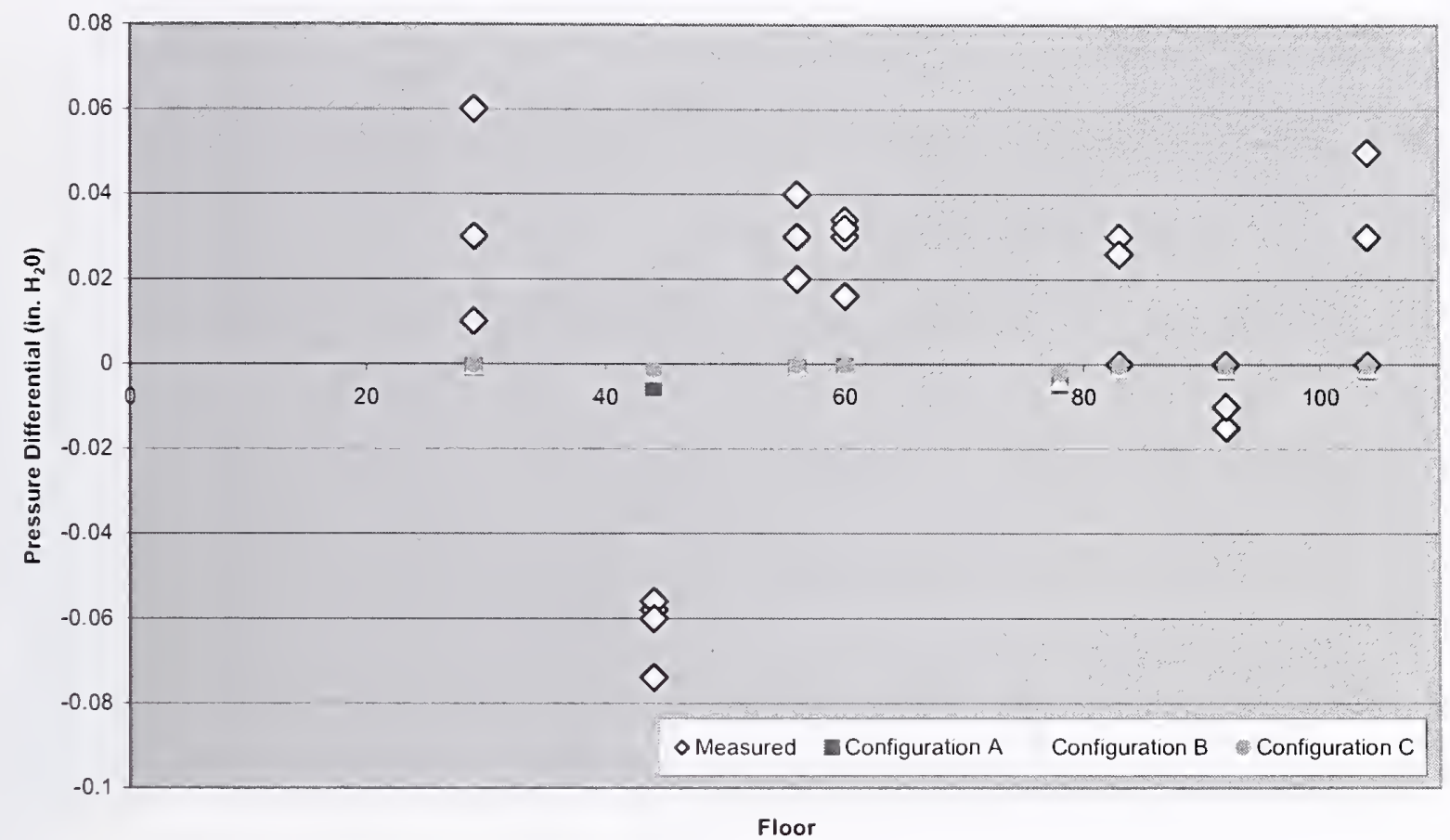

Figure $\mathrm{C}-10$. Mode 2, all fans set to summer normal, tenant doors.

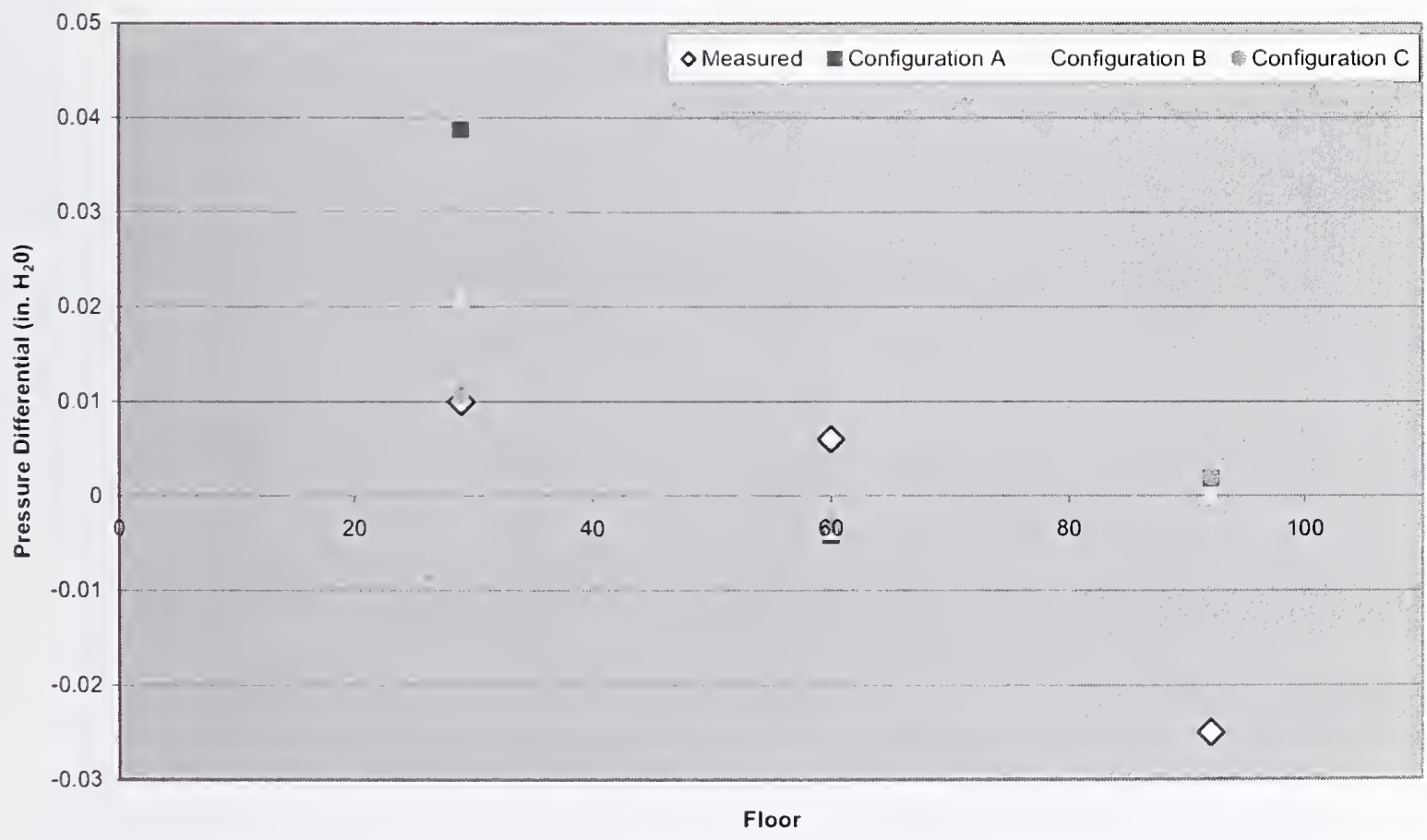

Figure $\mathrm{C}-11$. Mode 3, fan set for core pressurization for the full height of tower, stair 1. 


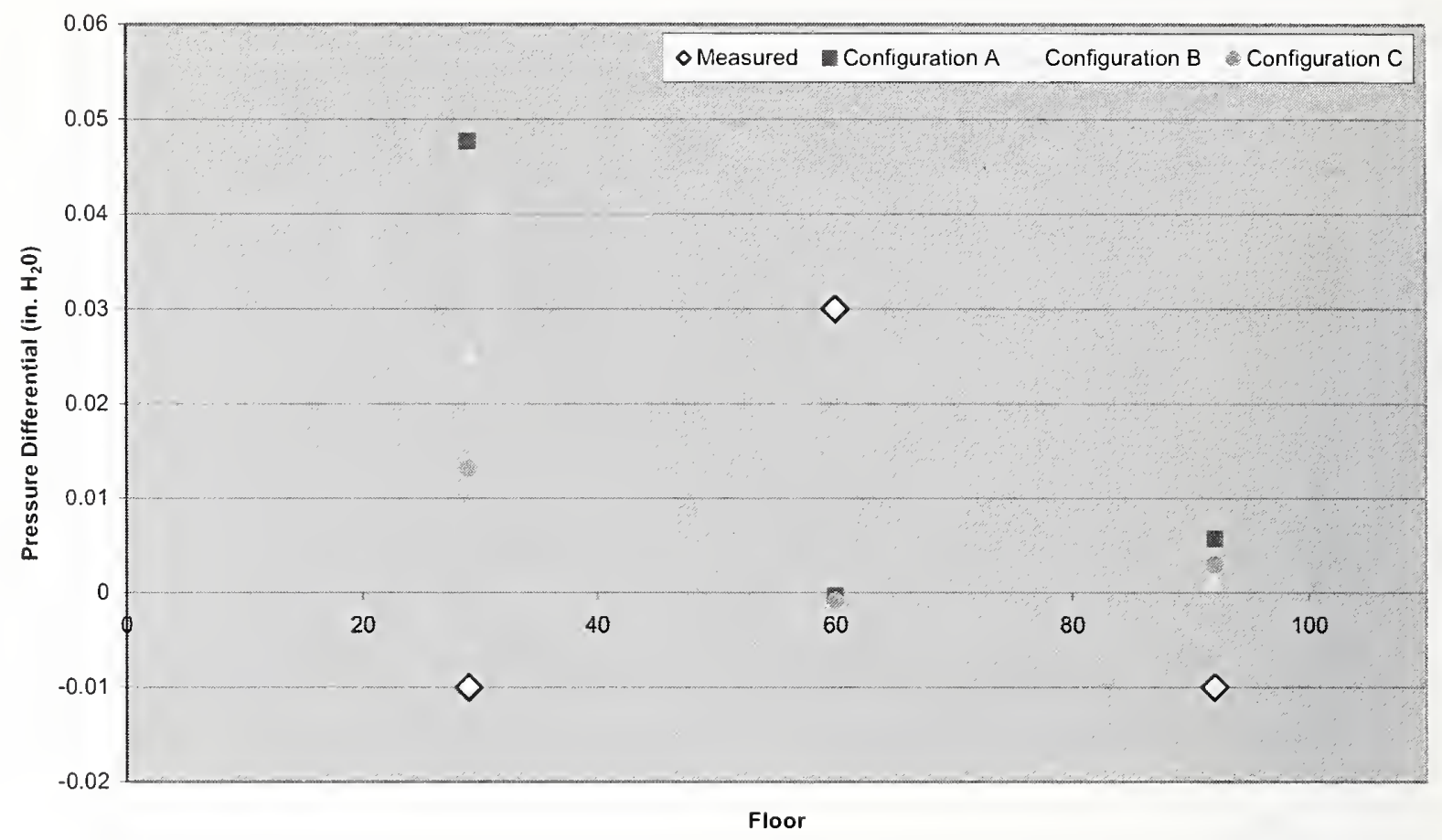

Figure C-12. Mode 3, fan set for core pressurization for the full height of tower, stair 2.

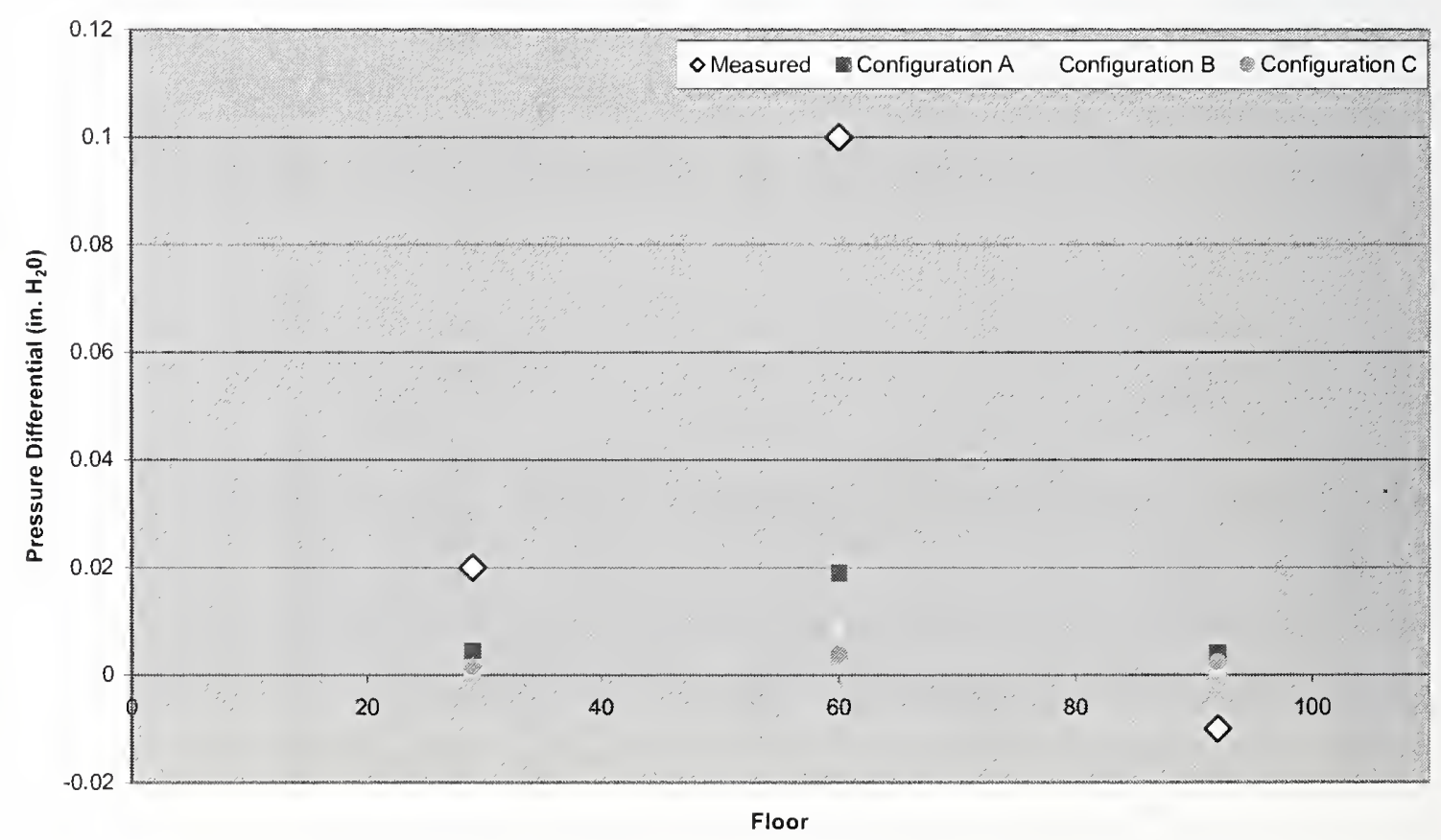

Figure C-13. Mode 3, fan set for core pressurization for the full height of tower, stair 3. 


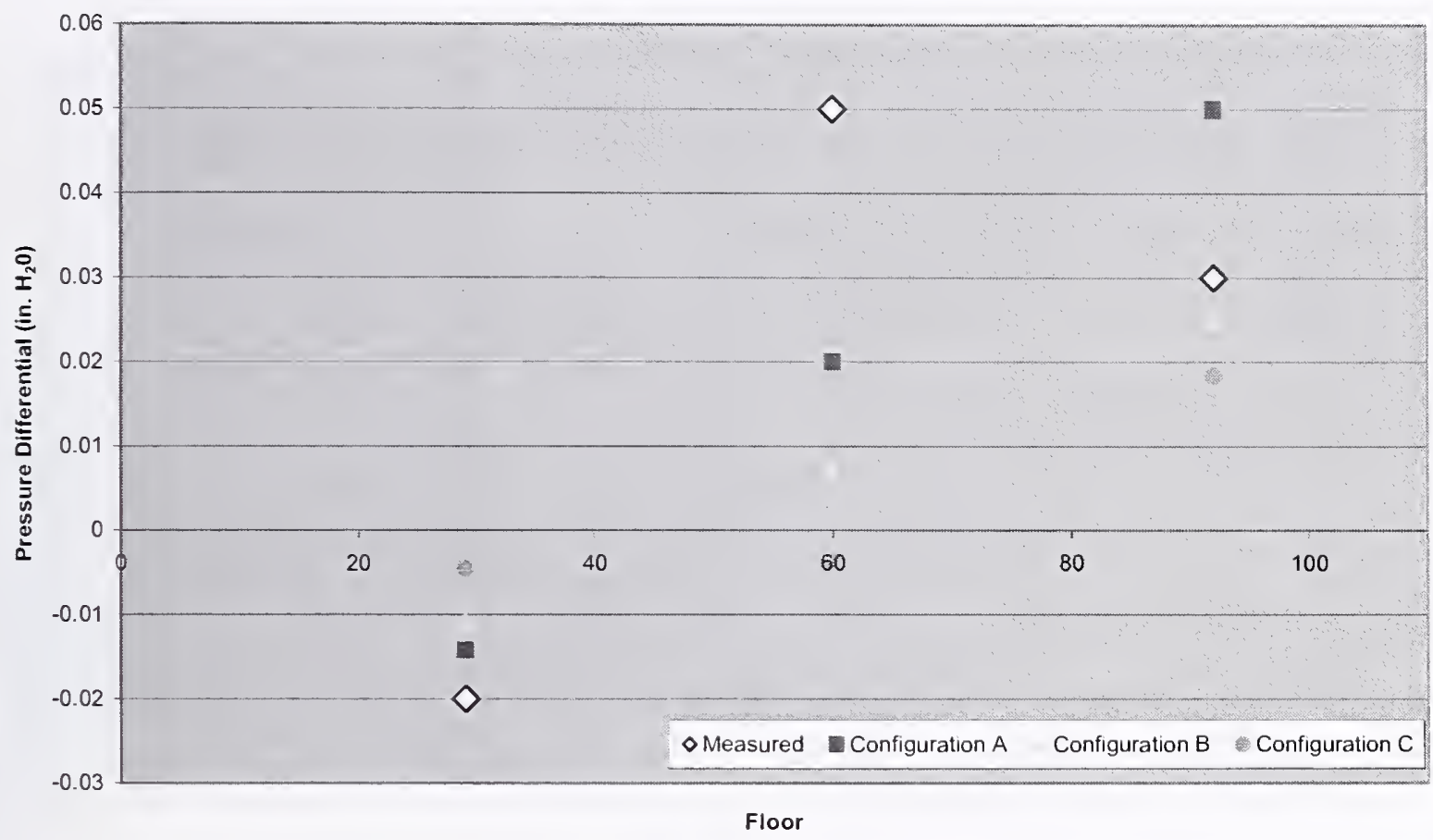

Figure C-14. Mode 3, fan set for core pressurization for the full height of tower, elevator 50 .

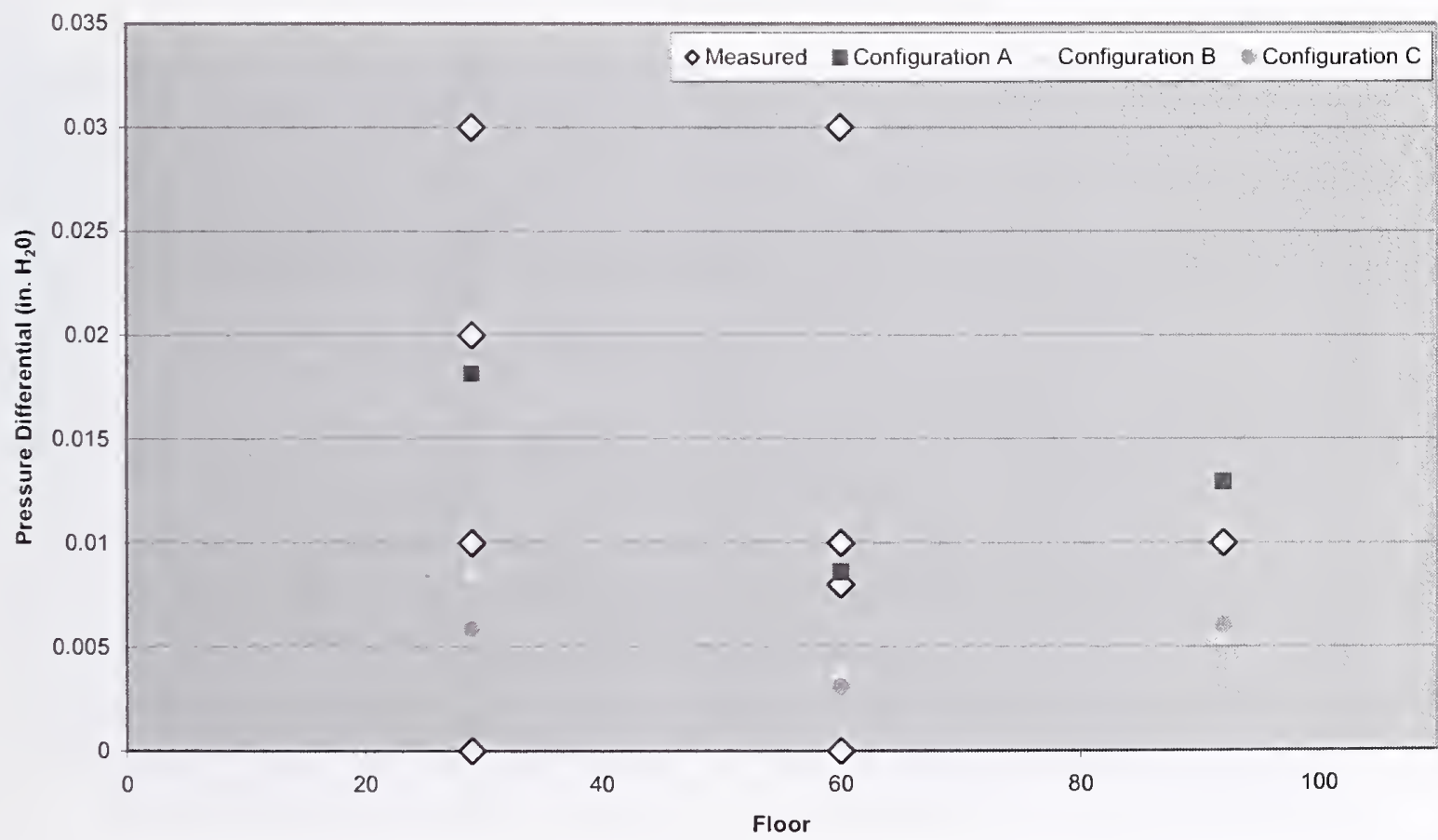

Figure C-15. Mode 3, fan set for core pressurization for the full height of tower, tenant doors. 


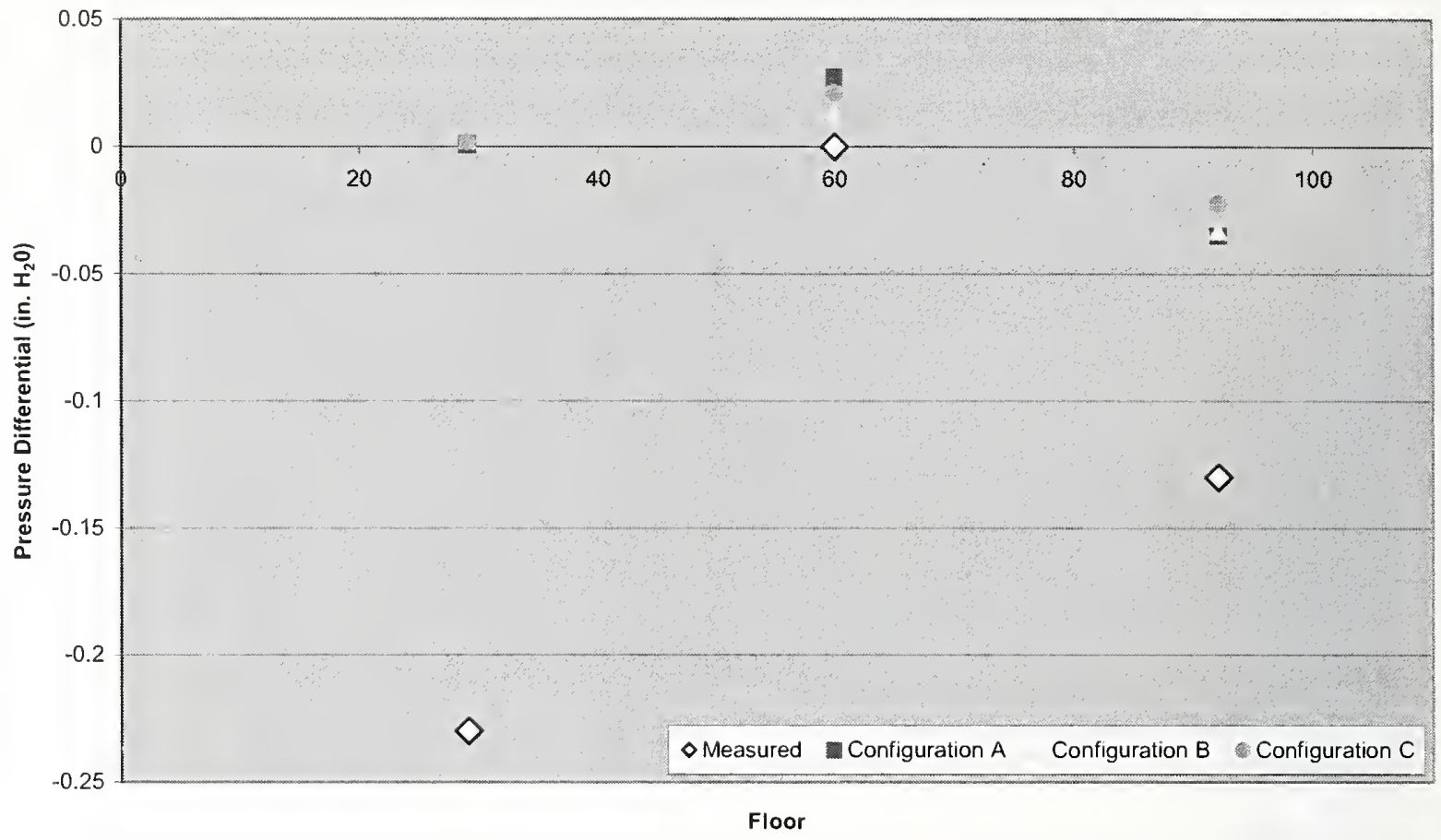

Figure C-16. Mode 4, floors 59 through 91 set for core pressurization, all other floors 100 percent recirculation, stair 1.

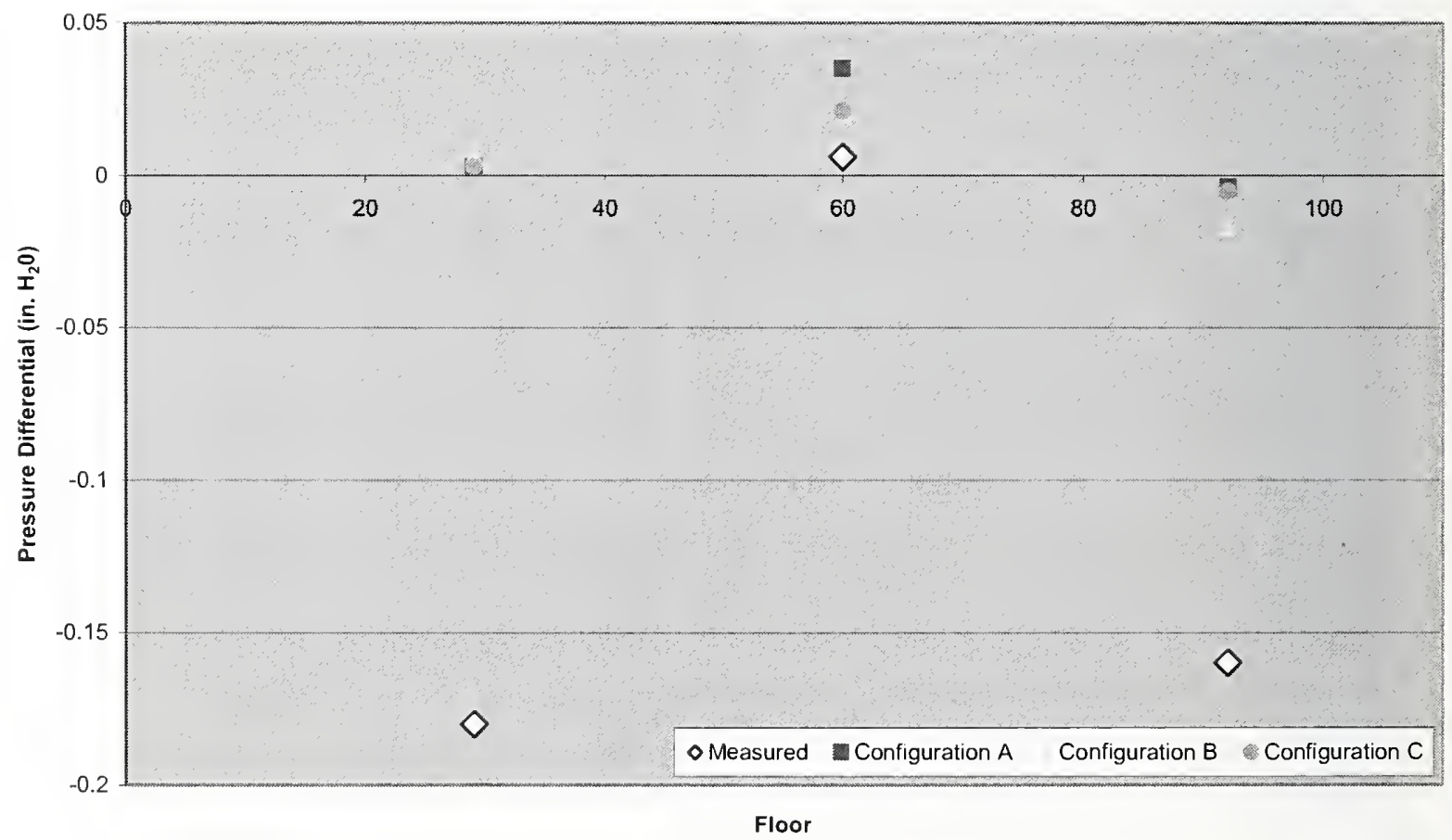

Figure C-17. Mode 4, floors 59 through 91 set for core pressurization, all other floors 100 percent recirculation, stair 2. 


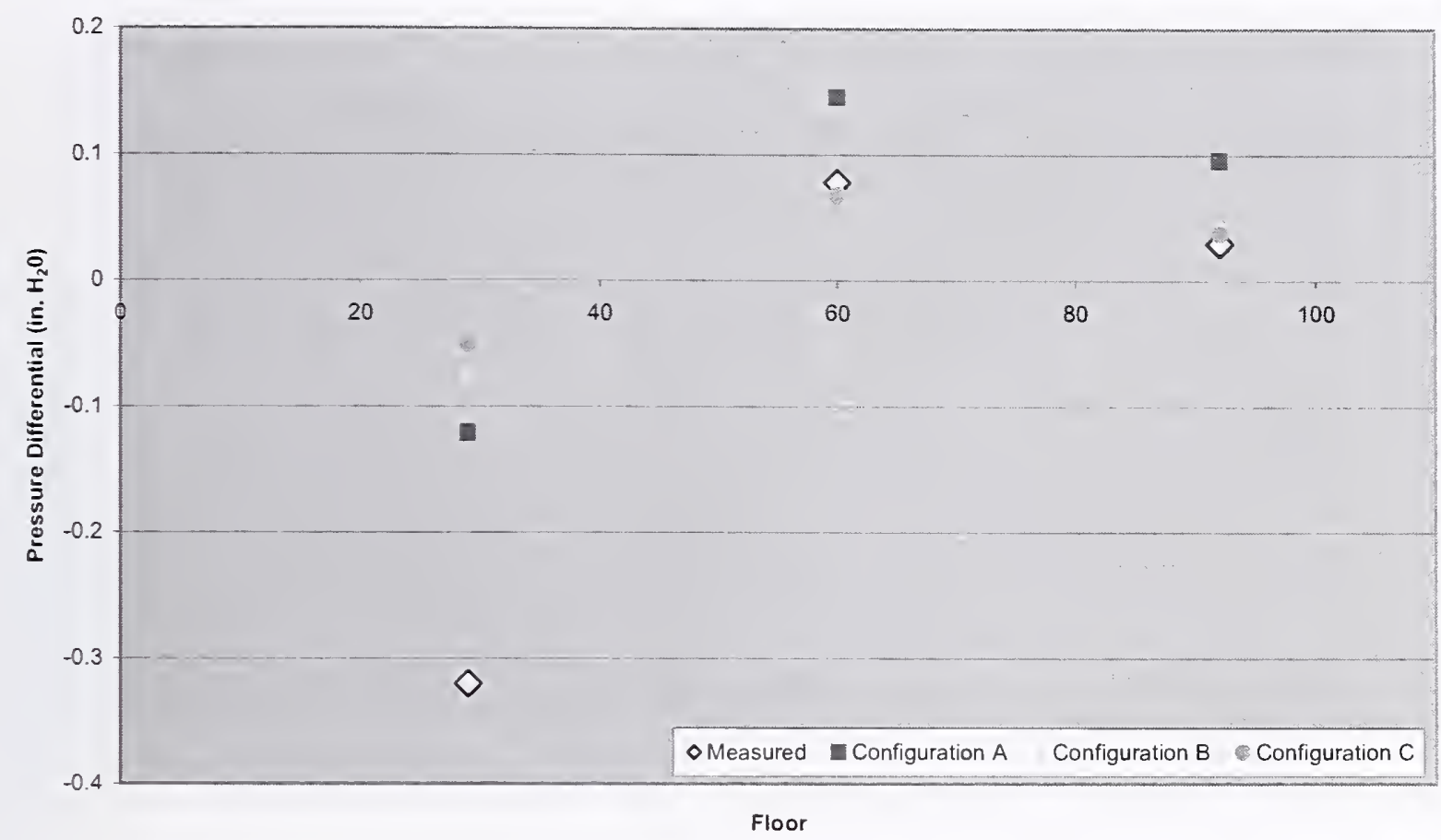

Figure C-18. Mode 4, floors 59 through 91 set for core pressurization, all other floors 100 percent recirculation, stair 3 .

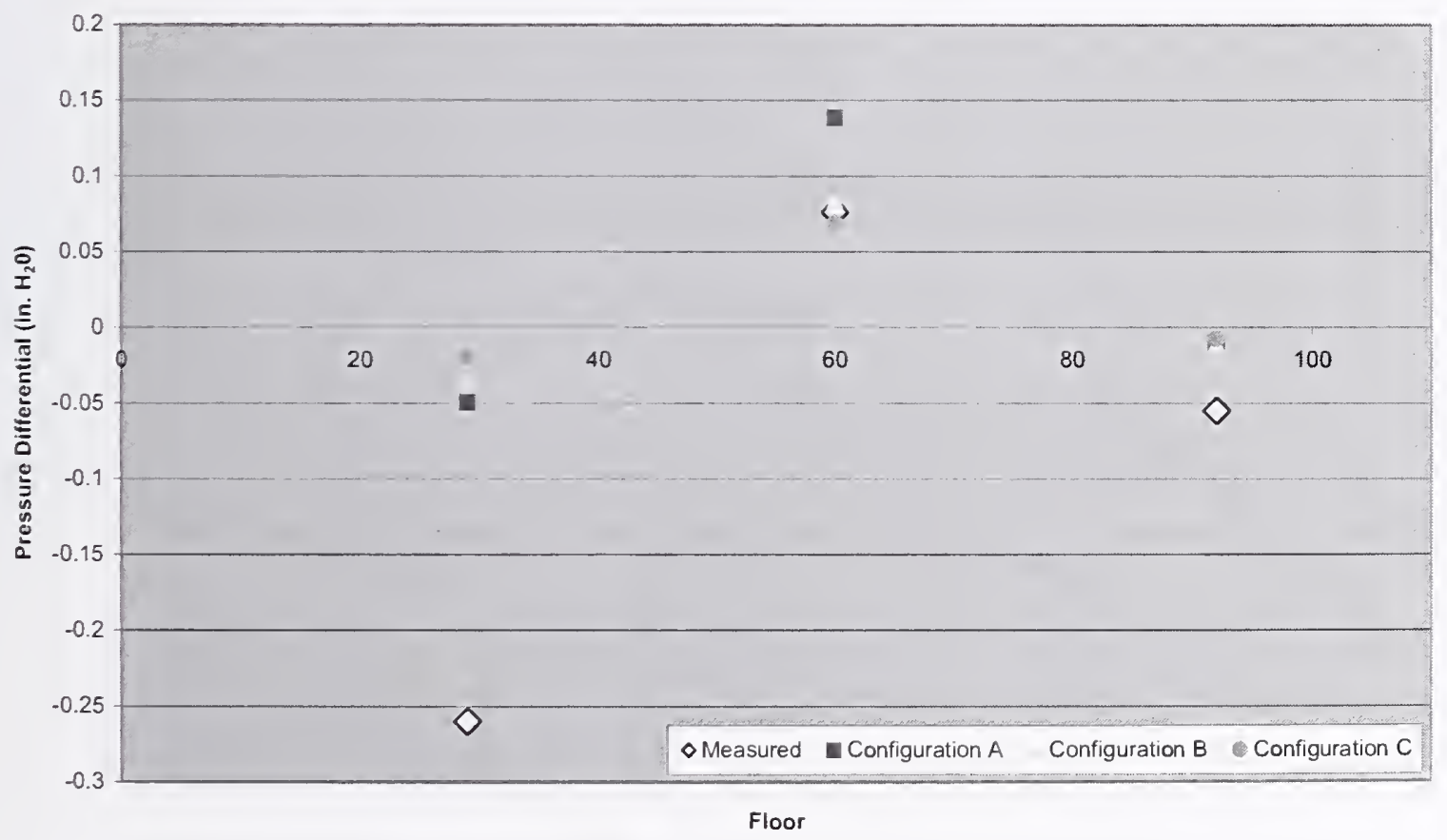

Figure C-19. Mode 4, floors 59 through 91 set for core pressurization, all other floors 100 percent recirculation, elevator 50. 


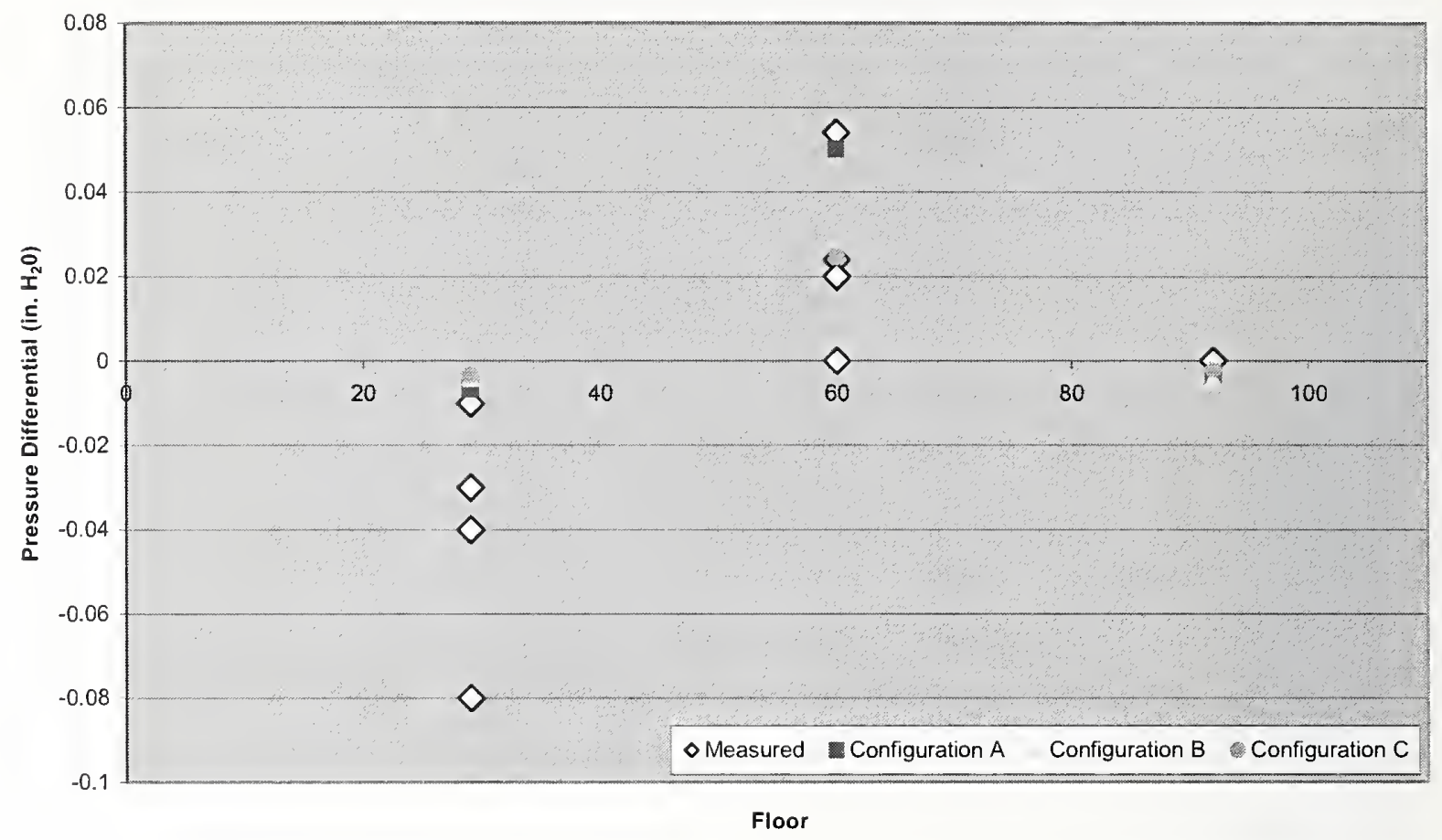

Figure C-20. Mode 4, floors 59 through 91 set for core pressurization, all other floors 100 percent recirculation, tenant doors.

\section{C.3.4 Affect of Temperature Variation}

As discussed in Appendix B (Sec. B.1.4), testing of Modes 1 through 4 conducted in support of the $1996 \mathrm{HAI} / \mathrm{DCE}$ study took place on June 30, 1996, between 1:00 a.m. and 3:00 p.m. The National Oceanic and Atmospheric Administration reported a temperature range of $60^{\circ} \mathrm{F}$ to $75^{\circ} \mathrm{F}$ on this date. Since the 1996 study does not document when during the stated time period each test was performed, it is unclear what the temperature was during each test. This had the potential to impact predicted pressure differentials due to the impact of stack effect. As seen in Figs. C-21 through C-25, predicted pressure differentials varied only slightly over a wide range of assumed temperatures. Therefore, Mode 1 was calibrated using an outside temperature of $60^{\circ} \mathrm{F}$ since it was assumed that this test would have logically been run first, during the early morning period. Modes 2 through 4 were calculated assuming an outside air temperature of $70^{\circ} \mathrm{F}$. 


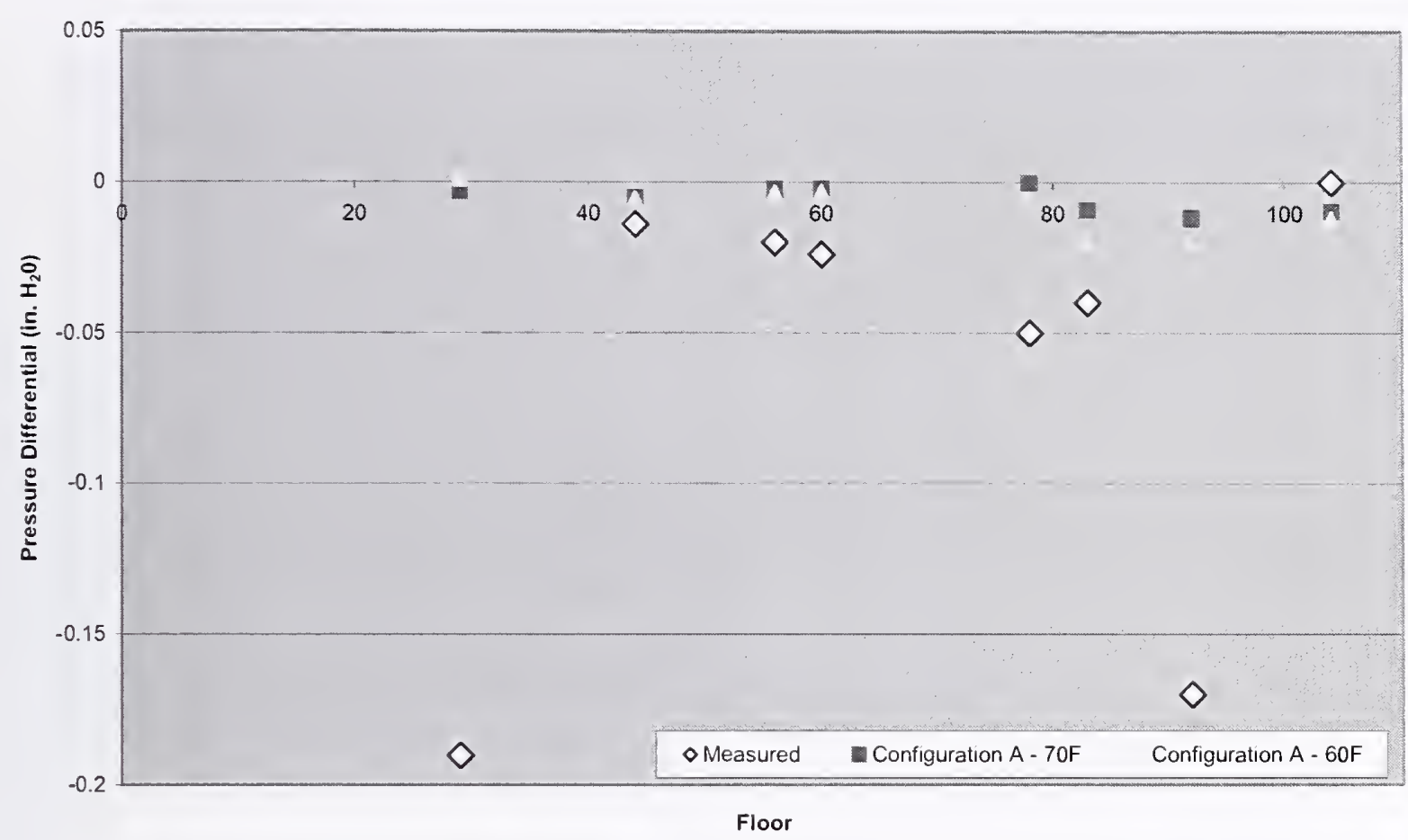

Figure C-21. Mode 2, all fans set to summer normal, configuration $A$ at $60^{\circ} \mathrm{F}$ and $70^{\circ} \mathrm{F}$, stair 1 .

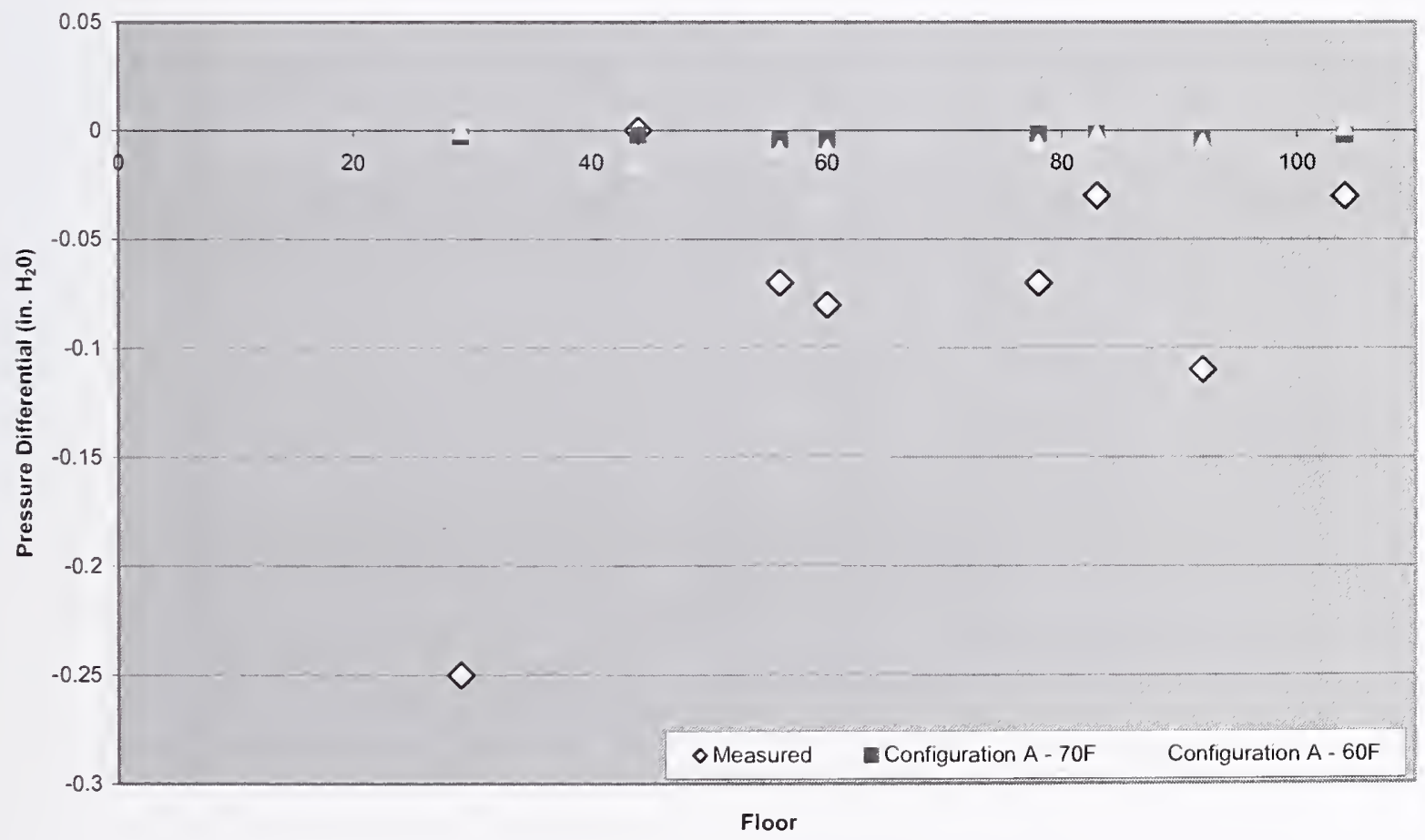

Figure C-22. Mode 2, all fans set to summer normal, configuration $\mathrm{A}$ at $60^{\circ} \mathrm{F}$ and $70^{\circ} \mathrm{F}$, stair 2 . 


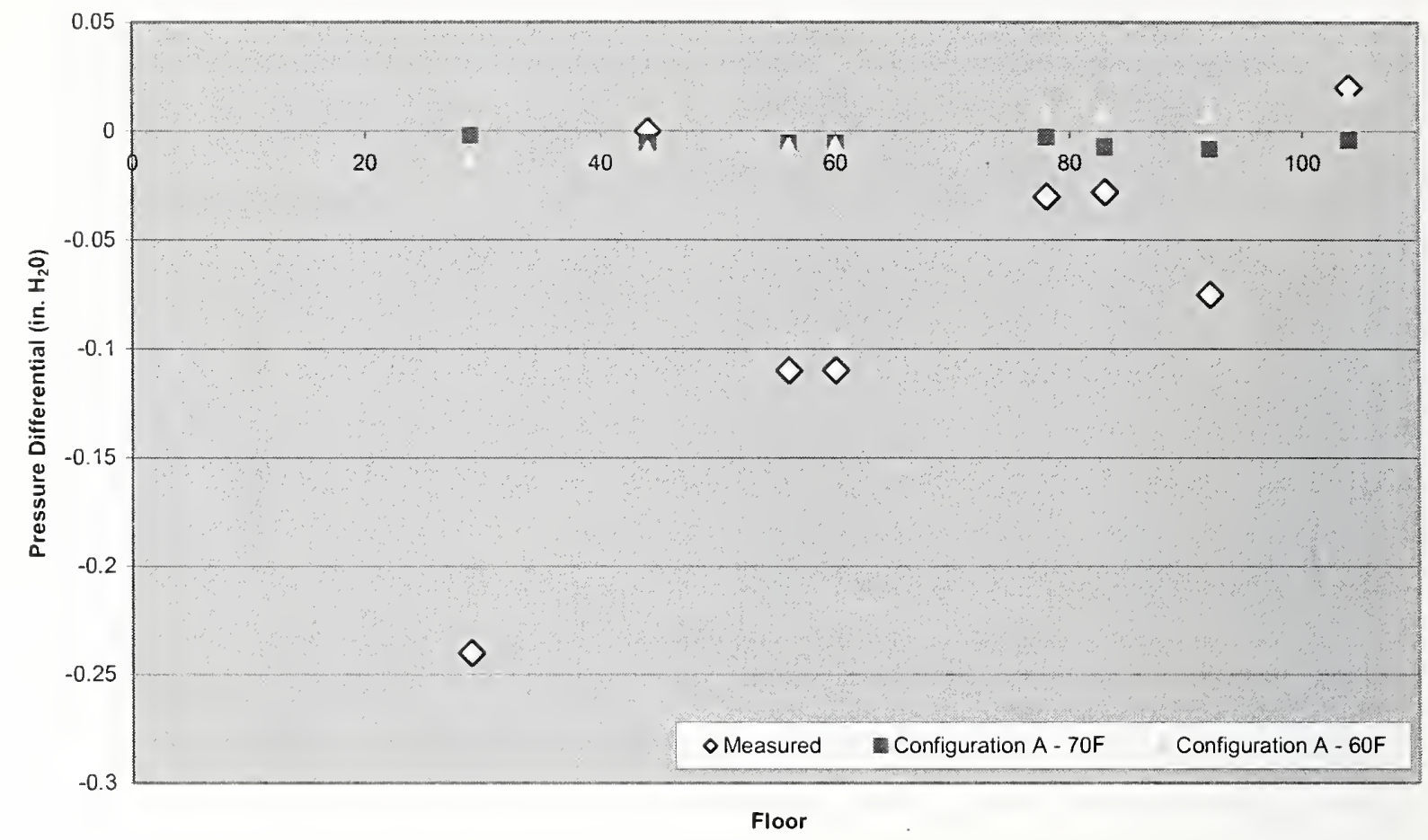

Figure $\mathrm{C}-23$. Mode 2, all fans set to summer normal, configuration $A$ at $60^{\circ} \mathrm{F}$ and $70^{\circ} \mathrm{F}$, stair 3 . 


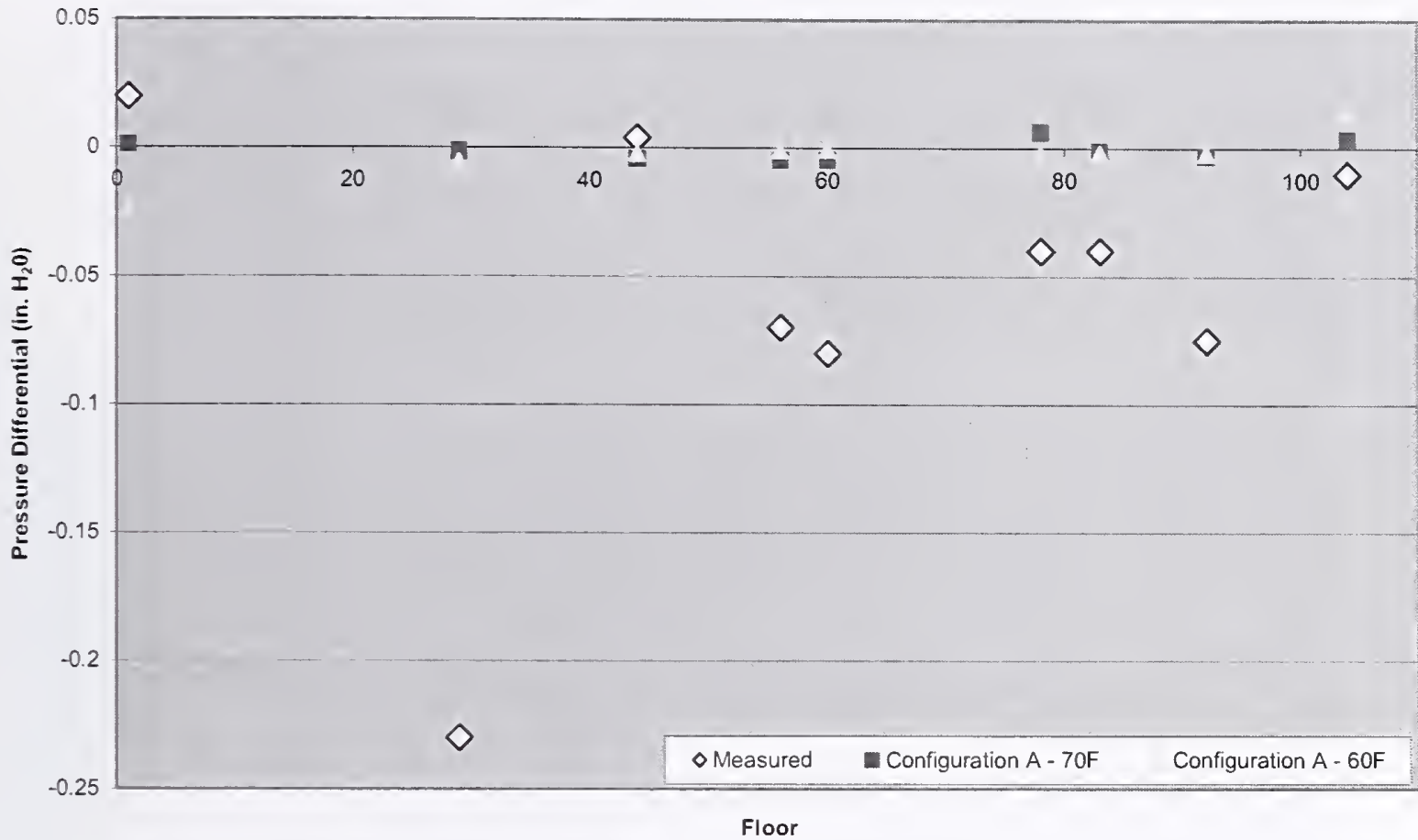

Figure C-24. Mode 2, all fans set to summer normal, configuration $A$ at $60^{\circ} \mathrm{F}$ and $70^{\circ} \mathrm{F}$, elevator 50 .

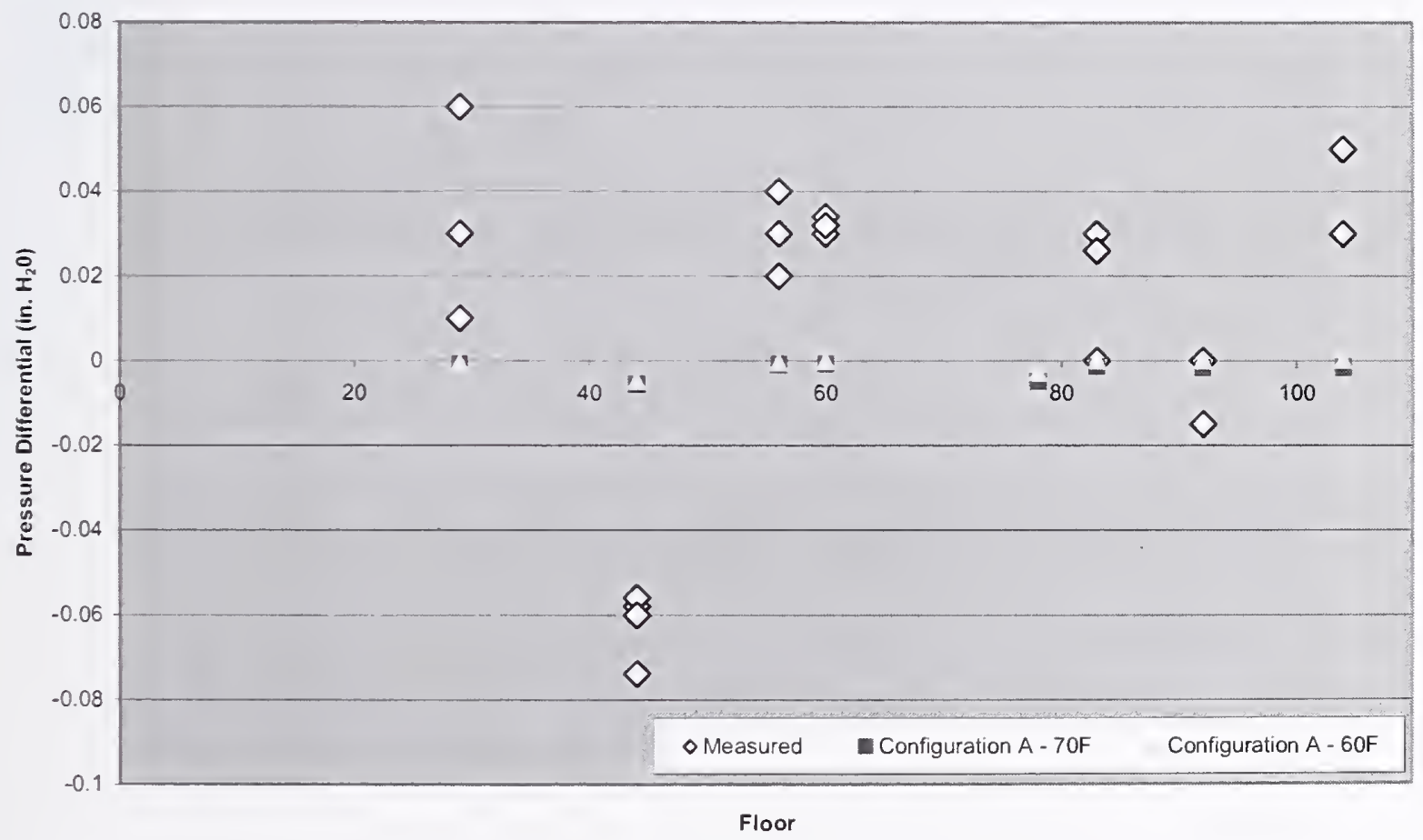

Figure C-25. Mode 2, all fans set to summer normal, configuration $A$ at $60^{\circ} \mathrm{F}$ and $70^{\circ} \mathrm{F}$, tenant doors. 


\section{C.3.3 Affects of Wind Velocity}

As discussed in Appendix B (Sec. B.1.4), the $1996 \mathrm{HAI} / \mathrm{DCE}$ reported that during the testing performed using Modes 1 through 4, wind was fairly constant at $2 \mathrm{mph}$. In Figs. C-26 through C-30, wind was varied between $0 \mathrm{mph}$ and $20 \mathrm{mph}$ to test whether variation in wind conditions would affect the calibration of the model. As seen in these figures, wind had no notable effect on the predicted pressure differentials, and was therefore not considered in the calibration of the model.

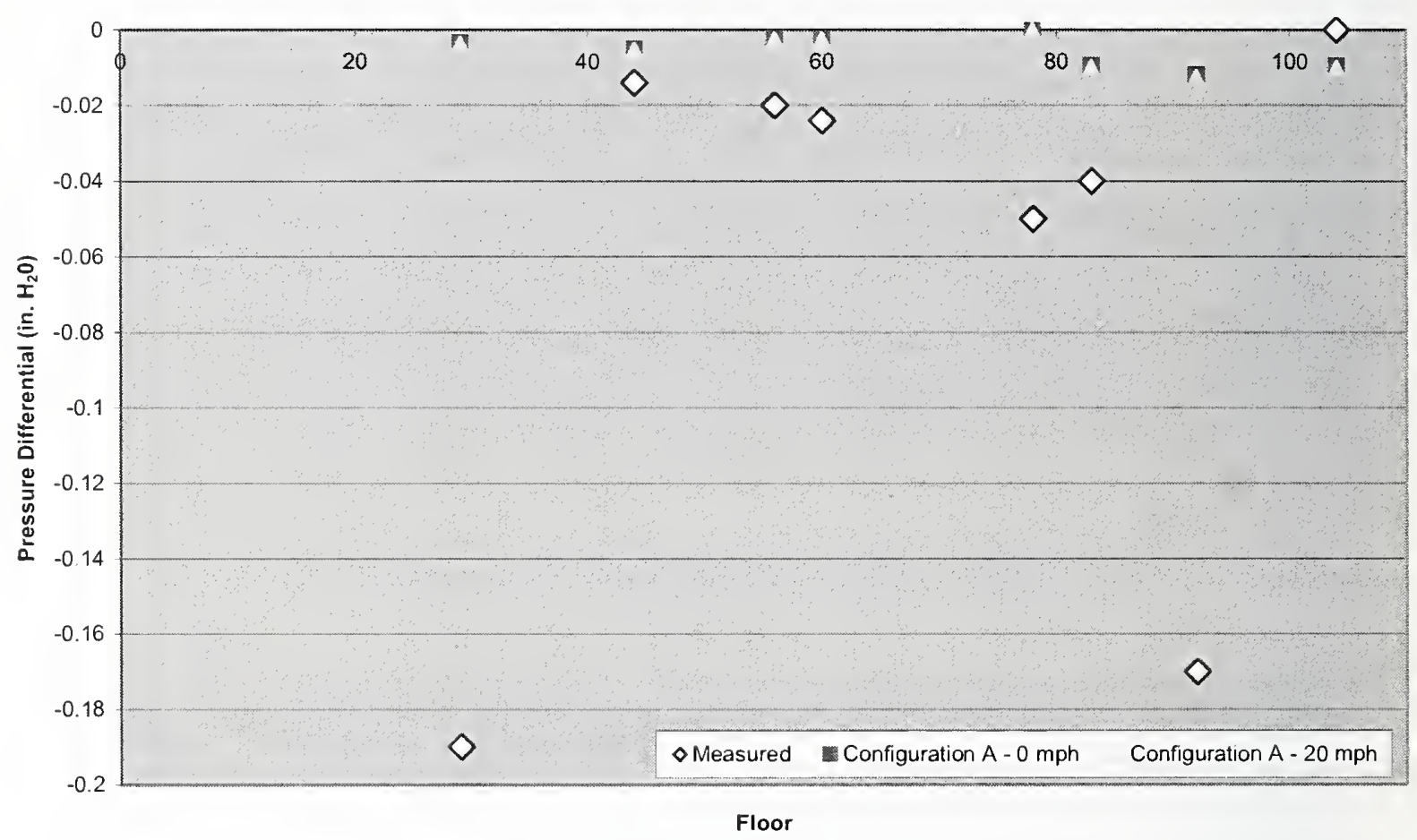

Figure $\mathrm{C}-26$. Mode 2, all fans set to summer normal, configuration $\mathrm{A}, 0-20 \mathrm{mph}$ wind, stair 1. 


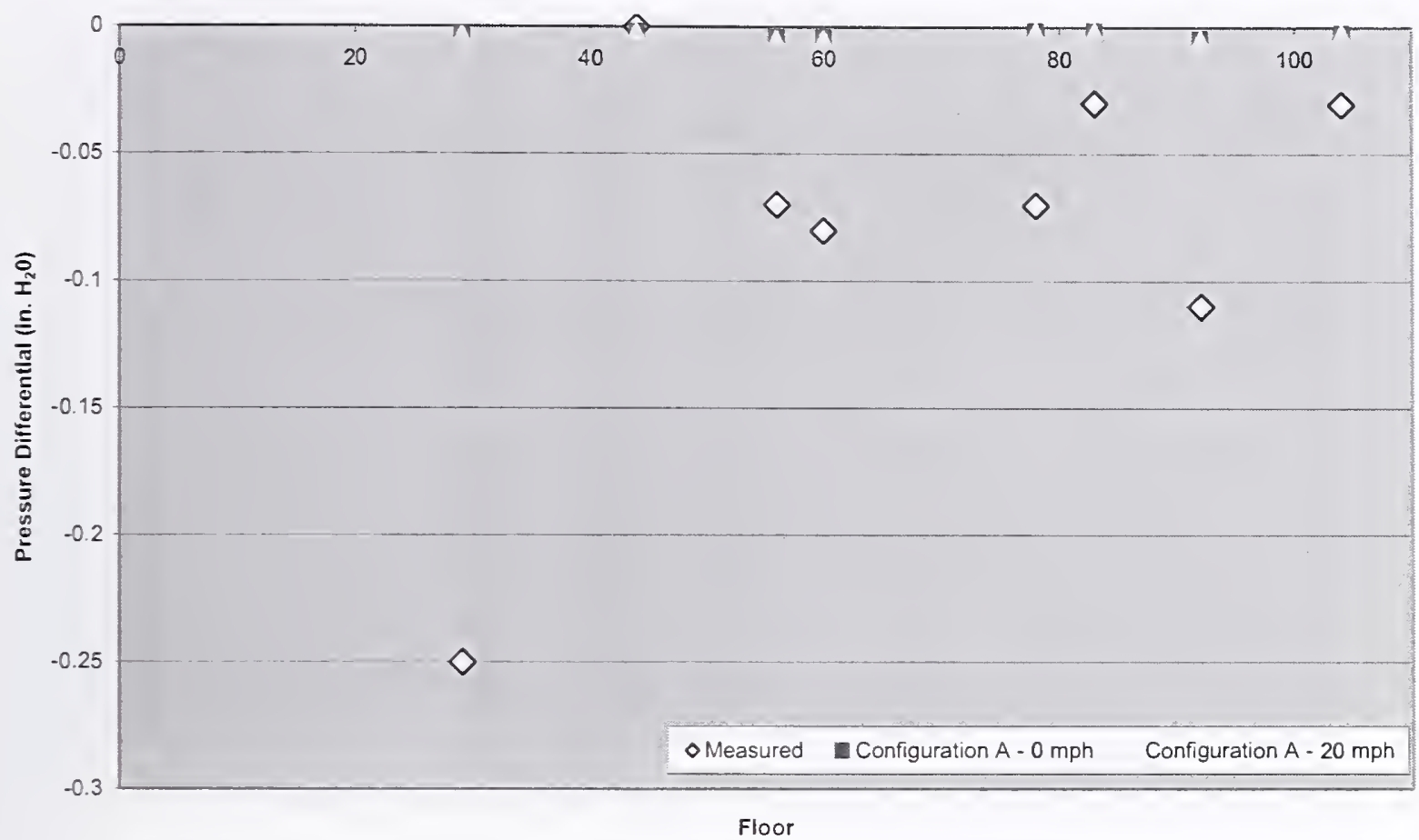

Figure $\mathrm{C}-27$. Mode 2, all fans set to summer normal, configuration A, 0-20 mph wind, stair 2.

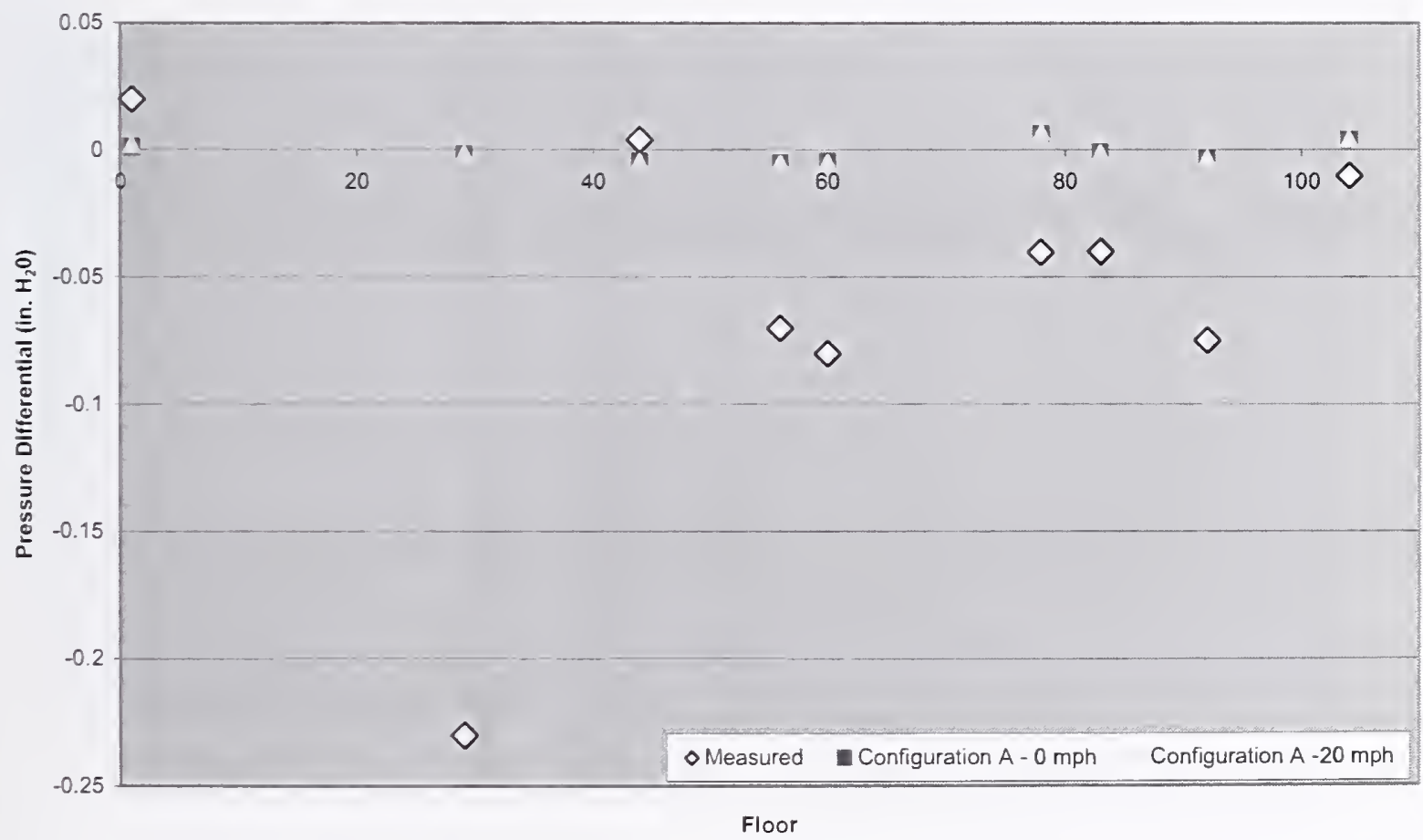

Figure C-28. Mode 2, all fans set to summer normal, configuration $\mathrm{A}, 0-20 \mathrm{mph}$ wind, stair 3 . 


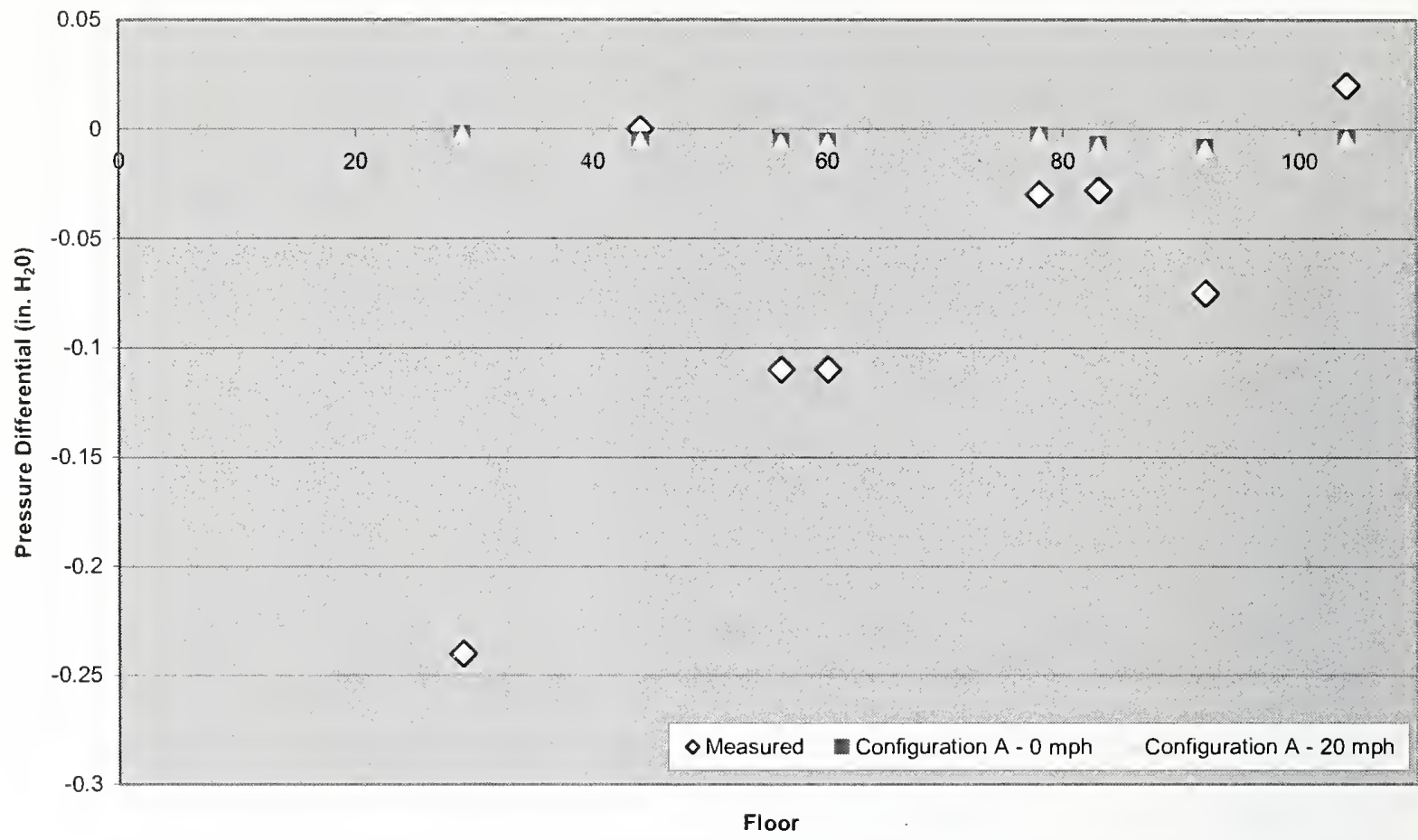

Figure C-29. Mode 2, all fans set to summer normal, configuration A, 0-20 mph wind, elevator 50 .

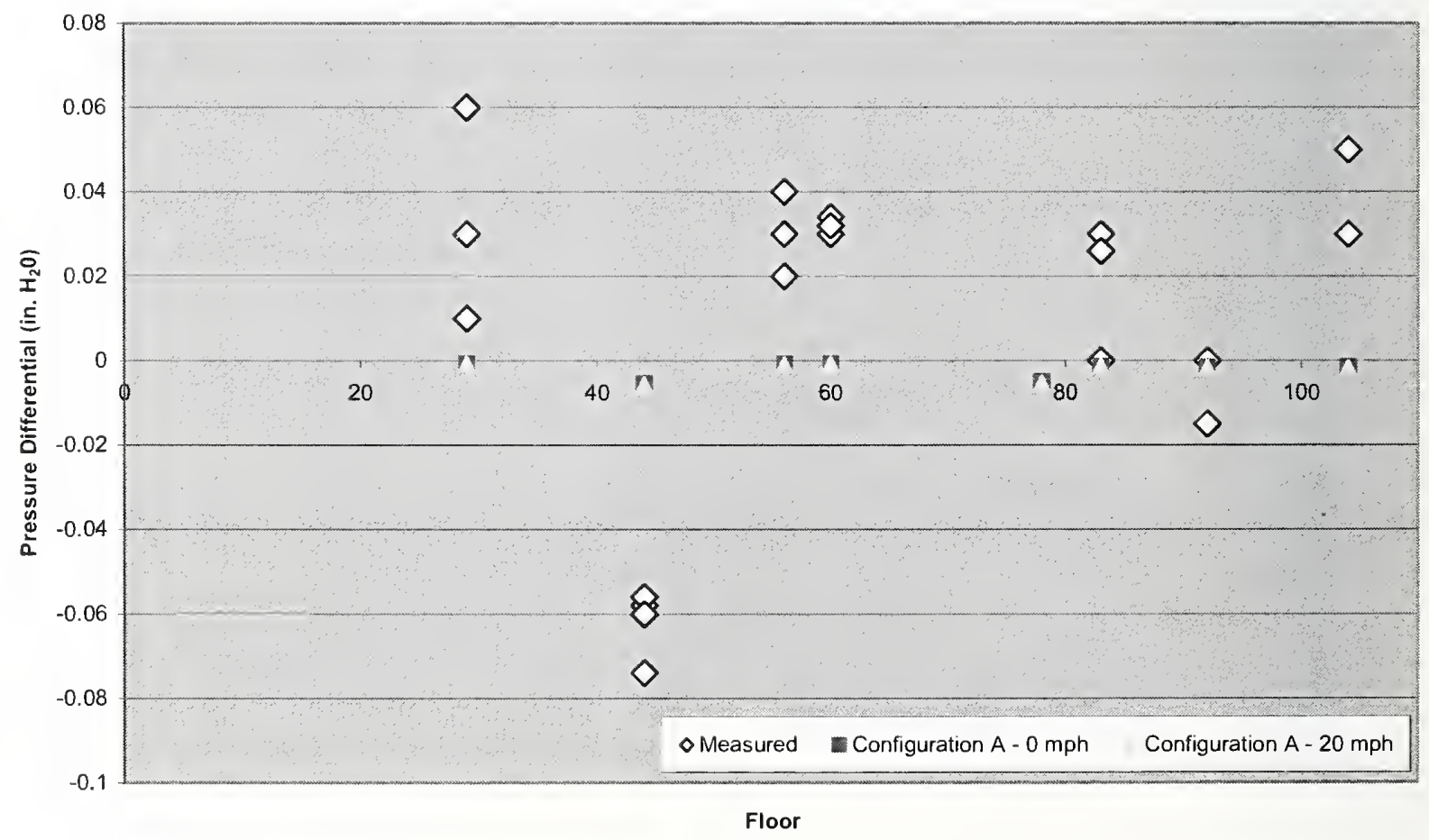

Figure $\mathrm{C}-30$. Mode 2, all fans set to summer normal, configuration A, 0-20 mph wind, elevator 50 . 


\section{C.4 FACTORS AFFECTING CALIBRATION}

There are a number of factors or combinations of factors which may help explain disagreement between the measured pressures and simulated pressure including:

- Pressure gauge accuracy and user error

- Actual outdoor temperature as a function of height was not known. The outdoor temperature in CONTAM is assumed to be uniform across the exterior face of the building

- Architectural changes to individual floors that may substantially alter pressure differentials at individual points. Potential changes include

- Number of tenant doors located between core and interior space

- Number and size of wall transfer grills

- Configuration of tenant doors (i.e., open, partially open, closed)

- Presences of convenience stairs

- Configuration of stair doors (i.e., open, partially open, closed)

- Configuration of stair transition doors (i.e., open, partially open, closed).

- Configuration of elevator doors (i.e., open, partially open, closed) CONTAM simulations assumed all stair doors, stair transition doors, tenant doors, and elevator doors over the entire height of the building, were completely closed. CONTAM simulations assumed the number of tenant doors remained consistent on each floor. CONTAM simulations also assumed the number and size of wall transfer grills remained consistent on each floor. Additional factors that may have contributed to variations between simulated and measured pressure are discussed in Section C.2.3.

- Tenant changes on individual floors to architecture and/or ventilation system.

- Actual supply and return rates on each floor were not measured. Simulations show that the rate of air being supplied and returned, and more importantly the ratio between them, will have a dramatic effects build pressures.

- Instructions given to building engineers to set various HVAC modes may have been misinterpreted. For example, when a "purge" command was given, building engineers may have aligned equipment differently than what was assumed. Small fans not thought to impact the sequence may have been inadvertently left on, affecting overall pressure differentials.

\section{C.5 CALIBRATION SUMMARY}

During the calibration of the 2004 CONTAM model there were too many independent variables (leakage types, wind/weather conditions, HVAC system alignments, design versus measured supply/return airflow, 
unknown architectural changes to individual floor plans) to allow for a single model configuration that matched all of the data for the various ventilation modes tested.

It was therefore determined that in order to capture the uncertainty involved in the type of modeling being performed, and the potential range of results given this uncertainty that the three separate building configurations discussed in this appendix (configurations A, B, and C) would be carried forth in the modeling performed for this report.

\section{C.6 REFERENCES}

HAI (Hughes Associates, Inc.) and DCE (Dillon Consulting Engineers). 1996. Smoke Managemrent Evahtuation Study of The World Trade Center Complex Excluding the Concourse and Plaza. Prepared for the PANYNJ (Port Authority of New York and New Jersey). New York, NY.

Klote, J. H., and J. A. Milke. 2002. Principles of Smoke Management. American Society of Heating Refrigeration and Air-Conditioning Engineers (ASHRAE). Atlanta, GA.

McAllister, T., ed. 2002. World Trade Center Building Performance Study: Data Collection, Prelininary Observations, and Recommendations. FEMA 403. Federal Emergency Management Agency. Washington, DC, May. 

